CAIQUE ROBERTO DE ALMEIDA

ANÁLISE DO COMPORTAMENTO TÉRMICO DE ESTACAS GEOTÉRMICAS EM SOLO ARENOSO 
CAIQUE ROBERTO DE ALMEIDA

\title{
ANÁLISE DO COMPORTAMENTO TÉRMICO DE ESTACAS GEOTÉRMICAS EM SOLO ARENOSO
}

Versão revisada

\author{
Dissertação apresentada à Escola Politécnica da \\ Universidade de São Paulo para a obtenção do título de \\ Mestre em Ciências. \\ Área de Concentração: \\ Engenharia Geotécnica \\ Orientador: \\ Profa. Dra. Maria Eugênia Gimenez Boscov
}

São Paulo 
Autorizo a reprodução e divulgação total ou parcial deste trabalho, por qualquer meio convencional ou eletrônico, para fins de estudo e pesquisa, desde que citada a fonte.

Este exemplar foi revisado e corrigido em relação à versão original, sob responsabilidade única do autor e com a anuência de seu orientador.

São Paulo, $\underline{15}$ de fevereiro de $\underline{2021}$

Assinatura do autor: $\quad$ Caique de llmeida

Assinatura do orientador: Maria Engenia Gimemy Bossor

\section{Catalogação-na-publicação}

de Almeida, Caique Roberto

Análise do comportamento térmico de estacas geotérmicas em solo arenoso / C. R. de Almeida -- versão corr. -- São Paulo, 2021.

$210 \mathrm{p}$.

Dissertação (Mestrado) - Escola Politécnica da Universidade de São Paulo. Departamento de Engenharia de Estruturas e Geotécnica.

1.Testes de Resposta Térmica 2.Estacas geotérmicas 3.Fluxo térmico 4.Modelagem numérica I.Universidade de São Paulo. Escola Politécnica. Departamento de Engenharia de Estruturas e Geotécnica II.t. 


\section{DEDICATÓRIA}

A meus pais Sérgio Roberto de Almeida e Lúcia Maria Alves de Almeida. 


\section{AGRADECIMENTOS}

Meus sinceros agradecimentos à Professora Maria Eugênia Gimenez Boscov, por mostrar-me os horizontes da Pesquisa e da Ciência nos anos em que estive sob sua orientação. À Professora Cristina de Hollanda Cavalcanti Tshua, por concordar em coorientar-me e por introduzir-nos no universo de estacas geotérmicas. Ao Professor Cyro Albuquerque Neto, pelas inúmeras contribuições relacionadas aos fenômenos térmicos e à elaboração do modelo numérico aqui apresentado. Ao Professor Fernando Saboya Albuquerque Júnior, pela sólida contribuição de sua experiência e por apresentar-nos à comunidade científica que atua com estacas geotérmicas.

Aos professores Kurt André Pereira Amann, Ciro Humes e Roy Borden, por apresentarem-me a Geotecnia e seus a temas de Pesquisa. Aos professores do Programa de PósGraduação em Engenharia Civil da Universidade de São Paulo, cujos ensinamentos foram fundamentais para minha formação como mestre.

Aos alunos de Iniciação Científica Luís Augusto Aragão Tarelow e Luíza Palheta Barakat, pela ativa participação nas diferentes etapas da Pesquisa.

A meus pais Sérgio Roberto de Almeida e Lúcia Maria Alves de Almeida, a meu irmão Cauê Bruno de Almeida e à minha avó Francisca Ribeiro da Silva, pelo incondicional apoio. 
"What we know is a drop. What we don't know is an ocean." Isaac Newton 


\section{RESUMO}

A busca por matrizes energéticas renováveis de caráter sustentável tem motivado o uso de estacas geotérmicas como uma forma de se aproveitar as estruturas de fundações profundas de edificações para, em países de clima tropical, dissipar-se calor de ambientes internos de prédios em camadas superficiais de solo. A climatização por aquecimento com estacas geotérmicas é uma técnica amplamente empregada por países europeus, onde rigorosos invernos tornam mandatórios os gastos com sistemas de calefação. $\mathrm{O}$ sistema geotérmico por estacas é acoplado ao conjunto Ground Source Heat Pump (GSHP) e se baseia na circulação de um fluido por um circuito fechado de tubos conectados à estaca e à bomba de calor. $\mathrm{O}$ presente trabalho tem por objetivo estudar o comportamento térmico de estacas geotérmicas assentes em solo arenoso saturado por meio de simulações numéricas, para identificar as variáveis de maior interesse para projeto. O modelo numérico foi desenvolvido com o programa ANSYS CFX versão 19.2, uma ferramenta CFD (Computational Fluid Dynamics) de alto desempenho. Para a validação do modelo numérico, utilizaram-se dados de ensaio de Teste de Resposta Térmica (TRT) realizado na Escola Politécnica da USP. Nas simulações em regime estacionário, as variáveis estudadas foram: diâmetro e comprimento das estacas; condutividade térmica do solo, do concreto e do material das tubulações; grau de saturação do solo; a temperatura de entrada no sistema e a velocidade do fluido circulante. Observa-se que temperatura de entrada do fluido, diâmetro e comprimento da estaca são as variáveis que causam maiores aumentos nas taxas de transferência de calor total. As variáveis comprimento e diâmetro não afetam realmente a eficiência térmica, pois as taxas de transferência de calor normalizadas pouco variaram. Considerando-se as taxas de transferência de calor por unidade de parâmetro, as variáveis mais relevantes são: resistência de contato, grau de saturação e condutividade térmica do concreto.

Palavras-chave: Testes de Resposta Térmica. Estacas geotérmicas. Fluxo térmico. Modelagem numérica. 


\begin{abstract}
The search for sustainable renewable energy matrices has motivated the use of geothermal piles to take advantage of deep building foundation structures to, in tropical climate countries, dissipate heat from building to soil layers. Heating with geothermal piles is a technique widely used by European countries, where severe winters make spending on heating system mandatory. The geothermal pile system is coupled to the Ground Source Heat Pump (GSHP) assembly and is based on the circulation of a fluid through a closed circuit of pipes connected to the pile and to the heat pump. The present work aims to study the thermal behaviour of geothermal piles in a saturated sandy soil using numerical simulations to identify the variables of greatest interest to the project. The numerical model was developed with the ANSYS CFX version 19.2 program, a high performance CFD (Computational Fluid Dynamics) tool. Data from a Thermal Response Test (TRT) test carried out at the Polytechnic School of the University of São Paulo were used to calibrate the numerical model. In the steady state simulations, the variables studied were: diameter and length of piles; thermal conductivity of soil, concrete and pipe; degree of soil saturation; system inlet temperature; and circulating fluid velocity. Fluid inlet temperature, pile diameter and pile length are the variables that cause the greatest increases in the total heat transfer rates. However, the variables pile length and pile diameter do not really affect the thermal efficiency of the system, as normalized heat transfer rates showed unimportant variation. Regarding the heat transfer rates per unit of parameter, the most relevant variables are contact resistance, degree of saturation and thermal conductivity of the concrete.
\end{abstract}

Keywords: Thermal Response Tests. Geothermal piles. Thermal flow. Numerical modelling. 


\section{SUMÁRIO}

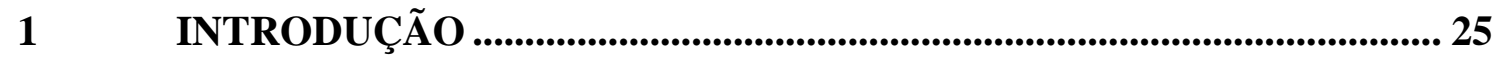

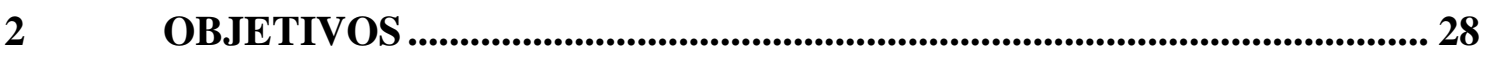

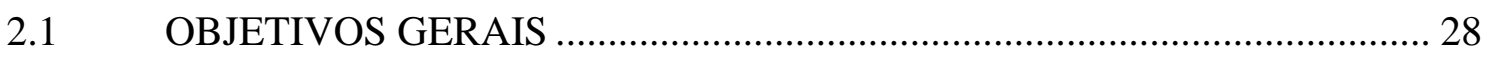

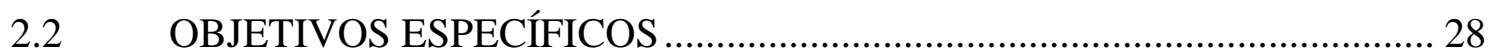

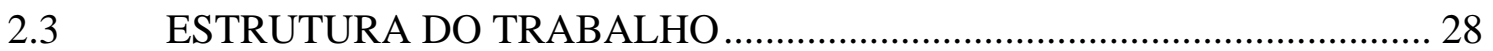

3 REVISÃO BIBLIOGRÁFICA ........................................................................ 30

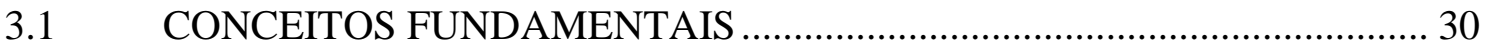

3.1.1 Mecanismos de transferência de calor............................................................... 30

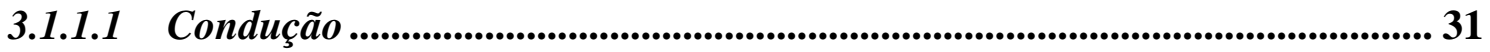

3.1.1.2 Convecção

3.1.1.3 Radiação ....................................................................................................................... 34

3.1.2 Propriedades térmicas dos solos ............................................................ 36

3.1.2.1 Capacidade térmica e calor específico ..................................................... 36

3.1.2.2 Condutividade térmica .................................................................................... 40

3.1.2.3 Difusividade térmica ............................................................................................ 38

3.1.3 Transferência de calor em solos .......................................................................... 41

3.1.3.1 Comportamento da temperatura superficial .............................................. 41

3.1.3.2 A influência de propriedades geotécnicas na troca térmica dos solos ......... 43

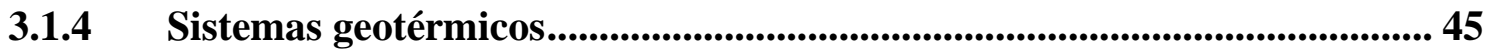

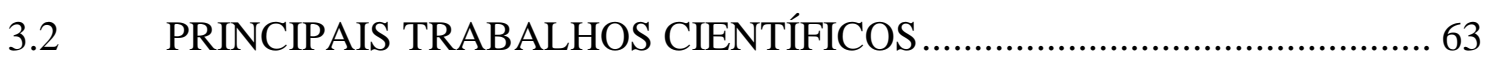

3.2.1 Comportamentos térmico e termo-hidráulico ............................................. 63

3.2.2 Comportamento termo-hidro-mecânico.............................................................. 76

3.2.3 Comportamento termo-hidro-mecânico/químico........................................ 93

3.2.4 Síntese dos trabalhos científicos .......................................................... 96

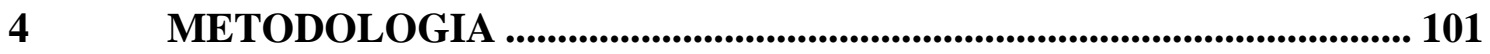

4.1 CARACTERIZAÇÃO GEOTÉCNICA ............................................... 101 
4.2 ENSAIO TRT E RESULTADOS EXPERIMENTAIS DISPONÍVEIS PARA

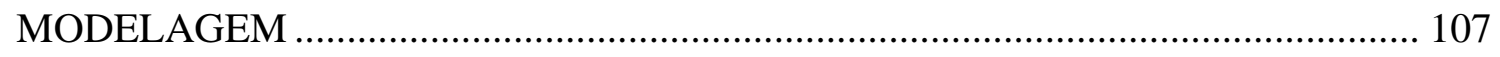

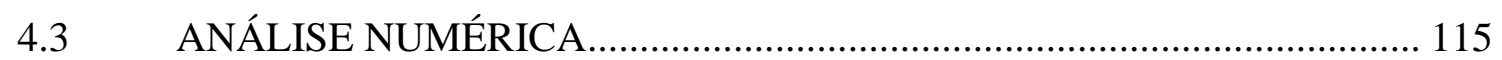

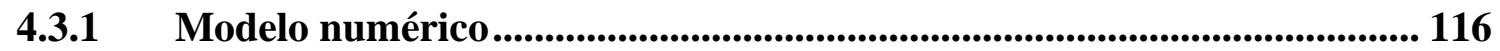

4.3.2 Hipóteses para o modelo numérico .............................................................. 119

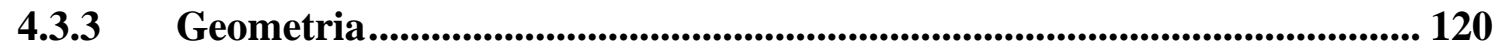

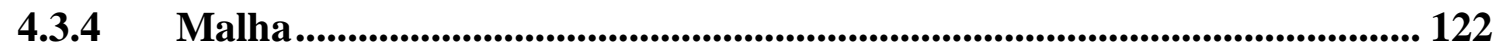

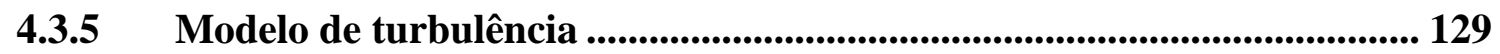

4.3.6 Validação do modelo numérico do ensaio TRT ........................................... 129

4.3.7 Estudo paramétrico em modelo numérico do ensaio TRT ...................... 133

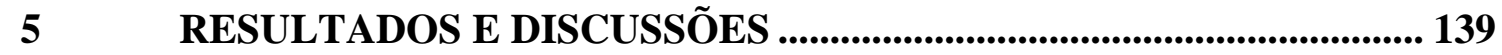

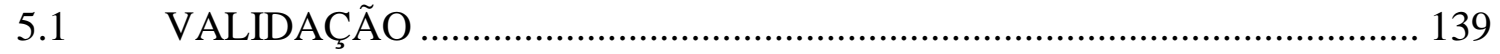

5.2 ESTUDO DE CONVERGÊNCIA DE MALHA ......................................... 143

5.3 VARIAÇÃO DO COMPRIMENTO DA ESTACA .................................... 144

5.4 VARIAÇÃO DO DIÂMETRO DA ESTACA ….......................................... 148

5.5 VARIAÇÃO DO ÍNDICE DE ESBELTEZ DA ESTACA ........................... 151

5.6 VARIAÇÃO DA CONDUTIVIDADE TÉRMICA DO CONCRETO .......... 153

5.7 VARIAÇÃO DA CONDUTIVIDADE TÉRMICA DO SOLO ..................... 160

5.8 VARIAÇÃO DO GRAU DE SATURAÇÃO DO SOLO .............................. 170

5.9 VARIAÇÃO DA TEMPERATURA DE ENTRADA DO FLUIDO CIRCULANTE

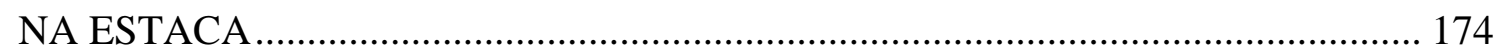

5.10 VARIAÇÃO DA VELOCIDADE/VAZÃO DO FLUIDO CIRCULANTE . 179

5.11 VARIAÇÃO DA RESISTÊNCIA TÉRMICA DOS TUBOS ...................... 187

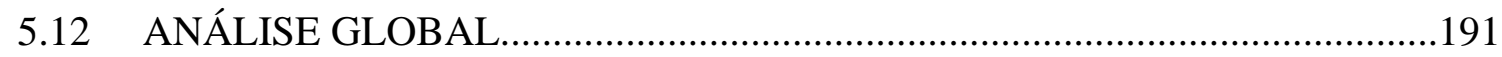

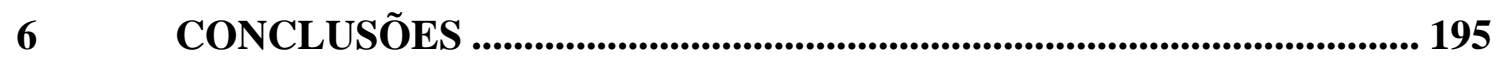

7 SUGESTÕES PARA NOVAS PESQUISAS ...................................... 199

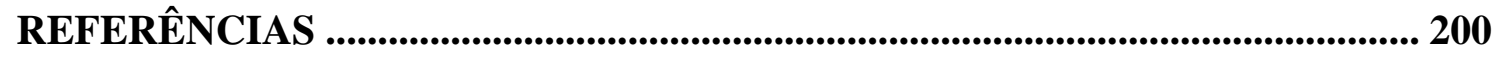




\section{LISTA DE ILUSTRAÇÕES}

Figura 1.1 - Construção de estacas geotérmicas e economia de CO2 no Reino Unido........... 25

Figura 1.2 - Esquema ilustrativo de furos trocadores de calor ............................................26

Figura 1.3 - Esquema ilustrativo de um sistema de estacas geotérmicas...............................26

Figura 3.1 - Comportamento da temperatura com a profundidade do solo ............................. 42

Figura 3.2 - Função idealizada de flutuação da temperatura superficial do solo..................... 43

Figura 3.3 - Relação entre grau de saturação e trocas térmicas em profundidade .................... 44

Figura 3.4 - Condutividade e difusividade térmicas em função da umidade volumétrica do

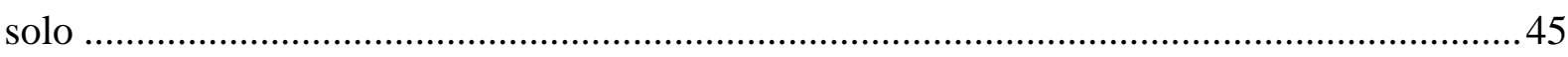

Figura 3.5 - Funcionamento de uma bomba de calor........................................................ 48

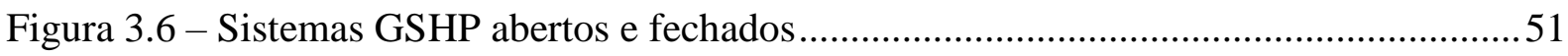

Figura 3.7 - Tipos de estacas geotérmicas em relação à disposição dos tubos ........................51

Figura 3.8 - Esquema de uma instalação com bomba de calor híbrida acoplada a estacas geotérmicas com opção de livre resfriamento

Figura 3.9 - Esquema de uma instalação com bomba de calor e estacas geotérmicas e sistema de resfriamento ativo

Figura 3.10 - Esquema de uma instalação com bomba de calor e estacas geotérmicas com

sistemas de armazenamento (coletor solar, refrigerador seco ou ar de exaustão)

Figura 3.11 - Esquema de uma instalação com bomba de calor e estacas geotérmicas

separadas com armazenamento de energia por fonte térmica do ar .56

Figura 3.12 - Componentes do equipamento de um ensaio TRT ............................................58

Figura 3.13 - Componentes do equipamento de um ensaio TRT móvel .................................59

Figura 3.14 - Esquema de execução de ensaio TRT em campo experimental .........................64

Figura 3.15 - Ensaio TRT em São Carlos: dados monitorados de temperatura ambiente

( $\left.\mathrm{T}_{\text {ambient }}\right)$ e temperatura do fluido na entrada $\left(\mathrm{T}_{\text {in }}\right)$ e saída (Tout) dos tubos de PEAD.............65

Figura 3.16 - Geometria do modelo numérico elaborado .........................................................66

Figura 3.17 - Malha elaborada para uma metade simétrica do problema ................................66

Figura 3.18 - Malha elaborada para uma metade simétrica do problema (eixos x e y em

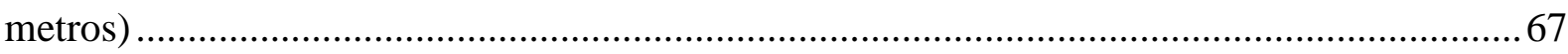

Figura 3.19 - Distribuição de temperaturas (enfoques experimental e numérico)...................68

Figura 3.20 - Comportamento de temperaturas ao longo do tempo ………............................ 70

Figura 3.21 - Esquema de distribuição de estacas no campo experimental da EESC USP.....72

Figura 3.22 - Resultados numéricos e experimentais obtidos na validação do modelo ...........73 
Figura 3.23 - Perfil de solo do campus experimental da UnB .

Figura 3.24 - Instalação da armadura da estaca com oito circuitos de tubos em "U"

Figura 3.25 - Diagrama carregamento x deslocamento de uma estaca de energia em condições não perturbada, após aquecimento e após resfriamento 77

Figura 3.26 - Respostas térmicas no corpo da estaca ensaiada 79

Figura 3.27 - Respostas térmicas em um furo localizado a $0,8 \mathrm{~m}$ do centro da estaca..... 79

Figura 3.28 - Esquema representativo do ensaio em centrífuga 81

Figura 3.29 - Distribuição de deformações axiais e tensões térmicas ao longo da profundidade para o ensaio de modelo reduzido em centrífuga 82

Figura 3.30 - Distribuição de deformações axiais e tensões termicamente induzidas ao longo da profundidade para o monitoramento do ensaio em tamanho real ..................................... 83

Figura 3.31 - Curvas carga-recalque para diferentes tempos............................................... 85

Figura 3.32 - Modelo físico bidimensional de uma estaca de energia................................... 86

Figura 3.33 - Malha adotada para as simulações numéricas ................................................... 87

Figura 3.34 - Perfil de temperaturas no sistema geotérmico .................................................. 88

Figura 3.35 - Variação de temperaturas para diferentes velocidades de fluxo de água............90

Figura 3.36 - Comparação entre resultados dos programas ANSYS e RSAS ........................90

Figura 3.37 - Relação entre a velocidade do fluxo de água subterrânea e média das temperaturas de entrada e saída da água circulante nos circuitos de tubos de PEAD ..............91

Figura 3.38 - Modelo numérico de estaca de diâmetro 0,13 m.

Figura 3.39 Temperatura de saída do tubo durante ensaio TRT em estaca de diâmetro $0,13 \mathrm{~m}$

Figura 4.1 - Perfil de solo no local onde foi realizado o ensaio TRT. 102

Figura 4.2 - Locação de sondagens próximas ao prédio da administração da EPUSP: (a) plano

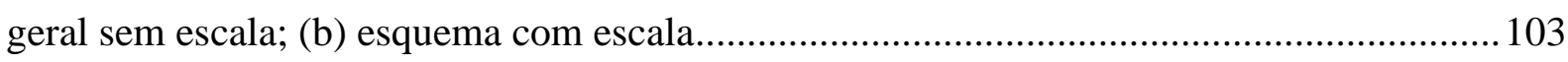

Figura 4.3 - Perfil de solo próximo ao prédio da administração da EPUSP ........................... 103

Figura 4.4 - Locação de sondagens nas adjacências do Centro de Técnicas de Construção

Civil: (a) plano geral sem escala; (b) esquema com escala ................................................... 104

Figura 4.5 - Perfil de solo relacionado à sondagem S1 ...................................................... 105

Figura 4.6 - Perfil de solo relacionado à sondagem S2 .................................................. 106

Figura 4.7- Perfil de solo relacionado à sondagem S3 ..................................................... 107

Figura 4.8 - Construção da estaca geotérmica: perfuração ................................................... 108

Figura 4.9 - Construção da estaca geotérmica: armadura e tubos......................................... 109

Figura 4.10 - Construção da estaca geotérmica: concretagem.............................................. 109 
Figura 4.11 - Instalação dos sensores de temperatura nos pontos de entrada e saída dos tubos de PEAD

Figura 4.12 - Esquema do aparato experimental empregado.

Figura 4.13 - Variação de temperatura com o tempo no ensaio de circulação de água

Figura 4.14 - Variação das temperaturas do fluido e ambiente durante o ensaio TRT.

Figura 4.15 - Resistência térmica da estaca durante o ensaio TRT

Figura 4.16 - Temperatura média do fluido circulante x logaritmo do tempo.

Figura 4.17 - Geometria representativa do ensaio TRT.

Figura 4.18 - Detalhe da geometria da face superior da estaca

Figura 4.19 - Detalhe da geometria curva da tubulação em formato em "U"

Figura 4.20 - Distribuição de elementos na malha do fluido na região da curva em "U” .....123

Figura 4.21 - Disposição de elementos tetraédricos e prismáticos no encontro das malhas do concreto e fluido

Figura 4.22 - Malha do solo do entorno da estaca com relação ao eixo XY

Figura 4.23 - Detalhe da malha de solo no encontro com a malha da estaca com relação ao eixo XY

Figura 4.24 - Malha do solo do entorno com relação ao eixo XZ ...................................... 125

Figura 4.25 - Malha do solo do entorno em vista tridimensional ....................................... 126

Figura 4.26 - Malha da estaca de concreto em vista tridimensional ..................................... 127

Figura 4.27 - Malha da estaca de concreto em relação ao eixo XZ ..................................... 127

Figura 4.28 - Malha do solo do tundo da estaca em vista tridimensional.

Figura 4.29 - Detalhe do encontro das malhas do solo circundante, solo de fundo e estaca de concreto

Figura 5.1 -Taxa de transferência de calor por interface em função do tempo

Figura 5.2 - Variação da temperatura média por interface em função do tempo

Figura 5.3 - Distribuição de temperaturas no plano XY e na profundidade de 7,5 $\mathrm{m}$ do sistema geotérmico para o instante $200 \mathrm{~h}$. 142

Figura 5. 4 - Zona de influência térmica no instante $200 \mathrm{~h}$ 142

Figura 5.5 - Diâmetro de influência térmica em função do tempo

Figura 5.6 - Estudo de convergência de malha para a região do fluido circulante. 144

Figura 5.7 - Taxa de transferência de calor em função do comprimento da estaca geotérmica, por interface 145

Figura 5.8 - Taxa de transferência de calor normalizada pelo comprimento da estaca em função do comprimento da estaca geotérmica, por interface 
Figura 5.9 - Taxa de transferência de calor normalizada pela área da superfície da estaca em função do comprimento da estaca geotérmica, por interface

Figura 5.10 - Temperatura média em função do comprimento da estaca, por interface......... 148

Figura 5.11 - Taxa de transferência de calor em função do diâmetro da estaca geotérmica, por interface

Figura 5.12 - Taxa de transferência de calor normalizada pelo comprimento em função do diâmetro da estaca geotérmica, por interface

Figura 5.13 - Taxa de transferência de calor normalizada pela área da superfície da estaca em função do diâmetro da estaca geotérmica, por interface

Figura 5.14 - Temperatura média em função do diâmetro da estaca geotérmica, por interface

Figura 5.15 - Taxa de transferência de calor em função do índice de esbeltez da estaca geotérmica, por interface, série 1

Figura 5.16 - Taxa de transferência de calor em função do índice de esbeltez da estaca geotérmica, por interface, série 2 .

Figura 5.17 - Taxa de transferência de calor em função da condutividade térmica do concreto, por interface

Figura 5.18 - Temperatura média em função da condutividade térmica do concreto da estaca geotérmica, por interface

Figura 5.19 - Distribuição de temperaturas na estrutura de concreto da estaca, no plano XZ, com condutividade térmica do concreto de $0,17 \mathrm{~W} \cdot \mathrm{m}^{-1} \cdot \mathrm{K}^{-1}$

Figura 5.20 - Distribuição de temperaturas na estrutura de concreto da estaca, no plano XZ, com condutividade térmica do concreto de $3,85 \mathrm{~W} \cdot \mathrm{m}^{-1} \cdot \mathrm{K}^{-1}$

Figura 5.21 - Transferência de calor em função da condutividade térmica do concreto considerando os cenários 1 e 2

Figura 5.22 - Temperatura média na interface concreto-solo em função da condutividade térmica do concreto considerando os cenários 1 e 2

Figura 5.23 - Diâmetro de influência térmica em função da condutividade térmica do concreto considerando os cenários 1 e 2

Figura 5.24 - Zona de influência térmica condutividade do concreto $0,17 \mathrm{~W} \cdot \mathrm{m}^{-1} \cdot \mathrm{K}^{-1}$

Figura 5.25 - Zona de influência térmica condutividade do concreto $3,85 \mathrm{~W} \cdot \mathrm{m}^{-1} \cdot \mathrm{K}^{-1}$

Figura 5.26 - Taxa de transferência de calor total em função da condutividade térmica do solo, por interface 
Figura 5.27 - Temperatura média em função da condutividade térmica do solo, por interface

Figura 5.28 - Distribuição de temperaturas na estrutura de concreto da estaca, no plano XZ, com condutividade térmica do solo de $0,90 \mathrm{~W} \cdot \mathrm{m}^{-1} \cdot \mathrm{K}^{-1}$

Figura 5.29 - Distribuição de temperaturas na estrutura de concreto da estaca, no plano XZ, com condutividade térmica do solo de $3,70 \mathrm{~W} \cdot \mathrm{m}^{-1} \cdot \mathrm{K}^{-1}$.

Figura 5.30 - Taxa de transferência de calor total função da condutividade térmica do concreto considerando os cenários 1 e 2

Figura 5.31 - Temperatura média em função da condutividade térmica do solo considerando os cenários 1 e 2

Figura 5.32 - Diâmetro de influência térmica em função da condutividade térmica do solo considerando os cenários 1 e 2 .

Figura 5.33 - Zona de influência térmica - condutividade térmica do solo $0,9 \mathrm{~W} \cdot \mathrm{m}^{-1} \cdot \mathrm{K}^{-1} \ldots .166$ Figura 5.34 - Zona de influência térmica - condutividade térmica do solo $3,7 \mathrm{~W} \cdot \mathrm{m}^{-1} . \mathrm{K}^{-1} \ldots .166$ Figura 5.35 - Taxa de transferência de calor total em função da condutividade térmica do solo para calor específico constante, por interface.

Figura 5.36 - Temperatura média em função da condutividade térmica do solo para calor específico constante, por interface.

Figura 5.37 - Taxa de transferência de calor total em função do calor específico do solo para condutividade térmica do solo constante, por interface

Figura 5.38 - Temperatura média por interface em função do calor específico do solo para condutividade térmica do solo constante, por interface

Figura 5.39 - Taxa de transferência de calor em função grau de saturação do solo, por interface

Figura 5.40 - Temperatura média em função do grau de saturação do solo, por interface.... 171 Figura 5.41 - Taxa de transferência de calor total em função do grau de saturação considerando os cenários 1 e 2 .

Figura 5.42 - Temperatura média em função do grau de saturação do solo considerando os cenários 1 e 2

Figura 5.43 - Diâmetro de influência térmica em função do grau de saturação solo considerando os cenários 1 e 2

Figura 5.44 - Variação da taxa de transferência de calor total por interface em função da temperatura de entrada do fluido circulante 
Figura 5.45 - Temperatura média em função da temperatura de entrada do fluido circulante, por interface

Figura 5.46 - Diferença de temperatura do fluido circulante nos pontos de entrada e de saída dos tubos em função da temperatura de entrada do fluido circulante 176

Figura 5.47 - Taxa de transferência de calor total em função da temperatura de entrada do fluido circulante considerando os cenários 1 e 2

Figura 5.48 - Temperatura média em função da temperatura de entrada do fluido circulante considerando os cenários 1 e 2 .

Figura 5.49 - Diâmetro de influência térmica em função da temperatura de entrada do fluido circulante considerando os cenários 1 e 2

Figura 5.50 - Taxa de transferência de calor em função da variação da velocidade do fluido circulante, por interface

Figura 5.51 - Diferença entre as temperaturas de entrada e saída do fluido circulante em função da variação da velocidade/vazão do fluido circulante

Figura 5.52 - Distribuição de temperaturas próximas aos tubos na porção superior da estaca (vazão de $100 \mathrm{~L} / \mathrm{min}$ ), no plano XZ no centro da estaca

Figura 5.53 - Distribuição de temperaturas em função da vazão, por interface

Figura 5.54 - Distribuição de temperaturas no plano XY e na profundidade de 7,5 m (vazão de $100 \mathrm{~L} / \mathrm{min}$ ) do sistema geotérmico

Figura 5.55 - Zona de influência térmica considerando a vazão de $0,1 \mathrm{~L} / \mathrm{min}$

Figura 5.56 - Zona de influência térmica considerando a vazão de $100 \mathrm{~L} / \mathrm{min}$

Figura 5.57 - Diâmetro de influência térmica em função da velocidade do fluido circulante em diferentes cenários

Figura 5.58 - Taxa de transferência de calor em função da velocidade do fluido circulante em diferentes cenários 186

Figura 5.59 - Distribuição de temperaturas na interface concreto/solo em diferentes cenários

Figura 5.60 - Taxa de transferência de calor em função da resistência térmica de contato na interface tubo/concreto, por interface

Figura 5.61 - Temperatura média em função da resistência térmica de contato na interface tubo/concreto, por interface

Figura 5.62 - Diâmetro de influência térmica em função da resistência térmica de contato na interface tubo/concreto 
Figura 5.63 - Distribuição de temperaturas na estrutura de concreto da estaca, no plano XZ, com resistência térmica de contato de $0,048 \mathrm{~m}^{2} . \mathrm{K} / \mathrm{W}$

Figura 5.64 - Distribuição de temperaturas na estrutura de concreto da estaca, no plano XZ, com resistência térmica de contato de $0,01818 \mathrm{~m}^{2} . \mathrm{K} / \mathrm{W}$

Figura 5.65 - Distribuição de temperaturas na estrutura de concreto da estaca, no plano XZ, com resistência térmica de contato de $0,00012 \mathrm{~m}^{2} . \mathrm{K} / \mathrm{W}$

Figura 5.66 - Síntese das variações de taxas de transferência de calor total por parâmetro analisado 


\section{LISTA DE TABELAS}

Tabela 3.1 - Valores típicos de capacidade térmica para diferentes solos

Tabela 3.2 - Valores de condutividade térmica em função de diferentes graus de saturação e

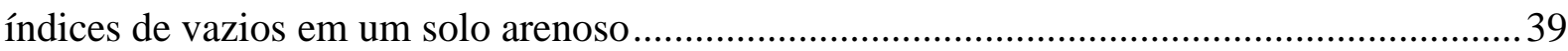

Tabela 3.3 - Valores típicos de condutividade térmica para diferentes solos ..........................39

Tabela 3.4 - Valores de condutividade térmica à temperatura de $10{ }^{\circ} \mathrm{C}$.................................40

Tabela 3.5 - Comparação das características de cada tipo de instalação .................................57

Tabela 3.6 - Parâmetros de entrada do modelo numérico........................................................95

Tabela 3.7 - Ordem cronológica das principais referências em estacas geotérmicas ..............97

Tabela 3.8 - Objetos de estudo das principais referências em estacas geotérmicas ................98

Tabela 4.1 - Resultados do ensaio de circulação de água ....................................................112

Tabela 4.2 - Resumo das temperaturas medidas no ensaio de circulação de água ................ 115

Tabela 4.3 - Parâmetros obtidos no ensaio de circulação de água ........................................ 115

Tabela 4.4 - Parâmetros de entrada e condições de contorno empregados.............................132

Tabela 4.5 - Materiais, espessuras (e), condutividades térmicas (k) e resistências térmicas (R) empregadas no estudo paramétrico............................................................................... 134

Tabela 4.6 - Valores de velocidade do fluido circulante (juntamente à vazão, número de

Reynolds e tipo de regime) utilizados no estudo paramétrico ............................................. 135

Tabela 4.7 - Tipos de concretos analisados e seus parâmetros térmicos ................................ 136

Tabela 4.8 - Tipos de solos analisados e seus parâmetros térmicos ...................................... 136

Tabela 4.9 - Variação da condutividade térmica do solo........................................................ 137

Tabela 4.10 - Variação do calor específico do solo ............................................................ 137

Tabela 4.11 - Variação da condutividade térmica com o grau de saturação, porosidade e

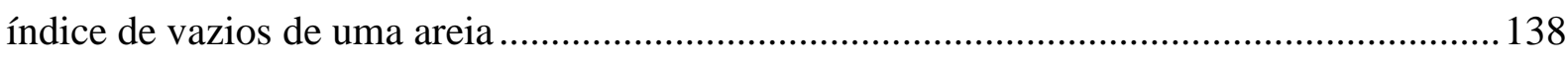

Tabela 5.1 - Comparação dos valores experimentais e numéricos de temperatura de saída do fluido.

Tabela A.1 - Detalhamento dos valores de incerteza combinada e desvio em termos de temperatura de saída para os instantes $50 \mathrm{~h}, 100 \mathrm{~h}$ e $200 \mathrm{~h}$

Tabela A.2 - Síntese dos valores de temperatura de saída experimental e desvio associados à raiz da incerteza combinada

Tabela A.3 - Detalhamento dos valores de incerteza combinada em termos de vazão mássica para os instantes $50 \mathrm{~h}, 100 \mathrm{~h}$ e $200 \mathrm{~h}$ 
Tabela A.4 - Síntese dos valores de temperatura de vazão mássica associados à raiz da incerteza combinada 


\section{LISTA DE ABREVIATURAS E SIGLAS}

ABNT - Associação Brasileira de Normas Técnicas

ASHP - Air Source Heat Pump

CEN - Comité Européen de Normalisation

CFD - Computational Fluid Dynamics

CICS - Centro de Inovação em Construção Sustentável

COP - Coefficient of Performance

CPVC - Policloreto de Vinila Clorado

EESC - Escola de Engenharia de São Carlos

EPUSP - Escola Politécnica da Universidade de São Paulo

FEI - Fundação Educacional Inaciana

GSHP - Ground Source Heat Pump

IGSHPA - International Ground Source Heat Pump Association

$\mathrm{K}$ - Potássio

MDF - Método das Diferenças Finitas

MEF - Método dos Elementos Finitos

MVF - Método dos Volumes Finitos

NBR - Norma Brasileira

OGS - OpenGeoSys

PEAD - Polietileno de Alta Densidade

PEX - Polietileno Reticulado Monocamada

PT 100 - Platinum Resistance Thermometers

PVC - Policloreto de Vinila

RMS - Root Mean Square

SP - São Paulo

SPT - Standard Penetration Test

$\mathrm{T}$ - Térmico

TH - Termo Hidráulico

Th - Tório

THM - Termo Hidro Mecânico

TM - Termo Mecânico

TRT - Teste de Resposta Térmica

T s exp. - Temperatura de saída do fluido circulante experimental 
T s num. - Temperatura de saída do fluido circulante numérica

U - Urânio

UENF - Universidade Estadual do Norte Fluminense

UnB - Universidade de Brasília

USP - Universidade de São Paulo 


\section{LISTA DE SÍMBOLOS}

$A_{0}$ - Amplitude da flutuação de temperatura superficial (K)

$a_{p}$ - Coeficiente representativo do volume de controle obtido na discretização das equações de conservação

$A_{s}$ - Área normal à direção de transferência de calor por condução $\left(\mathrm{m}^{2}\right)$

$C$ - Capacidade térmica do material (J.K $\left.\mathrm{K}^{-1}\right)$

$c$ - Calor específico do material $\left(\mathrm{J} \cdot \mathrm{kg}^{-1} \cdot \mathrm{K}^{-1}\right)$

$C O P_{\text {aquec }}$ - Coeficiente de Desempenho no ciclo de aquecimento

$\mathrm{COP}_{\text {Rev,aquec }}$ - Coeficiente de Desempenho reversível no ciclo de aquecimento

COP $P_{\text {refr }}$ - Coeficiente de Desempenho no ciclo de refrigeração

COP $P_{\text {Rev,refr }}$ - Coeficiente de Desempenho reversível no ciclo de refrigeração

$c_{p}$ - Capacidade térmica do material a pressão constante $\left(\mathrm{J} \mathrm{kg}^{-1} \cdot \mathrm{K}^{-1}\right)$

$c_{w}$ - Capacidade térmica específica da água, equivalente a $4182 \mathrm{~J} \cdot \mathrm{kg}^{-1} \cdot \mathrm{K}^{-1}$

$D$ - Diâmetro da tubulação (m)

$d T / d x$ - Gradiente de temperatura na direção analisada $\left(\mathrm{K} \cdot \mathrm{m}^{-1}\right)$

$h$ - Coeficiente de transferência de calor por convecção $\left(\mathrm{W} \cdot \mathrm{m}^{-2} \cdot \mathrm{K}^{-1}\right)$

$h_{o t}$ - Entalpia específica total $\left(\mathrm{m}^{2} \cdot \mathrm{s}^{-2}\right)$

$\mathrm{k}$ - Condutividade térmica $\left(\mathrm{W} \cdot \mathrm{m}^{-1} \cdot \mathrm{K}^{-1}\right)$

$L$ - Espessura da parede dos tubos de PEAD (m)

$L_{c}$ - Comprimento característico

$m$ - Massa do corpo $(\mathrm{kg})$

$\dot{m}_{\text {entrada }}$ - Vazão mássica de entrada $\left(\mathrm{kg} . \mathrm{s}^{-1}\right)$;

$N u$ - Número de Nusselt

$P$ - Pressão estática $(\mathrm{Pa})$

$q$ - Calor

$\dot{q}$ - Taxa de calor total (W)

$\dot{q}_{\text {cond }}$ - Taxa de energia térmica transferida por condução (W)

$\dot{q}_{c o n v}$ - Taxa de energia térmica transferida por convecção (W)

$\dot{q}_{\text {emit }}$ - Taxa de energia térmica emitida por radiação (W)

$\dot{q}_{\text {rad }}$ - Máxima taxa de energia térmica emitida por radiação (W)

$\dot{q}_{H}$ - Taxa de calor liberado a temperaturas superiores

$\dot{q}_{L}$ - Taxa de calor absorvido a baixas temperaturas 
$R$ - Resistência térmica dos tubos de PEAD $\left(\mathrm{m}^{2} . \mathrm{K}^{-\mathrm{W}^{-1}}\right)$

$R_{b}$ - Resistência térmica da estaca de energia $\left(\mathrm{m} \cdot \mathrm{K}^{-1} \cdot \mathrm{W}^{-1}\right)$

$r_{b}$ - Raio da estaca geotérmica (m)

$R_{e}$ - Número de Reynolds

$S_{E}$ - Termo fonte $\left(\mathrm{W} \cdot \mathrm{m}^{-3}\right)$

$S_{m}$ - Termo fonte $\left(\mathrm{kg} \cdot \mathrm{m}^{-2} \cdot \mathrm{s}^{-2}\right)$

$t$ - Instante de tempo analisado (s)

$T_{E}$ - Temperatura estática $(\mathrm{K})$

$T_{\text {entrada }}$ - Temperatura de entrada $(\mathrm{K})$

$T_{H}$ - Temperatura do meio mais quente

$T_{L}$ - Temperatura do meio mais frio

$T_{\text {méd }}$ - Temperatura média da superfície e do perfil de solo (K)

$T_{s}$ - Temperatura absoluta em que a energia é emitida (K)

$T_{s}$ - Temperatura da superfície $(\mathrm{K})$

$T_{\text {saída }}$ - Temperatura de saída (K)

$T_{\infty}$ - Temperatura do fluido suficientemente longe da superfície $(\mathrm{K})$

$T(0, t)$ - Temperatura na superfície do solo $(\mathrm{z}=0)(\mathrm{K})$

$U$ - Vetor velocidade $\left(\mathrm{m} . \mathrm{s}^{-1}\right)$

$v$ - Velocidade do fluido $\left(\mathrm{m} . \mathrm{s}^{-1}\right)$

V - Volume de controle

$W$ - Trabalho introduzido no sistema

$\alpha$ - Difusividade térmica $\left(\mathrm{m}^{2} \cdot \mathrm{s}^{-1}\right)$

$\delta_{\zeta}$ - Variação da variável qualquer

$\Delta Q$ - Variação de energia térmica do corpo (J)

$\Delta t$ - Passo de tempo (s)

$\Delta T$ - Variação de temperatura do corpo $(\mathrm{K})$

$\Delta T_{f}$ - Variação de temperatura do fluido circulante durante o ensaio (K)

$\varepsilon$ - Dissipação de energia turbulenta

0 - Passo de tempo antecedente

$k$ - Energia cinética turbulenta

$\lambda$ - Coeficiente angular da regressão linear do diagrama de variação da temperatura média do

fluido versus o logaritmo do tempo

$\mu$ - Viscosidade dinâmica do fluido (N.s.m ${ }^{-2}$ ) 
$\rho$ - Massa específica do material $\left(\mathrm{kg} \cdot \mathrm{m}^{-3}\right)$

$\rho_{w}$ - Massa específica da água, equivalente a $10^{3} \mathrm{~kg} \cdot \mathrm{m}^{-3}$

$\sigma$ - Constante de Stefan-Boltzmann, com valor de 5,67 x $10^{-8} \mathrm{~W} \cdot \mathrm{m}^{-2} \cdot \mathrm{K}^{-4}$

$\tau$ - Tensor de tensões $(\mathrm{Pa})$

$\omega$ - Frequência radial $(2 . \pi / 86400 \mathrm{~s})\left(\mathrm{s}^{-1}\right)$ 


\section{INTRODUÇÃO}

Os contínuos processos de desenvolvimento econômico e crescimento populacional em grandes centros urbanos ao redor do mundo motivaram, nos últimos anos, a busca incessante por matrizes energéticas renováveis de caráter sustentável. Em megalópoles, onde a verticalização das construções surge como instrumento preponderante na expansão das cidades, a redução do consumo de energia elétrica na climatização de ambientes internos em edifícios constitui uma importante preocupação.

A utilização de estacas geotérmicas, também denominadas estacas de energia ou estacas trocadoras de calor surgem como possibilidade de se aproveitar as estruturas de fundações profundas de edificações para, em países de clima tropical, dissipar-se a energia térmica de grandes prédios em camadas superficiais de solo. A climatização por aquecimento com estacas geotérmicas já é uma técnica amplamente empregada por países europeus, onde rigorosos invernos tornam mandatórios os gastos com sistemas de calefação (LOVERIDGE e POWRIE, 2013; ROTTA LORIA, 2015), sendo que seu uso cresce, em média, $10 \%$ ao ano (CURTIS et al., 2005). A Figura 1.1 apresenta o total de estacas geotérmicas instaladas e as quantidades de $\mathrm{CO}_{2}$ economizados anualmente, no Reino Unido, a partir do uso de estacas geotérmicas.

Figura 1.1 - Construção de estacas geotérmicas e economia de CO2 no Reino Unido

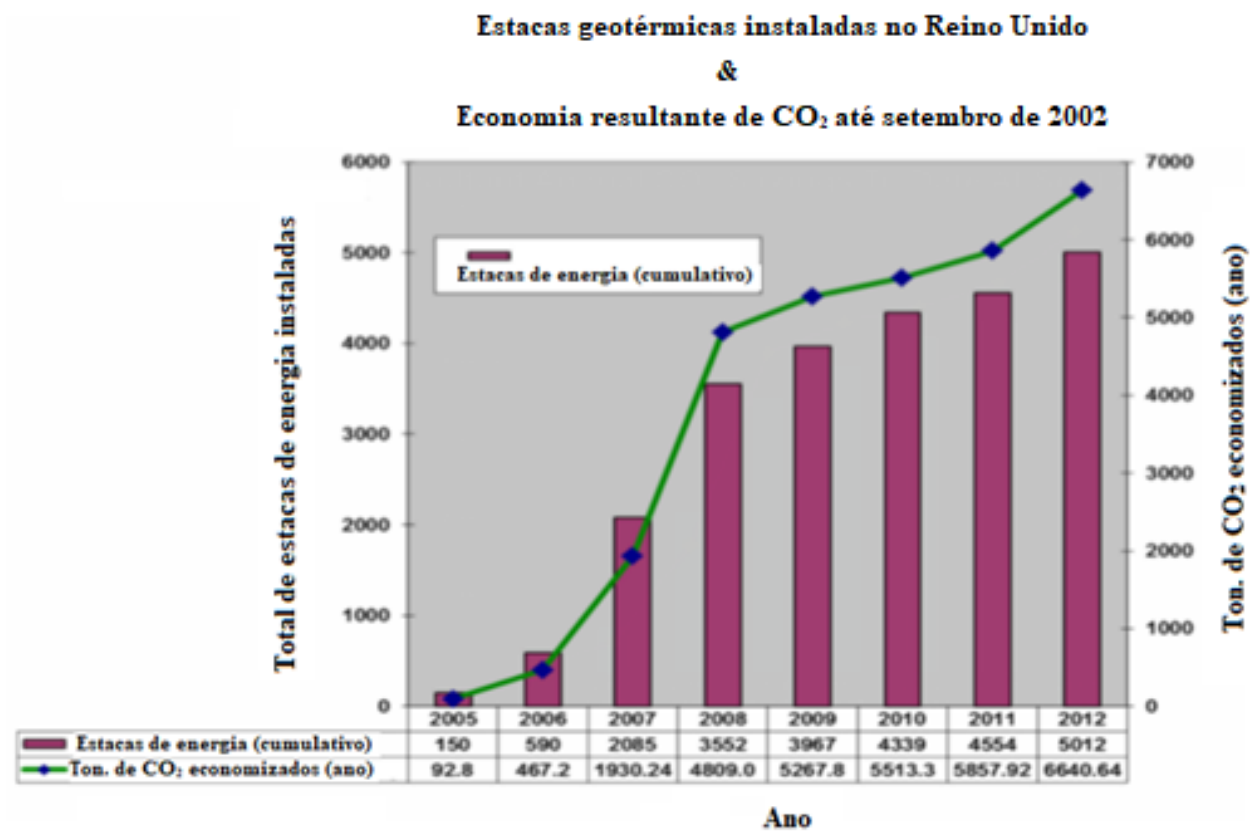

Fonte: Autor, adaptado de Amis e Loveridge (2014) 
O sistema geotérmico de fundações profundas representa um promissor uso de tecnologia de energia renovável, haja vista sua capacidade de resfriamento ou aquecimento de espaços internos de edificações a custos relativamente baixos, além de reduzir a emissão de $\mathrm{CO}_{2}$. Sistemas geotérmicos instalados em furos independentes das fundações dos prédios já vêm sendo utilizados nos Estados Unidos desde 1930 (VILELA, 2004). A Figura 1.2 ilustra o uso de furos no subsolo para promover troca de calor. As estacas geotérmicas, por outro lado, incorporam o sistema de tubos geotérmicos durante a construção da fundação, reduzindo custos de instalação (CARVALHO, 2015).

Figura 1.2 - Esquema ilustrativo de furos trocadores de calor

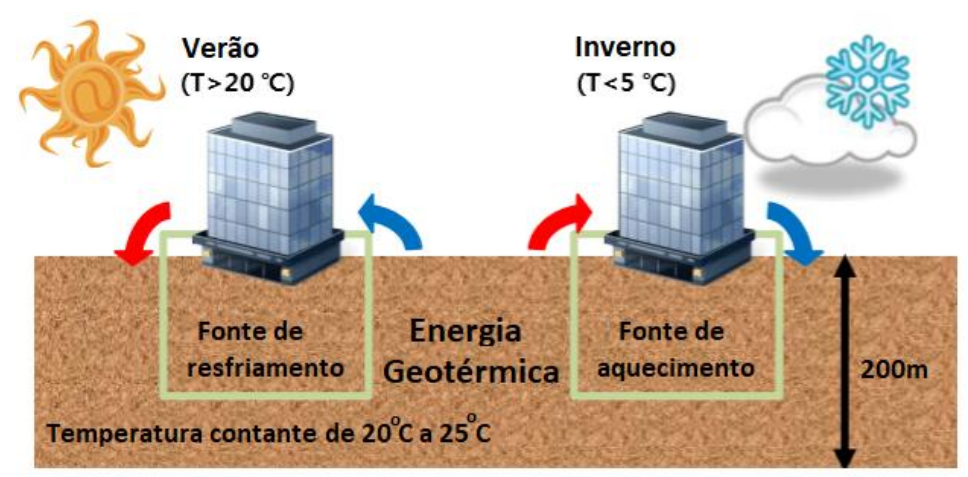

Fonte: Autor, adaptado de Laloui et al. (2006)

A Figura 1.3 exibe a utilização de um sistema de estacas geotérmicas, em substituição aos furos, para a climatização de edifícios e unidades industriais.

Figura 1.3 - Esquema ilustrativo de um sistema de estacas geotérmicas

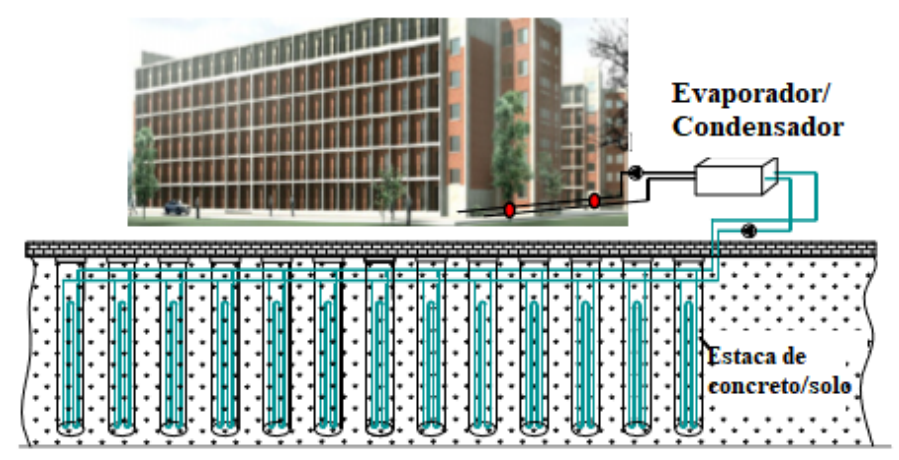

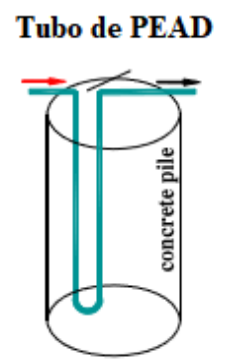

Circuito em "U"
Tubo de PEAD

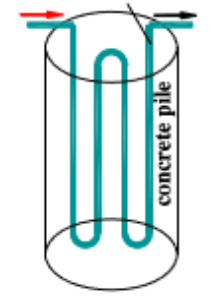

Circuito em "W"

Fonte: Autor, adaptado de Gao et al. (2008) 
Um sistema geotérmico por estacas é basicamente composto por três elementos: a bomba de calor, o sistema trocador de calor com o solo e o sistema de tubos que transmite o ar resfriado ou aquecido para o edifício (KRAMER e BASU, 2014). Tal conjunto, denominado Ground Source Heat Pump (GSHP), fundamenta-se na circulação de um fluido (como água) por um circuito fechado de tubos acoplados à estaca. O sistema GSHP pode ser utilizado para resfriar ou aquecer a habitação ou indústria localizada na superfície, visto que a temperatura no subsolo, a partir de certa profundidade, é constante.

Não obstante a utilização de sistemas trocadores de calor acoplados ao solo desde a década de 1980 na Europa - Brandl (2006) reporta a instalação das primeiras estacas de energia no ano de 1984, na Áustria -, o uso dessa tecnologia no Brasil é ainda incipiente. A linha de pesquisa coordenada pela Profa. Dra. Cristina de Hollanda Cavalcanti Tsuha (coorientadora deste projeto) na Escola de Engenharia de São Carlos da USP (EESCUSP) é pioneira sobre o uso de estacas geotérmicas em solos tropicais. Os trabalhos desenvolvidos até o momento no Brasil tiveram por objeto de estudo a simulação numérica e a análise experimental de estacas piloto, iniciando-se neste ano o primeiro uso reportado de estacas geotérmicas em edificações, no edifício-laboratório CICS Living Lab na Escola Politécnica da USP (EPUSP).

Neste projeto de pesquisa objetiva-se a análise do comportamento térmico de estacas geotérmicas situadas em um solo arenoso saturado, característico do subsolo na EPUSP, por meio de modelagem numérica e da interpretação de um ensaio do tipo Teste de Resposta Térmica (TRT) realizado na área de construção do CICS Living Lab. O subsolo na região é constituído de solo arenoso e saturado, com lençol freático variando sazonalmente de $2 \mathrm{~m}$ a $3 \mathrm{~m}$ de profundidade. O presente trabalho visa contribuir à compreensão do desempenho de estacas geotérmica em solos arenosos e saturados em função de variáveis geotécnicas e geométricas.

Esta dissertação deu início à linha de pesquisa de estacas geotérmicas na EPUSP, com a parceria da EESC-USP, representada pela Profa. Dra. Cristina de Hollanda Cavalcanti Tsuha, que coorienta este trabalho e disponibilizou dados de pesquisas anteriores, e do Centro Universitário FEI, representado pelo Prof. Dr. Cyro Albuquerque Neto, colaborando na modelagem numérica e nas questões de transferência de calor. 


\section{OBJETIVOS}

\subsection{OBJETIVO GERAL}

O presente trabalho tem por objetivo geral o estudo do comportamento térmico de estacas geotérmicas assentes em solo arenoso saturado por meio de simulações numéricas em função de variáveis geotécnicas e geométricas.

\subsection{OBJETIVOS ESPECÍFICOS}

Os objetivos específicos da pesquisa são:

- O desenvolvimento de modelo matemático, por meio do software ANSYS CFX, de uma estaca geotérmica assente em solo saturado;

- Validação do modelo com resultados provenientes de um ensaio TRT executado na Escola Politécnica da Universidade de São Paulo;

- Analisar, a partir do modelo numérico validado, mudanças no comportamento do sistema geotérmico com a alteração de parâmetros geotécnicos, hidráulicos, térmicos e geométricos;

- Distinguir os parâmetros que mais influenciam o desempenho do sistema geotérmico;

- Propor critérios para os parâmetros mais influentes que otimizem o desempenho do sistema geotérmico.

\subsection{ESTRUTURA DO TRABALHO}

O presente trabalho está dividido em sete capítulos. O primeiro capítulo introduz o tema de estacas geotérmicas, mostrando sua importância energética, casos de uso em diferentes países e os princípios da tecnologia Ground Source Heat Pump (GSHP) acoplada a estacas geotérmicas. O segundo capítulo situa os objetivos gerais e específicos da pesquisa. No terceiro capítulo apresenta-se uma revisão bibliográfica que abrange itens referentes à transferência de calor em fluidos e solos, aos fundamentos de sistemas geotérmicos, à interpretação e execução de ensaios TRT e à eficiência de estacas geotérmicas. O terceiro capítulo aborda também os principais trabalhos científicos em 
estacas geotérmicas a partir do enfoque dos comportamentos térmico e termo-hidráulico, termo-hidro-mecânico e termo-hidro-mecânico/químico. No quarto capítulo detalha-se a metodologia empregada para a análise, que inclui: a caracterização geotécnica do solo em que foi realizado o ensaio TRT; o procedimento de execução do ensaio TRT e seus resultados; e os fundamentos teóricos, parâmetros utilizados e hipóteses adotadas na elaboração do modelo numérico. No quinto capítulo são apresentados e discutidos os resultados obtidos pelas simulações numéricas e, quando possível, são feitas comparações com resultados experimentais. No sexto capítulo são apresentadas as conclusões desta pesquisa. No sétimo capítulo são feitas sugestões para novas pesquisas em estacas geotérmicas a partir dos resultados apresentados nesta dissertação. 


\section{REVISÃO BIBLIOGRÁFICA}

No presente item constam princípios e mecanismos de transferência de calor aplicados a solos, comportamento térmico dos solos, funcionamento de sistemas geotérmicos e estacas geotérmicas, ensaios de Teste de Resposta Térmica (TRT) e uma revisão de trabalhos científicos sobre o tema.

\subsection{CONCEITOS FUNDAMENTAIS}

Estacas geotérmicas funcionam como elementos que suportam cargas estruturais e que atuam como trocadores de calor. No interior das fundações há fluido (usualmente água ou etilenoglicol) circulando por tubos (como PEAD), o que constitui um meio de transporte para o calor. Este é transferido da superestrutura ou solo pelos tubos, a depender do propósito do sistema - a energia térmica pode ser transmitida para o solo quando se opera com o intuito de resfriar uma edificação ou pode ser retirada do solo em ciclos de aquecimento de construções (BOUAZZA et al., 2013; NGUYEN et al., 2017).

No sistema solo-estaca ocorrem processos térmicos (ciclos de aquecimento e resfriamento), mecânicos (desenvolvimento de tensões e deformações) e hidráulicos (fluxo de água e mudanças na sucção do solo) acoplados. Por exemplo, quando a estaca transfere calor do edifício para o solo, a dilatação do concreto por aquecimento aumenta a resistência por atrito lateral da fundação, provocando ganhos em sua resistência mecânica. Por outro lado, o resfriamento do conjunto pode ocasionar a redução da resistência do solo por conta da contração da estaca e de um consequente alívio de tensões no maciço de solo (FU, 2017; MURPHY e MCCARTNEY, 2014).

\subsubsection{Mecanismos de transferência de calor}

A fim de fundamentar o fluxo de calor no solo, é necessário conceituar o significado de energia térmica. Energia térmica é aquela relacionada unicamente à temperatura absoluta de um sistema, ao passo que a temperatura de um sistema é diretamente proporcional à energia cinética média de suas moléculas constituintes.

A energia é transmitida - através do elemento transitório denominado calor sempre que houver um gradiente de temperatura no interior de um sistema ou entre sistemas distintos. O calor é definido como a transferência de energia térmica intra ou 
intersistêmica, dada, exclusivamente, pela diferença de temperatura absoluta existente. A unidade de calor pode ser expressa em Joule $\left(1 \mathrm{~J}=1 \mathrm{~kg} \cdot \mathrm{m}^{2} \cdot \mathrm{s}^{-2}\right)$ ou em Caloria (1 Caloria $=4,186 \mathrm{~J})$. O calor é uma grandeza vetorial.

A taxa de transferência de calor constitui-se na transferência de energia térmica (q) em função de uma unidade temporal, ou seja, em taxa de calor $(\dot{q})$ transferida em um dado intervalo de tempo de exposição $(\Delta \mathrm{t})$, de acordo com a Equação (3.1), e é medida em Watt $(\mathrm{J} / \mathrm{s})$.

$$
\dot{q}=\frac{q}{\Delta t}
$$

O fluxo térmico - também denominado fluxo de calor - é a taxa de transferência de calor por unidade de área perpendicular à direção de transferência de calor, medido em W.m ${ }^{-2}$. Este fluxo consiste em grandeza vetorial, com direção igual à do gradiente de temperatura e sentido oposto ao mesmo, e módulo calculado pela Equação (3.2).

$$
q^{\prime \prime}=\frac{\dot{q}}{A}=\frac{q}{\Delta t A}
$$

Há três mecanismos de transferência de calor: condução, convecção e irradiação. Além disso, há o fenômeno do calor latente ou calor de transformação, que é a quantidade de calor que uma unidade de massa de determinada substância deve receber ou ceder para mudar de fase. Por exemplo, a água absorve calor para sua evaporação; em seguida, ocorre o movimento convectivo do vapor e sua posterior condensação, com liberação de energia (HILLEL, 1998).

\subsubsection{Condução}

Condução é a forma de transferência de calor de partículas com maior energia térmica (maior agitação molecular) para partículas de menor energia térmica (menor agitação molecular) em virtude de interações entre as partículas de uma substância. Apesar de ser um fenômeno predominante em sólidos, a condução também ocorre em líquidos e gases (ÇENGEL, 2003).

A taxa de condução de calor por um dado meio depende de fatores como sua geometria, material constituinte e gradiente de temperatura. Além disso, a taxa de 
transferência de calor em uma direção por dado plano é proporcional à diferença de temperatura (naquela direção) e à área normal ao fluxo de calor, mas inversamente proporcional à espessura do meio, segundo a Lei de Fourier para a transmissão de calor por condução, expressa pela Equação (3.3):

$$
\dot{q}_{\text {cond }}=-k \cdot A_{s} \cdot d T / d x
$$

Em que:

- $\dot{q}_{\text {cond }}$ é a taxa de energia térmica transferida por condução (W);

- $k$ é a condutividade térmica do material, isto é, a medida da capacidade do material transmitir calor $\left(\mathrm{W} \cdot \mathrm{m}^{-1} \cdot \mathrm{K}^{-1}\right)$;

- $\quad A_{s}$ é a área normal à direção de transferência de calor por condução $\left(\mathrm{m}^{2}\right)$;

- $d T / d x$ é o gradiente de temperatura, ou seja, a razão entre a diferença de temperatura e a espessura do meio $\left(\mathrm{K} \cdot \mathrm{m}^{-1}\right)$.

O sinal negativo da Equação de Fourier deve-se ao fato de que o calor é conduzido na direção em que há redução de temperatura, o que torna o gradiente negativo conforme as temperaturas diminuem para valores crescentes de $x$. O sinal negativo garante que o valor de energia seja expresso em quantidade positiva (CARSLAW e JAEGER, 1986). Em solos anisotrópicos, a condutividade térmica apresenta diferentes valores conforme as direções analisadas $\left(k_{x}, k_{y}, k_{z}\right)$.

Em estacas geotérmicas, o processo de condução ocorre na parede dos tubos de PEAD, na estrutura sólida da estaca (concreto, aço e tubos de PEAD), na água, no contato entre solo e estaca e no interior do maciço de solo (contato entre os grãos).

\subsubsection{Convecção}

Convecção é o modo de transferência de calor que ocorre entre um fluido e uma superfície limitante (sólida ou outro fluido) devido ao movimento do próprio fluido. $\mathrm{O}$ fenômeno envolve efeitos combinados de condução e movimentação de fluidos. Por um lado, movimentações mais rápidas de fluidos aumentam a troca térmica por convecção. Por outro lado, fluidos em repouso condicionam a troca térmica entre superfícies sólidas e fluidos adjacentes à pura condução (KAYS e CRAWFORD, 1993). 
A convecção pode ser natural ou forçada. A convecção natural é causada pelas diferenças de densidade em uma massa de fluido associadas a regiões com diferentes temperaturas e pressões. É provocada por forças de empuxo induzidas por diferentes massas específicas em função da variação da temperatura e pressão na massa do fluido. Na convecção forçada, o fluido é forçado a transitar sobre uma superfície por ação de meios externos, a exemplo de ventoinhas, bombas e vento. Ou seja, a convecção forçada é resultante do movimento do fluido imposto externamente por um gradiente hidráulico.

A Lei de Resfriamento de Newton expressa matematicamente o fenômeno de transferência de calor por convecção, conforme Equação (3.4):

$$
\dot{q}_{\text {conv }}=h \cdot A_{s} \cdot\left(T_{s}-T_{\infty}\right)
$$

Em que:

- $\dot{q}_{c o n v}$ é a taxa de energia térmica transferida por convecção (W);

- $\quad h$ é o coeficiente de transferência de calor por convecção $\left(\mathrm{W} \cdot \mathrm{m}^{-2} \cdot \mathrm{K}^{-1}\right)$;

- $A_{s}$ é a área da seção transversal pela qual ocorre a transmissão de calor $\left(\mathrm{m}^{2}\right)$;

- $T_{s}$ é a temperatura da superfície (K);

- $T_{\infty}$ é a temperatura do fluido suficientemente longe da superfície (K).

O coeficiente de transferência de calor por convecção não é uma propriedade do fluido, mas um parâmetro determinado experimentalmente cujo valor depende das variáveis que influenciam o fenômeno físico, a exemplo da superfície e geometria do meio, da velocidade do fluido (fluxo advectivo) e do regime correspondente (laminar ou turbulento, em diferentes níveis) (VILELA, 2004).

Em problemas envolvendo convecção forçada em tubos, é comum adimensionalizar o coeficiente $h$, como mostra a Equação (3.5):

$$
N u=\frac{h \cdot L_{c}}{k}
$$

Em que:

- $\quad N u$ é o número de Nusselt;

- $L_{c}$ é o comprimento característico. 
O número de Nusselt representa o ganho em termos de transferência de calor como resultado da relação convecção/condução em um fluido. Quanto maior o número de Nusselt, maior é a efetividade da troca de calor por convecção.

A relação entre o número de Nusselt e a vazão do fluido (através do número de Reynolds) em problemas de convecção forçada interna em tubos circulares com fluxo laminar é apresentada pela Equação de Colburn, sintetizada na Equação (3.6):

$$
N u=0,023 \cdot \operatorname{Re}^{4 / 5} \cdot \operatorname{Pr}^{1 / 3}
$$

Em que $\operatorname{Pr}$ representa o número de Prandtl, definido pela Equação (3.7):

$$
\operatorname{Pr}=\frac{\text { Difusividade molecular da quantidade de movimento }\left(\mathrm{m}^{2} / \mathrm{s}\right)}{\text { Difusividade molecular de calor }\left(\mathrm{m}^{2} / \mathrm{s}\right)}=\frac{v}{\alpha}
$$

Para água, o número de Prandtl varia de 1,7 a 13,7 (SIDEBOTHAM, 2015).

Para escoamentos turbulentos em tubos circulares, quando o fluido é aquecido, utiliza-se a Equação (3.8):

$$
N u=0,023 \cdot \operatorname{Re}^{4 / 5} \cdot \operatorname{Pr}^{0,4}
$$

Na prática, é comum a utilização de fluxo turbulento para convecção forçada interna, pois o coeficiente de transferência de calor por convecção é maior.

Em estacas geotérmicas pode ocorrer convecção: entre a água e o ar presentes nos vazios do solo (convecção natural), a água no interior da tubulação (convecção forçada), e na troca térmica das superfícies de solo e concreto com o ar (convecção natural e, na ocorrência de vento, convecção forçada) (BAYESTEH et al., 2016).

\subsubsection{Radiação}

Radiação é a energia emitida na forma de ondas eletromagnéticas (ou fótons) como resultado de alterações nas configurações eletrônicas de átomos e moléculas (HOWELL et al., 2016). Uma das principais diferenças entre a radiação e os outros mecanismos de transferência de calor é o fato de que, na radiação, o fluxo térmico não 
depende de um meio interveniente, ocorrendo com maior velocidade no vácuo, onde os fótons ou ondas eletromagnéticas transitam na velocidade da luz.

A Lei de Stefan-Boltzmann determina a máxima taxa de radiação que pode ser emitida dada uma temperatura absoluta $T_{s}$, como exibe a Equação (3.9):

$$
\dot{q}_{\text {rad }}=\sigma \cdot A_{s} \cdot T_{s}^{4}
$$

Em que:

- $\dot{q}_{\text {rad }}$ é a máxima taxa de energia térmica emitida por radiação (W);

- $\sigma$ é a constante de Stefan-Boltzmann, com valor de 5,67 x $10^{-8} \mathrm{~W} \cdot \mathrm{m}^{-2} \cdot \mathrm{K}^{-4}$;

- $A_{s}$ é a área da superfície pela qual a energia é emitida $\left(\mathrm{m}^{2}\right)$;

- $T_{s}$ é a temperatura absoluta em que a energia é emitida (K).

A radiação térmica é emitida por corpos em virtude de sua temperatura (isto é, todos os corpos acima do zero absoluto emitem radiação térmica). A transmissão de calor por irradiação é tão mais significativa quanto maior o aumento de temperatura de um objeto. A radiação é um fenômeno que ocorre em sólidos, líquidos e gases, que emitem, absorvem e transmitem radiação térmica. Por outro lado, há sólidos que são considerados opacos à radiação térmica, como metais e madeiras, uma vez que a radiação emitida pelo interior de tais materiais não atinge sua superfície. Segundo Incropera et al. (2007), frequentemente os líquidos são admitidos como superfícies opacas (porções de irradiação são refletidas); os gases são considerados transparentes (porções de irradiação são transmitidas); e os sólidos podem ser classificados como opacos.

Um conceito fundamental para a compreensão da radiação térmica é o do corpo negro - nesse tipo de superfície a radiação seria emitida integralmente. Em condições reais a taxa de calor emitida é inferior à radiação do corpo negro (BERGMAN et al., 2007) e a Equação (3.9) é reduzida por um fator $\varepsilon$, denominado emissividade, que varia no intervalo $0 \leq \varepsilon \leq 1$, como sintetiza a Equação (3.10):

$$
\dot{q}_{\text {emit }}=\varepsilon \cdot \sigma \cdot A_{s} \cdot T_{s}^{4}
$$

Em que:

- $\dot{q}_{\text {emit }}$ é a taxa de energia térmica emitida por radiação (W). 
A absortividade $\alpha$ é a fração da energia incidente por radiação que é absorvida por uma superfície. Seu valor também se encontra no intervalo $0 \leq \alpha \leq 1$ e um corpo negro é, além de um perfeito emissor $(\varepsilon=1)$, um perfeito absorvedor $(\alpha=1)$. Em superfícies opacas, a porção de energia incidente não absorvida pela superfície é refletida (MODEST, 2013). A Equação (3.11) representa matematicamente tais considerações:

$$
\dot{q}_{\text {absorvida }}=\alpha \cdot \dot{q}_{\text {incidente }}
$$

A diferença entre as taxas de radiação emitida e absorvida por uma superfície é denominada transferência líquida de calor por radiação. Caso a taxa de radiação absorvida seja maior do que a taxa de radiação emitida a superfície ganhará energia. Do contrário, a superfície perderá energia por radiação.

No caso de uma superfície em uma temperatura absoluta $T_{s}$, completamente coberta por uma superfície negra ou de maior temperatura $T_{r e d o r}$, a taxa de transferência líquida de calor por radiação será dada pela Equação (3.12):

$$
\dot{q}_{\text {rad }}=\varepsilon \cdot \sigma \cdot A_{s} \cdot\left(T_{s}{ }^{4}-T_{\text {redor }}{ }^{4}\right)
$$

Em estacas geotérmicas esse mecanismo pode ser notado na superfície do solo, que recebe calor, através do sol, na forma de ondas eletromagnéticas. Pelo fato de a temperatura superficial do solo estar em torno de $300 \mathrm{~K}$, a radiação emitida por sua superfície possui picos em comprimentos de onda de cerca de $10 \mu \mathrm{m}$ (HILLEL, 1998). Além disso, o solo troca calor por radiação com o céu e as vizinhanças.

\subsubsection{Propriedades térmicas dos solos}

Os parâmetros mais pertinentes do solo são: capacidade térmica, condutividade térmica e difusividade térmica, dependentes do peso específico e da umidade dos solos (HILLEL, 1998; LEE et al., 2013; SÁNCHEZ et al., 2015; HASSEN et al., 2016).

\subsubsection{Capacidade térmica e calor específico}

A capacidade térmica de um material é definida como sua propriedade de armazenar energia térmica (BERGMAN et al., 2007; GAO et al., 2008; BRETTMAN et 
al., 2010). A capacidade térmica (C) relaciona a quantidade de energia na forma de calor fornecida a um corpo à variação de temperatura por ele experimentada.

A capacidade térmica pode ser expressa pela Equação (3.13):

$$
C=\frac{\Delta q}{\Delta T}
$$

Em que:

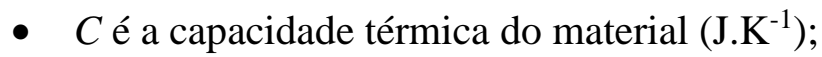

- $\Delta q$ é a variação de energia térmica do corpo (J);

- $\Delta T$ é a variação de temperatura do corpo $(\mathrm{K})$.

A capacidade térmica por unidade de massa corresponde ao calor específico (também designado capacidade térmica específica) (c), como assinala a Equação (3.14):

$$
c=\frac{C}{m}=\frac{\Delta q}{m \cdot \Delta T}
$$

Em que:

- $\quad c$ é o calor específico do material $\left(\mathrm{J} \cdot \mathrm{kg}^{-1} \cdot \mathrm{K}^{-1}\right)$;

- $m$ é a massa do corpo $(\mathrm{kg})$;

- $C$ é a capacidade térmica do material $\left(\mathrm{J} . \mathrm{K}^{-1}\right)$.

Em solos, a capacidade térmica depende da composição mineralógica e orgânica da fase sólida do material, de sua massa específica aparente e, principalmente, da quantidade de água no solo (FU, 2017; BOUAZZA et al., 2013).

A capacidade térmica dos solos pode ser estimada a partir da soma ponderada da capacidade térmica das fases que compõe o solo (sólido, água e ar). Além disso, a maior parte dos minerais que constituem o solo possuem valores bastante próximos de densidade dos grãos (cerca de 2,65 g. $\mathrm{cm}^{-3}$ ) e de capacidade térmica volumétrica (cerca de 2,0 x $\left.10^{6} \mathrm{~J}^{\mathrm{m}} \mathrm{m}^{-3} \cdot \mathrm{K}^{-1}\right)($ HILLEL, 1998; NARSILIO et al., 2015).

A Tabela 3.1 ilustra valores de capacidade calorífica volumétrica e capacidade térmica específica de solos compilados por Lhendup et al. (2014). 
Tabela 3.1 - Valores típicos de capacidade térmica para diferentes solos

\begin{tabular}{ccc}
\hline Material & $\begin{array}{c}\text { Capacidade térmica } \\
\text { volumétrica }\left(\mathrm{kJ} \cdot \mathrm{m}^{-3} \cdot \mathrm{K}^{-1}\right)\end{array}$ & $\begin{array}{c}\text { Capacidade térmica } \\
\text { específica }\left(\mathrm{J} \cdot \mathrm{kg}^{-1} \cdot \mathrm{K}^{-1}\right)\end{array}$ \\
\hline Pedregulho & $2200-2700$ & $846,2-1038,5$ \\
Areia & $2500-3000$ & $1315,8-1578,9$ \\
Silte & $2500-3100$ & $1389,9-1722,2$ \\
Argila & $2200-3200$ & $1294,1-1882,4$ \\
\hline
\end{tabular}

Fonte: Autor, adaptado de Lhendup et al., 2014

\subsubsection{Condutividade térmica}

Define-se a condutividade térmica $(k)$ como a taxa de calor transferida através da unidade de espessura de um material por unidade de área e por unidade de diferença de temperatura. Portanto, a condutividade térmica de um material reflete sua capacidade de conduzir calor. Materiais com altos valores de condutividade térmica são designados condutores, enquanto baixos valores de condutividade térmica são indicadores da existência de um material isolante térmico (OZUDOGRU e OLGUN, 2014; GEHLIN e NORDELL, 1998; MIMOUNI, 2014).

A partir da Lei de Fourier é possível definir matematicamente a condutividade térmica, conforme a Equação (3.16):

$$
k=-\frac{\dot{q}_{c o n d}}{d T / d x}
$$

Em que:

- $\dot{q}_{\text {cond }}$ é a taxa de energia térmica transferida por condução (W.m²);

- $k$ é a condutividade térmica do material $\left(\mathrm{W} \cdot \mathrm{m}^{-1} \cdot \mathrm{K}^{-1}\right)$;

- $d T / d x$ é o gradiente de temperatura na direção analisada $\left(\mathrm{K}^{-\mathrm{m}^{-1}}\right)$.

A condutividade térmica dos solos depende de sua composição mineralógica e do teor de matéria orgânica, além das frações em volume de água e ar. Considerando-se que a condutividade térmica do $\operatorname{ar}\left(0,025 \mathrm{~W} \cdot \mathrm{m}^{-1} \cdot \mathrm{K}^{-1}\right)$ é bastante inferior à condutividade da água $\left(0,6 \mathrm{~W} \cdot \mathrm{m}^{-1} \cdot \mathrm{K}^{-1}\right.$ a $\left.10{ }^{\circ} \mathrm{C}\right)$ e do material sólido, a existência de vazios no solo preenchidos 
por ar diminui a condutividade térmica do solo (HILLEL 1998; LHENDUP et al., 2014; SÁNCHEZ et al., 2015).

A Tabela 3.2 mostra resultados experimentais de condutividade térmica em função de diferentes valores de índice de vazios e grau de saturação em um solo arenoso, enquanto a Tabela 3.3 ilustra valores de condutividade térmica de diferentes tipos de solo. Já a Tabela 3.4 apresenta a condutividade térmica dos constituintes do solo à temperatura de referência de $10{ }^{\circ} \mathrm{C}$.

Tabela 3.2 - Valores de condutividade térmica em função de diferentes graus de saturação e índices de vazios em um solo arenoso

\begin{tabular}{ccc}
\hline Grau de saturação & Índice de vazios & Condutividade térmica $\left(\mathrm{W} \cdot \mathrm{m}^{-1} \cdot \mathrm{K}^{-1}\right)$ \\
\hline 0,015 & 0,80 & 0,90 \\
0,188 & 0,87 & 1,35 \\
0,311 & 0,78 & 1,75 \\
0,480 & 0,81 & 2,10 \\
0,715 & 0,79 & 2,40 \\
1,000 & 0,81 & 2,65 \\
\hline
\end{tabular}

Fonte: Autor, adaptado de Sánchez et al., 2015

Tabela 3.3 - Valores típicos de condutividade térmica para diferentes solos

\begin{tabular}{cc}
\hline Material & Condutividade térmica $\left(\mathrm{W} \cdot \mathrm{m}^{-1} \cdot \mathrm{K}^{-1}\right)$ \\
\hline Pedregulho & $2,0-3,3$ \\
Areia & $1,5-2,5$ \\
Silte & $1,4-2,0$ \\
Argila & $0,9-1,8$ \\
\hline
\end{tabular}

Fonte: Autor, adaptado de Lhendup et al., 2014 
Tabela 3.4 - Valores de condutividade térmica à temperatura de $10{ }^{\circ} \mathrm{C}$

\begin{tabular}{ccc}
\hline Material & Condutividade térmica $\left(\mathrm{W} \cdot \mathrm{m}^{-1} \cdot \mathrm{K}^{-1}\right)$ & Referência \\
\hline Quartzo & 8,80 & Lhendup et al. (2014) \\
Gibsita & 2,60 & Hokai (1971) \\
Caulinita & 2,80 & Midttomme et al. (1997) \\
Hematita & 11,29 & Hokai (1971) \\
Goethita & 2,91 & Hokai (1971) \\
Rutilo & 5,12 & Hokai (1971) \\
Ilita & 1,80 & Hokai (1971) \\
Matéria orgânica & 0,25 & Lhendup et al. (2014) \\
Água (líquida) & 0,57 & Lhendup et al. (2014) \\
Gelo & 2,20 & Lhendup et al. (2014) \\
Ar & 0,025 & Lhendup et al. (2014) \\
\hline
\end{tabular}

A ordem de grandeza da condutividade térmica de solos é inferior a de metais (um bom condutor como o cobre possui $k=380 \mathrm{~W} \cdot \mathrm{m}^{-1} \cdot \mathrm{K}^{-1}$ ), mas superior a de gases (um mau condutor como o dióxido de carbono possui $\left.k=0,014 \mathrm{~W} \cdot \mathrm{m}^{-1} \cdot \mathrm{K}^{-1}\right)$. É possível observar na Tabela 3.4 como a reduzida condutividade térmica do ar o caracteriza como um isolante térmico quando comparado à condutividade térmica dos demais materiais.

\subsubsection{Difusividade térmica}

Descreve-se a difusividade térmica como a capacidade que um material possui de conduzir calor em comparação à sua disposição de armazenar energia térmica. Trata-se a difusividade térmica como uma representação de o quão rápido o calor se difunde por um material. Em termos matemáticos, tal propriedade pode ser expressa pela Equação (3.15):

$$
\alpha=\frac{k}{\rho \cdot c_{p}}
$$

Em que:

- $\alpha$ é a difusividade térmica $\left(\mathrm{m}^{2} \cdot \mathrm{s}^{-1}\right)$;

- $\quad c_{p}$ é a capacidade térmica do material a pressão constante $\left(\mathrm{J} \mathrm{kg}^{-1} \cdot \mathrm{K}^{-1}\right)$; 
- $\quad k$ é a condutividade térmica do material $\left(\mathrm{W} \cdot \mathrm{m}^{-1} \cdot \mathrm{K}^{-1}\right)$;

- $\rho$ é a densidade aparente do material $\left(\mathrm{kg} \cdot \mathrm{m}^{-3}\right)$.

0 produto $\rho . c_{p}$ representa a capacidade de armazenamento de calor de um material por unidade de volume. Ao dispor-se do quociente entre a condutividade térmica $k$ e da capacidade térmica $\rho . c_{p}$, obtém-se uma razão entre o quão bem um material conduz calor pela sua capacidade de armazená-lo. Solos com altos valores de densidade, em estado seco, apresentam difusividades de cerca de $0,52 \times 10^{-6} \mathrm{~m}^{2} . \mathrm{s}^{-1}$ (HILLEL, 1998; CARVALHO, 2015).

\subsubsection{Transferência de calor em solos}

No interior de maciços de solos, o mecanismo de transferência de calor predominante é a condução, governada pela Lei de Fourier (MITCHELL, 1993; SÁNCHEZ et al., 2015; MCCARTNEY et al., 2013; FARE, 2015; LOVERIDGE e POWRIE, 2013; HILLEL, 1998). Isto ocorre pois os fluxos térmicos por convecção e radiação são desprezíveis quando comparados à taxa de calor transmitida por condução. A radiação pode ser considerada irrelevante em condições usuais e a convecção é considerável somente em casos com elevada disponibilidade de água ou ar, isto é, em solos e rochas de alta permeabilidade e saturados.

\subsubsection{Comportamento da temperatura superficial}

A temperatura superficial do solo está sujeita a variações climáticas e atmosféricas. Fatores geográficos (regiões de clima seco, chuvoso ou sujeito a nevascas, em caráter perene ou sazonal) e temporais (a exemplo de consideráveis amplitudes térmicas diárias), bem como condições topográficas e de cobertura vegetal, influenciam diretamente a troca térmica da superfície do solo com o ar atmosférico (BRANDL, 2006; HILLEL, 1998; SÁNCHEZ et al., 2018).

Para solos lateríticos da região de São Carlos, a temperatura do solo a partir de profundidades de $4 \mathrm{~m}$ tende a ser aproximadamente constante e da ordem de $24{ }^{\circ} \mathrm{C}$ (BANDEIRA NETO, 2015; MORAIS e TSUHA, 2016). You et al. (2017) verificaram uma tendência de estabilização de temperaturas em cerca de $16^{\circ} \mathrm{C}$ a partir de $10 \mathrm{~m}$ de 
profundidade para subsolos da região de Tianjin, China. Em Cecinato e Loveridge (2015) apresenta-se a temperatura de $12{ }^{\circ} \mathrm{C}$ como representativa dos solos da Europa Central. Nagano et al. (2005) mediram temperaturas médias de $9,3^{\circ} \mathrm{C}$ a partir de profundidades de 5 m em regiões frias do Japão. Estudos de Brandl (2006) corroboram a tendência de estabilização da temperatura natural do solo a partir de determinada profundidade, conforme explicita a Figura 3.1:

Figura 3.1 - Comportamento da temperatura com a profundidade do solo

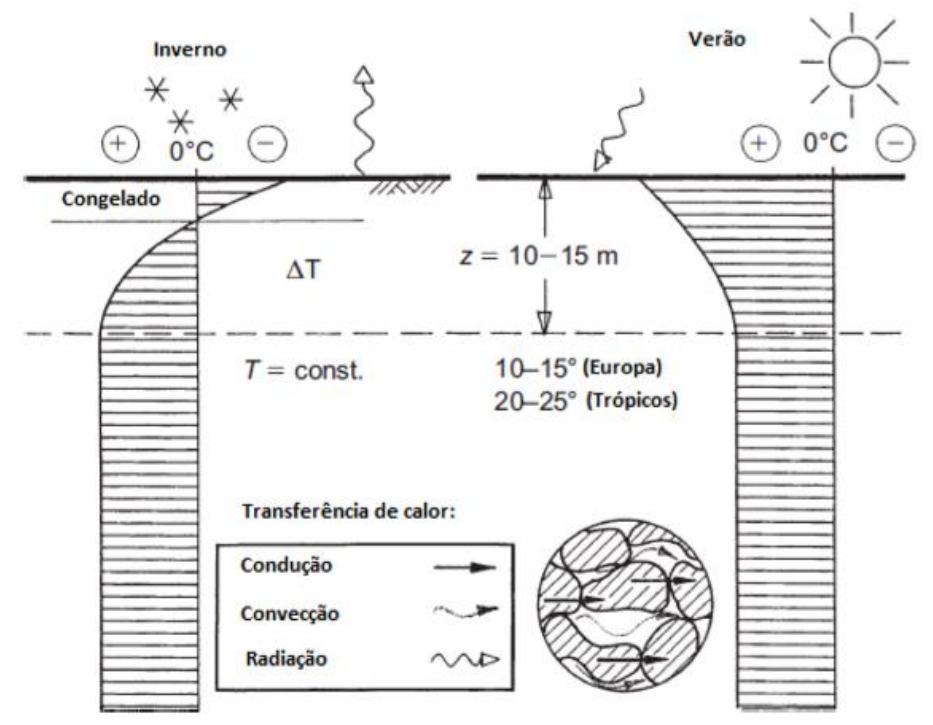

Fonte: Autor, adaptado de Brandl (2006)

Para analisar o comportamento da temperatura superficial do solo, é comum a proposição de um modelo matemático fundamentado na premissa, ainda que simplificada, de que em todas as profundidades a oscilação da temperatura é sinusoidal e puramente harmônica. Assume-se a existência de uma temperatura média para todo o subsolo e são desprezados os efeitos de variações em parâmetros como refletividade, capacidade térmica e condutividade térmica (conforme o solo umedece ou seca) (HILLEL, 1998; MURPHY e MCCARTNEY, 2014). Em termos gerais e para condições diárias, tal proposição é apresentada pela Equação (3.17):

$$
T(0, t)=T_{\text {méd }}+A_{0} \cdot \operatorname{sen}(\omega . t)
$$

Em que:

- $T(0, t)$ é temperatura na superfície do solo $(\mathrm{z}=0)(\mathrm{K})$; 
- $T_{\text {méd }}$ é a temperatura média da superfície e do perfil de solo (K);

- $A_{0}$ é a amplitude da flutuação de temperatura superficial (K);

- $\omega$ é a frequência radial $(2 . \pi / 86400 \mathrm{~s})\left(\mathrm{s}^{-1}\right)$;

- $t$ é o instante de tempo analisado (s).

A Figura 3.2 ilustra a função idealizada de flutuação da temperatura superficial do solo.

Figura 3.2 - Função idealizada de flutuação da temperatura superficial do solo

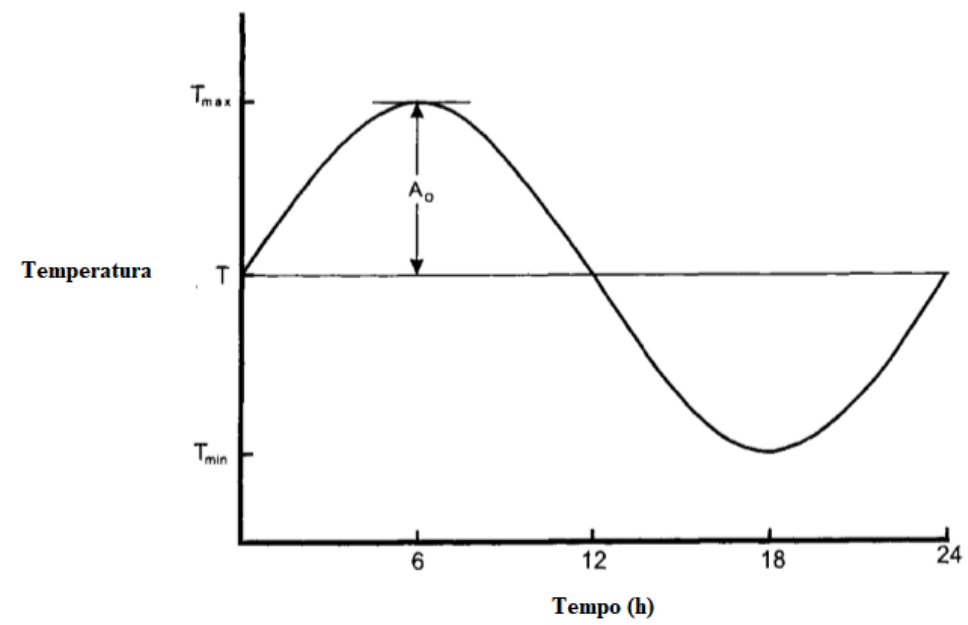

Fonte: Autor, adaptado de Hillel (1998)

\subsubsection{A influência de propriedades geotécnicas na troca térmica dos solos}

Considerando-se que a condução é o mecanismo predominante de transferência de calor em solos, é possível inferir que o aumento da porosidade de um solo resulta na redução de sua condutividade térmica, uma vez que maiores e mais numerosos vazios tendem a diminuir a superfície de contato para a condução de calor entre os grãos de solo. Por outro lado, menores índices de vazios correspondem a maiores densidades. Portanto, infere-se que densidade e condutividade térmica são diretamente proporcionais (MURPHY et al., 2013; YOU et al., 2017).

A concentração de determinados tipos de minerais - olivinas, piroxênios, anfibolitos e, em especial, o quartzo - aumenta a condutividade térmica de solos, conforme sugere a Tabela 3.3. Por outro lado, o aumento de temperatura pode alterar a condutividade térmica de um mineral: no caso do quartzo, a elevação da temperatura reduz sua condutividade térmica, enquanto para o diabásio, o efeito é contrário. Para a 
amplitude térmica e níveis de temperatura proporcionados por estacas geotérmicas, contudo, tais efeitos não são verificados (HILLEL, 1998; ROBERTSON, 1988).

Em linhas gerais, o aumento do grau de saturação de um solo pode ser interpretado como a substituição de ar (um isolante térmico) que existe entre os poros, por água (que possui maior condutividade térmica, conforme Tabela 3.3). Por estarem em profundidades de solo relativamente pequenas, estacas geotérmicas são suscetíveis a variações sazonais de umidade e grau de saturação, que influenciam diretamente seu comportamento térmico. Em maiores profundidades, sob o nível de água, as trocas térmicas são reduzidas (SÁNCHEZ et al., 2015). A Figura 3.3 ilustra tais afirmações.

Figura 3.3 - Relação entre grau de saturação e trocas térmicas em profundidade

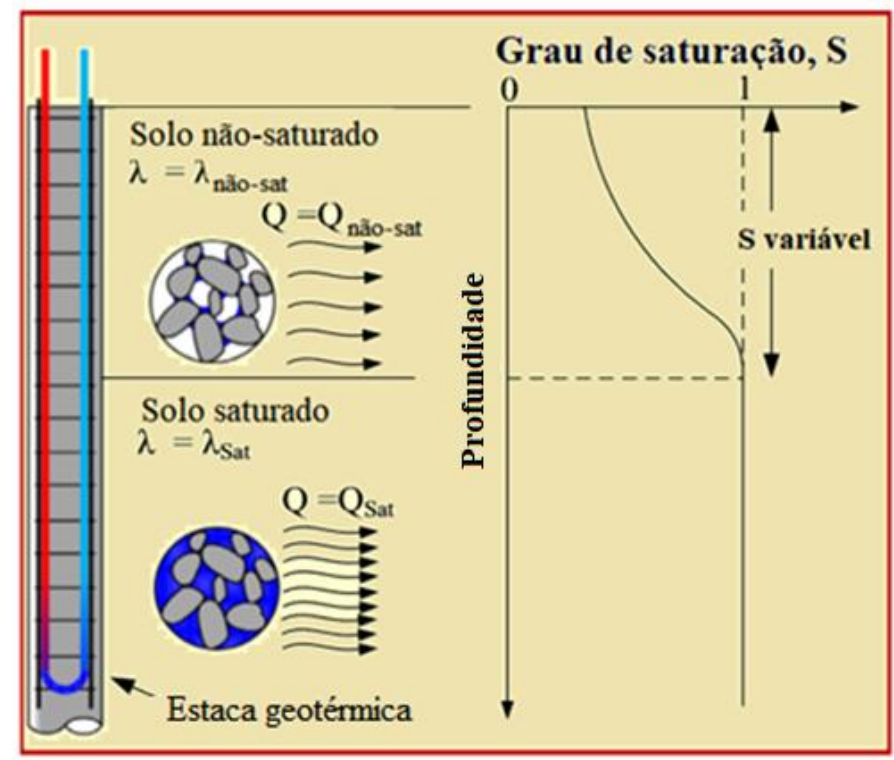

Fonte: Autor, adaptado de Sánchez (2015)

A Figura 3.4 mostra a influência da água nos parâmetros de condutividade e difusividade térmicos de uma areia, uma argila e uma turfa.

Choi et al. (2011) investigaram o desempenho de uma estaca geotérmica em cenários saturado e não saturado. Os resultados mostraram que as flutuações no nível de água ocasionaram uma redução de cerca de $40 \%$ na taxa de troca de calor em comparação ao cenário de saturação completa.

O estado em que o solo se encontra (compacidade ou consistência) também é relevante para o aumento ou diminuição dos parâmetros térmicos do material. Areias compactas e bem graduadas, por exemplo, possuem maior superfície de contato entre as partículas, fator que favorece trocas térmicas por condução (FAROUKI, 1981). 
Figura 3.4 - Condutividade e difusividade térmicas em função da umidade volumétrica

Condutividade térmica do solo

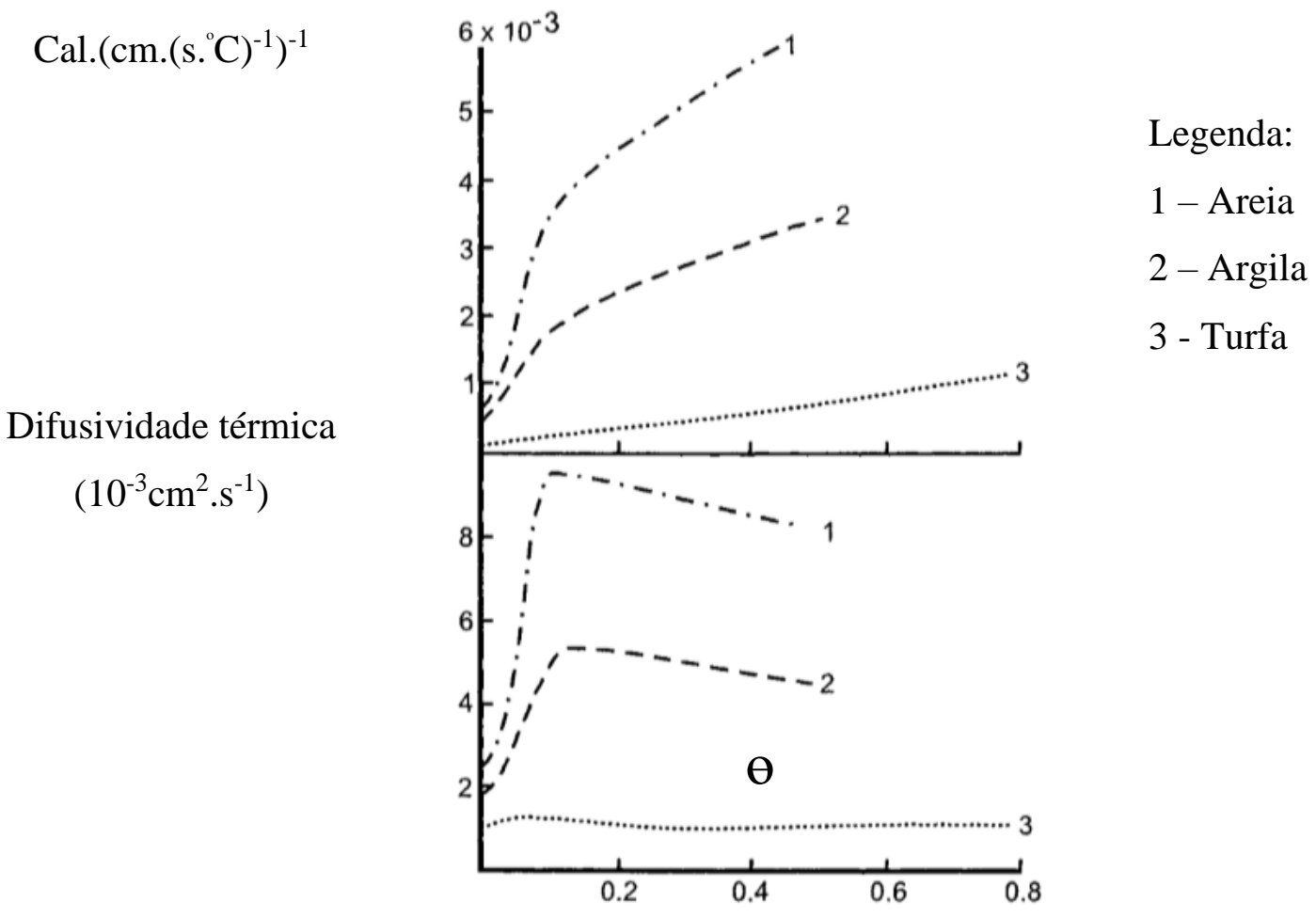

Fonte: Autor, adaptado de Hillel (1998)

Há, entretanto, outras variáveis que influenciam diretamente as propriedades térmicas do solo: tamanho das partículas, formato das partículas e arranjo estrutural são alguns exemplos. Em materiais finos, o aumento da porosidade diminui a influência do formato dos grãos nas trocas térmicas. Cascalhos finos e bem graduados, por sua vez, possuem reduzido índice de vazios e porosidade, o que acarreta maior superfície de contato e torna secundária a importância do formato dos grãos sobre a condutividade do material (CAMPANELLA e MITCHELL, 1968; MORITZ, 1995; OROZCO, 2016).

\subsubsection{Sistemas geotérmicos}

\subsubsection{Energia geotérmica}

Energia geotérmica é aquela presente no interior da Terra e responsável por originar fenômenos geológicos em escala planetária. Os modernos modelos relacionados 
à energia geotérmica partem da premissa de que o calor é continuamente gerado pelo decaimento de isótopos radioativos de urânio $\left(\mathrm{U}^{238}, \mathrm{U}^{235}\right)$, tório $\left(\mathrm{Th}^{232}\right)$ e potássio $\left(\mathrm{K}^{40}\right)$ (DICKSON e FANELLI, 2004).

De caráter contínuo, renovável e sustentável, o uso de energia geotérmica aumentou exponencialmente desde a Segunda Guerra Mundial. As aplicações mais comuns são: geração de energia elétrica, mecanismos de uso direto do calor (bombas de calor ligadas ao solo, bombas de calor de águas subterrâneas e bombas de calor de águas superficiais), aplicações na agricultura e na aquacultura, aquecimento de estufas, além de sua utilização na indústria.

A classificação de recursos geotérmicos é feita em três classes: recursos de alta temperatura $\left(\mathrm{T} \geq 150{ }^{\circ} \mathrm{C}\right)$, recursos de temperatura intermediária $\left(150{ }^{\circ} \mathrm{C}>\mathrm{T} \geq 90{ }^{\circ} \mathrm{C}\right) \mathrm{e}$ recursos de baixa temperatura $\left(\mathrm{T}<90{ }^{\circ} \mathrm{C}\right)$. Tecnologias que visam a geração de energia elétrica encontram respaldo econômico na utilização de recursos de alta temperatura. Estacas e furos geotérmicos, por sua vez, são empregados com recursos de baixa temperatura (ASHRAE, 2011; CECINATO e LOVERIDGE, 2015).

\subsubsection{Bombas de calor e refrigeradores}

Bombas de calor são dispositivos que possuem por finalidade absorver calor de ambientes com temperaturas mais baixas para liberá-lo em ambientes com temperaturas mais elevadas, a fim de aquecê-los. Em sistemas refrigeradores retira-se calor de ambientes com menor temperatura para refrigerá-los, dissipando-se o calor absorvido em ambientes mais quentes. Todavia, o calor flui espontaneamente da maior para a menor temperatura; para causar o movimento contrário, é necessário fornecer energia ao sistema.

Os fundamentos teóricos de bombas de calor e refrigeradores são o Ciclo de Carnot, que aborda a transformação de trabalho em energia térmica, e a Segunda Lei da Termodinâmica, que afirma que os processos ocorrem em um dado sentido, e não em qualquer sentido. $\mathrm{O}$ enunciado de Clausius afirma que "o calor não pode fluir, de forma espontânea, de um corpo de temperatura menor para um outro de temperatura mais alta" (ÇENGEL, 2003; IENO e NEGRO, 2004). De forma complementar, o enunciado de Kelvin-Planck estabelece que "é impossível a construção de uma máquina que, ao operar em um ciclo termodinâmico, converta toda a quantidade de calor recebido em trabalho (rendimento de $100 \%$ )". 
O sistema da bomba de calor e de refrigeradores é composto por um circuito fechado, um fluido refrigerante, um compressor e uma válvula de expansão, juntamente ao evaporador e ao condensador. Fluidos refrigerantes, muito utilizados em sistemas de transferência de calor, evaporam a baixas temperaturas e, nas passagens de fase líquida a gasosa e vice-versa, calor é liberado ou retirado do ambiente (troca de calor latente).

Em um sistema refrigerador, o fluido entra em contato com o ambiente que está sendo resfriado e possui temperatura inferior à do ambiente (já passou pela válvula de expansão, como se verá a seguir). O calor do ambiente é absorvido pelo fluido que circula em um sistema de tubos denominado evaporador. Como resultado, o fluido líquido passa ao estado de vapor a baixa pressão. O fluido refrigerante, portanto, entra no evaporador e se vaporiza, absorvendo o calor do ambiente a ser refrigerado. $\mathrm{O}$ vapor é então sugado pelo compressor, que aumenta sua pressão e sua temperatura. O fluido estará na condição de vapor superaquecido a maior temperatura e pressão. Finalmente, o fluido passa por um outro sistema de tubos, o condensador, onde calor é liberado para o entorno (ambiente externo) e o fluido condensa como líquido ainda a alta pressão. O líquido passa então pela válvula de expansão, sendo submetido a uma queda brusca de pressão e de temperatura. A seguir, o fluido adentra novamente o ambiente a ser refrigerado com menor temperatura, recomeçando o ciclo.

Uma bomba de calor se baseia no mesmo princípio do refrigerador, mas é empregada para passar o calor de um ambiente de menor temperatura a um outro de maior temperatura, como o interior de uma residência, a fim de aquecê-la. O compressor envia fluido a alta pressão e temperatura a um condensador no interior do ambiente a ser aquecido, onde o calor é liberado por estar em uma temperatura superior. Em seguida, o fluido passa pela válvula de expansão, onde tem sua temperatura (e pressão) diminuída a um valor inferior à temperatura do ambiente externo, de onde se absorve calor no evaporador.

No caso de um sistema refrigerador, objetiva-se a redução de temperatura a partir da retirada de calor do ambiente. A descarga de calor no entorno quente (do lado do condensador) é uma consequência do processo. Porém, bombas de calor visam manter altas as temperaturas de um local para usos específicos ao absorver calor de uma fonte sob temperaturas baixas. Uma bomba de calor pode retirar energia de diferentes fontes, como solo, água e ar. Basicamente, existem três etapas: o calor é retirado do ambiente, a temperatura do fluido circulante é aumentada e o calor é empregado para uma finalidade específica (OZUDOGRU et al., 2014; MA et al., 2017). 
Para o funcionamento dos ciclos descritos é necessária a introdução de trabalho no sistema para que o fluido possa percorrer o ciclo termodinâmico e retirar energia do ambiente externo (frio) para liberá-lo no ambiente interno (quente) ou depositar calor no ambiente externo (quente) ao retirá-lo do ambiente interno (frio). O trabalho é introduzido no compressor na forma de energia elétrica externa. A diferença entre as taxas de calor liberado a temperaturas superiores $\left(\dot{q}_{H}\right)$ e absorvido a baixas temperaturas $\left(q_{L}\right)$ resulta no trabalho a ser introduzido no sistema $(W)$.

A Figura 3.5 sintetiza o ciclo de uma bomba de calor no cenário em que o sistema retira energia térmica de uma fonte fria para um destino de maior temperatura.

Figura 3.5 - Funcionamento de uma bomba de calor

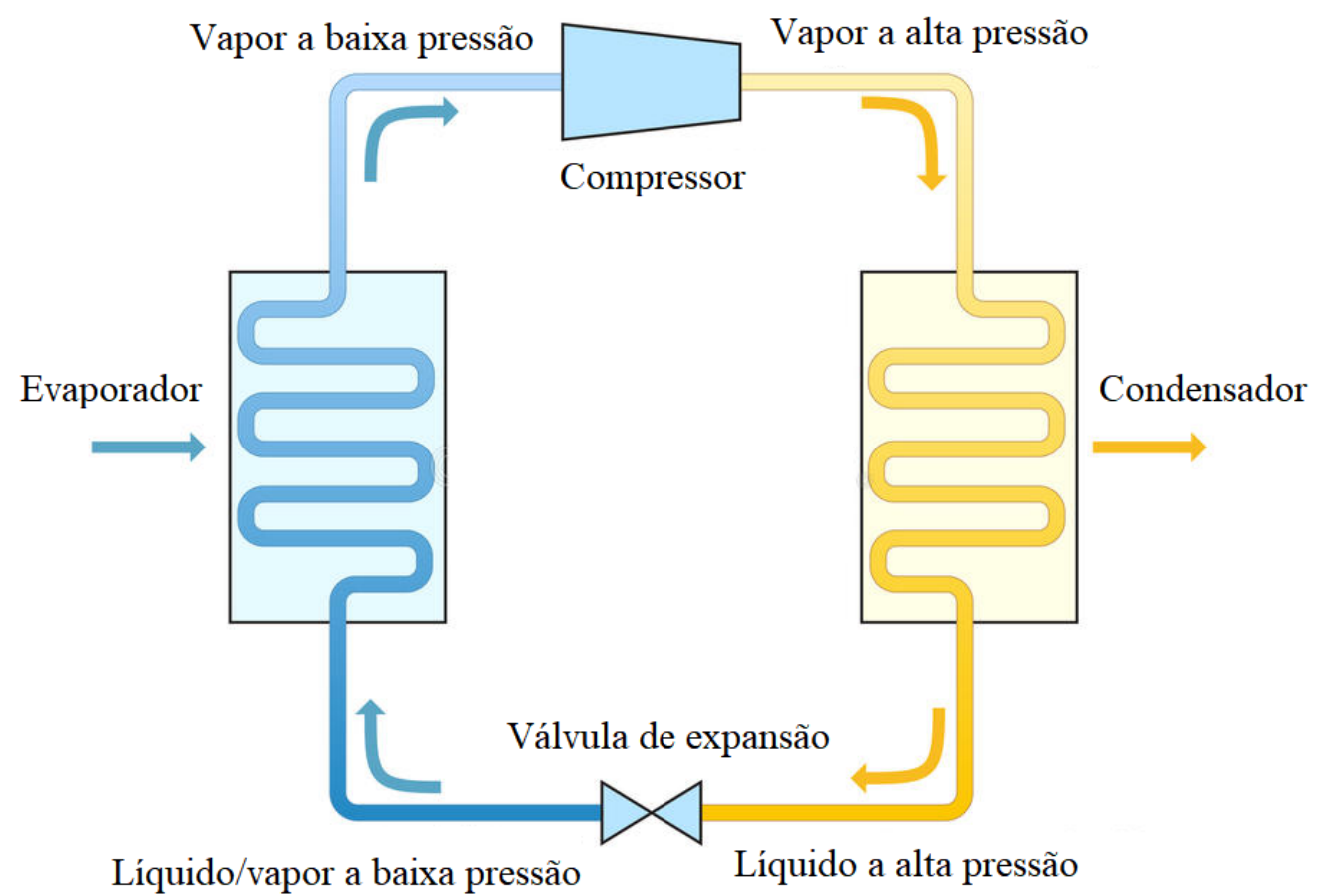

Fonte: Autor, adaptado de Mimouni (2014)

Em bombas de calor acopladas a estacas geotérmicas, quanto maior a quantidade de energia disponível no solo para ser absorvida pelo ciclo termodinâmico a menores temperaturas e posteriormente liberada a temperaturas superiores, menor será a quantidade de trabalho a ser introduzido no compressor, reduzindo custos com energia elétrica e aumentando a eficiência do sistema. Assim, o solo desempenha a função de fonte de energia térmica. Quanto maior a quantidade de energia disponível no solo maior será a sustentabilidade e a eficiência do sistema geotérmico, pois menores quantidades de energia elétrica deverão ser inseridas no ciclo termodinâmico. 
Por outro lado, em sistemas refrigeradores acoplados a estacas geotérmicas, quanto menor a temperatura do solo, isto é, quanto menor a quantidade de energia térmica disponível no solo, maior será o seu potencial em receber o calor retirado pelo ciclo termodinâmico de ambientes sendo refrigerados. Nesse sentido, o solo desempenha a função de depósito de energia térmica. Quanto menor a quantidade de energia térmica disponível no solo menor será a quantidade de trabalho a ser introduzida no sistema. Quanto menor a temperatura do solo maior será o gradiente de temperaturas entre o fluido com maior temperatura que passou pelo compressor e o solo, possibilitando maiores trocas térmicas.

O uso de estacas geotérmicas possibilita a diminuição da quantidade de energia introduzida através do compressor, uma vez que elas proporcionam o aproveitamento da energia natural do solo para o aumento da temperatura do fluido circulante ou utilizam o solo como um meio em que o calor é dissipado. Ao aquecer ambientes, as estacas geotérmicas diminuem a quantidade de trabalho introduzido pelo compressor pois possibilitam a absorção no fluido de energia proveniente do solo. A diminuição da quantidade de trabalho introduzido no sistema representa um considerável ganho em relação a aquecedores que puramente convertem energia elétrica em térmica.

Ao resfriar ambientes, as estacas geotérmicas propiciam a diminuição da quantidade de energia introduzida no sistema, com menor aumento de temperatura e pressão do fluido circulante pelo compressor, pois o solo, a partir de determinadas profundidades, encontra-se a temperaturas constantes da ordem de $20^{\circ} \mathrm{C}$ a $25^{\circ} \mathrm{C}$, enquanto o ar a temperatura ambiente pode atingir $40{ }^{\circ} \mathrm{C}$ em regiões tropicais durante o verão.

Portanto, uma vantagem da utilização de estacas geotérmicas está em se utilizar o solo, que possui temperaturas aproximadamente constantes ao longo do ano a partir de profundidades específicas, para se rejeitar ou retirar calor. Além disso, elimina-se a necessidade de equipamentos adicionais para extrair ou rejeitar calor no solo, implicando também em uma vantagem estética em relação a furos geotérmicos. Nesses, é necessária a escavação de solo e construção de estrutura no subsolo para que ocorram trocas térmicas entre o fluido e o solo. No caso de estacas geotérmicas, utilizam-se as próprias estruturas de fundações. 


\subsubsection{Tecnologia Ground Source Heat Pump e seu acoplamento a fundações}

A tecnologia Ground Source Heat Pump (GSHP) é definida como bombas de calor que utilizam o solo como fonte de energia térmica ou como um meio para a dissipação de calor. Como é utilizada em profundidades rasas (onde estão assentes a maior parte das fundações convencionais), classifica-se como recurso geotérmico de baixa temperatura (BOURNE-WEBB et al., 2009; KRAMER e BASU, 2014).

Além da própria bomba de calor, a tecnologia GSHP compõe-se também de circuitos primário e secundário. O circuito primário consiste em uma tubulação que pode estar em contato direto com o solo ou acoplado a um sistema de fundações. O circuito secundário, por sua vez, está conectado aos ambientes da edificação a ser climatizada e incorporado às estruturas da construção (CARVALHO, 2015).

Os circuitos de um sistema GSHP podem ainda ser classificados como abertos ou fechados: sistemas fechados são aqueles em que o fluxo é cíclico e repetitivo, enquanto sistemas abertos buscam ou conduzem o fluxo até um aquífero.

A Figura 3.6 ilustra alguns tipos de sistemas abertos e fechados em contato direto com o solo, além de se aprofundar na configuração dos circuitos fechados: há circuitos fechados e horizontais, em que a disposição dos tubos exige bastante espaço; sistemas fechados verticais, amplamente utilizados na Europa; e circuitos com acesso a corpos hídricos subterrâneos, em que as tubulações atravessam um corpo hídrico, como um aquífero. Também existem sistemas fechados de poços, onde a tubulação faz uso de poços pré-escavados e estacas geotérmicas (CARVALHO, 2015; FU, 2017; FARE, 2015).

A tecnologia GSHP pode ser vinculada a outros tipos de obras, como aeroportos, pavimentos e estacionamentos, muros de arrimo e contenções, entre outros (BRANDL, 2006). Estacas geotérmicas acoplam a tecnologia GSHP a elementos de fundações profundas, que passam a ter dupla função: suporte estrutural e trocadores de calor (SÁNCHEZ et al., 2015; HASSEN et al., 2016). A Figura 3.7 ilustra diferentes tipos de estacas geotérmicas. 
Figura 3.6 - Sistemas GSHP abertos e fechados

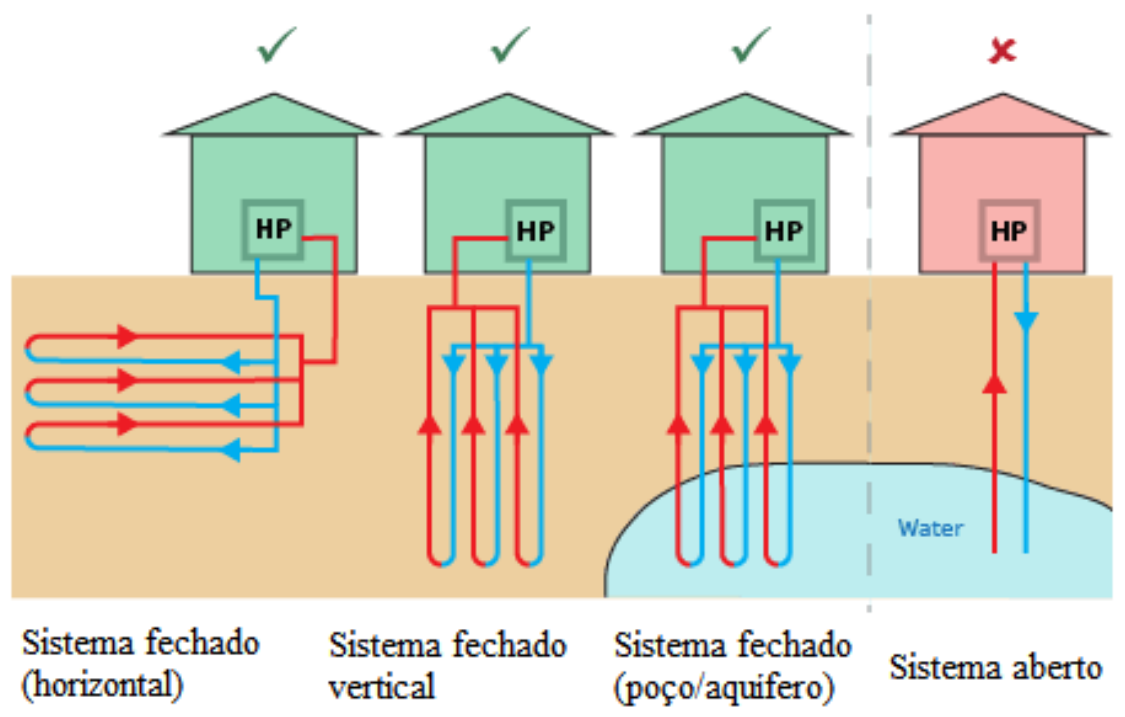

Fonte: Autor, adaptado de Fu (2017)

Figura 3.7 - Tipos de estacas geotérmicas em relação à disposição dos tubos

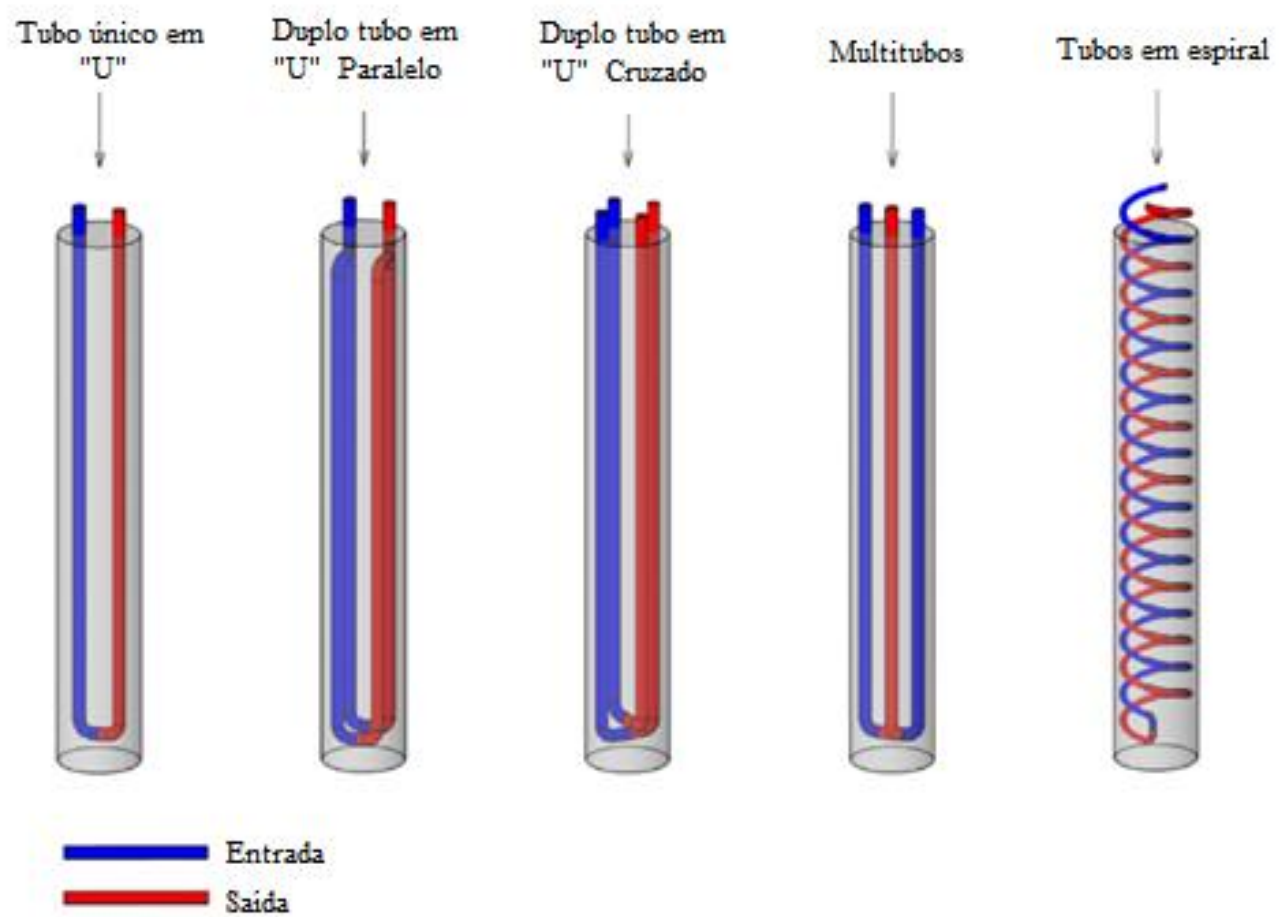

Fonte: Autor, adaptado de Carvalho (2015)

A Figura 3.8 apresenta uma das mais comuns aplicações de estacas geotérmicas em prédios. Apesar de híbrido, o esquema a seguir é utilizado com maior frequência para aquecer o ambiente interno de prédios. 
Figura 3.8 - Esquema de uma instalação com bomba de calor híbrida acoplada a estacas geotérmicas com opção de livre resfriamento

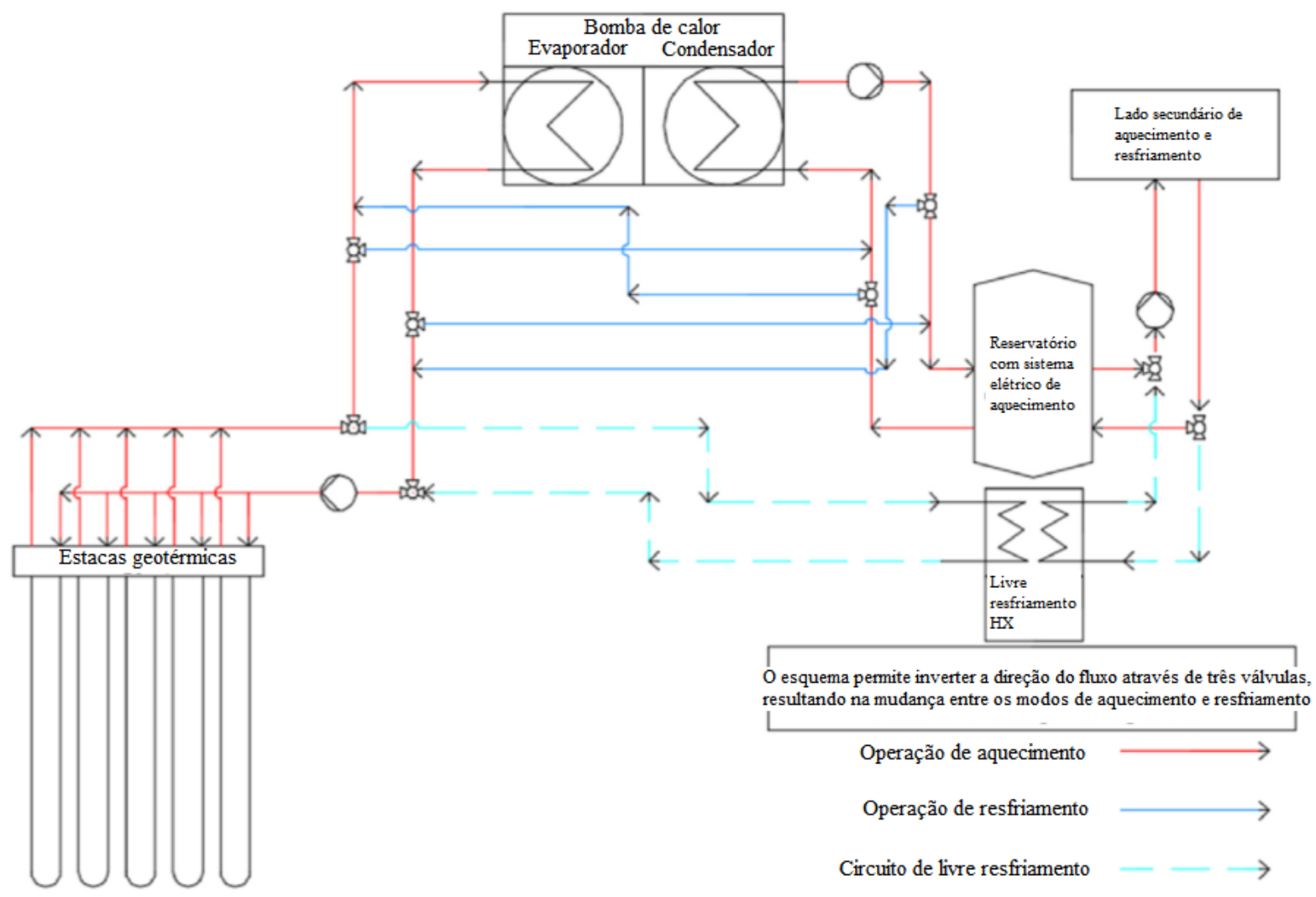

Fonte: Autor, adaptado de Fadejev et al. (2017)

Quando o ambiente interno, designado em Fadejev et al.(2017) como lado secundário, demanda aquecimento, a bomba de calor inicia sua operação e aquece o fluido circulante que atinge o reservatório de calor. Para isso, é utilizado o ciclo destacado em vermelho, em que o fluido do circuito absorve calor do solo pelas estacas geotérmicas e o conduz ao evaporador, que introduz a energia térmica absorvida na bomba de calor. Em seguida, introduz-se trabalho ao sistema e, de acordo com o ciclo apresentado no item 3.1.4.2, o calor é expelido pelo condensador para o fluido, que é direcionado ao reservatório e ao lado secundário. Quando a temperatura no tanque se torna inferior a um valor previamente determinado e a operação da bomba de calor não é capaz de garantir tal nível de temperatura, o sistema elétrico de aquecimento inicia sua operação e aquece o fluido no tanque para o valor desejado de temperatura (FADEJEV et al., 2017).

Por outro lado, quando o lado secundário demanda resfriamento, o fluido que circula pelas estacas geotérmicas é direcionado para a região de livre resfriamento. Essa região é composta por um trocador de calor onde a tubulação quente, proveniente do lado 
secundário, se encontra com a tubulação fria, oriunda das estacas geotérmicas. Dessa forma, direciona-se o calor do lado secundário para as estacas geotérmicas por meio de um trocador de calor, sem o uso da tecnologia bomba de calor.

Caso seja necessário um nível de resfriamento adicional, um circuito opcional de resfriamento é conectado a três válvulas no circuito da bomba de calor. A função dessas válvulas é inverter a direção do fluxo na bomba de calor, o que resulta na inversão da operação da bomba de calor, originando um refrigerador. Portanto, esta configuração pode atuar no sentido de resfriar ou aquecer o volume de fluido que está no reservatório. O circuito de resfriamento ativo pode ser considerado em prédios onde o livre resfriamento é incapaz de suprir toda a demanda de resfriamento dos ambientes internos. Apesar disso, este sistema não é capaz de aquecer e resfriar diferentes ambientes de um prédio simultaneamente (FADEJEV et al., 2017).

Um prédio residencial de dois andares localizado na cidade de Hokkaido, Japão, operou de acordo com a solução apresentada na Figura 3.8. Medidas de cinco meses revelaram que 26 estacas geotérmicas de $9 \mathrm{~m}$ de profundidade produziram $78 \mathrm{kWh}$ por metro de estaca no lado do condensador da bomba de calor. A menor temperatura mínima do ar ambiente foi de $-17{ }^{\circ} \mathrm{C}$. O coeficiente médio de desempenho da bomba de calor (calor liberado ou extraído dividido pelo trabalho realizado pelo compressor) foi de 3,9 (FADEJEV et al., 2017).

O esquema da instalação apresentada na Figura 3.9 pode ser aplicado a prédios que necessitem suprir demandas de aquecimento e resfriamento de forma simultânea. $O$ ciclo apresentado em vermelho, em que se retira calor do solo para aquecer ambientes internos da construção, designados em Fadejev et al. (2017) como lado secundário, opera de forma idêntica ao processo apresentado para o esquema referente à Figura 3.8. Entretanto, a partir da comparação dos esquemas apresentados pelas Figuras 3.8 e 3.9, percebe-se que há, na Figura 3.9, a adição de um refrigerador e um reservatório, de forma que tanto a bomba de calor quanto o refrigerador podem operar simultaneamente, não sendo necessário inverter o funcionamento de nenhum dos sistemas.

A demanda de resfriamento de um prédio é atendida pela operação de livre resfriamento, em que se transfere calor do lado secundário para as estacas geotérmicas. Quando o livre resfriamento não é capaz de manter a temperatura em um nível previamente determinado, a bomba de calor localizada no ciclo de refrigeração opera como refrigerador e inicia sua operação. O calor oriundo do lado secundário é absorvido pelo evaporador e, de acordo com o ciclo apresentado no item 3.1.4.2, o condensador 
expele energia térmica para o circuito das estacas geotérmicas, que transferem o calor para o solo. A energia térmica transferida ao solo pela operação de resfriamento pode ser aproveitada pelo simultâneo ciclo de aquecimento, que retira calor do solo para o aquecimento de outros ambientes internos, também localizados no lado secundário. Caso necessário, o excesso de calor gerado é direcionado a sistemas de resfriamento localizados no teto do prédio (FADEJEV et al., 2017).

Figura 3.9 - Esquema de uma instalação com bomba de calor e estacas geotérmicas e sistema de resfriamento ativo

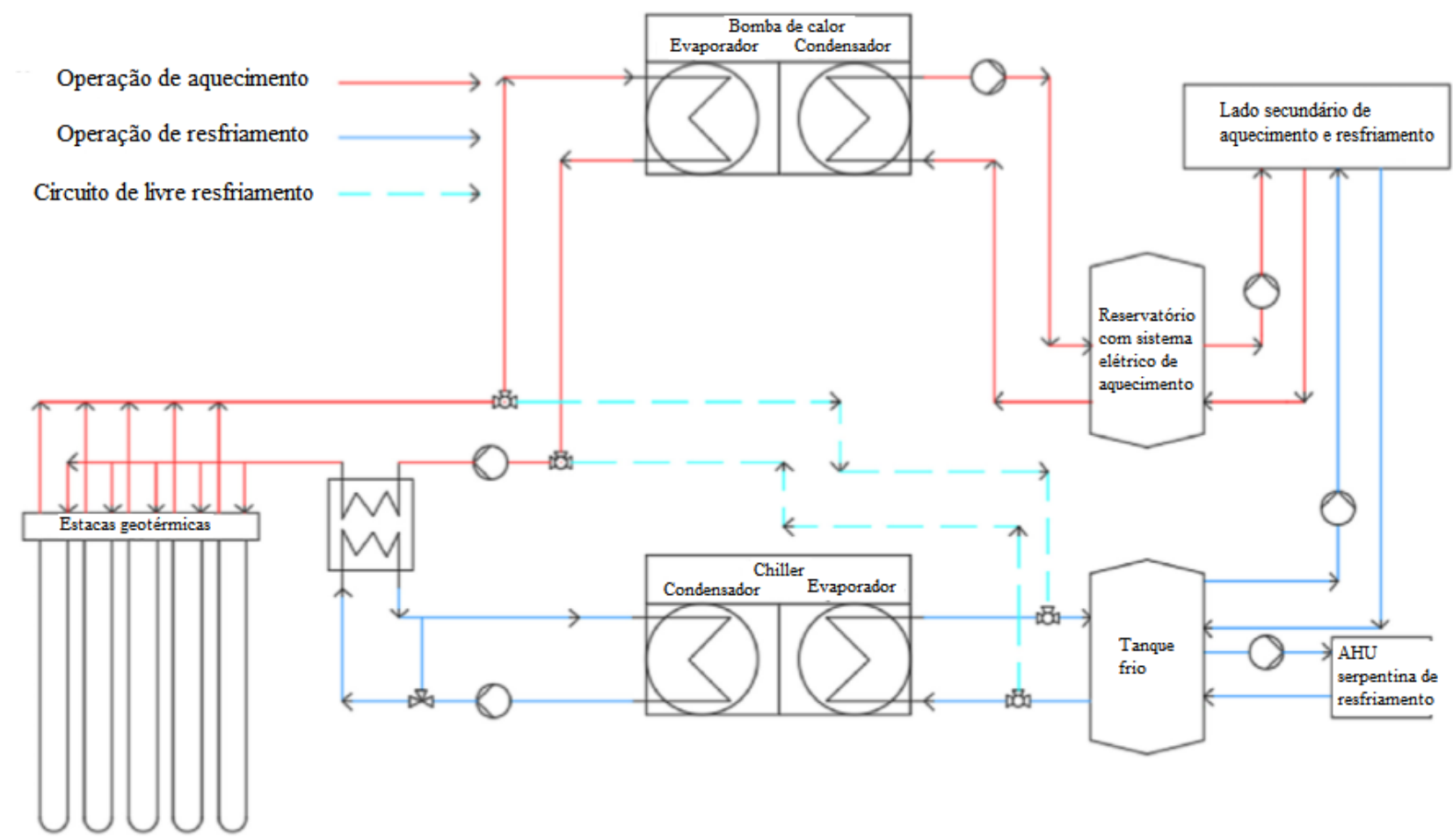

Fonte: Autor, adaptado de Fadejev et al. (2017)

Este sistema foi utilizado no terminal E do aeroporto de Zurique, onde 306 estacas de concreto de 26,8 m de profundidade e diâmetros externos que variam de $900 \mathrm{~mm}$ a $1500 \mathrm{~mm}$ operam com uma bomba de calor de capacidade de $630 \mathrm{~kW}$. Medições anuais revelaram que a bomba de calor produziu $2210 \mathrm{MWh}$, cobrindo $73 \%$ de toda a demanda de aquecimento. O livre resfriamento supriu $53 \%$ da necessidade anual de resfriamento. O coeficiente de desempenho estimado foi de 4,5 (FADEJEV et al., 2017).

Dado que a falta de equilíbrio na extração e rejeição de calor em estacas geotérmicas pode ocasionar perdas significativas no desempenho de longo prazo, pode ser necessário usar armazenamento de energia térmica para manter a operação estável. A 
solução apresentada na Figura 3.10 é adequada para prédios localizados em regiões de clima frio com baixas temperaturas médias ambientes anuais. A fonte de captura para armazenamento de calor pode variar: armazenamento solar (coletor solar), fonte de ar (refrigerador seco) ou ar de exaustão.

Figura 3.10 - Esquema de uma instalação com bomba de calor e estacas geotérmicas com sistemas de armazenamento (coletor solar, refrigerador seco ou ar de exaustão)

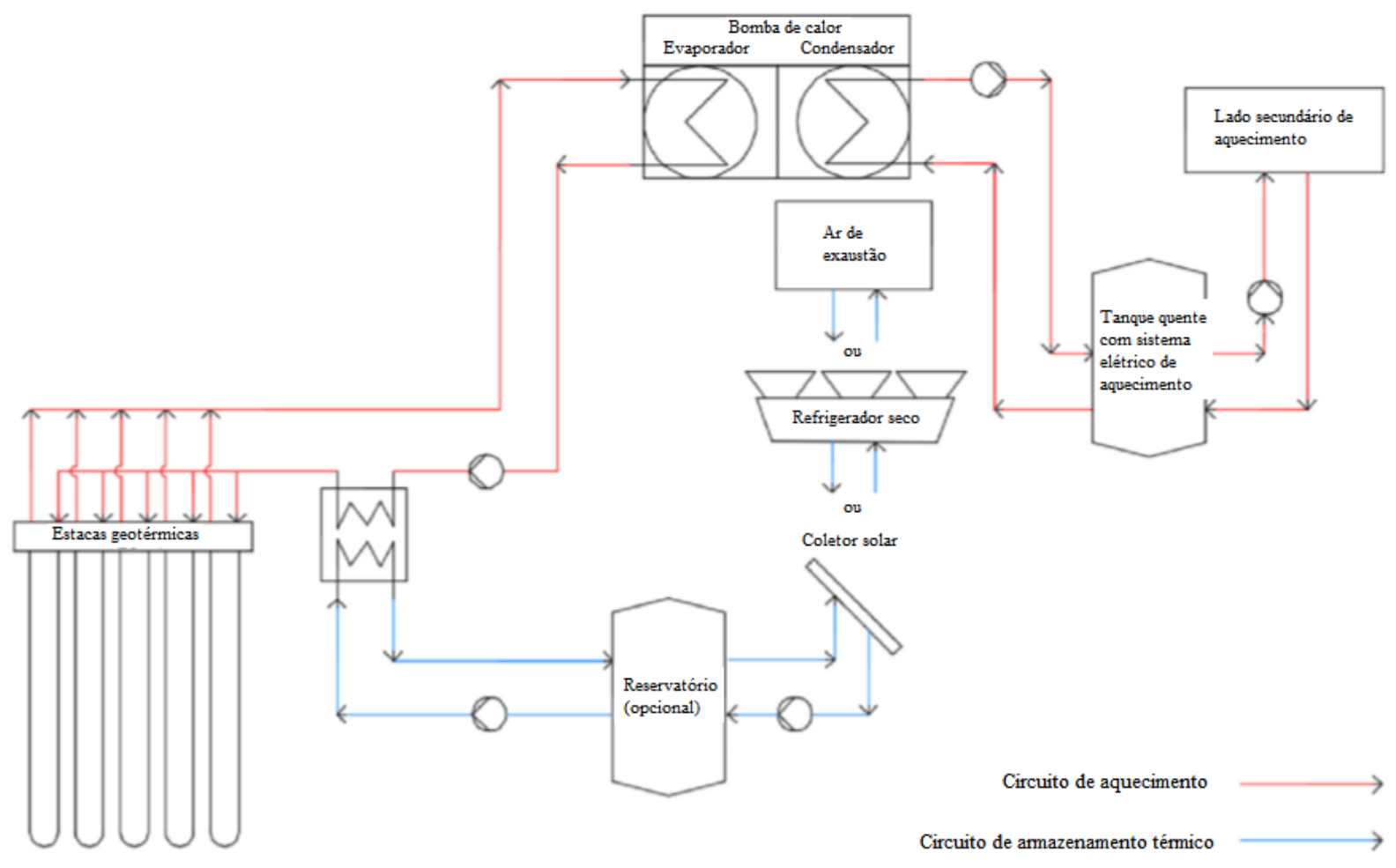

Fonte: Autor, adaptado de Fadejev et al. (2017)

Na Figura 3.10, além do circuito de aquecimento similar aos apresentados nas Figuras 3.8 e 3.9, existe também um esquema de armazenamento de energia térmica baseado em diferentes tecnologias que retiram calor de uma fonte externa e o direcionam a um reservatório ou ao circuito das estacas geotérmicas. Tais dispositivos permitem o uso sustentável do calor presente no ar e em fontes solares para o aquecimento do circuito relacionado a estacas geotérmicas (FADEJEV et al., 2017).

Outra possibilidade de acoplamento de bombas de calor a estacas geotérmicas é apresentada na Figura 3.11, que mostra soluções de armazenamento de energia em regime sazonal para as estações de inverno e verão. Durante o inverno, a operação de aquecimento ocorre através da bomba de calor, extraindo-se calor das estacas geotérmicas em situação de aquecimento (de acordo com o circuito em vermelho, similar às soluções 
apresentadas nas Figuras 3.8, 3.9 e 3.10) e o refrigerador seco, que extrai calor das estacas em resfriamento. Na operação de resfriamento (verão) o calor é injetado nas estacas em resfriamento, enquanto o refrigerador seco injeta calor do ar nas estacas geotérmicas em aquecimento (FADEJEV et al., 2017).

Figura 3.11 - Esquema de uma instalação com bomba de calor e estacas geotérmicas separadas com armazenamento de energia por fonte térmica do ar

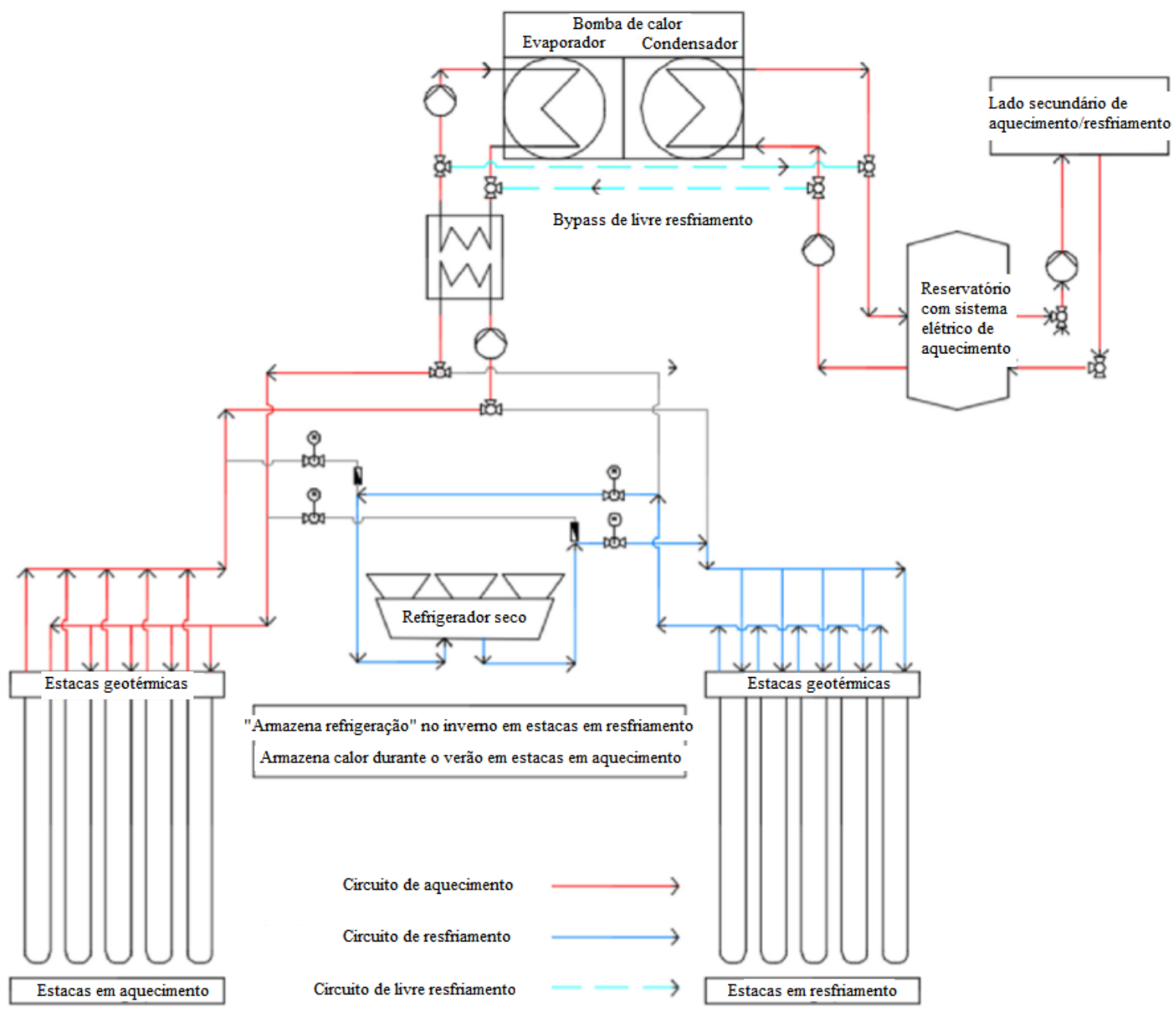

Fonte: Autor, adaptado de Fadejev et al. (2017)

Nesta configuração a operação do sistema geotérmico pressupõe armazenamento de energia térmica (durante o verão o refrigerador seco introduz calor nas estacas em aquecimento, onde a energia térmica é armazenada) ou o aumento do potencial de dissipação de energia térmica, chamado por Fadejev et al. (2017) de armazenamento de refrigeração, visto que o refrigerador seco extrai calor das estacas e o direciona ao circuito 
de aquecimento. A energia ou potencial térmico armazenados são depois empregados para auxiliar o funcionamento do sistema geotérmico, conforme a necessidade.

Existe também a opção de livre resfriamento, responsável por suprir a maior parte da demanda anual de resfriamento de edificações acopladas a estacas geotérmicas. Nesta configuração não é possível que os circuitos de aquecimento e resfriamento operem simultaneamente, sendo que o circuito de livre resfriamento depende de um by-pass, que isola a bomba de calor, como mostra a Figura 3.11.

A Tabela 3.5 apresenta uma comparação das configurações de estacas geotérmicas acopladas a bombas de calor e sistemas de armazenamento de energia térmica descritos. A cada esquema são relacionados os atributos: circuitos de aquecimento, de resfriamento livre, de resfriamento ativo, aquecimento e resfriamento simultâneos, armazenamento térmico e quantidade de demanda de resfriamento anual coberta pelo circuito de resfriamento livre. Com base em tais características é possível definir qual a configuração de sistema geotérmico mais adequado para ser instalado em novas construções.

Tabela 3.5 - Comparação das características de cada tipo de instalação

\begin{tabular}{|c|c|c|c|c|}
\hline- & Fig. 3.8 & Fig. 3.9 & Fig. 3.10 & Fig. 3.11 \\
\hline Aquecimento & $\mathrm{X}$ & $\mathrm{X}$ & $\mathrm{X}$ & $\mathrm{X}$ \\
\hline Resfriamento livre & $\mathrm{X}$ & $\mathrm{X}$ & $\mathrm{X}$ & $\mathrm{X}$ \\
\hline Resfriamento ativo & $\mathrm{X}$ & $\mathrm{X}$ & & \\
\hline Aquecimento e resfriamento simultâneos & & $\mathrm{X}$ & & \\
\hline Armazenamento térmico & & & $\mathrm{X}$ & $\mathrm{X}$ \\
\hline Demanda de resfriamento coberta pelo resfriamento livre & $49 \%$ & $78 \%$ & $7 \%$ & - \\
\hline
\end{tabular}

Fonte: Autor, adaptado de Fadejev et al., 2017

\subsubsection{Ensaio Teste Resposta Térmica (T.R.T)}

A estimativa dos parâmetros térmicos dos solos é, em geral, uma tarefa de natureza complexa. Por vezes, recorre-se a valores clássicos apresentados na literatura (a exemplo das Tabelas 3.1, 3.3 e 3.4), que não são universais, uma vez que a geologia e as condições de saturação dos solos variam em diferentes localidades e ao longo do tempo. A retirada de amostras do campo para posterior análise em laboratório, através do ensaio da sonda-agulha, apresenta custos elevados e problemas operacionais. Como alternativa, 
há a execução de ensaios in situ do tipo TRT, que oferecem resultados representativos dos parâmetros térmicos de solos (LHENDUP et al., 2014; MA et al., 2017).

Define-se o TRT como um ensaio realizado in situ, onde é feita injeção ou retirada de calor do solo a taxa constante por meio de um furo, para estimar propriedades térmicas dos solos em profundidades específicas. Os parâmetros obtidos são a condutividade térmica e a resistência térmica (ABDELAZIZ et al., 2014; BANDEIRA NETO, 2015).

O equipamento do ensaio consiste em, pelo menos, um tubo em formato de " $U$ " (geralmente de PEAD) instalado no interior de um furo no subsolo, por onde circula um fluido (em geral água), que insere ou retira calor do solo. Utilizam-se bomba de água para circulação do fluido, aquecedor/bomba de calor, medidor de vazão da tubulação, sensores de temperatura para medir a temperatura ambiente e nas posições de entrada e saída do fluido e um sistema de aquisição de dados. O equipamento deve estar localizado próximo a uma fonte confiável de energia elétrica. No Brasil é comum o uso de água como fluido circulante, pois para as temperaturas usuais não são necessários fluidos anticongelantes (ABDELAZIZ et al., 2014; BANDEIRA NETO, 2015; MORAIS e TSUHA, 2016).

A Figura 3.12 esquematiza os componentes do equipamento do ensaio TRT.

Figura 3.12 - Componentes do equipamento de um ensaio TRT

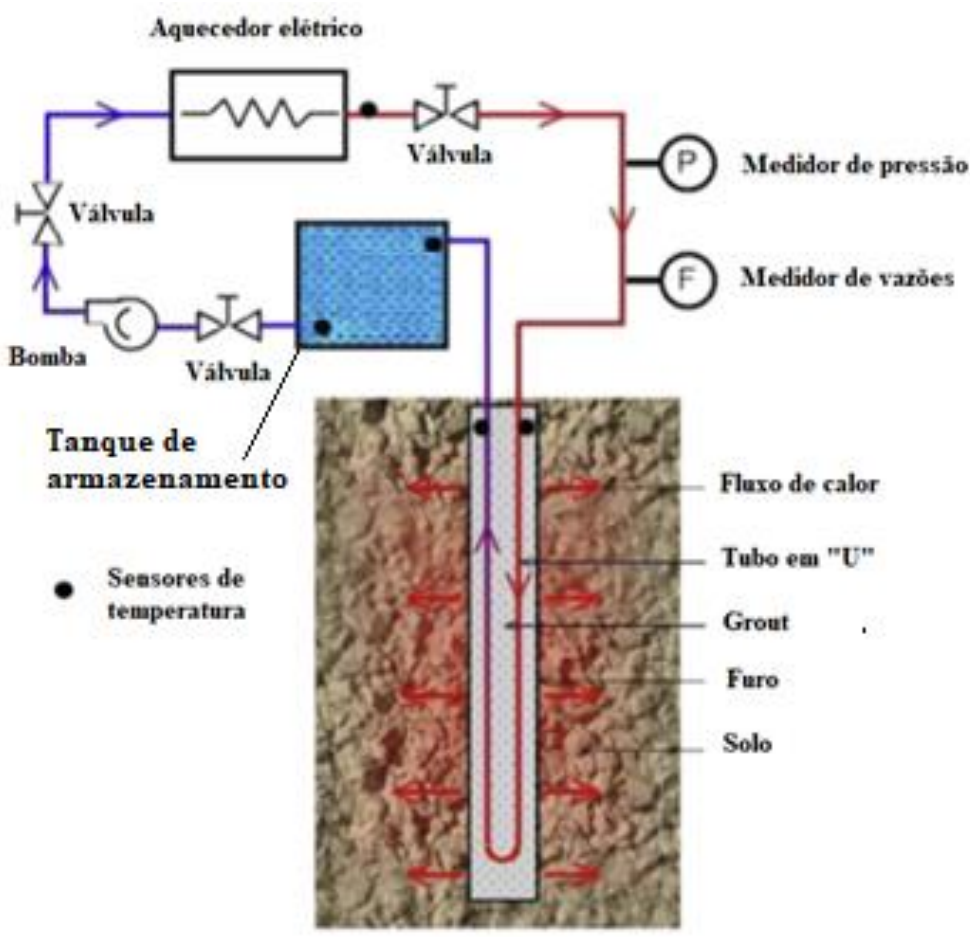

Fonte: Autor, adaptado de Sánchez et al. (2015) 
A Figura 3.13 ilustra a disposição de um equipamento móvel de TRT.

Figura 3.13 - Componentes do equipamento de um ensaio TRT móvel

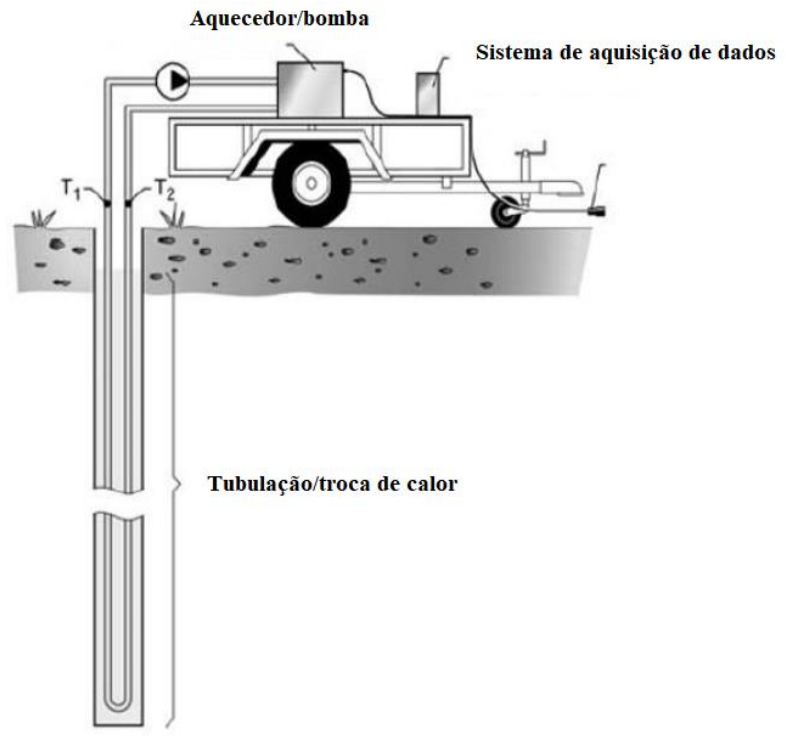

Fonte: Bandeira Neto (2015)

Recomendações são realizadas na CEN/TC 341 N525 (2011) para ensaios do tipo TRT: a potência calorífica oferecida deve ser compatível com a condutividade térmica do solo; a bomba hidráulica deve ocasionar escoamento turbulento no interior dos tubos de PEAD; antes da realização do ensaio, é necessário aguardar três dias depois do preenchimento do furo com concreto para solos de baixa condutividade térmica e cinco dias para solos de elevada condutividade térmica; não se permitem escavações localizadas a $10 \mathrm{~m}$ da borda do furo. É fundamental a medida da temperatura do solo em situação não perturbada e a da temperatura do fluido circulante sem aquecimento. É indispensável esperar-se que as medidas de temperatura do fluido circulante estabilizem-se.

O início do ensaio ocorre com a ativação do aquecedor, fornecendo potência térmica constante (entre 50 e $80 \mathrm{~W} \cdot \mathrm{m}^{-1}$ ), em período mínimo de 48 horas e descartandose as leituras instáveis de, ao menos, as primeiras 12 horas de ensaio. Para tempos iguais ou superiores a 70 horas, os parâmetros de condutividade e resistividade térmicos não sofrem consideráveis alterações de valores (LHENDUP et al., 2014).

As medições realizadas no ensaio são: temperaturas de entrada e saída do fluido circulante, temperatura do ar ambiente, temperatura do solo não perturbado, energia térmica inserida ou retirada do sistema e vazão do fluido nos tubos de PEAD. 
A avaliação dos resultados experimentais é feita por meio da aplicação do teorema da fonte linear de calor, que pressupõe fonte de calor permanente, linear e infinitamente longa. Além disso, o solo é tomado como um meio semi-infinito e homogêneo, e a transferência de calor na interface solo-estaca é constante na direção radial. Assume-se que a temperatura inicial do solo é equivalente a $\mathrm{T}_{0}$ em todo o maciço e desprezam-se possíveis fluxos de água subterrânea (GEHLIN, 2002; MORAIS e TSUHA, 2018).

A Equação (3.18) expressa mudanças na temperatura do solo em virtude do fluxo de calor segundo o teorema da fonte linear de calor:

$$
\Delta T_{g}(t, r)=\frac{\dot{q}_{t}}{4 \pi k}\left[\ln \left(4 \propto t / r^{2}\right)-\gamma\right]
$$

Em que:

- $\Delta T_{g}$ é a variação de temperatura do solo $(\mathrm{K})$;

- $\dot{q}_{t}$ é a taxa de calor injetada por unidade de comprimento da estaca (W.m ${ }^{-1}$ );

- $k$ é a condutividade térmica do solo $\left(\mathrm{W} \cdot \mathrm{m}^{-1} \cdot \mathrm{K}^{-1}\right)$;

- $\quad r$ é a distância radial entre a fonte de calor e o ponto de interesse no solo (m);

- $\quad t$ é a duração do ensaio TRT (s);

- $\quad \gamma$ é a constante de Euler $(\gamma=0,5772)$;

- $\alpha$ é a difusividade térmica $\left(\mathrm{m}^{2} \cdot \mathrm{s}^{-1}\right)$.

Por outro lado, a resistência térmica $R_{b}$ entre o fluido circulante e a parede da estaca pode ser determinada através da Equação (3.19):

$$
\Delta T_{f}(t, r)=\dot{q}_{t} R_{b}+\frac{\dot{q}_{t}}{4 \pi k}\left[\ln \left(4 \propto t / r_{b}^{2}\right)-\gamma\right]
$$

Em que:

- $\Delta T_{f}$ é a variação de temperatura do fluido circulante durante o ensaio (K);

- $R_{b}$ é a resistência térmica da estaca de energia $\left(\mathrm{m} \cdot \mathrm{K}^{-1} \cdot \mathrm{W}^{-1}\right)$;

- $r_{b}$ é o raio da estaca geotérmica (m). 
Finalmente, determina-se a condutividade térmica efetiva do solo a partir do diagrama de variação da temperatura média do fluido versus o logaritmo do tempo com a Equação (3.20):

$$
k_{e f f}=\frac{\dot{q}_{t}}{4 \pi \lambda}
$$

Em que:

- $\lambda$ é o coeficiente angular da regressão linear do diagrama de variação da temperatura média do fluido versus o logaritmo do tempo.

\subsubsection{Eficiência de estacas geotérmicas}

A eficiência deve ser avaliada com relação à troca de calor das estacas e com relação ao sistema geotérmico. A diferença entre as temperaturas de entrada e saída do fluido circulante é uma medida da quantidade de energia térmica transmitida do fluido ao conjunto estaca e solo, ou vice-versa (BRANDL, 2006; OROZCO, 2016). A determinação da troca de calor em toda a estaca (utilizada para o cálculo da eficiência térmica total), portanto, é feita considerando-se a troca de calor da água.

Das Equações (3.1) e (3.9) infere-se a Equação (3.21):

$$
\dot{q}=\frac{q}{\Delta t}=\frac{C \Delta T}{\Delta t}
$$

Considerando-se a massa de água que circula por toda a estaca obtém-se a Equação (3.22), que pode ser reescrita na forma da Equação (3.23):

$$
\begin{gathered}
\dot{q}=m_{w} \frac{c_{w} \Delta T}{\Delta t} \\
\dot{q}=c_{w} \cdot \dot{m} \cdot\left(T_{\text {entrada }}-T_{\text {saída }}\right)
\end{gathered}
$$

Em que:

- $\quad \dot{q}$ é a taxa de calor total (W);

- $c_{w}$ é a capacidade térmica específica da água, equivalente a $4182 \mathrm{~J} \cdot \mathrm{kg}^{-1} \cdot \mathrm{K}^{-1}$;

- $\quad \dot{m}$ é a vazão mássica $\left(\mathrm{kg} . \mathrm{s}^{-1}\right)$; 
- $T_{\text {entrada }}$ é a temperatura de entrada $(\mathrm{K})$;

- $T_{\text {saída }}$ é a temperatura de saída (K);

Pode-se calcular a taxa de calor normalizada por metro de estaca pela Equação (3.24):

$$
\dot{q}_{\text {normal }}=c_{w} \cdot \dot{m}_{w} \cdot\left(\frac{T_{\text {entrada }}-T_{\text {saída }}}{L_{e}}\right)
$$

Em que:

- $L_{e}$ é o comprimento da estaca (m);

- $\dot{q}_{\text {normal }}$ é a taxa de calor normalizada $\left(\mathrm{W} \cdot \mathrm{m}^{-1}\right)$.

O Coeficiente de Desempenho (COP - Coefficient of Performance) avalia a eficiência do sistema ao relacionar o resultado desejado ao trabalho exigido. Para refrigeradores, o resultado desejado é a taxa de calor absorvido do ambiente a baixas temperaturas, que é comparado ao trabalho necessário à operação do sistema, como observa a Equação (3.25):

$$
C O P_{\text {refr }}=\frac{\dot{q}_{L}}{W}=\frac{\dot{q}_{L}}{\dot{q}_{H}-\dot{q}_{L}}=\frac{1}{\frac{\dot{q}_{H}}{\dot{q}_{L}}-1}
$$

Em que:

- $C O P_{\text {refr }}$ é o Coeficiente de Desempenho no ciclo de refrigeração;

- $\quad \dot{q}_{L}$ é a taxa de calor absorvido a baixas temperaturas;

- $\dot{q}_{H}$ é a taxa de calor liberado a temperaturas superiores;

- $W$ é o trabalho introduzido no sistema.

Para bombas de calor, onde ocorre transferência de calor para meios de temperaturas mais elevadas, o Coeficiente de Desempenho é calculado através da Equação (3.26):

$$
C O P_{\text {aquec }}=\frac{\dot{q}_{H}}{W}=\frac{\dot{q}_{H}}{\dot{q}_{H}-\dot{q}_{L}}=\frac{1}{1-\frac{\dot{q}_{L}}{\dot{q}_{H}}}
$$

Em que:

- $C O P_{\text {aquec }}$ é o Coeficiente de Desempenho no ciclo de aquecimento. 
Pela segunda lei da Termodinâmica, refrigeradores ou bombas de calor idealmente reversíveis, a exemplo do Ciclo de Carnot, permitem reescrever as estimativas máximas possíveis de Coeficiente de Desempenho, como assinalam as Equações (3.27) e (3.28):

$$
\begin{aligned}
C O P_{\text {Rev }, \text { refr }} & =\frac{1}{\frac{T_{H}}{T_{L}}-1} \\
C O P_{\text {Rev }, \text { aquec }} & =\frac{1}{1-\frac{T_{L}}{T_{H}}}
\end{aligned}
$$

Em que:

- $C O P_{\text {Rev,refr }}$ é o Coeficiente de Desempenho reversível no ciclo de refrigeração;

- $C O P_{\text {Rev,aquec }}$ é o Coeficiente de Desempenho reversível no ciclo de aquecimento;

- $T_{H}$ é a temperatura do meio mais quente;

- $T_{L}$ é a temperatura do meio mais frio.

\subsection{PRINCIPAIS TRABALHOS CIENTÍFICOS}

\subsubsection{Comportamentos térmico e termo-hidráulico}

Estudos experimentais relacionados ao comportamento de estruturas geotérmicas encontram registro em 1983 quando, em Estocolmo, Morgesen apresentou um artigo que tratava de ensaios TRT (ECES, 2013). Tais ensaios logo se tornaram uma alternativa a procedimentos de laboratório, caros e pouco representativos dos parâmetros geotérmicos de solos in situ. Reforça esta hipótese a adaptação dos dispositivos para a realização de ensaios TRT na categoria móvel, como reportam os trabalhos de Gehlin (2002) e Austin (1998).

Morais e Tsuha (2016) mostram a relevância de ensaios TRT para o projeto de fundações geotérmicas a partir da instalação de uma estaca geotérmica de comprimento 12 m e diâmetro 0,5 m no campo experimental de São Carlos da USP. A área possui solos tropicais não-saturados, com camadas superficiais de areias argilosas lateríticas sobre arenito residual. A instalação de sensores ao longo da estaca e no solo circundante permitiu a verificação de temperatura natural (não perturbada por aquecimento e resfriamento) de $24{ }^{\circ} \mathrm{C}$. A Figura 3.14 explicita o esquema de execução do ensaio TRT. 
Figura 3.14 - Esquema de execução de ensaio TRT em campo experimental

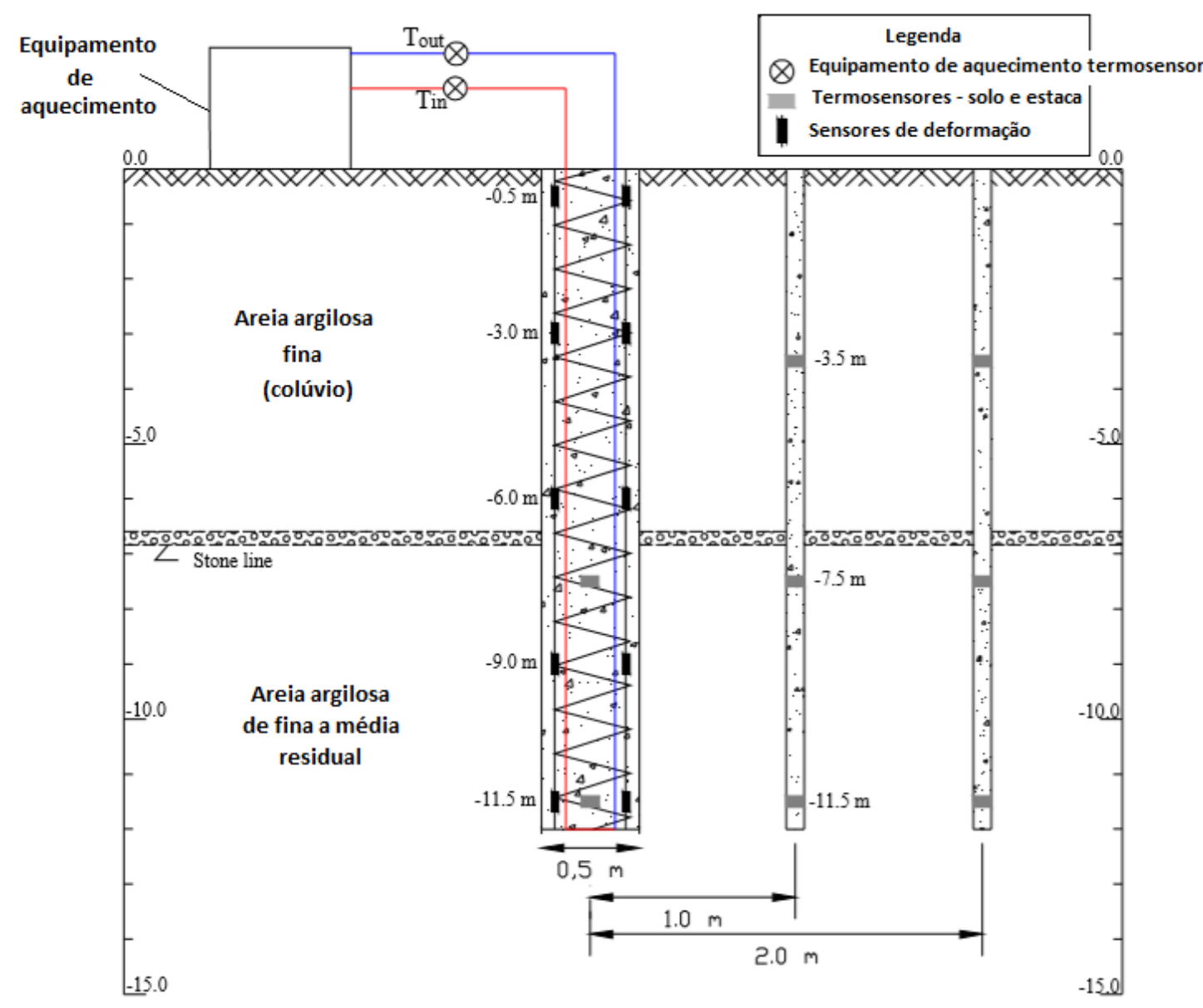

Fonte: Autor, adaptado de Morais e Tsuha (2016)

O sistema geotérmico foi submetido a um ciclo de aquecimento de 8,5 dias, permitindo-se a seguir que a estaca se recuperasse através da dissipação natural de calor. A distribuição de temperaturas ao redor da estaca indicou um raio de influência térmica de $2 \mathrm{~m}$ a $3 \mathrm{~m}$, dependendo do instante dos ciclos de aquecimento e resfriamento. O raio de influência térmica é definido em Fare (2015) como a distância medida a partir do centro da estaca, na metade de seu comprimento, até o ponto do solo cuja temperatura é alterada em $1 \mathrm{~K}$ com relação à sua temperatura na condição não perturbada. A Figura 3.15 sintetiza os principais resultados dessa pesquisa. 
Figura 3.15 - Ensaio TRT em São Carlos: dados monitorados de temperatura ambiente ( $\left.T_{\text {ambient }}\right)$ e temperatura do fluido na entrada $\left(T_{\text {in }}\right)$ e saída $\left(T_{\text {out }}\right)$ dos tubos de PEAD

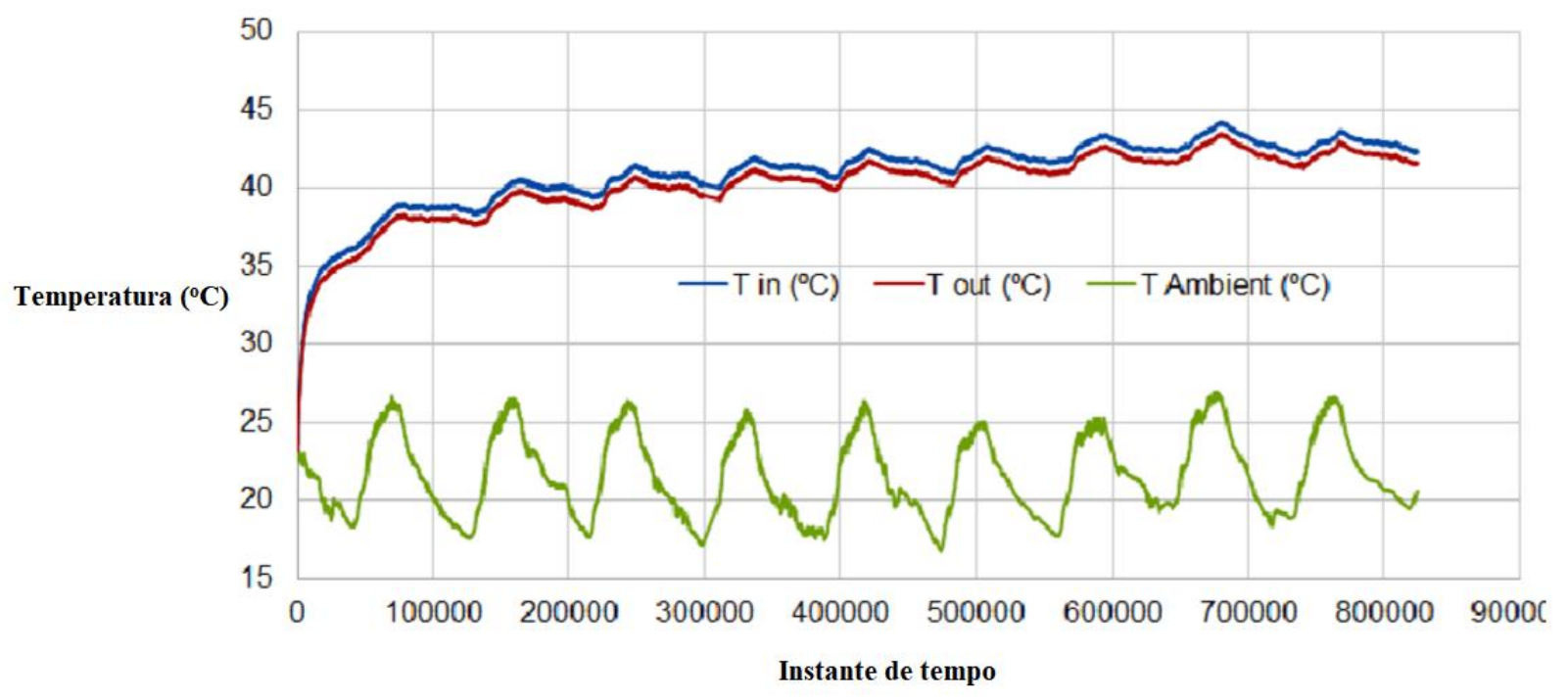

Fonte: Autor, adaptado de Morais e Tsuha (2016)

Conclusões similares foram utilizadas em Ozudogru e Olgun (2014) como hipóteses simplificadoras para a validação numérica e 3D de estacas geotérmicas. A partir de ensaios TRT de diâmetro $0,45 \mathrm{~m}$ e comprimento $20 \mathrm{~m}$ (estaca) e de diâmetro $0,15 \mathrm{~m}$ e comprimento $100 \mathrm{~m}$ (furo) em solo arenoso, os autores verificaram experimentalmente um raio de influência térmica de 2,5 $\mathrm{m}$ a partir da parede. Medições de campo indicaram que a temperatura natural do solo é de $15{ }^{\circ} \mathrm{C}$. Esses dados foram utilizados para analisar o comportamento do sistema com o software COMSOL Multiphysics. Partiu-se das premissas de que o mecanismo de transferência de calor por condução governa as trocas térmicas com o solo e de que este é um meio sólido, isotrópico e homogêneo. Considerouse que a transmissão de calor ocorre preferencialmente na direção radial e que as trocas térmicas ao longo do eixo vertical da estaca são desprezíveis. O modelo não levou em consideração a armadura existente no ensaio em verdadeira grandeza, considerando que pouco influencia as trocas térmicas do sistema, além da dificuldade de modelá-la numericamente. A Figura 3.16 ilustra a geometria do modelo numérico elaborado.

A Figura 3.17 mostra a malha elaborada para os diferentes domínios em uma metade simétrica do problema, visando a redução do custo computacional. 
Figura 3.16 - Geometria do modelo numérico elaborado

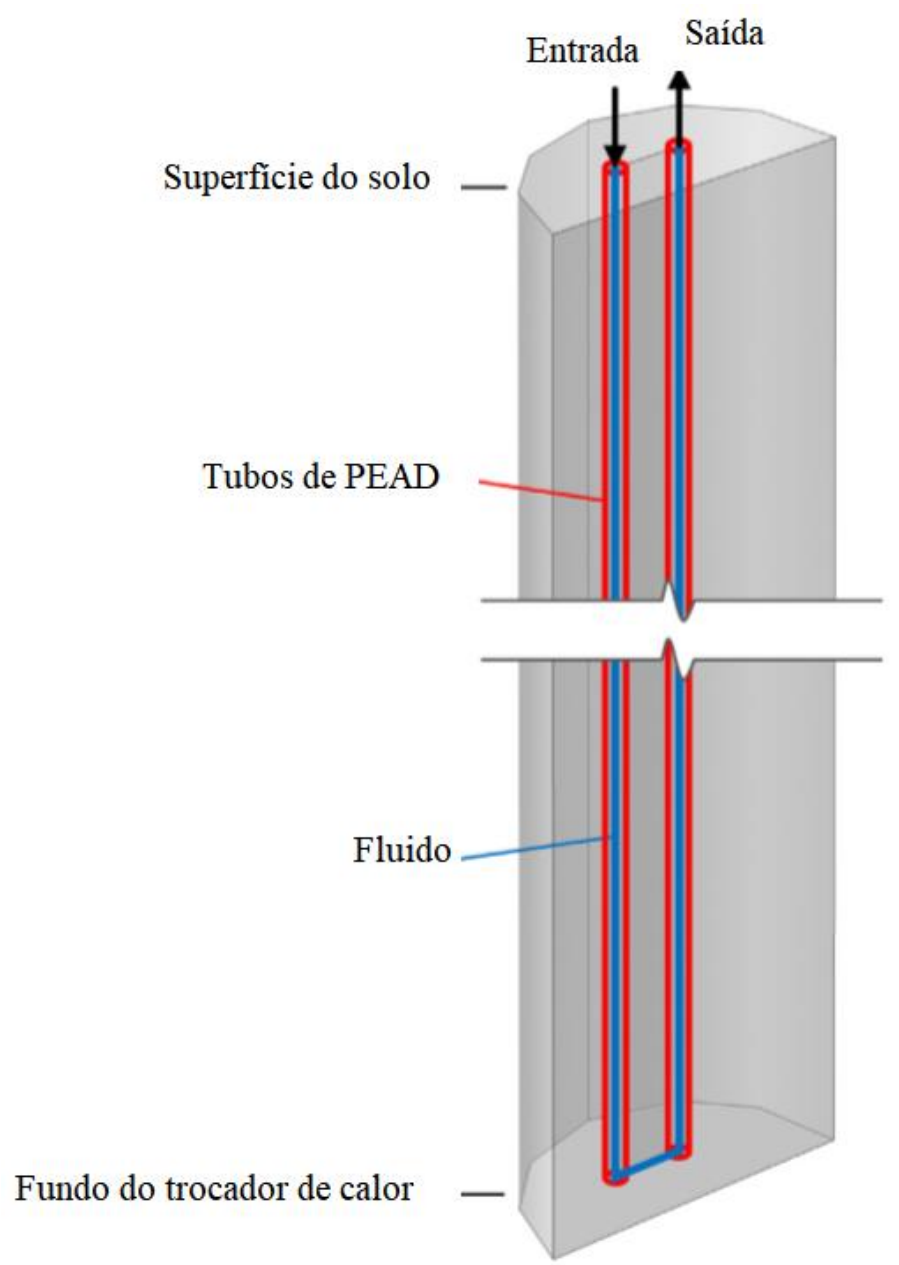

Fonte: Autor, adaptado de Ozudogru e Olgun (2014)

Figura 3.17 - Malha elaborada para uma metade simétrica do problema

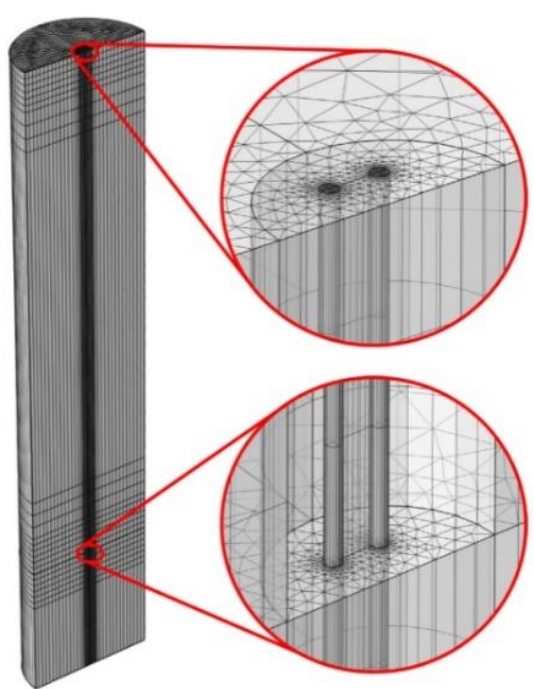

Fonte: Ozudogru e Olgun (2014) 
Ozudogru e Olgun (2014) empregaram o teorema da fonte linear de calor para interpretar os dados provenientes da execução do ensaio TRT, obtendo condutividade térmica de $2 \mathrm{~W} \cdot \mathrm{m}^{-1} \cdot \mathrm{K}^{-1}$. A Figura 3.18 permite observar os resultados numéricos para a distribuição de temperaturas no entorno da estaca para o instante de 100 h após o início do ensaio. Os resultados simulados são bastante próximos dos resultados experimentais.

Figura 3.18 - Malha elaborada para uma metade simétrica do problema (eixos x e y em metros)

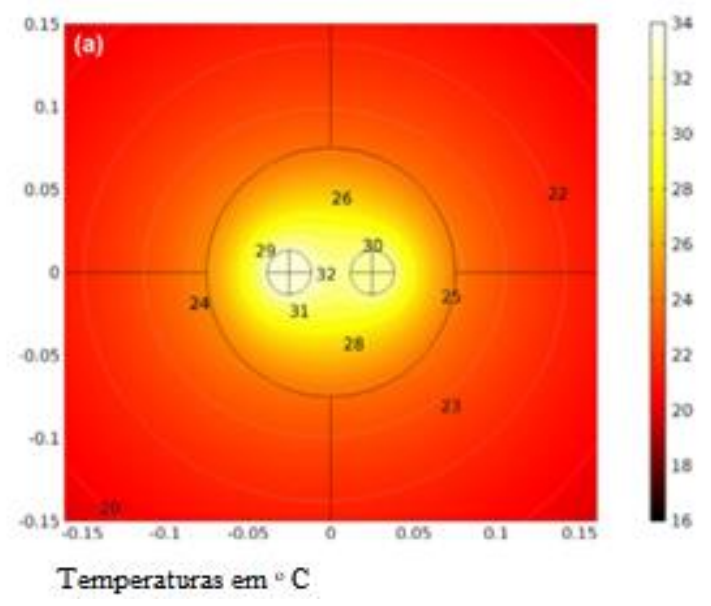

Fonte: Autor, adaptado de Ozudogru e Olgun (2014)

A Figura 3.19 apresenta a distribuição de temperaturas observadas no ensaio TRT, em diferentes instantes de tempo, para sensores localizados em furos dispostos a distâncias radiais variáveis com relação à parede da estaca, assim como valores obtidos numericamente. Nota-se que, conforme a distância radial a partir da parede da estaca aumenta, as temperaturas diminuem. Além disso, percebe-se a proximidade entre os valores de temperatura obtidos com bases experimental e numérica.

Assim como Ozudogru e Olgun (2014), Thompson III (2013) adotou as seguintes hipóteses para a modelagem numérica: existe troca de calor entre as superfícies dos domínios de solo e concreto e o ar; no início do ensaio, as temperaturas do fluido e concreto são dependentes da temperatura do solo, sendo as temperaturas iniciais iguais para os diferentes materiais que compõe o sistema geotérmico; o fluido circulante é incompressível e sua viscosidade é constante; durante o ensaio não se alteram a saturação e a condutividade térmica do solo, bem como parâmetros de densidade, capacidade térmica e condutividade térmica do fluido, tubos de PEAD, concreto e solo; e as camadas 
de solo são homogêneas, de modo que densidade, peso específico e parâmetros térmicos não variam dentro de seus limites físicos.

Figura 3.19 - Distribuição de temperaturas (enfoques experimental e numérico)

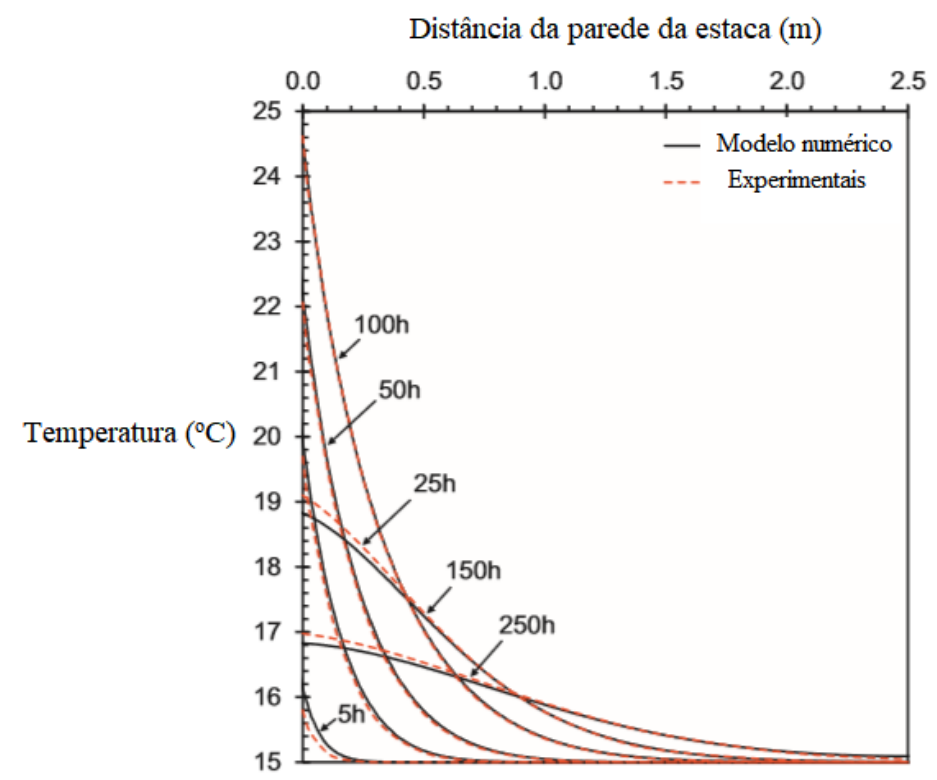

Fonte: Autor, adaptado de Ozudogru e Olgun (2014)

Thompson III (2013) utilizou o software ANSYS CFX para a validação do modelo de um ensaio TRT por estaca, de diâmetro $0,30 \mathrm{~m}$ e comprimento $25 \mathrm{~m}$, em solos arenosos e argilosos em regime transiente. O estudo conclui que, conforme o diâmetro da estaca geotérmica aumenta, o desempenho do sistema melhora. A eficiência do conjunto também aumenta com o número de circuitos de tubos em " $U$ ". $\mathrm{O}$ autor acredita que o programa numérico desenvolveu satisfatoriamente os cenários analisados, uma vez que os resultados experimentais e numéricos de temperatura do fluido na saída $\left(T_{\text {out }}\right)$ dos tubos de PEAD foi inferior a $0,5^{\circ} \mathrm{C}$.

Ma et al. (2017) realizaram um ensaio TRT por furo trocador de calor de diâmetro 0,15 m e comprimento 117 m em um solo arenoso da região de Binzhou, na província de Shandong, China. O tubo enterrado é de polietileno e o furo foi preenchido por uma areia de graduação média (condutividade $2,00 \mathrm{~W} \cdot \mathrm{m}^{-1} \cdot \mathrm{K}^{-1}$ ). Inferiu-se que a condutividade térmica do solo varia no intervalo de 1,67 a $1,97 \mathrm{~W} \cdot \mathrm{m}^{-1} \cdot \mathrm{K}^{-1}$. A temperatura inicial dos diferentes materiais do sistema geotérmico era $17,32{ }^{\circ} \mathrm{C}$. O ensaio durou 72 horas, desprezando-se as 12 horas iniciais de medições. A modelagem computacional, por meio 
do software TRNSYS, adicionou às hipóteses apresentadas em Ozudogru e Olgun (2014) e Thompson III (2013) o desenvolvimento de simulações em regime transiente.

Ma et al. (2017) argumentam que é fundamental atingir a estabilidade nos ensaios TRT; para isso, recomendam que a duração do ensaio seja de ao menos 50 h e que os dados referentes ao trecho inicial, quando a estabilidade não foi alcançada, sejam desprezados. Em termos práticos, os autores indicam o descarte dos dados pertencentes às horas iniciais de $12 \mathrm{~h}$ a $30 \mathrm{~h}$, a depender da dificuldade de se atingir estabilidade. Gehlin (2002) estima que tal intervalo seja de $12 \mathrm{~h}$ a $20 \mathrm{~h}$ e Austin (1998) sustenta o descarte de 12 h. Em Ma et al. (2017) mostra-se que, por conta do fato de que em condições de estabilidade as variáveis do sistema geotérmico apresentam pequenas variações ao longo do tempo, é plausível a hipótese de modelagem numérica em regime estacionário.

Bouazza et al. (2015), durante as $12 \mathrm{~h}$ iniciais da execução de um ensaio TRT, notaram variações entre as temperaturas de entrada e saída do fluido inferiores a $1{ }^{\circ} \mathrm{C}$, enquanto em condições de estabilidade tais diferenças chegaram a $5{ }^{\circ} \mathrm{C}$. Isso se deve ao fato de que o calor leva algum tempo para superar a resistência térmica das paredes dos tubos e do concreto.

Nagano et al. (2005) avaliaram as características térmicas de solos em regiões frias do Japão, em Sapporo, através de ensaios TRT em duas estacas geotérmicas metálicas de diâmetro 0,4 m e duas de diâmetro 0,165 m, todas de comprimento $40 \mathrm{~m}$. O subsolo era composto por camadas de argila, areia vulcânica e pedregulho. O sistema geotérmico operou de modo a retirar energia do solo. O coeficiente de condutividade térmica médio estimado foi de $1,5 \mathrm{~W} \cdot \mathrm{m}^{-1} \cdot \mathrm{K}^{-1}$. Os autores mostraram que, mantendo-se a temperatura de entrada do fluido constante, o calor extraído por unidade de comprimento das estacas estabilizava-se após 10 dias de duração do ensaio, quando seria razoável assumir comportamento estacionário ao invés de transiente. Além disso, estimaram-se as temperaturas de saída do tubo por meio de um modelo analítico, para valores de condutividade térmica de $1,0 \mathrm{~W} \cdot \mathrm{m}^{-1} \cdot \mathrm{K}^{-1}, 1,5 \mathrm{~W} \cdot \mathrm{m}^{-1} \cdot \mathrm{K}^{-1} \mathrm{e} 2,0 \mathrm{~W} \cdot \mathrm{m}^{-1} \cdot \mathrm{K}^{-1}$. A Figura 3.20 assinala como se comportam as temperaturas de entrada medidas $\left(T_{i n}\right)$ e de saída medidas e calculadas $\left(T_{\text {out }}\right)$ do fluido circulante ao longo do tempo. Nota-se a proximidade entre os valores experimentais e analíticos de $\left(T_{\text {out }}\right)$ para a curva correspondente à condutividade térmica de $1,5 \mathrm{~W} \cdot \mathrm{m}^{-1} \cdot \mathrm{K}^{-1}$. 
Figura 3.20 - Comportamento de temperaturas ao longo do tempo

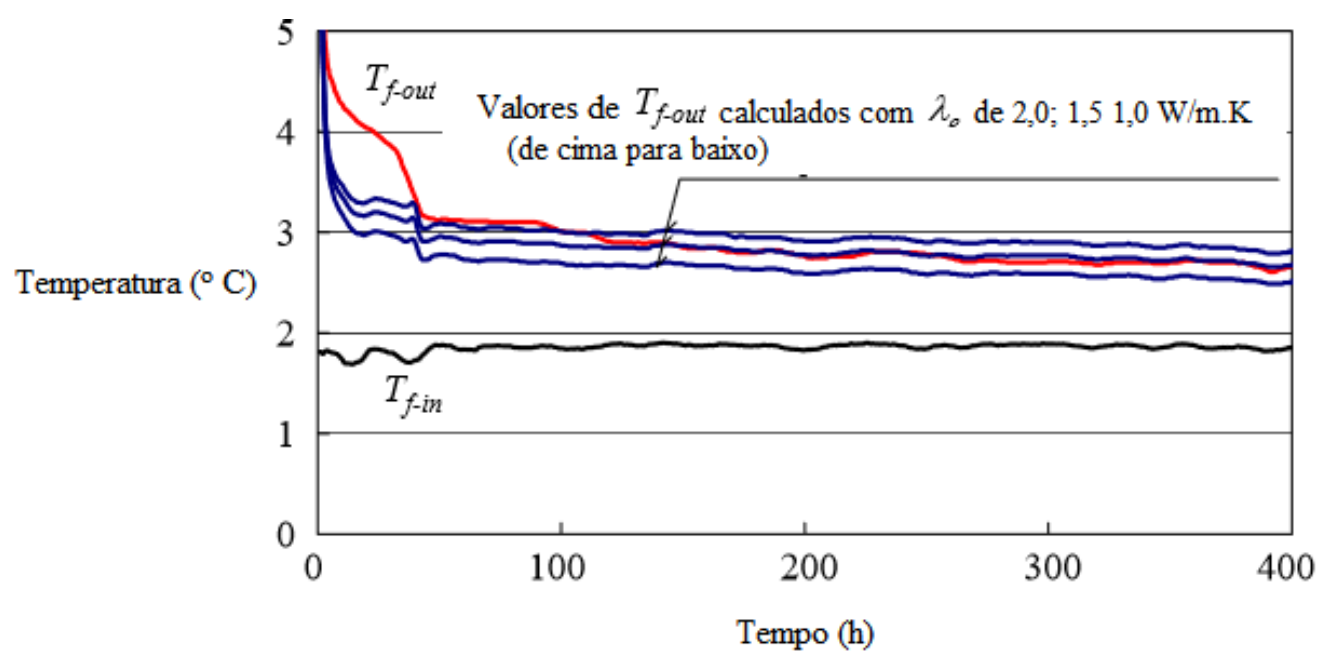

Fonte: Autor, adaptado de Nagano et al. (2005)

Cecinato e Loveridge (2015) elaboraram um modelo numérico 3D de fluxo de calor transiente pelo Método de Elementos Finitos, para uma análise paramétrica da eficiência de estacas geotérmicas em solos dos tipos argila e silte em função de diversas variáveis. As principais conclusões dos autores são: o número de tubulações e o comprimento da estaca são os parâmetros que mais influenciam o desempenho do sistema geotérmico, sendo que é preponderante o valor total da superfície da tubulação disponível para trocas de calor por convecção forçada, e a condutividade térmica é a terceira variável que mais influencia o comportamento térmico da estaca.

Abdelaziz et al. (2014) agregaram um enfoque analítico a problemas envolvendo a resposta térmica de estacas geotérmicas para investigar se a hipótese de solo homogêneo no caso de ensaios TRT em furos geotérmicos, com profundidades que variam de $60 \mathrm{~m}$ a $100 \mathrm{~m}$, é realmente fundamentada, já que os parâmetros térmicos podem apresentar grande variabilidade ao longo da profundidade. Os autores estratificaram o subsolo em camadas representativas do perfil real e propuseram o conceito de superposição, com base no teorema de fonte de calor de Kelvin, para determinar as mudanças de temperaturas e, consequentemente, dos parâmetros térmicos em diferentes profundidades. Segundo o teorema, uma linha pode ser tratada como a combinação de pontos sequencialmente posicionados. Calcula-se a mudança de temperatura em um local específico do meio homogêneo com a fórmula da fonte de calor para um ponto. Em seguida, realiza-se uma integração ao longo da linha para contabilizar os efeitos de outras fontes de calor em forma de ponto nesse determinado local de interesse. Conclui-se que, para furos a partir 
de $60 \mathrm{~m}$, os erros entre os modelos estratificado e homogêneo encontram-se no intervalo de $10 \%$ a $25 \%$. Para menores profundidades, comuns em problemas que envolvem estacas geotérmicas, tais erros tornam-se desprezíveis.

Bandeira Neto (2015) estudou duas estacas geotérmicas de diâmetros 0,25 m e 0,50 m e comprimento $12 \mathrm{~m}$ em um perfil de solo tropical não saturado, em que a camada superficial é composta por uma areia argilosa coluvial e laterítica (com alta porosidade) sobre um solo residual de arenito (saprolito). A temperatura média natural do solo é de $24{ }^{\circ} \mathrm{C}$, considerada alta em comparação aos estudos geotérmicos realizados na América do Norte, Ásia e Europa. O autor verificou também os efeitos da posição do nível de água, vazão do fluido que circula pelos tubos de PEAD e duração do ensaio sobre o desempenho do sistema geotérmico. Encontraram-se taxas de troca de calor por metro de estaca com o solo que variam de $79 \mathrm{~W} \cdot \mathrm{m}^{-1} \mathrm{a} 110 \mathrm{~W} \cdot \mathrm{m}^{-1}$.

Além disso, mostrou-se que o aumento do diâmetro e da quantidade de tubos no interior da estaca aumentam a taxa de calor trocada, bem como a condutividade térmica do sistema. Por não isolar tais variáveis em seu estudo experimental, o autor não pôde determinar seus ganhos específicos. Por outro lado, comprovou-se que pequenas variações no nível de água não influenciam os resultados do ensaio, enquanto a variação da velocidade do fluido circulante afeta tanto as taxas de calor trocadas entre a estaca e o solo quanto as temperaturas de entrada e saída do fluido circulante nos tubos.

Em conformidade com as observações experimentais de Ozudogru e Olgun (2014) e Morais e Tsuha (2016), em Bandeira Neto (2015) constata-se que, após 9,5 dias de duração de ensaio, quando este alcançou condições de estabilidade, o raio de influência térmica da estaca foi de 2,5 $\mathrm{m}$. Os valores de condutividade térmica, calculados a partir do teorema da fonte linear de calor, variaram de $2,8 \mathrm{~W} \cdot \mathrm{m}^{-1} \cdot \mathrm{K}^{-1}$ a $3,2 \mathrm{~W} \cdot \mathrm{m}^{-1} \cdot \mathrm{K}^{-1}$, considerados elevados para solos não saturados, mas justificáveis por conta das grandes quantidades de quartzo, assim como de óxidos provenientes da laterização. A Figura 3.21 apresenta o esquema de distribuição de estacas no campo experimental da EESC USP.

Orozco (2016) utilizou os dados experimentais de Bandeira Neto (2015) para calibrar um modelo numérico, construído com o software COMSOL Multiphysics, para um estudo paramétrico do comportamento de estacas geotérmicas assentes em solos não saturados. Esse estudo deu início à linha de pesquisa sobre estacas geotérmicas na Universidade de Brasília, sob coordenação do Prof. Dr. Renato da Cunha. 
Figura 3.21 - Esquema de distribuição de estacas no campo experimental da EESC USP

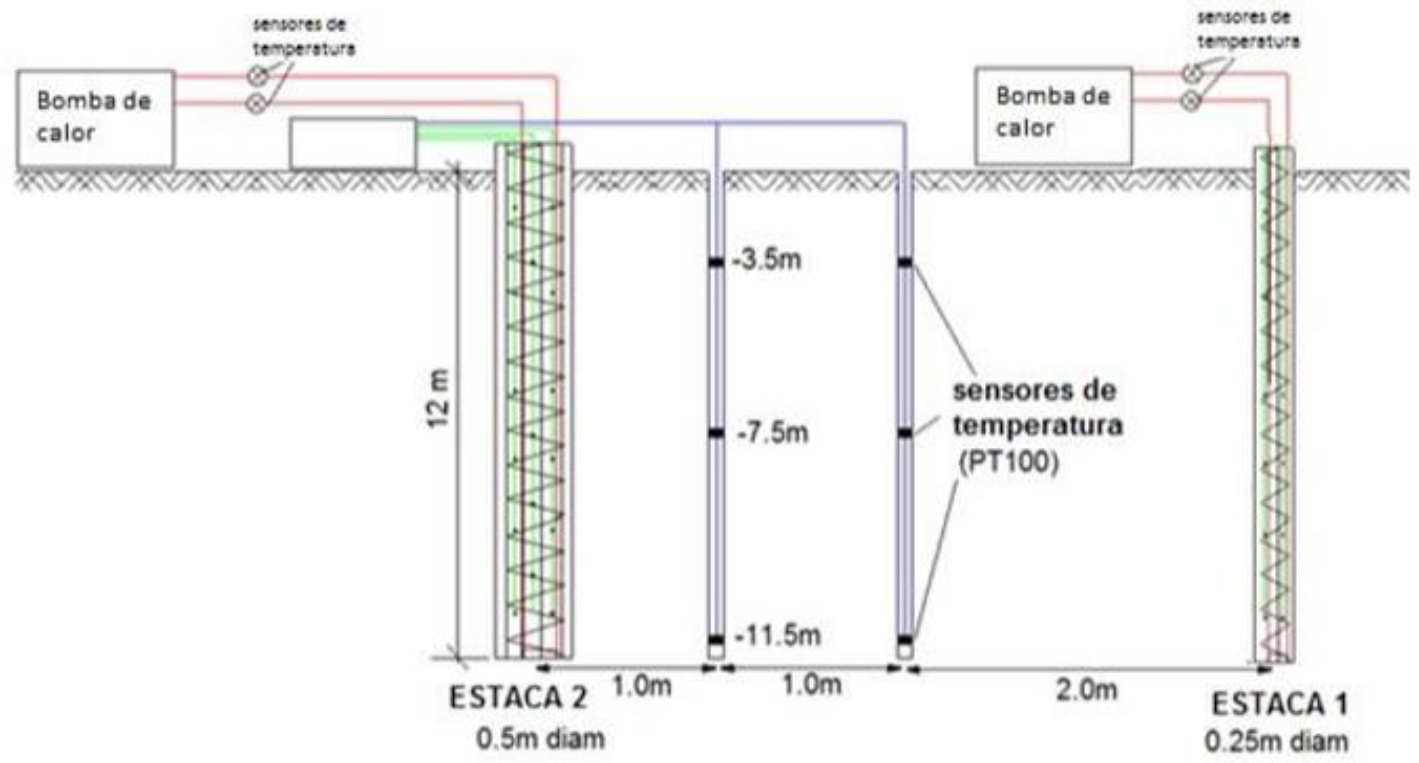

Fonte: Bandeira Neto (2015)

Primeiramente, Orozco (2016) efetuou uma análise de sensibilidade para identificar condições ótimas para as simulações no software COMSOL Multiphysics. Algumas de suas conclusões foram: elementos de malha hexaédricos fornecem menor tempo de processamento quando comparados a elementos prismáticos e tetraédricos; elementos tetraédricos implicam em maior eficiência na obtenção de resultados; a maior densidade da malha afeta consideravelmente o tempo de processamento, mas não implica em resultados numéricos muito diferentes; os resultados não são sensíveis a variações nas dimensões do domínio do solo. Posteriormente, Orozco (2016) calibrou o modelo numérico com os dados experimentais obtidos por Bandeira Neto (2015). A Figura 3.22 ilustra a proximidade entre os resultados numéricos e experimentais obtidos em Orozco (2016) na etapa de validação do modelo numérico.

A seguir procedeu-se ao estudo paramétrico com a variação de parâmetros geométricos, geotécnicos, hidráulicos e térmicos. Foram obtidas as seguintes conclusões focadas na melhoria da eficiência térmica do sistema: o uso de concretos de alta densidade provoca não apenas a melhoria das propriedades mecânicas da estaca, mas melhora também os níveis de troca de calor entre o solo e o concreto (para condutividades térmicas de $1,15 \mathrm{~W} \cdot \mathrm{m}^{-1} \cdot \mathrm{K}^{-1}, 1,25 \mathrm{~W} \cdot \mathrm{m}^{-1} \cdot \mathrm{K}^{-1}, 1,50 \mathrm{~W} \cdot \mathrm{m}^{-1} \cdot \mathrm{K}^{-1}, 1,75 \mathrm{~W} \cdot \mathrm{m}^{-1} \cdot \mathrm{K}^{-1}, 2,00 \mathrm{~W} \cdot \mathrm{m}^{-1} \cdot \mathrm{K}^{-1}, 2,25$ $\mathrm{W} \cdot \mathrm{m}^{-1} \cdot \mathrm{K}^{-1}, 2,52 \mathrm{~W} \cdot \mathrm{m}^{-1} \cdot \mathrm{K}^{-1}, 2,75 \mathrm{~W} \cdot \mathrm{m}^{-1} \cdot \mathrm{K}^{-1} \mathrm{e} 3,00 \mathrm{~W} \cdot \mathrm{m}^{-1} \cdot \mathrm{K}^{-1}$ obtiveram-se taxas de calor normatizadas de 51,7 W.m ${ }^{-1}$, 53,8 W.m ${ }^{-1}, 58,4 \mathrm{~W} \cdot \mathrm{m}^{-1}, 62,3 \mathrm{~W} \cdot \mathrm{m}^{-1}, 65,6 \mathrm{~W} \cdot \mathrm{m}^{-1}$, 
68,4 W.m ${ }^{-1}$, 70,9 W.m ${ }^{-1}, 73,1 \mathrm{~W} \cdot \mathrm{m}^{-1}$ e $75,0 \mathrm{~W} \cdot \mathrm{m}^{-1}$, respectivamente); o aumento da condutividade térmica do solo possibilita melhor desempenho do sistema (considerandose variações dos valores de condutividade térmica originais de $-20 \%$ a $+20 \%$ notaramse variações das taxas de calor normatizadas de 61,7 W.m ${ }^{-1}$ a 68,7 W.m ${ }^{-1}$, respectivamente); o aumento do número de tubulações da estaca propicia melhores respostas térmicas; maiores gradientes de temperatura, isto é, maiores diferenças de temperatura entre a água circulante e o solo proporcionam melhor rendimento (para configurações de tubulação em "U”, “2U” e "3U" obtiveram-se taxas de calor normalizadas por comprimento linear de 65,87 W.m ${ }^{-1}$, 139,21 W.m ${ }^{-1}$ e 153,43 W.m ${ }^{-1}$, respectivamente); acréscimos de velocidade do fluxo de água circulante do sistema aumentam as taxas de troca de calor do sistema geotérmico (para configurações de tubulação em "U” variou-se a vazão média de 1,2 L.min'-1 a 27,8 L.min'-1, inferindo-se taxas de calor de 40,84 W.m-1 a 65,57 W.m ${ }^{-1}$, respectivamente); diminuir a espessura dos tubos por onde circula o fluido significa reduzir a resistência térmica do material, o que permite melhores trocas de calor (variou-se a espessura da tubulação de $2 \mathrm{~mm}$ a $10 \mathrm{~mm}$, obtendo-se taxas de troca de calor de $68,85 \mathrm{~W} \cdot \mathrm{m}^{-1}$ a $50,51 \mathrm{~W} \cdot \mathrm{m}^{-1}$, respectivamente); a variação do nível freático pouco altera a eficiência do sistema (variou-se o nível de água entre as profundidades de $7 \mathrm{~m}$ e $12 \mathrm{~m}$, obtendo-se taxas de troca de calor de 66,25 W.m ${ }^{-1}$ a $65,16 \mathrm{~W} \cdot \mathrm{m}^{-1}$, respectivamente).

Figura 3.22 - Resultados numéricos e experimentais obtidos na validação do modelo

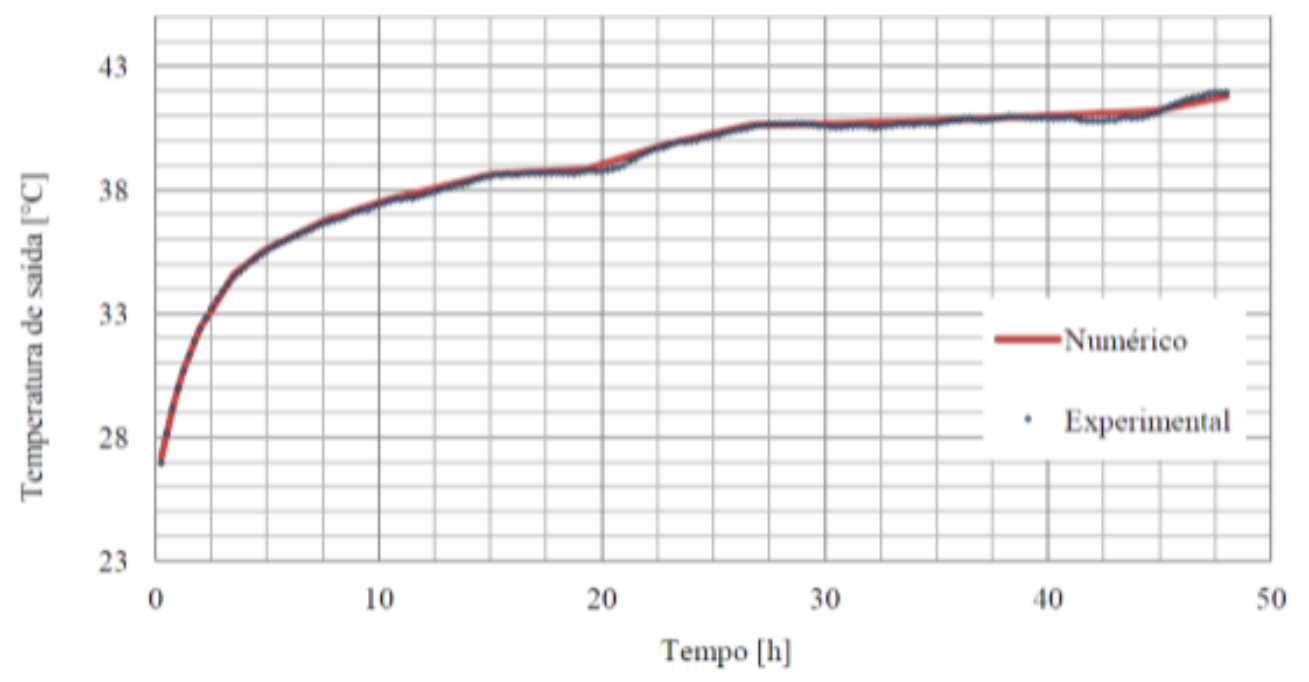

Fonte: Autor, adaptado de Orozco (2016) 
Sousa Júnior (2017) simulou, por meio do software COMSOL Multiphysics, diferentes blocos de estacas executados no Distrito Federal Brasileiro. Os parâmetros térmicos utilizados foram estimados por meio da análise de aspectos geológicogeotécnicos da região. As simulações objetivaram verificar a influência na eficiência de sistemas geotérmicos das variáveis: número de estacas por bloco de fundação, diâmetro da estaca e número de voltas de tubulações por estaca. $\mathrm{O}$ autor conclui que é recomendada a utilização de duas voltas nas tubulações para blocos com quatro ou mais estacas de diâmetros de 0,3 m e 0,4 m. Para estacas de diâmetro $0,6 \mathrm{~m}$ a recomendação é de três voltas na tubulação para máxima troca de calor. Notou-se que, quando se interceptam os bulbos de temperatura de estacas de um mesmo bloco, a eficiência do conjunto de estacas diminui. Por fim, o bom desempenho das fundações geotérmicas é atribuído aos elevados valores de condutividade térmica dos solos locais (de 2 a $3 \mathrm{~W} \cdot \mathrm{m}^{-1} \cdot \mathrm{K}^{-1}$ ). O perfil de solo do campus experimental é ilustrado pela Figura 3.23.

Figura 3.23 - Perfil de solo do campus experimental da UnB

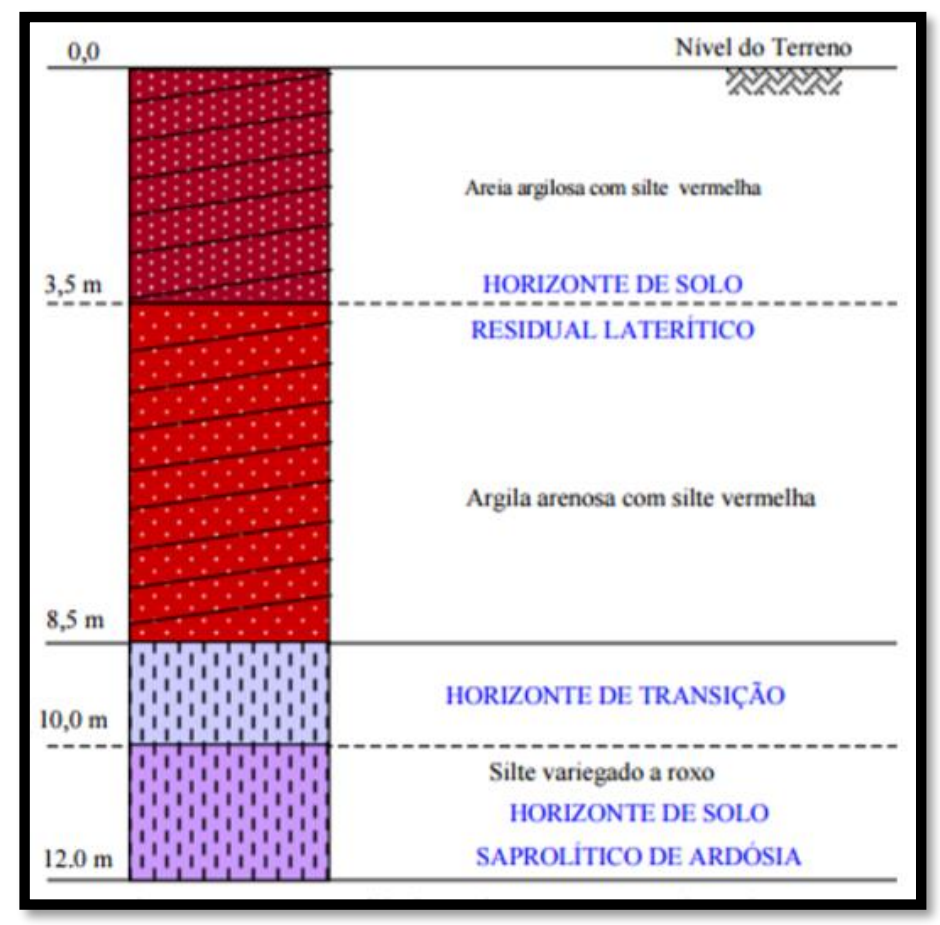

Fonte: Autor, adaptado de Sousa Júnior (2017)

Seguindo a linha de pesquisa de estudos paramétricos, em Sekine et al. (2005) são exploradas novas configurações para a disposição de tubos em fundações geotérmicas. A 
construção de uma estaca geotérmica de diâmetro $1,5 \mathrm{~m}$ e comprimento $20 \mathrm{~m}$ possibilitou a instalação de oito circuitos de tubos em formato "U”, como mostra a Figura 3.24.

Figura 3.24 - Instalação da armadura da estaca com oito circuitos de tubos em "U"

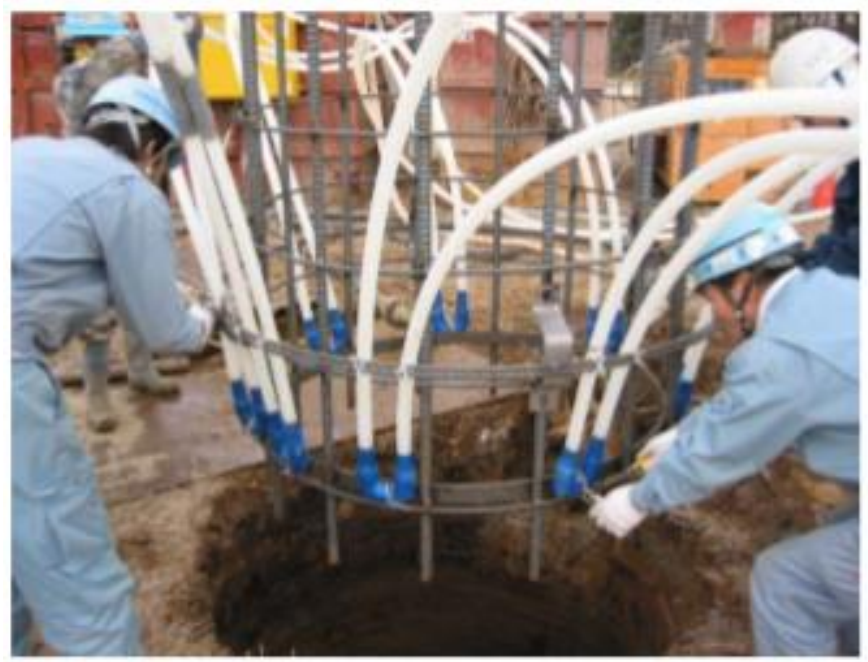

Fonte: Sekine et al (2005)

Sekine et al. (2005) efetuaram ensaios TRT em estacas cujos diâmetros variam de 1,5 m a 4 m. Foram empregados tubos de PEAD de diâmetro externo $34 \mathrm{~mm}$ e diâmetro interno $27 \mathrm{~mm}$, com vazão no interior dos tubos de 27 L.min ${ }^{-1}$ e temperatura não perturbada do solo de $17^{\circ} \mathrm{C}$. A taxa de calor rejeitado por estaca encontrou-se no intervalo de $186 \mathrm{~W} . \mathrm{m}^{-1}$ a $201 \mathrm{~W} \cdot \mathrm{m}^{-1} \mathrm{e}$, por par de tubos, foi de $25 \mathrm{~W} \cdot \mathrm{m}^{-1}$. Avaliou-se também o rendimento do sistema com o indicador COP de 4,89 para o ciclo de resfriamento, o que implica em uma eficiência 1,17 vezes superior a sistemas ASHP (Air Source Heat Pump). Por fim, a estimativa de custos revelou maior atratividade para estacas geotérmicas (US\$ $0,79 . \mathrm{W}^{-1}$ ) em comparação a furos trocadores de calor (US\$ $3 \cdot \mathrm{W}^{-1}$ ). O estudo foi conduzido na Universidade de Tóquio, em Chiba.

Fare (2015) analisou, por meio do Método das Diferenças Finitas, trocas de calor entre solo e estaca geotérmica através de diferentes modelos numéricos (um modelo de fonte cilíndrica anular de calor para o escoamento do fluido circulante pelos tubos e um modelo de transferência simultânea de calor em ambas as seções de um tubo em "U" embutido em uma estaca) que capturaram importantes características quanto à dissipação do fluxo de calor. Os resultados obtidos foram comparados a dados experimentais oriundos de ensaios TRT, modelos físicos e ensaios de sonda-agulha.

Significantes contribuições desse trabalho foram: 
(i) o aumento da temperatura do fluido que circula na estaca geotérmica provoca aumento de pressão neutra no solo. Por outro lado, o excesso de pressão neutra diminui imediatamente após cessar a circulação de fluido quente no interior da estaca. Os máximos valores de pressão neutra induzida foram encontrados na base da estaca e o excesso de pressão neutra diminui conforme aumenta-se a distância radial do centro da estaca. Após um ciclo completo de aquecimento, isto é, um ciclo de aquecimento seguido pelo resfriamento do sistema geotérmico até sua temperatura inicial, o excesso de pressão neutra é negativo em todos os pontos, por conta da redução do teor de umidade;

(ii) resultados numéricos foram utilizados para desenvolver expressões para previsão das taxas de transferência de calor total de uma estaca geotérmica em determinadas condições;

(iii) para os sistemas analisados, definiu-se a seguinte hierarquia (do parâmetro que mais influencia para o que menos influencia o desempenho da estaca) para os parâmetros de entrada: condutividade térmica do solo, diferença entre a temperatura de entrada do fluido e a temperatura inicial do solo e a velocidade de circulação do fluido pelos tubos;

(iv) Diferenças de eficiência de estacas geotérmicas resultam da variabilidade de diferentes parâmetros de projeto, operacionais e de campo.

Além disso, Fare (2015) destaca que o fluxo turbulento deve ser considerado para maximizar as taxas de calor transferidas da estaca para o solo. O gradiente de temperatura induzido pela injeção ou extração de calor em estacas origina fluxo de água em solos saturados. O vórtice de fluido induzido em uma região que circunda a estaca facilita a dissipação de calor para o solo saturado, aumentando a eficiência térmica do sistema.

\subsubsection{Comportamento termo-hidro-mecânico}

Laloui et al. (2006) empreenderam os primeiros estudos sobre o comportamento termo-hidro-mecânico de estacas geotérmicas através de análises experimentais e numéricas com o Método de Elementos Finitos. Entre os principais resultados e conclusões, citam-se: o mapeamento do perfil de temperaturas iniciais em profundidade; a obtenção das deformações verticais e radiais decorrentes dos ciclos de aquecimento e resfriamento; a verificação de que as deformações durante o aquecimento não são uniformes, mas dependentes do atrito que se desenvolve ao longo do fuste; no ciclo de 
resfriamento há reversibilidade das deformações e as tensões ocasionadas não são suficientes para levar ao desenvolvimento de deformações plásticas.

Bouazza et al. (2013) realizaram um ensaio de campo com o intuito de avaliar o impacto de efeitos acoplados causados pela variação de cargas e temperaturas em uma estaca geotérmica instrumentada. A fundação, assente em solo arenoso, recebeu células de Osterberg para a execução de provas de carga estática, strain gauges, termistores e transdutores de deslocamento para o monitoramento de diferentes variáveis durante os períodos de aquecimento, resfriamento e carregamento mecânico. Também a temperatura do solo circundante foi observada durante o ensaio. A estaca ensaiada tinha diâmetro 0,6 $\mathrm{m}$, comprimento $16 \mathrm{~m}$ e três circuitos de tubos de PEAD em formato "U".

A Figura 3.25 apresenta os deslocamentos resultantes da prova de carga estática executada em uma estaca geotérmica com temperatura natural (não perturbada) e após ciclos de aquecimento e resfriamento.

Figura 3.25 - Diagrama carregamento x deslocamento de uma estaca de energia em condições não perturbada, após aquecimento e após resfriamento

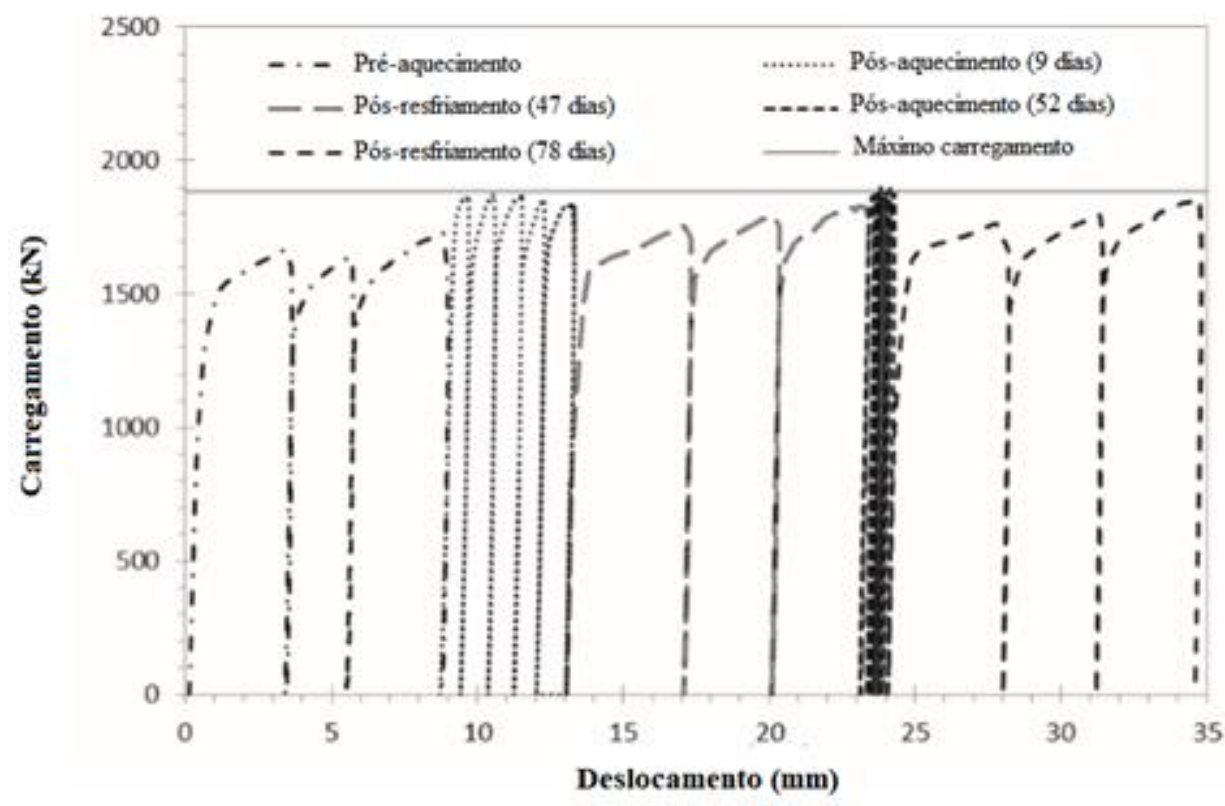

Fonte: Autor, adaptado de Bouazza et al. (2013)

Os resultados indicam que, durante o ciclo de aquecimento, o aumento da temperatura da estaca provoca uma lenta dilatação do concreto, de forma que sua capacidade de carga (principalmente devido à mobilização de atrito lateral) aumenta. 
Entretanto, no posterior ciclo de resfriamento, a capacidade de carga da fundação diminuiu vagarosamente para valores próximos ao cenário de temperatura não perturbada, uma vez que o concreto se contraiu para suas condições iniciais. Portanto, há um ganho de resistência durante o período de aquecimento, que é perdido durante o ciclo de resfriamento. Em comparação às condições iniciais da fundação, não há ganho ou perda de resistência.

Em continuidade, Bouazza et al. (2015) focaram no desempenho térmico e na resistência ao cisalhamento lateral do sistema geotérmico. Apesar de ocorrer variação de temperaturas no solo circundante, a estaca geotérmica forneceu ao solo taxas constantes de calor. A resistência ao cisalhamento lateral não foi afetada pelos ciclos de aquecimento e resfriamento.

Algumas importantes observações resultantes do estudo experimental: as temperaturas do sistema geotérmico aumentaram durante o ciclo de aquecimento e diminuíram de forma constante no ciclo de resfriamento natural, sem a ocorrência de atraso (time lag), isto é, o pico de temperatura é atingido no exato momento em que o ciclo de aquecimento é realizado. A redução de temperaturas ocorre uniforme e rapidamente até 5 dias depois do encerramento do ensaio e em 20 dias após a finalização do ensaio TRT a temperatura do solo circundante atinge o valor anterior ao ensaio, caracterizando o período de recuperação. Neste caso, a fundação geotérmica leva, para recuperação completa, o dobro de tempo necessário ao aquecimento e estabilidade do sistema. Conforme mencionado, a dissipação de calor ocorre mais rapidamente no início do intervalo de tempo posterior ao fim do ciclo de aquecimento e tende a estabilizar-se.

A Figura 3.26 apresenta as respostas térmicas no corpo da estaca geotérmica ensaiada por meio de termo sensores localizados em diferentes profundidades. É notável que, ao interromper-se o aquecimento, ocorre a queda imediata de temperaturas da estaca. A Figura 3.27 ilustra a variação da temperatura ao longo de tempo em um furo localizado a $0,8 \mathrm{~m}$ do centro da estaca.

Através de prova de carga estática, calculou-se a capacidade de carga anterior ao ciclo de aquecimento de $1650 \mathrm{kN}$. Quando o estágio de aquecimento atingiu condições de estabilidade a capacidade de carga passou a 1860 kN. Segundo Bouazza et al. (2013), o incremento de resistência deve-se ao aumento de resistência lateral em virtude da expansão do concreto e do efeito de secagem do solo. 
Figura 3.26 - Respostas térmicas no corpo da estaca ensaiada

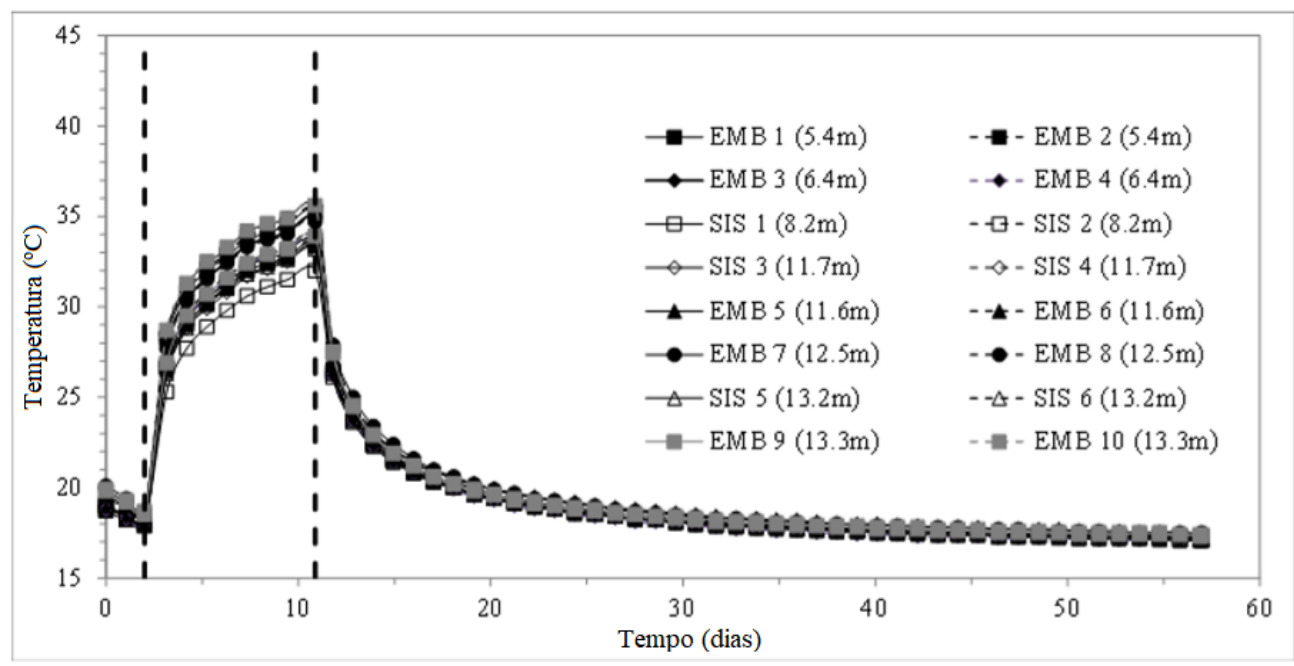

Fonte: Autor, adaptado de Bouazza et al. (2015)

Figura 3.27 - Respostas térmicas em um furo localizado a $0,8 \mathrm{~m}$ do centro da estaca

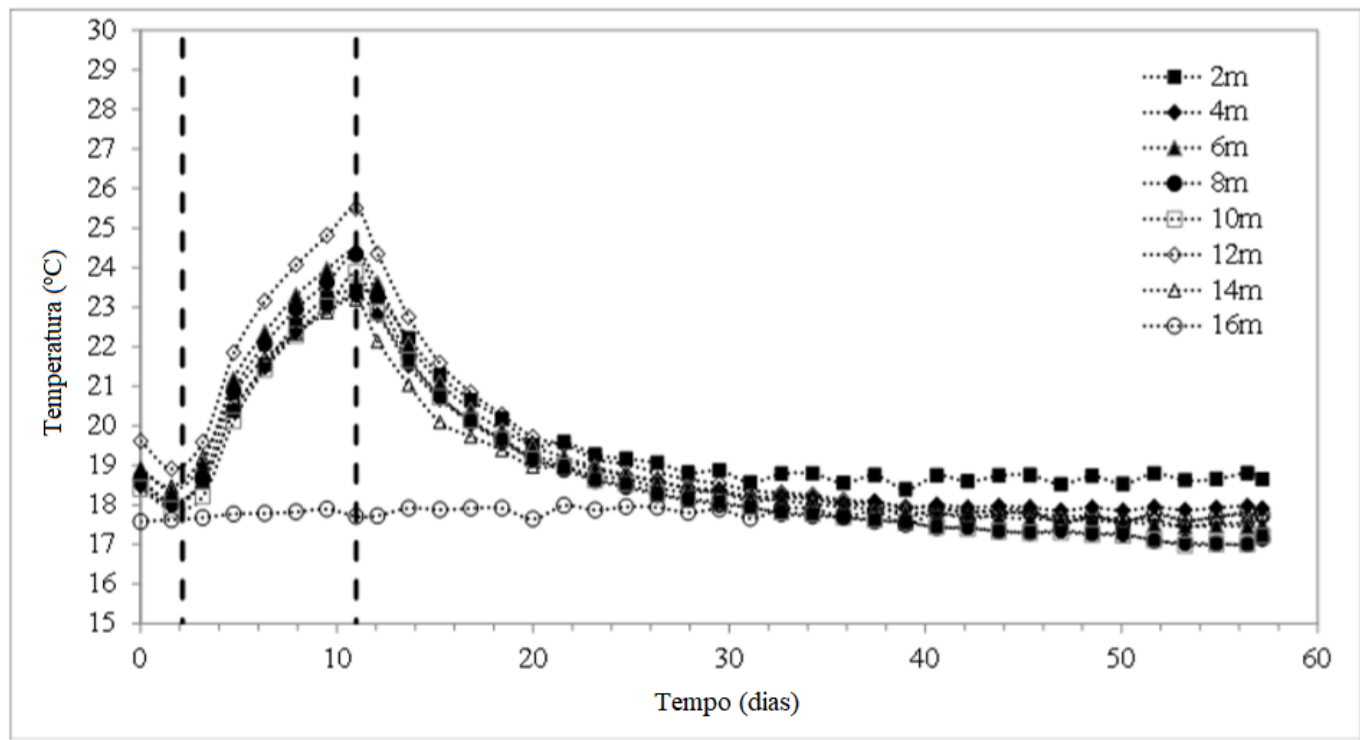

Fonte: Autor, adaptado de Bouazza et al. (2015)

Mais resultados são explorados em Singh et al. (2015), onde são observadas as respostas térmicas através de dois furos, localizados a $0,8 \mathrm{~m}$ e 2,3 $\mathrm{m}$ do centro da estaca, sendo que tanto a estaca como os furos são instrumentados. Dois tipos de ciclos de aquecimento foram desenvolvidos: o primeiro utilizando-se apenas um circuito em "U" e o segundo empregando-se três circuitos em "U”. Os ciclos de aquecimento ocorreram ao longo de vários dias e, quando finalizados, permitiu-se o resfriamento natural do sistema geotérmico, de forma a obter-se o tempo de recuperação. 
No ciclo de aquecimento do ensaio com apenas um circuito em "U" notou-se distribuição não uniforme de calor no interior da estaca. Para o caso de três circuitos em "U" a distribuição de calor no interior da estaca ocorre com maior uniformidade.

Em todos os cenários percebe-se maior incremento de temperatura na profundidade de $12 \mathrm{~m}$, uma vez que em tal região há uma camada de areia densa com elevado teor de quartzo, portanto com maior condutividade térmica. É interessante a ocorrência de um atraso (time lag) na dissipação de calor conforme a distância da fonte de calor aumenta. Por fim, a taxa de troca de calor no sistema geotérmico depende diretamente da diferença de temperatura entre fluido circulante e solo, bem como da velocidade de fluxo circulante.

Bourne-Webb et al. (2009) realizaram provas de carga convencionais com ciclos de aquecimento em estacas geotérmicas em argilas de Londres, percebendo que ciclos de resfriamento promovem contração na estrutura de concreto e as extremidades da estaca ficam livres para se movimentar; e que a expansão radial da estaca mobiliza maiores parcelas de atrito lateral.

Uma sólida pesquisa sobre desempenho termo-hidro-mecânico de estacas geotérmicas é encontrada em McCartney et al. (2013). Os autores realizaram estudos experimentais em centrífuga e em uma estaca geotérmica operando abaixo de um prédio de 8 andares em Denver (EUA). Uma das limitações do estudo é a impossibilidade de reproduzir-se no ensaio em centrífuga as condições do solo in situ.

A fundação ensaiada em centrífuga possuía comprimento de 533,4 mm e diâmetro de $25 \mathrm{~mm}$, e foi instalada no centro de um recipiente cilíndrico preenchido com uma camada de silte não saturado e de resistência uniforme. A ponta inferior da fundação estava engastada sobre a base do contêiner, dando origem a uma condição de contorno de limite inferior com deslocamentos nulos. Realizou-se o carregamento controlado, em ciclo de aquecimento (com desenvolvimento livre de deslocamentos).

A Figura 3.28 apresenta a evolução de tensões e deformações no modelo reduzido ensaiado em centrífuga.

$\mathrm{Na}$ fundação real, de comprimento $14,8 \mathrm{~m}$ e diâmetro $0,91 \mathrm{~m}$, o comportamento termo-hidro-mecânico do conjunto esteve associado às restrições impostas pelo edifício. Foram utilizados três circuitos de PEAD em "U" para o ensaio. 
Figura 3.28 - Esquema representativo do ensaio em centrífuga
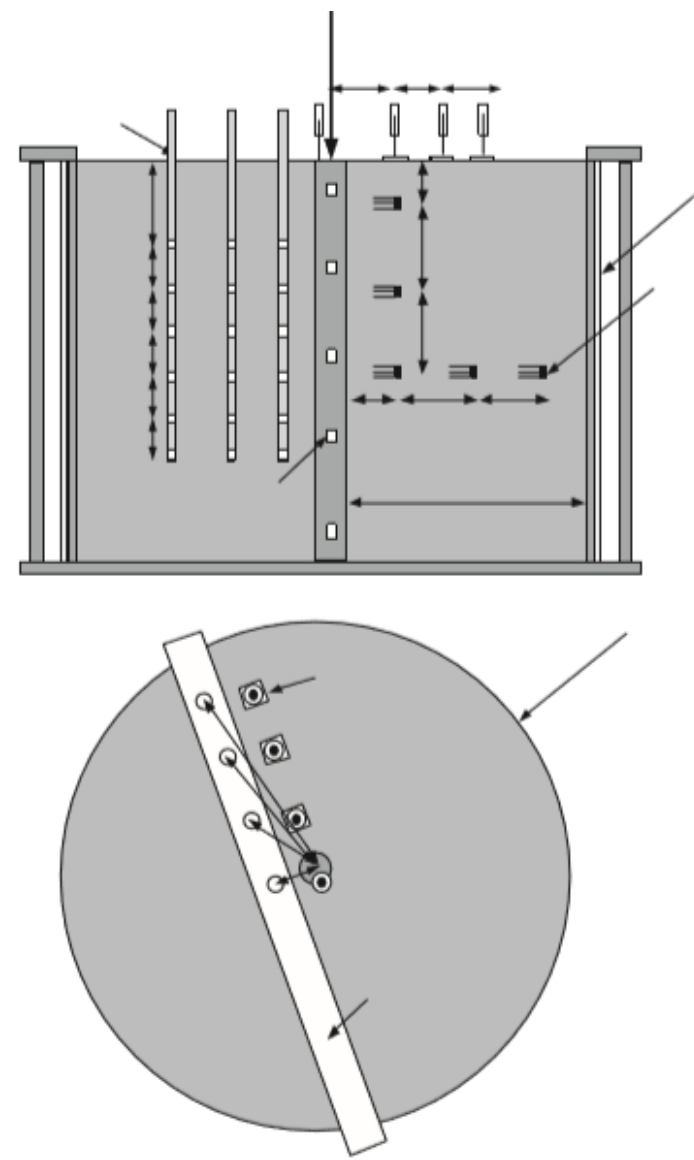

Fonte: McCartney et al. (2013)

Como resultados, verificou-se que a distribuição de tensões no ensaio em centrífuga indica maior concentração de tensões junto à extremidade inferior da fundação (com tensões desprezíveis na extremidade superior do modelo reduzido). No ensaio in situ, por outro lado, a distribuição de tensões mostrou-se uniforme ao longo da profundidade da estaca.

A Figura 3.29 apresenta a distribuição de deformações axiais e tensões térmicas ao longo da profundidade para o ensaio de modelo reduzido em centrífuga. 
Figura 3.29 - Distribuição de deformações axiais e tensões térmicas ao longo da profundidade para o ensaio de modelo reduzido em centrífuga
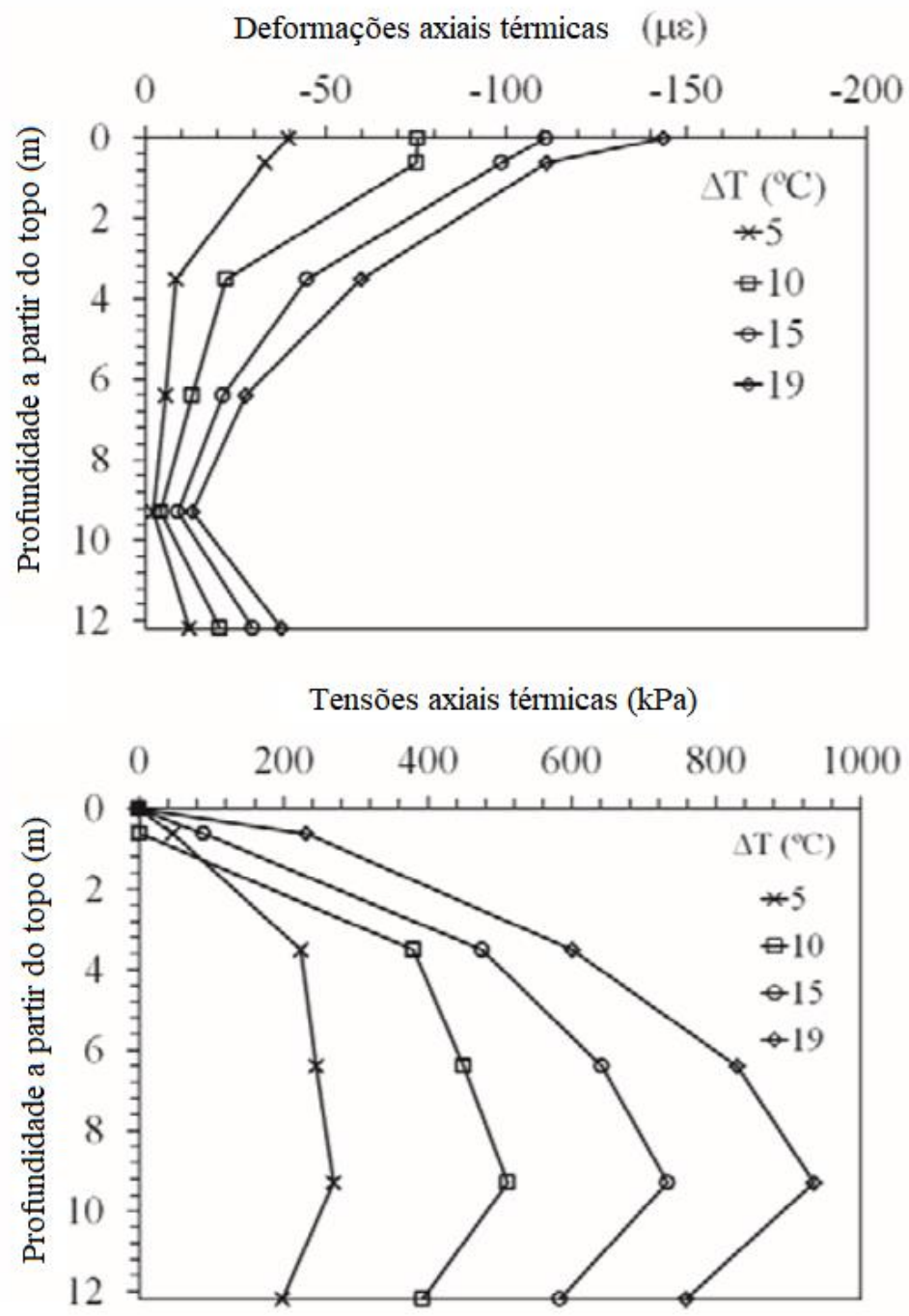

Fonte: Autor, adaptado de McCartney et al. (2013)

A Figura 3.30 apresenta a distribuição de deformações axiais e tensões termicamente induzidas ao longo da profundidade para o monitoramento do ensaio em tamanho real. 
Figura 3.30 - Distribuição de deformações axiais e tensões termicamente induzidas ao longo da profundidade para o monitoramento do ensaio em tamanho real
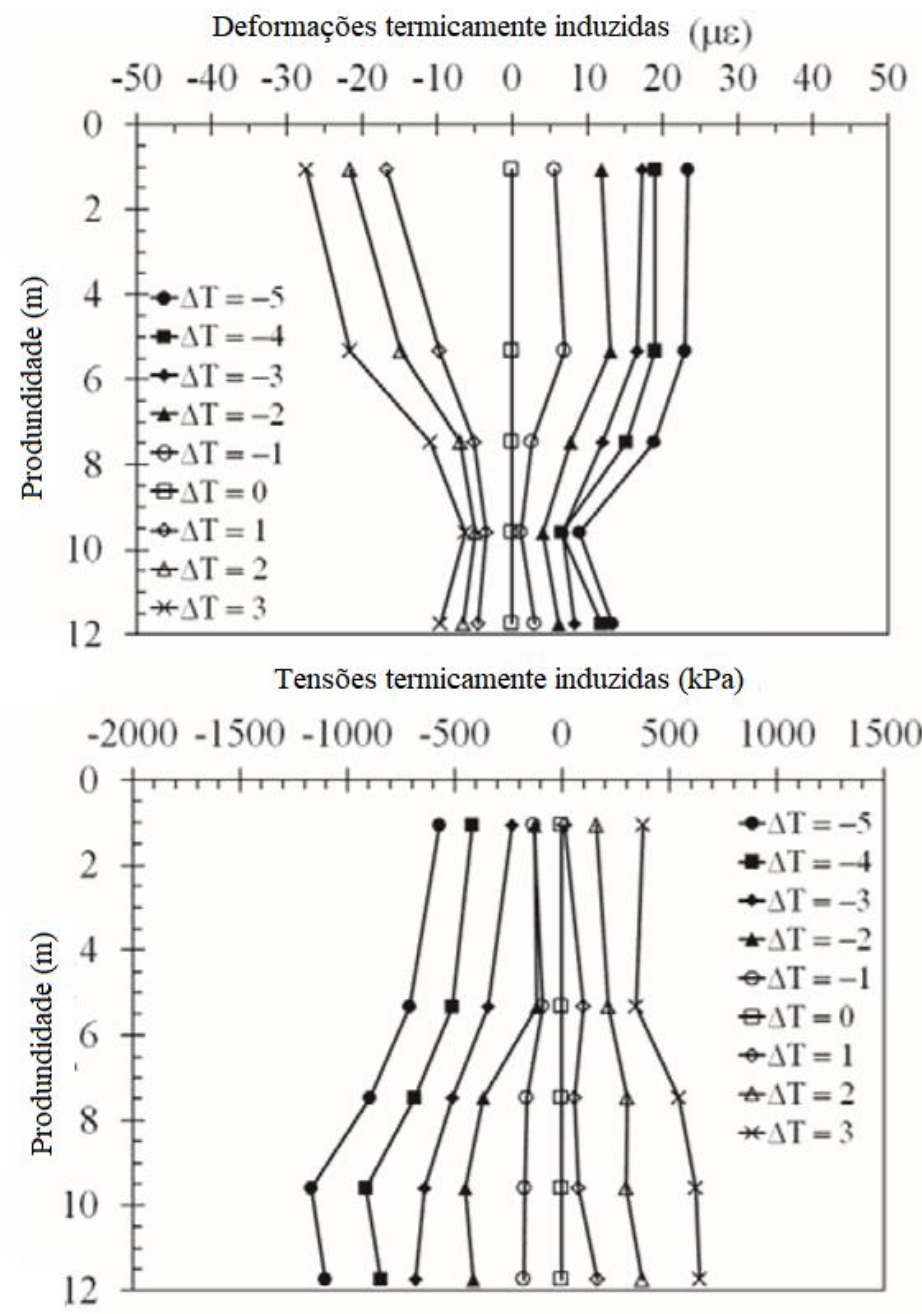

Fonte: Autor, adaptado de McCartney et al. (2013)

Uma evolução do estudo apresentado em McCartney et al. (2013) é encontrado em Murphy e McCartney (2014), com a modificação de um dispositivo capaz de medir o impacto da temperatura no desenvolvimento in situ de curvas tensão x deformação para interfaces de solo e concreto. $\mathrm{O}$ aparato, designado pelos autores como de cisalhamento térmico, possui diâmetro de 101,6 mm, é conectado por hastes metálicas de $1 \mathrm{~m}$ cada e foi instalado em um perfil de solo de argila e silte da região de Boulder. É constituído por aquecedores embutidos em concreto, juntamente a um dispositivo de carregamento pneumático para aplicação de tensões normais e um sistema de carregamento automatizado com controle de deslocamento vertical e medição de carga. As temperaturas são controladas através de uma bomba de calor localizada na superfície. 
Verificou-se que a temperatura não possui considerável impacto na resistência ao cisalhamento de pico ou ângulo de atrito, o que reforça a hipótese de que a temperatura não influencia consideravelmente o desenvolvimento de curvas carga-recalque.

Brandl (1998) reuniu casos históricos de implementação de estacas geotérmicas, bem como resultados de instrumentações e ensaios in situ. O principal estudo de caso consiste na instalação de 175 estacas geotérmicas, de diâmetro 1,20 m e comprimentos variáveis de 9,0 a 10,5 m. De forma similar a Murphy e McCartney (2014), o autor concluiu que a resistência por atrito lateral, ao longo do fuste das estacas, sofre consideráveis alterações ao absorver calor do solo para transferi-lo a edificações.

No departamento de Engenharia Civil da Universidade do Texas, um grupo de pesquisas liderado pelo professor Marcelo Sánchez conduziu estudos similares aos de Murphy e McCartney (2014). Sánchez et al. (2014) comentam que, embora a literatura técnica tenha explorado tensões e deformações termicamente induzidas em fundações geotérmicas, bem como o efeito de ciclos de aquecimento e resfriamento nas propriedades geotécnicas e geotérmicas do solo, pouca atenção tem sido dada às deformações lentas (creep) causadas por variações de temperatura.

Sánchez et al. (2014) realizaram ensaios em estacas geotérmicas (diâmetro 0,18 $\mathrm{m}$ e comprimento $5,50 \mathrm{~m}$ ) assentes em argilas de alta plasticidade, nas quais circulou-se fluido quente por um circuito em forma de "U" composto por tubos de PEAD variandose os carregamentos mecânicos. Para isso, aplicaram-se, no topo da estaca, carregamentos de $40 \mathrm{kN}, 100 \mathrm{kN}, 150 \mathrm{kN}, 200 \mathrm{kN}$ e $256 \mathrm{kN}$, durante o período de 1 hora. A seguir, iniciou-se a circulação de água pela estaca, com o fluido aquecido pela ação da bomba de calor a cerca de $15{ }^{\circ} \mathrm{C}$, por $4 \mathrm{~h}$. Após $5 \mathrm{~h}$ do início da aplicação dos carregamentos mecânicos, finalizou-se o ensaio. Monitorou-se o desenvolvimento da curva carga $x$ recalque, bem como as temperaturas no solo e na estaca, a temperatura e a umidade do ar e a temperatura de entrada e saída do fluido nos tubos. Constatou-se que, com o aumento da temperatura, há aumento na taxa de deslocamentos por creep. Na estrutura de concreto submetida a aquecimento e resfriamento, por sua vez, os deslocamentos e concentrações de tensões foram insignificantes.

A Figura 3.31 mostra a curva de carga x recalque para o ensaio realizado, levando-se em consideração os instantes: $\mathrm{t}=0$ minutos (início do ciclo de aquecimento), $\mathrm{t}=60$ minutos e $\mathrm{t}=300$ minutos (final do ciclo de aquecimento). São apresentadas as curvas extrapoladas para 50 anos nos cenários com e sem geotermia, obtidas com o modelo matemático proposto pela Equação (3.29), desenvolvido por Briaud et al. (1997a) 
partir de dezenas de ensaios in situ em estacas no campo experimental da Universidade do Texas A\&M. Os resultados indicam que, caso o sistema opere em condições estacionárias de aquecimento, o desenvolvimento de recalques por creep será, em situação mais extrema, 2,35 vezes maior se comparado ao caso em que não há geotermia.

$$
\frac{S_{t}}{S_{1}}=\left(\frac{t}{t_{1}}\right)^{n}
$$

Em que:

- $n$ é o componente viscoso;

- $\quad t$ é o tempo (min);

- $\quad t_{1}$ é o tempo de referência (min);

- $S_{t}$ é o deslocamento no tempo t (m);

- $S_{1}$ é o deslocamento no tempo $1(\mathrm{~m})$.

O componente viscoso é obtido pelo coeficiente linear da reta do diagrama de log $\left(\mathrm{S}_{\mathrm{t}} / \mathrm{S}_{\mathrm{t} 1}\right)$ versus $\log \left(\mathrm{t} / \mathrm{t}_{1}\right)$.

Figura 3.31 - Curvas carga-recalque para diferentes tempos

\section{Carga (kN)}

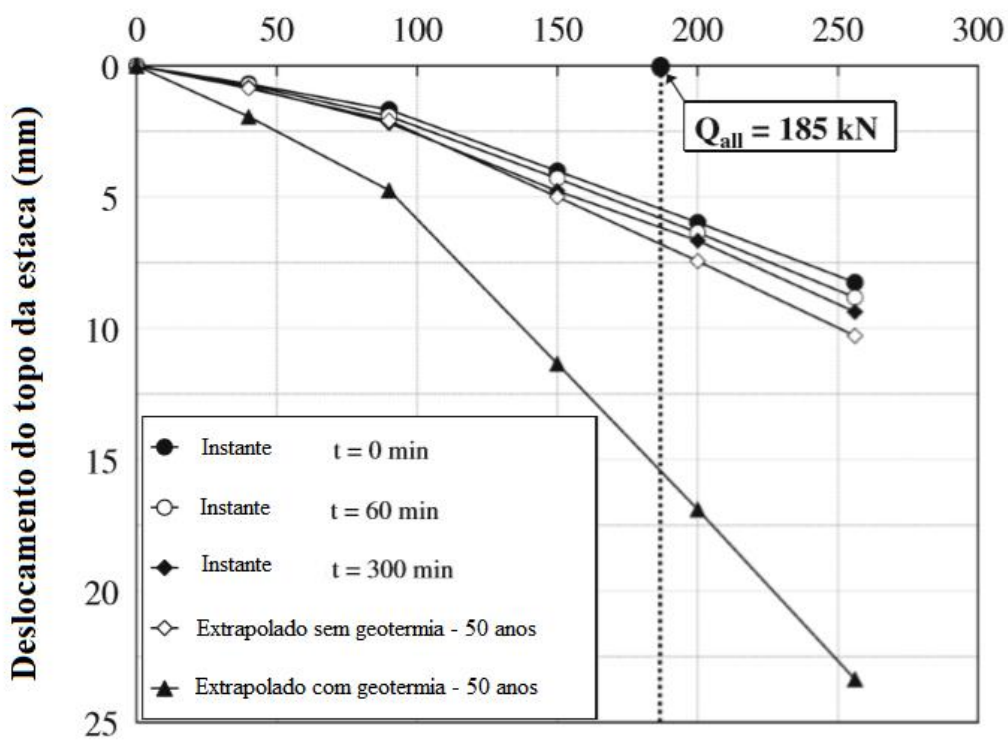

Fonte: Autor, adaptado de Sánchez et al. (2014) 
Sánchez et al. (2015) estudaram a influência da saturação nas propriedades térmicas do solo, considerando que estacas geotérmicas são relativamente curtas e por isso penetram em camadas de solo em que as condições de saturação variam com a profundidade. Realizaram-se análises numérica, experimental e analítica. A solução analítica baseia-se na teoria da fonte cilíndrica de calor e trata o solo como um meio semiinfinito, homogêneo e isotrópico. O resultado é multiplicado por uma função desenvolvida analiticamente, proposta pelos autores e denominada função de eficiência térmica, para determinar a taxa de transferência de calor para estacas geotérmicas em solos parcialmente saturados. A função de eficiência térmica relaciona o calor trocado entre a estaca geotérmica e o solo circundante e depende de inputs como grau de saturação do solo, propriedades térmicas do solo e da estaca e geometria da fundação.

No âmbito experimental desenvolveu-se, em laboratório, uma seção transversal de estaca com o objetivo de se avaliarem os efeitos causados por estados de saturação parcial do solo na troca de calor entre estaca e solo arenoso circundante. Assumiram-se condições bidimensionais de dissipação de calor, garantidas por meio do isolamento térmico do aparato em suas faces superior e inferior, fazendo uso de painéis isolantes de espuma. Um esquema representativo do modelo físico, com os pontos onde se mediram temperaturas, pode ser visto na Figura 3.32.

Figura 3.32 - Modelo físico bidimensional de uma estaca de energia

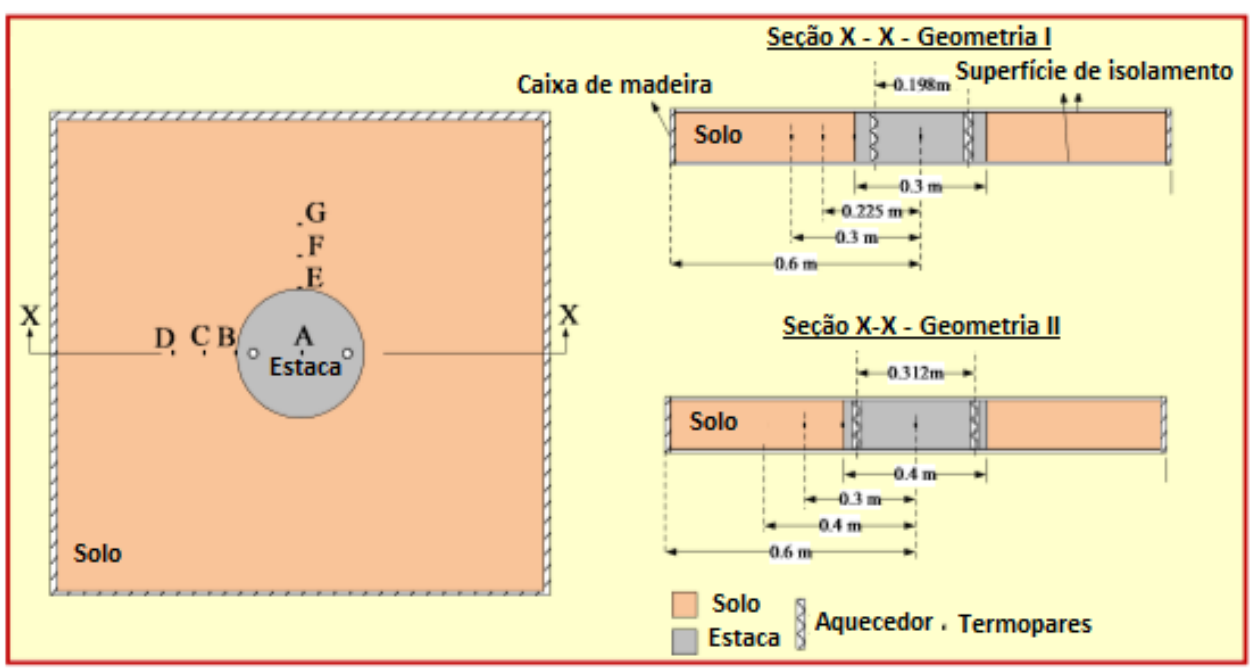

Fonte: Autor, adaptado de Sánchez et al. (2015)

Foram realizados ensaios com dois diferentes diâmetros da seção transversal, variando-se também o traço de concreto, de forma a criar-se condutividades térmicas de 
1,3 e $1,4 \mathrm{~W} \cdot \mathrm{m}^{-1} \cdot \mathrm{K}^{-1}$ para a Geometria I e a Geometria II, respectivamente. Variaram-se o índice de vazios e grau de saturação do solo para se obter equações analíticas referentes à taxa de propagação de calor. Todavia, não foram impostas condições de fluxo.

Os resultados permitiram determinar experimentalmente os valores da função de eficiência térmica para variáveis bem definidas de grau de saturação do solo, propriedades térmicas do solo e da estaca e da geometria da fundação. Concluiu-se que houve satisfatória proximidade entre os resultados experimentais e analíticos.

Validou-se um modelo numérico, baseado no Método de Elementos Finitos, para as condições: temperatura inicial dos materiais (concreto, solo arenoso e água) iguais à temperatura ambiente, $21{ }^{\circ} \mathrm{C}$; temperatura de $21{ }^{\circ} \mathrm{C}$ nos limites do perímetro da caixa de areia durante os ciclos de aquecimento e resfriamento; temperatura da água no interior dos tubos igual a $37^{\circ} \mathrm{C}$ para a Geometria I e $30^{\circ} \mathrm{C}$ para a Geometria II; e impermeabilidade nos limites do modelo físico.

A Figura 3.33 mostra a malha de elementos finitos empregada para as simulações no programa CODE_BRIGHT.

Figura 3.33 - Malha adotada para as simulações numéricas
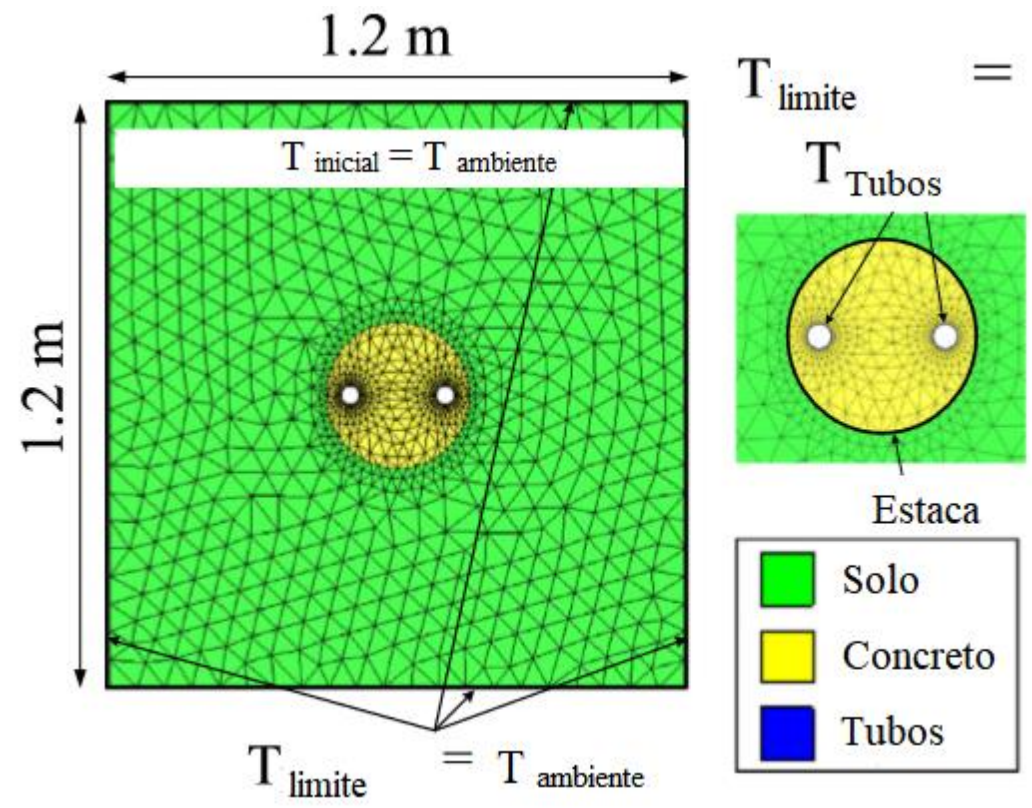

Fonte: Autor, adaptado de Sánchez et al. (2015)

Após a validação do modelo numérico, os autores simularam os experimentos de laboratório, obtendo resultados bastante próximos aos analíticos (em geral, diferenças inferiores a $0,5^{\circ} \mathrm{C}$ ). Mostrou-se que, entre máxima e mínima saturação, o desempenho do 
sistema geotérmico pode cair em até $40 \%$; que a eficiência térmica para areias é da ordem de 0,57; e que para as areias argilosas não houve impacto da variação do nível de água e a eficiência térmica foi de 0,95 .

Várias das análises experimentais e numéricas levantadas até aqui podem ser encontradas em um dos estudos mais completos veiculados na literatura e apresentado em You et al. (2017). Nessa pesquisa, parte-se da premissa que sistemas GSHP atravessam diferentes camadas de solo com propriedades geotécnicas e geotérmicas diferentes. Especificamente, os autores se dedicaram a entender como um desses parâmetros, o fluxo de água subterrâneo, afeta o desempenho do sistema.

A condutividade térmica do solo circundante foi investigada por ensaios TRT e através de amostras não perturbadas coletadas em campo. A distribuição de temperaturas em profundidade foi obtida por instrumentação da estaca, de diâmetro $0,42 \mathrm{~m}$ e comprimento $18 \mathrm{~m}$, assente em um perfil de solo composto por argila, silte e areia.

A Figura 3.34 apresenta o perfil de temperaturas para os instantes que precedem a execução do ensaio TRT, junto à estrutura de concreto da estaca e distâncias radiais de 0,7 m, 1,3 m e 1,9 m, medidos a partir do centro da seção transversal da fundação.

Figura 3.34 - Perfil de temperaturas no sistema geotérmico

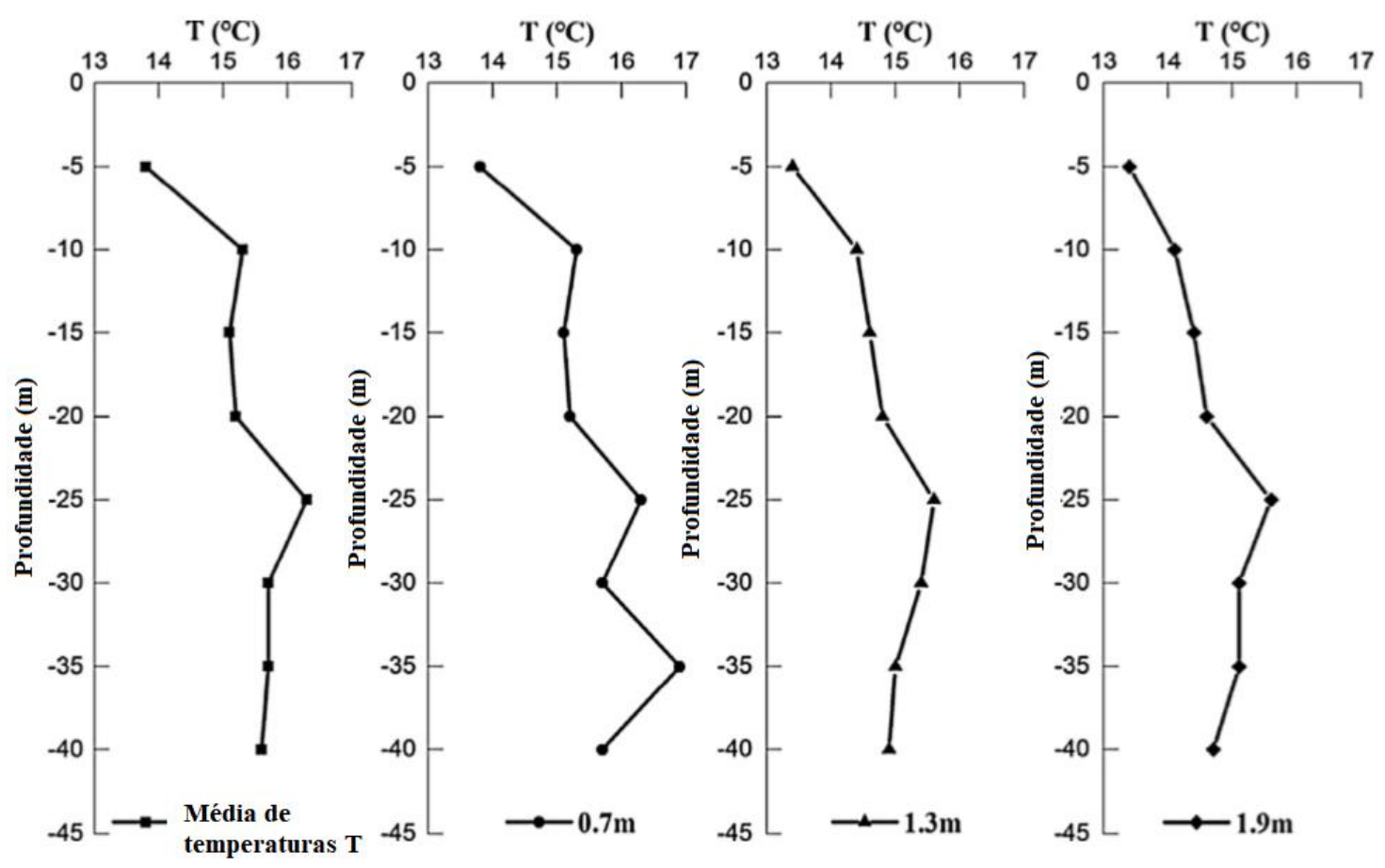

Fonte: Autor, adaptado de You et al. (2017) 
Determinaram-se os seguintes valores médios para o sistema geotérmico: condutividade térmica de $2,2 \mathrm{~W} \cdot \mathrm{m}^{-1} \cdot \mathrm{K}^{-1}$, transferência de calor por unidade de comprimento de estaca de $258 \mathrm{~W} / \mathrm{m}$ para o ciclo de aquecimento e $-76 \mathrm{~W} . \mathrm{m}^{-1}$ para o ciclo de resfriamento. Os ensaios de laboratório, por outro lado, resultaram em condutividade térmica média de $1,54 \mathrm{~W} \cdot \mathrm{m}^{-1} \cdot \mathrm{K}^{-1}$, inferior à determinada em condições in situ. Atribui-se tal disparidade à perda de umidade das amostras de solo na etapa de transporte.

A análise numérica foi realizada com o programa RSAS, um software fundamentado no Método de Elementos Finitos que soluciona problemas tridimensionais em regime transiente envolvendo trocas de calor. O modelo foi calibrado a partir de medições provenientes do ensaio TRT, inclusive considerando o efeito do fluxo de água subterrâneo na eficiência da estaca geotérmica. Uma notável diferença deste trabalho para as outras referências consultadas é a concepção numérica do solo a partir de um meio poroso (o que viabiliza a simulação da água percorrendo os vazios existentes entre os grãos de solo).

Após a validação, simulou-se a variação da velocidade do fluxo de água subterrânea. Percebeu-se que a taxa de crescimento da média das temperaturas de entrada e saída do fluxo de água circulante nos tubos diminuiu conforme a velocidade do fluxo de água subterrâneo aumentou. Como consequência, a condutividade térmica aumentou de 2,03 W.m $\mathrm{m}^{-1} \cdot \mathrm{K}^{-1}$ para $2,25 \mathrm{~W} \cdot \mathrm{m}^{-1} \cdot \mathrm{K}^{-1}$ (cerca de $10 \%$ ) quando a velocidade do fluxo de água nos vazios do solo aumentou de $0 \mathrm{~m} \cdot \mathrm{s}^{-1}$ para $5 \cdot 10^{-8} \mathrm{~m} \cdot \mathrm{s}^{-1}$. A conclusão dessas considerações é pragmática: até mesmo pequenas velocidades de fluxo de água subterrânea, em regime laminar, podem ter significantes efeitos na troca de calor de estacas geotérmicas.

A Figura 3.35 mostra resultados das simulações relacionando a variação de temperaturas ao longo do tempo para diferentes velocidades de fluxo de água subterrânea.

Os autores também compararam os resultados numéricos oriundos do programa RSAS com resultados obtidos pelo software ANSYS, amplamente utilizado em problemas que envolvem fluxo de água e trocas térmicas. No software ANSYS conduziram-se as simulações seguindo as mesmas premissas aplicadas ao modelo desenvolvido no software RSAS, incluindo a representação do solo como meio poroso.

A comparação é apresentada na Figura 3.36 e evidencia proximidade entre os dados fornecidos pelas simulações. 
Figura 3.35 - Variação de temperaturas para diferentes velocidades de fluxo de água

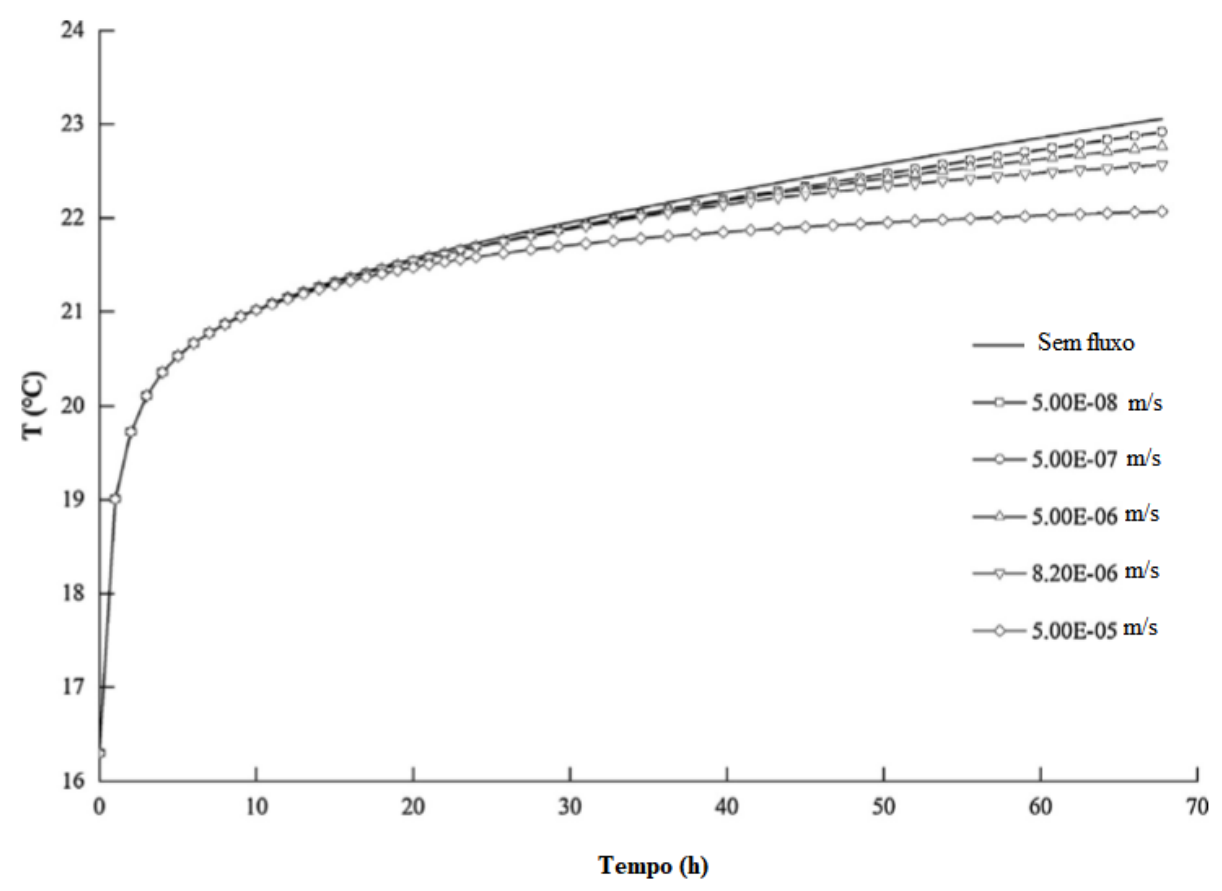

Fonte: Autor, adaptado de You et al. (2017)

F

Figura 3.36 - Comparação entre resultados dos programas ANSYS e RSAS

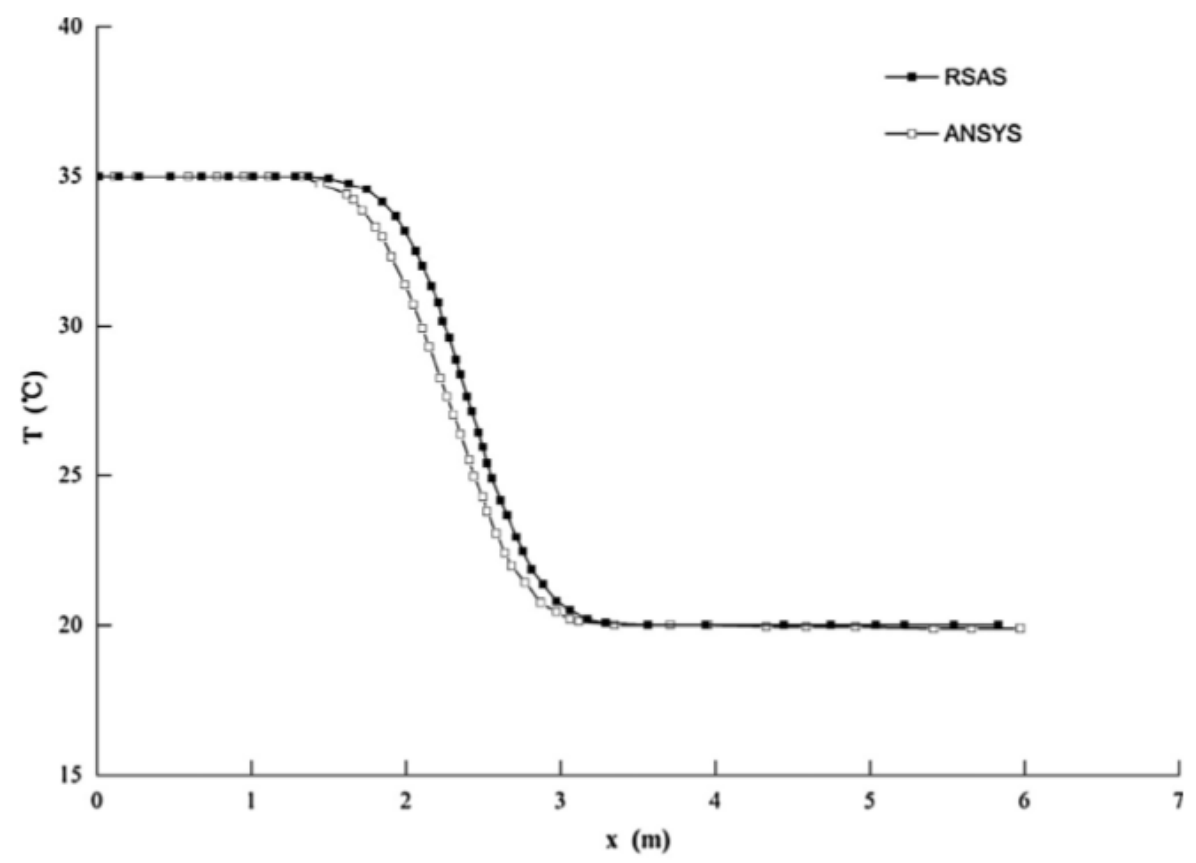

Fonte: Autor, adaptado de You et al. (2017) 
Também se empregou o Método de Elementos Finitos em 3D, com o programa RSAS, para simular o cenário de resfriamento do ensaio TRT. A temperatura de saída do fluido circulante diminuiu vagarosamente conforme a velocidade do fluxo de água subterrânea aumentou, denotando aumento nas taxas de troca de calor entre estaca e solo/água subterrânea, de $70 \mathrm{~W} \cdot \mathrm{m}^{-1}$ para $84,5 \mathrm{~W} \cdot \mathrm{m}^{-1}$ quando a velocidade do fluxo de água subterrânea aumentou de $0 \mathrm{~m} \cdot \mathrm{s}^{-1}$ para $5 \cdot 10^{-5} \mathrm{~m} \cdot \mathrm{s}^{-1}$.

Finalmente, as verificações numéricas e experimentais comprovaram que, em profundidade, a temperatura do sistema geotérmico era maior na ausência de fluxo de água subterrânea. À medida que aumenta-se a velocidade do fluxo de água, a temperatura do solo diminuiu até retornar a seu valor na condição não perturbada. Portanto, concluise que do ponto de vista de dissipação de calor no solo o fluxo de água subterrânea possui um impacto positivo. A Figura 3.37 mostra a relação entre velocidade do fluxo de água subterrânea e média das temperaturas de entrada e saída da água circulante nos circuitos de tubos de PEAD.

Figura 3.37 - Relação entre a velocidade do fluxo de água subterrânea e média das temperaturas de entrada e saída da água circulante nos circuitos de tubos de PEAD

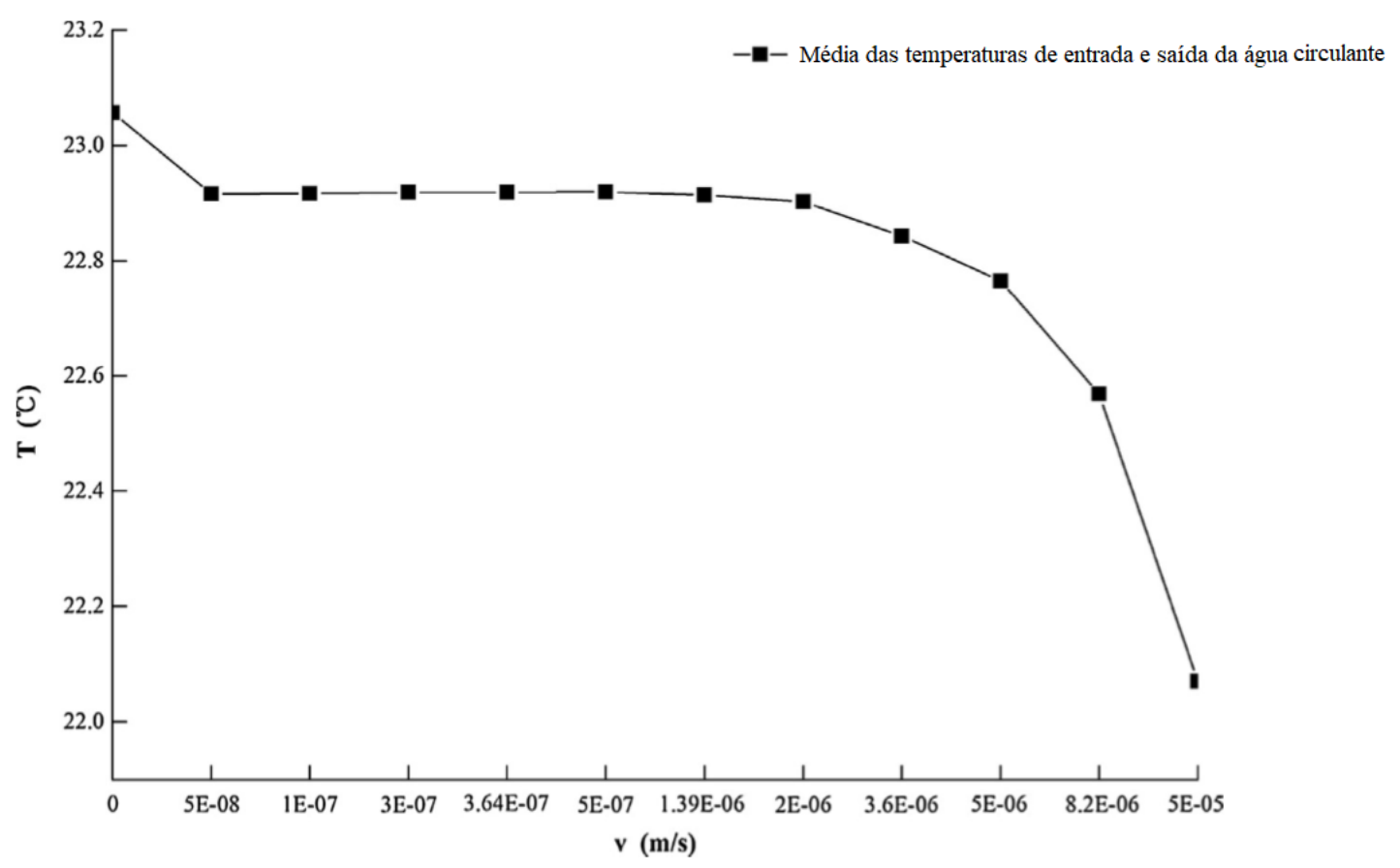

Fonte: Autor, adaptado de You et al. (2017)

Em Fu (2017) estuda-se a resistência ao cisalhamento em interfaces soloestrutura de estacas geotérmicas, partindo-se do princípio de que variações de temperatura 
provocam o movimento de água no solo e que este influencia as propriedades de transferência de calor do solo.

A pesquisa apresentada em $\mathrm{Fu}$ (2017) traz uma importante contribuição ao meio geotécnico, uma vez que desenvolve análises experimentais e numéricas em estacas geotérmicas em interação com solos não saturados. Verifica-se que nos ensaios laboratoriais de interface utilizando amostras de solo com baixo grau de saturação, a adesão aumentou, uma vez que o efeito positivo causado pela sucção na resistência foi maior do que o efeito negativo provocado pelo aumento das temperaturas. No entanto, em ensaios de interface em amostras de solo com alto grau de saturação, a adesão diminuiu com o aumento da temperatura, visto que o efeito positivo da sucção não foi grande o suficiente para superar o efeito negativo do aumento da temperatura. Além disso, destaca-se que o ângulo de atrito para ambas as amostras de solo (com diferentes graus de saturação) mudou ligeiramente com a mudança de temperatura.

Ferreira (2017) estudou o comportamento termomecânico de uma estaca geotérmica executada no campus da Universidade Estadual do Norte Fluminense, em Campos Goytacazes, no Rio de Janeiro. A região possui clima tropical com estação seca, média anual de temperatura de $24,1^{\circ} \mathrm{C}$ e temperatura média de $26,7{ }^{\circ} \mathrm{C}$ no verão.

Executou-se uma estaca geotérmica tipo raiz de diâmetro $40 \mathrm{~cm}$ e comprimento $12 \mathrm{~m}$ em um perfil de solo em que, até as profundidades de $3 \mathrm{~m}$ a $4 \mathrm{~m}$, há presença de argila com frações de silte e areia e, nas profundidades de $9 \mathrm{~m}$ a $11 \mathrm{~m}$ há argila marinha muito mole. O nível de água, entre as profundidades $4 \mathrm{~m}$ a 5,75 m nas duas sondagens, sofre influência do rio Paraíba do Sul. Utilizou-se concreto adensável, armaduras compostas por barras longitudinais de 9,5 mm de diâmetro e tubos PEX presos à armadura para a circulação de fluido. Extensômetros com medidores de temperatura foram instalados junto à estaca para a medição de deformações. Foram realizados dois ensaios TRT: o primeiro empregou vazão de 19,4 L.min ${ }^{-1}$ e carga térmica de 1,2 kW; o segundo usou vazão de 23,4 L.min ${ }^{-1}$ e carga térmica de 1,3 kW.

Observou-se que as temperaturas de entrada e de saída aumentam ao longo do tempo, revelando comportamento transiente no início dos ensaios TRT. Notou-se influência da temperatura ambiente nos ensaios, uma vez que houve o registro de picos nas temperaturas de entrada e saída juntamente aos picos ocorridos na temperatura da placa do arduíno, permanentemente submetido à temperatura ambiente.

Os dados foram interpretados por Ferreira (2017) com base na Teoria da Fonte Linear Infinita de Calor. Encontraram-se condutividades térmicas do solo de 2,15 
$\mathrm{W} \cdot \mathrm{m}^{-1} \cdot \mathrm{K}^{-1}$ (ensaio 1) e $2,41 \mathrm{~W} \cdot \mathrm{m}^{-1} \cdot \mathrm{K}^{-1}$ (ensaio 2). A temperatura média não perturbada do solo foi de $29,4{ }^{\circ} \mathrm{C}$. Durante o aquecimento, a estaca sofreu expansão, gerando deformações de tração e tensões compressivas, ocorrendo as maiores deformações por tração junto à cabeça e à ponta da estaca. As maiores tensões de compressão localizaramse no fuste. A autora concluiu que, apesar do fato de que as propriedades térmicas do local são favoráveis ao uso de estacas geotérmicas, a elevada temperatura não perturbada do solo local torna inviável o uso desta tecnologia para o resfriamento de ambientes internos de construções.

\subsubsection{Comportamento termo-hidro-mecânico/químico}

O estudo de problemas geotécnicos envolvendo o comportamento termo-hidromecânico/químico encontra sólido respaldo nas pesquisas lideradas pelo professor Olaf Kolditz (Helmhotz Centre for Environmental Research UFZ), que uniu grupos de pesquisa internacionais para viabilizar o projeto OpenGeoSys (OGS), uma iniciativa científica de código aberto (o que propicia a contribuição de diferentes pesquisadores e profissionais) para a simulação numérica de processos termo-hidro-mecânico-químicos em meios porosos.

O objetivo do projeto é fornecer uma estrutura numérica flexível, fundamentada em Método de Elementos Finitos e Volumes Finitos, para a resolução de problemas em meios porosos e fraturados em aplicações de Geotecnia e Hidrologia. O desenvolvimento do software passou por implementações baseadas em Fortran, C e C++ desde meados da década de 1980, de forma que hoje estão disponíveis para o público uma série de interfaces para as etapas de pré e pós-processamento (KOLDITZ et al., 2012).

Os autores do projeto OpenGeoSys (OGS) objetivam popularizar a plataforma numérica para as comunidades científica e do meio técnico, bem como ferramentas profissionais de engenharia de software, compilação independente e benchmarking automatizado. Publicaram um livro com contribuições de diferentes profissionais ao longo dos anos, juntamente à comunidade OpenGeoSys, que interage via e-mail e GitHub. Tal dinâmica favorece a validação da plataforma em problemas provenientes de diversos campos do conhecimento, fator que enriquece e corrige possíveis imprecisões numéricas da plataforma (KOLDITZ et al., 2012).

Segundo Kolditz et al. (2012), apesar da utilização de métodos computacionais desde a década de 1970 em problemas relacionados a adensamento, à construção de 
barragens e à exploração em campo de óleo e gás, somente nos últimos vinte anos houve progresso substancial, em termos experimentais e teóricos, sobre a modelagem numérica de efeitos acoplados de temperatura, hidráulica, mecânica e química. Além disso, a rápida e relativamente recente evolução da capacidade de processamento de computadores permitiu a resolução de problemas de elevados níveis de complexidade.

São diversas as aplicações da plataforma OpenGeoSys. No campo da Geotecnia, são encontrados exemplos na análise de sistemas geotérmicos profundos e submetidos a altas temperaturas, pressões e condições de tensões; no descarte de resíduos nucleares e quimicamente tóxicos e na captura e armazenamento de carbono. Assim, é necessário que o código compute peculiaridades do comportamento de diferentes tipos de rochas (cristalinas e vulcânicas), fluidos (água, vapor, metano, dióxido de carbono) e condições termodinâmicas (temperatura, pressões, salinidade) (KOLDITZ et al., 2012).

São encontradas pesquisas na plataforma OpenGeoSys sobre a análise de sistemas geotérmicos por ensaios TRT, furos e estacas geotérmicas. Shao et al. (2016) apresentam hipóteses, procedimentos e resultados de modelagem numérica de furos geotérmicos, a exemplo da Figura 3.38, que ilustra uma estaca geotérmica de diâmetro 0,13 m assente em um solo de condutividade térmica $2,78 \mathrm{~W} \cdot \mathrm{m}^{-1} \cdot \mathrm{K}^{-1}$.

Os parâmetros introduzidos na modelagem numérica, provenientes de um ensaio TRT, estão sintetizados na Tabela 3.6.

A Figura 3.39 mostra uma comparação entre as temperaturas de saída do tubo medidas em ensaio TRT e as temperaturas de saída calculadas por meio da plataforma OpenGeoSys. Nota-se que os resultados são bastante próximos.

Figura 3.38 - Modelo numérico de estaca de diâmetro 0,13 m

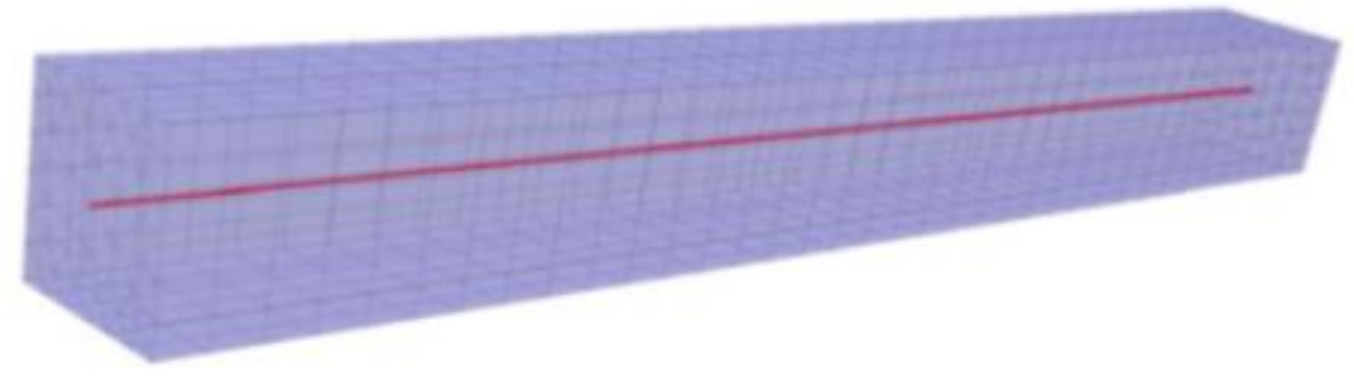

Fonte: Autor, adaptado de Shao et al. (2016) 
Tabela 3.6 - Parâmetros de entrada do modelo numérico

\begin{tabular}{|c|c|}
\hline Parâmetro & Valor \\
\hline Condutividade térmica do solo $\left(\mathrm{W} \cdot \mathrm{m}^{-1} \cdot \mathrm{K}^{-1}\right)$ & 2,78 \\
\hline Capacidade térmica do solo $\left(\mathrm{J} \cdot \mathrm{m}^{-3} \cdot \mathrm{K}^{-1}\right)$ & $3,2.10^{6}$ \\
\hline Diâmetro da estaca $(\mathrm{cm})$ & 13 \\
\hline Diâmetro dos tubos $(\mathrm{cm})$ & 2,73 \\
\hline Espessura dos tubos $(\mathrm{cm})$ & 0,3035 \\
\hline Distância entre tubos $(\mathrm{cm})$ & 5,3 \\
\hline Condutividade térmica dos tubos $\left(\mathrm{W} \cdot \mathrm{m}^{-1} \cdot \mathrm{K}^{-1}\right)$ & 0,39 \\
\hline Condutividade térmica do grout $\left(\mathrm{W} \cdot \mathrm{m}^{-1} \cdot \mathrm{K}^{-1}\right)$ & 0,806 \\
\hline Capacidade térmica do grout $\left(\mathrm{J} \cdot \mathrm{m}^{-3} \cdot \mathrm{K}^{-1}\right)$ & $3,8 \cdot 10^{6}$ \\
\hline
\end{tabular}

Fonte: Autor, adaptado de Shao et al. (2016)

Figura 3.39 - Temperatura de saída do tubo durante ensaio TRT em estaca de diâmetro $0,13 \mathrm{~m}$

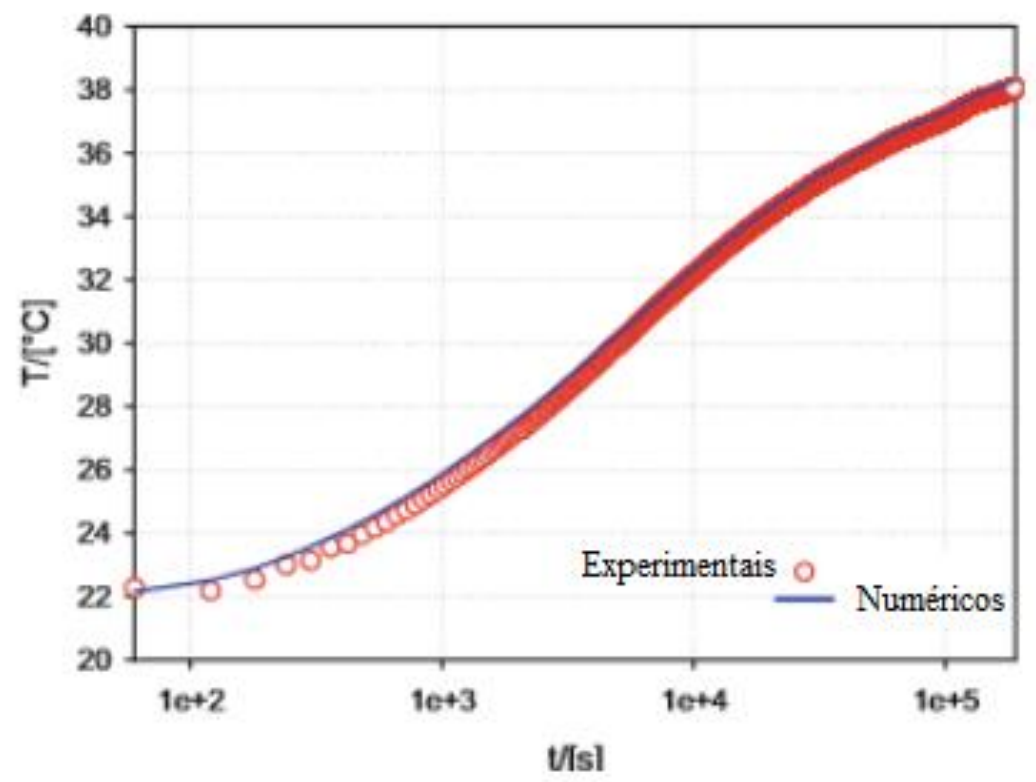

Fonte: Autor, adaptado de Shao et al. (2016)

Pagola (2018) reúne relevantes conclusões sobre o desempenho de estacas geotérmicas: em regime transiente, o impacto da capacidade térmica na recuperação térmica do subsolo é insignificante, uma vez que as temperaturas diminuem exponencialmente e convergem como assíntotas para um estado de estabilidade; a condutividade térmica também causa pequeno impacto na recuperação térmica do subsolo, com influência insignificante nas temperaturas de saída do fluido; sob influência do fluxo de água subterrânea há melhor recuperação térmica do subsolo conforme se 
aumenta a velocidade de Darcy (o aumento da velocidade de Darcy propicia o aumento do índice de recuperação do subsolo, exponencialmente, tendendo assintoticamente em direção à recuperação total); a perturbação do campo de temperaturas nas vizinhanças da estaca diminui com o aumento da velocidade do fluxo de água subterrânea; o COP da bomba de calor aumenta com incrementos na velocidade do fluxo de água subterrânea, ainda que a recuperação térmica total seja atingida; maiores temperaturas de saída do fluido circulante nos tubos evidenciam melhor o desempenho do sistema GSHP.

\subsubsection{Síntese dos trabalhos científicos}

Os trabalhos abordados, juntamente a outras importantes referências da literatura, são apresentados na Tabela 3.7, que tem por objetivo sintetizar, em ordem cronológica, as principais pesquisas e contribuições para o âmbito das pesquisas em estacas geotérmicas. Trabalhos provenientes dos mesmos grupos de pesquisa (ou de parcerias entre os grupos) são relacionados conforme a legenda.

A Tabela 3.8, por sua vez, sintetiza (por afinidade entre grupos de pesquisa) os principais objetos de estudo de relevantes linhas de pesquisa de estacas geotérmicas em termos de tipo de análise (experimental ou numérica), comportamento (térmico T, termohidráulico TH, termo-mecânico TM ou termo-hidro-mecânico THM), solo predominante (argila, silte, areia, pedregulho ou outro material) e dimensões da estaca (diâmetro e comprimento). Em alguns estudos são apresentados também dados de furos geotérmicos.

A revisão da literatura evidencia que não há análises que busquem explicar como variações de parâmetros geotérmicos, hidráulicos, estruturais e geométricos afetam o desempenho térmico de estacas geotérmicas. Tendo em vista o preenchimento desta lacuna este trabalho partiu de parâmetros usuais de projeto para relacionar variações paramétricas ao desempenho térmico do sistema.

Alguns dos trabalhos científicos apresentados nas Tabelas 3.7 e 3.8 não foram explicitamente analisados no item 3.2, uma vez que tratam de pontos consolidados em outras referências. 
Tabela 3.7 - Ordem cronológica das principais referências em estacas geotérmicas

\begin{tabular}{|c|c|}
\hline Ano & Referência \\
\hline 1998 & Orozco \\
\hline 1998 & Sousa Júnior \\
\hline 2005 & Brandl \\
\hline 2005 & Gehlin e Nordell \\
\hline 2006 & Nagano et al. \\
\hline 2008 & Sekine et al. \\
\hline 2009 & Laloui et al. \\
\hline 2010 & Gao et al. \\
\hline 2011 & Bourne-Webb et al. \\
\hline 2012 & Loveridge e Powrie \\
\hline 2013 & Brettman et al. \\
\hline 2013 & Bouazza et al. \\
\hline 2013 & McCartney et al. \\
\hline 2013 & Wang et al. \\
\hline 2013 & Bouazza et al. \\
\hline 2013 & Murphy et al. \\
\hline 2014 & Kramer e Basu \\
\hline 2014 & Thompson III \\
\hline 2014 & Sánchez et al. \\
\hline 2014 & Mimouni \\
\hline 2014 & Murphy e McCartney \\
\hline 2014 & Ozudogru e Olgun \\
\hline 2014 & Ozudogru et al. \\
\hline 2014 & Laloui e $\mathrm{Ng}$ \\
\hline 2014 & Abdelaziz et al. \\
\hline 2014 & Olgun et al. \\
\hline 2015 & You et al. \\
\hline 2015 & Lee et al. \\
\hline 2015 & Bandeira Neto \\
\hline 2015 & Cecinato e Loveridge \\
\hline 2015 & Sánchez et al. \\
\hline 2015 & Rotta Loria \\
\hline 2015 & Narsilio et al. \\
\hline 2015 & Fare \\
\hline 2015 & Carvalho \\
\hline 2016 & Bouazza et al. \\
\hline 2016 & Singh et al. \\
\hline 2016 & Morais e Tsuha \\
\hline 2016 & Shi et al. \\
\hline 2016 & Kiani e Bayesteh \\
\hline 2017 & Hassen et al. \\
\hline 2017 & Zhu \\
\hline 2017 & Nguyen et al. \\
\hline 2017 & Ma et al. \\
\hline 2018 & Morais e Tsuha \\
\hline 2018 & Sánchez et al. \\
\hline
\end{tabular}

\section{Legenda}

\begin{tabular}{|c|c|}
\hline Grupo & Local da pesquisa \\
\hline & Brasilia - Brasil \\
\hline & Viena - Áustria \\
\hline & Lausanne - Suíça \\
\hline & Shangai - China \\
\hline & Richmond - EUA \\
\hline & Melbourne - Austrália \\
\hline & Denver - EUA \\
\hline & Londres - Inglaterra \\
\hline & Texas - EUA \\
\hline & São Carlos - Brasil \\
\hline & Grupos variados \\
\hline
\end{tabular}


Tabela 3.8 - Objetos de estudo das principais referências em estacas geotérmicas

\begin{tabular}{|c|c|c|c|c|c|c|c|}
\hline \multirow[b]{2}{*}{ Ano } & \multirow[b]{2}{*}{ Referência } & \multirow[b]{2}{*}{ Local } & \multirow[b]{2}{*}{ Classificação } & \multirow[b]{2}{*}{ Foco } & \multirow[b]{2}{*}{ Solo predominante } & \multicolumn{2}{|c|}{ Dimensões } \\
\hline & & & & & & $\begin{array}{c}\mathbf{D} \\
(\mathbf{m})\end{array}$ & $\begin{array}{c}\mathbf{L} \\
(\mathbf{m})\end{array}$ \\
\hline \multirow{2}{*}{2016} & \multirow{2}{*}{ Orozco } & \multirow{2}{*}{ Brasil - Brasília } & \multirow{2}{*}{ Numérico } & \multirow{2}{*}{$\mathrm{T}$} & \multirow{2}{*}{ Areia argilosa e arenito } & 0,25 & 12,0 \\
\hline & & & & & & 0,50 & 12,0 \\
\hline 2017 & Sousa Júnior & Brasil - Brasília & Numérico & $\mathrm{TH}$ & Areia argilosa e silte & - & - \\
\hline \multirow{2}{*}{2015} & \multirow{2}{*}{ Bandeira Neto } & \multirow{2}{*}{ Brasil - São Carlos } & \multirow{2}{*}{ Experimental } & \multirow{2}{*}{$\mathrm{T}$} & \multirow{2}{*}{ Areia argilosa e arenito } & 0,50 & 12,0 \\
\hline & & & & & & 0,25 & 12,0 \\
\hline 2018 & Morais e Tsuha & Brasil - São Carlos & Experimental & $\mathrm{T}$ & Areia argilosa e arenito & 0,35 & 15,0 \\
\hline 2016 & Morais e Tsuha & Brasil - SP & Experimental & TH & Areia argilosa & 0,50 & 12,0 \\
\hline 1998 & Brandl & Viena - Áustria & Experimental & THM & Areia siltosa e silte argilosa & 1,20 & 9,0 \\
\hline 2017 & Nguyen et al. & Paris - França & Experimental & $\mathrm{TM}$ & Areia & 0,020 & - \\
\hline 2006 & Laloui et al. & Lausanne - Suíça & Experimental/numérico & THM & Areia e pedregulho & 0,88 & 25,8 \\
\hline 2014 & Mimouni & Lausanne - Suíça & Experimental/numérico & THM & Argila, areia com pedregulho & 0,90 & 28,0 \\
\hline 2016 & Shi et al. & Hong Kong - Japão & Experimental & $\mathrm{TM}$ & Argila sobreadensada & 0,022 & 0,42 \\
\hline 2014 & $\mathrm{Ng}$ et al. & Lausanne - Suíça & Experimental & THM & Argilas (caulinitas) & 0,022 & 0,42 \\
\hline 2015 & Rotta Loria et al. & Lausanne - Suíça & Numérico & TM & - & 0,032 & - \\
\hline \multirow{2}{*}{2013} & \multirow{2}{*}{ McCartney et al. } & \multirow{2}{*}{ Denver - EUA } & \multirow{2}{*}{ Experimental } & \multirow{2}{*}{ THM } & \multirow{2}{*}{ Silte } & 0,91 & 14,0 \\
\hline & & & & & & 0,025 & 0,53 \\
\hline 2014 & $\begin{array}{c}\text { Murphy e } \\
\text { McCartney }\end{array}$ & Denver - EUA & Experimental & THM & Silte & - & - \\
\hline 2013 & Murphy et al. & Denver - EUA & Experimental & $\mathrm{TM}$ & Areia siltosa com pedregulhos & 0,61 & 15,2 \\
\hline 2014 & Sánchez et al. & Texas - EUA & Experimental & THM & Argila & 0,18 & 5,5 \\
\hline \multirow{2}{*}{2015} & \multirow{2}{*}{ Sánchez et al. } & \multirow{2}{*}{ Texas - EUA } & \multirow{2}{*}{ Experimental/num./analítico } & \multirow{2}{*}{ THM } & \multirow{2}{*}{ Areia } & 0,3 & 0,25 \\
\hline & & & & & & 0,4 & 0,25 \\
\hline
\end{tabular}




\begin{tabular}{|c|c|c|c|c|c|c|c|}
\hline \multirow[b]{2}{*}{ Ano } & \multirow[b]{2}{*}{ Referência } & \multirow[b]{2}{*}{ Local } & \multirow[b]{2}{*}{ Classificação } & \multirow[b]{2}{*}{ Foco } & \multirow[b]{2}{*}{ Solo predominante } & \multicolumn{2}{|c|}{ Dimensões } \\
\hline & & & & & & $\begin{array}{c}\mathbf{D} \\
(\mathbf{m})\end{array}$ & $\begin{array}{c}\mathbf{L} \\
(\mathbf{m})\end{array}$ \\
\hline 2018 & Sánchez et al. & México & Experimental/numérico & THM & Areia siltosa & 0,60 & 15,0 \\
\hline 2016 & Wang et al. & Shangai - China & Analítico & THM & Areia & - & 16,0 \\
\hline 2013 & Bouazza et al. & $\begin{array}{l}\text { Melbourne - } \\
\text { Austrália }\end{array}$ & Experimental & $\mathrm{TM}$ & Areia & 0,60 & 16,0 \\
\hline 2011 & Bouazza et al. & $\begin{array}{c}\text { Melbourne - } \\
\text { Austrália }\end{array}$ & Experimental & $\mathrm{TM}$ & Areia & 0,60 & 16,0 \\
\hline 2015 & Bouazza et al. & $\begin{array}{c}\text { Melbourne - } \\
\text { Austrália }\end{array}$ & Experimental & TM & Areia & 0.6 & 16,0 \\
\hline 2015 & Singh et al. & $\begin{array}{c}\text { Melbourne - } \\
\text { Austrália }\end{array}$ & Experimental & $\mathrm{TM}$ & Areia & 0,6 & 16,0 \\
\hline \multirow{2}{*}{2010} & \multirow{2}{*}{ Brettman et al. } & \multirow{2}{*}{ Richmond - EUA } & \multirow{2}{*}{ Experimental/numérico } & \multirow{2}{*}{$\mathrm{TH}$} & \multirow{2}{*}{ Areia e silte } & 0,30 & 18,0 \\
\hline & & & & & & 0,45 & 18,0 \\
\hline \multirow{2}{*}{2014} & \multirow{2}{*}{ Ozudogru e Olgun } & \multirow{2}{*}{ Istambul - Turquia } & \multirow{2}{*}{ Numérico } & \multirow{2}{*}{$\mathrm{TH}$} & \multirow{2}{*}{ Areia } & 0,45 & 20,0 \\
\hline & & & & & & 0,15 & 100 \\
\hline 2014 & Ozudogru et al. & Istambul - Turquia & Numérico & $\mathrm{TH}$ & Areia argilosa e siltosa & 0,25 & 30,0 \\
\hline 2014 & Abdelaziz et al. & Istambul - Turquia & Analítico & $\mathrm{T}$ & Argila e areia saturadas & $\mathrm{d}$ & 20,0 \\
\hline 2014 & Olgun et al. & Istambul - Turquia & Experimental & $\mathrm{TM}$ & - & 0,20 & 20,0 \\
\hline 2013 & Loveridge e Powrie & Londres - Inglaterra & Experimental & $\mathrm{TH}$ & Argila e silte & 0,30 & 27,0 \\
\hline 2015 & Cecinato e Loveridge & Londres - Inglaterra & Experimental & $\mathrm{T}$ & Argila e silte & - & - \\
\hline 1998 & Gehlin e Nordell & Suécia & Experimental & $\mathrm{T}$ & - & 0,16 & - \\
\hline 2017 & $\mathrm{Fu}$ & Ottawa & Experimental & THM & Areia e argila & - & - \\
\hline 2009 & Bourne-Webb et al. & Londres - Inglaterra & Experimental & TM & Argila & 0,60 & 30,0 \\
\hline 2005 & Sekine et al. & China - Japão & Experimental & $\mathrm{TH}$ & Argila & 1,50 & 20,0 \\
\hline
\end{tabular}




\begin{tabular}{|c|c|c|c|c|c|c|c|}
\hline \multirow{2}{*}{ Ano } & \multirow{2}{*}{ Referência } & \multirow{2}{*}{ Local } & \multirow{2}{*}{ Classificação } & \multirow{2}{*}{ Foco } & \multirow{2}{*}{ Solo predominante } & \multicolumn{2}{|c|}{ Dimensões } \\
\hline & & & & & & $\mathbf{D}(\mathbf{m})$ & $\mathbf{L}(\mathbf{m})$ \\
\hline 2008 & Gao et al. & Shangai - China & Numérico & $\mathrm{TH}$ & Silte arenoso & 0,60 & 25,0 \\
\hline 2017 & Ferreira & Goytacazes - RJ & Experimental & $\mathrm{TM}$ & Areia e argila & 0,40 & 12,0 \\
\hline 2015 & Narsilio et al. & $\begin{array}{l}\text { Córdoba - } \\
\text { Argentina }\end{array}$ & Experimental/numérico & $\mathrm{TH}$ & $\begin{array}{c}\text { Silte argiloso, silte arenoso e } \\
\text { areia }\end{array}$ & 0,60 & 9,5 \\
\hline 2016 & Bayesteh et al. & Qom - Irã & Numérico & TM & Solos finos & 0,5 & 52,0 \\
\hline 2016 & Hassen et al. & Paris - França & Experimental & TM & Argila & 0,020 & 0,8 \\
\hline 2013 & Lee et al. & $\begin{array}{l}\text { Seoul - Coreia do } \\
\text { Sul }\end{array}$ & Experimental/numérico & $\mathrm{TM}$ & Areia e argila & 0,5 & 20,0 \\
\hline 2014 & Kramer e Basu & Pensilvânia - EUA & Experimental & TM & Areia & 0,60 & 25,0 \\
\hline 2015 & Carvalho & Coimbra - Portugal & Experimental & $\mathrm{TH}$ & Areia & 0,14 & - \\
\hline 2017 & Ma et al. & Shandong - China & Experimental/numérico & $\mathrm{T}$ & Areia & 0,15 & 117 \\
\hline 2005 & Nagano et al. & Hanamaki - Japão & Experimental & $\mathrm{TH}$ & Argila, areia e pedregulho & 0,165 & 40,0 \\
\hline
\end{tabular}




\section{METODOLOGIA}

Neste item constam: (i) caracterização geotécnica do subsolo, (ii) procedimentos, equipamentos e resultados do ensaio TRT realizado na EPUSP; (iii) fundamentação teórica, hipóteses e etapas da modelagem numérica (validação e estudo paramétrico).

\subsection{CARACTERIZAÇÃO GEOTÉCNICA}

Um furo de sondagem e ensaios de resistência à penetração (SPT) de $20 \mathrm{~m}$ de profundidade foram realizados nas proximidades do local em que se realizou o ensaio TRT (terreno pertencente ao prédio de Engenharia Civil da EPUSP), fornecendo o perfil de solo apresentado na Figura 4.1. O perfil de solo é predominantemente composto por areia argilosa, a qual é coberta por argila orgânica silto-arenosa (espessura de 1,0 m) e, no topo, por uma camada de 2,5 m de argila silto-arenosa de vermelha a cinza e orgânica. A posição do nível de água, que varia de $2 \mathrm{~m}$ a $4 \mathrm{~m}$ de profundidade, encontrou-se a 1,9 $\mathrm{m}$ abaixo do topo do terreno para o ensaio executado (MORAIS e TSUHA, 2018).

Ensaios de resistência à penetração efetuados em outras localidades do terreno evidenciaram perfis de solo similares.

A Figura 4.2 apresenta a locação de duas sondagens próximas ao prédio da administração da EPUSP. A Figura 4.3 ilustra o perfil de solo encontrado nessas sondagens. Nota-se a existência de um aterro superficial de argila siltosa, média a rija, roxa, amarela e cinza de cerca de $2 \mathrm{~m}$ de espessura. Segue uma camada de espessura variável (1 m a $2 \mathrm{~m}$ ) composta por argila orgânica silto arenosa, mole e preta. O material restante, responsável por compor a maior porção do perfil, consiste em uma areia de granulação variada, pouco siltosa, medianamente compacta a compacta, de coloração cinza. O nível de água está situado a profundidades variáveis entre 2,92 m e 3,19 m. 
Figura 4.1 - Perfil de solo no local onde foi realizado o ensaio TRT

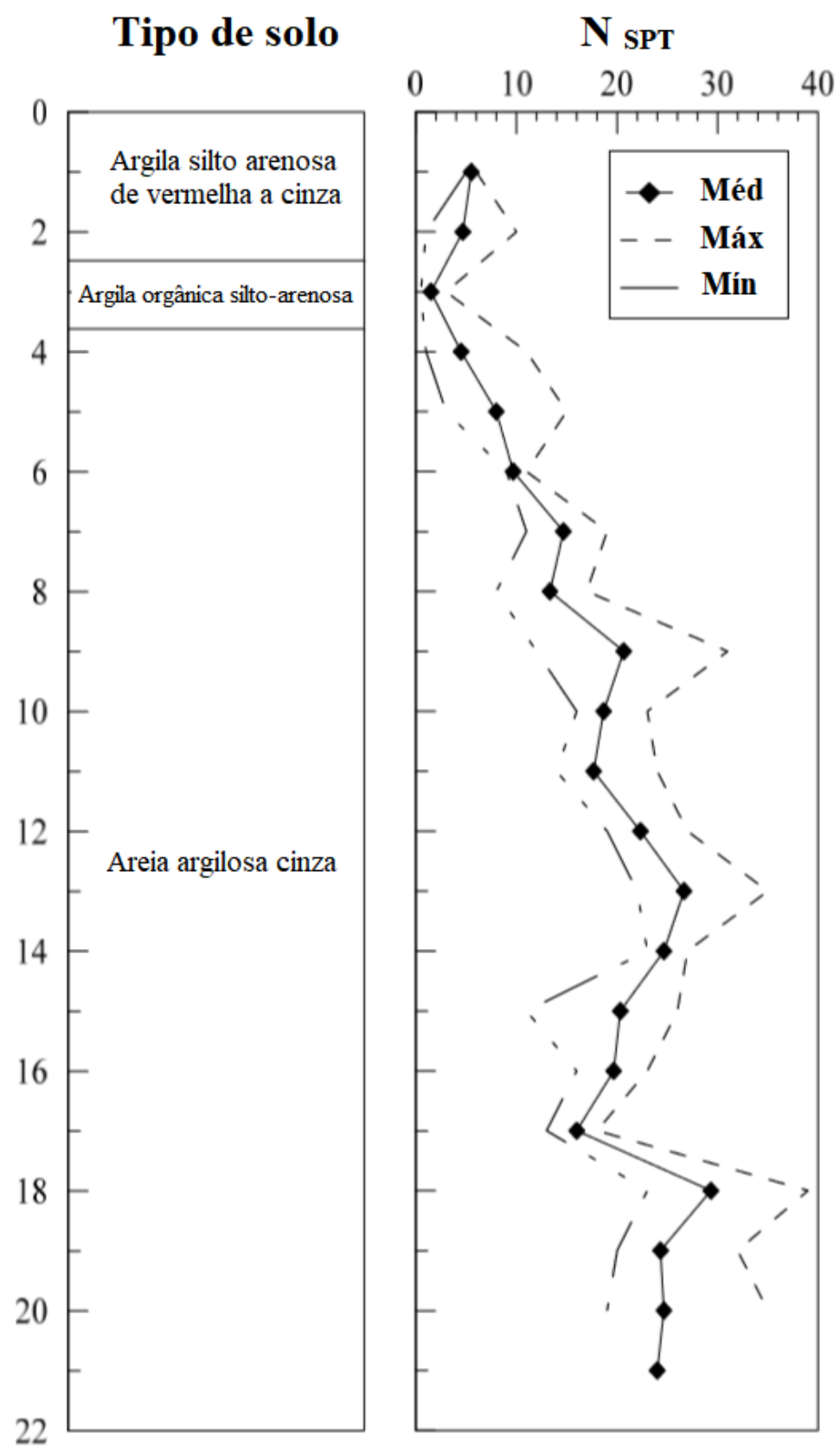

Fonte: Morais e Tsuha (2018) 
Figura 4.2 - Locação de sondagens próximas ao prédio da administração da EPUSP: (a) plano geral sem escala; (b) esquema com escala

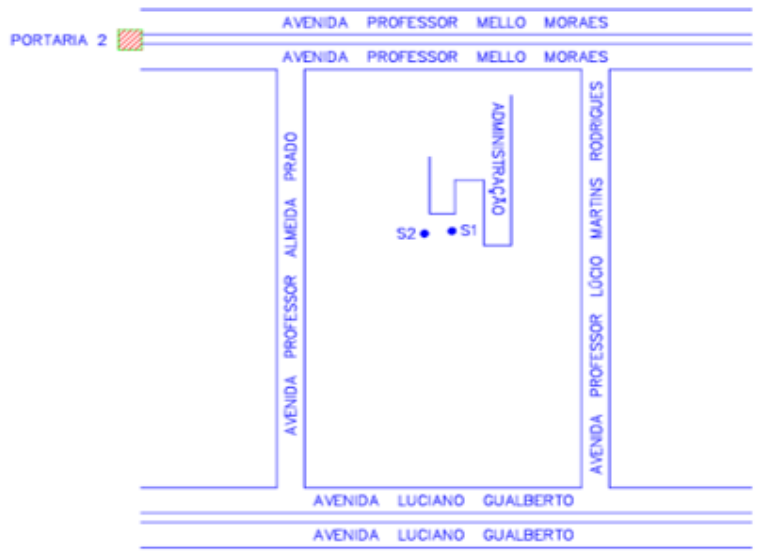

(a)

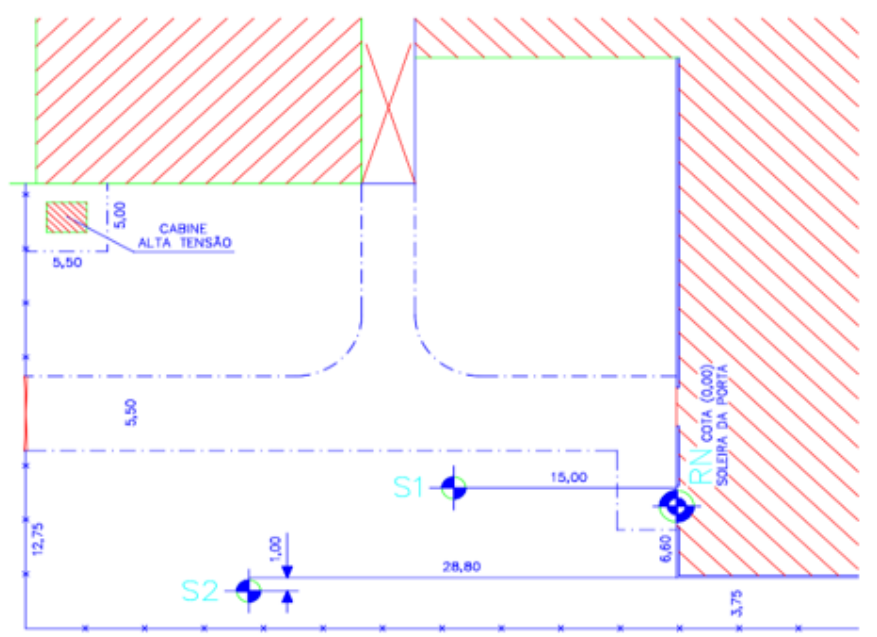

(b)

Fonte: Miyashiro (2015)

Figura 4.3 - Perfil de solo próximo ao prédio da administração da EPUSP

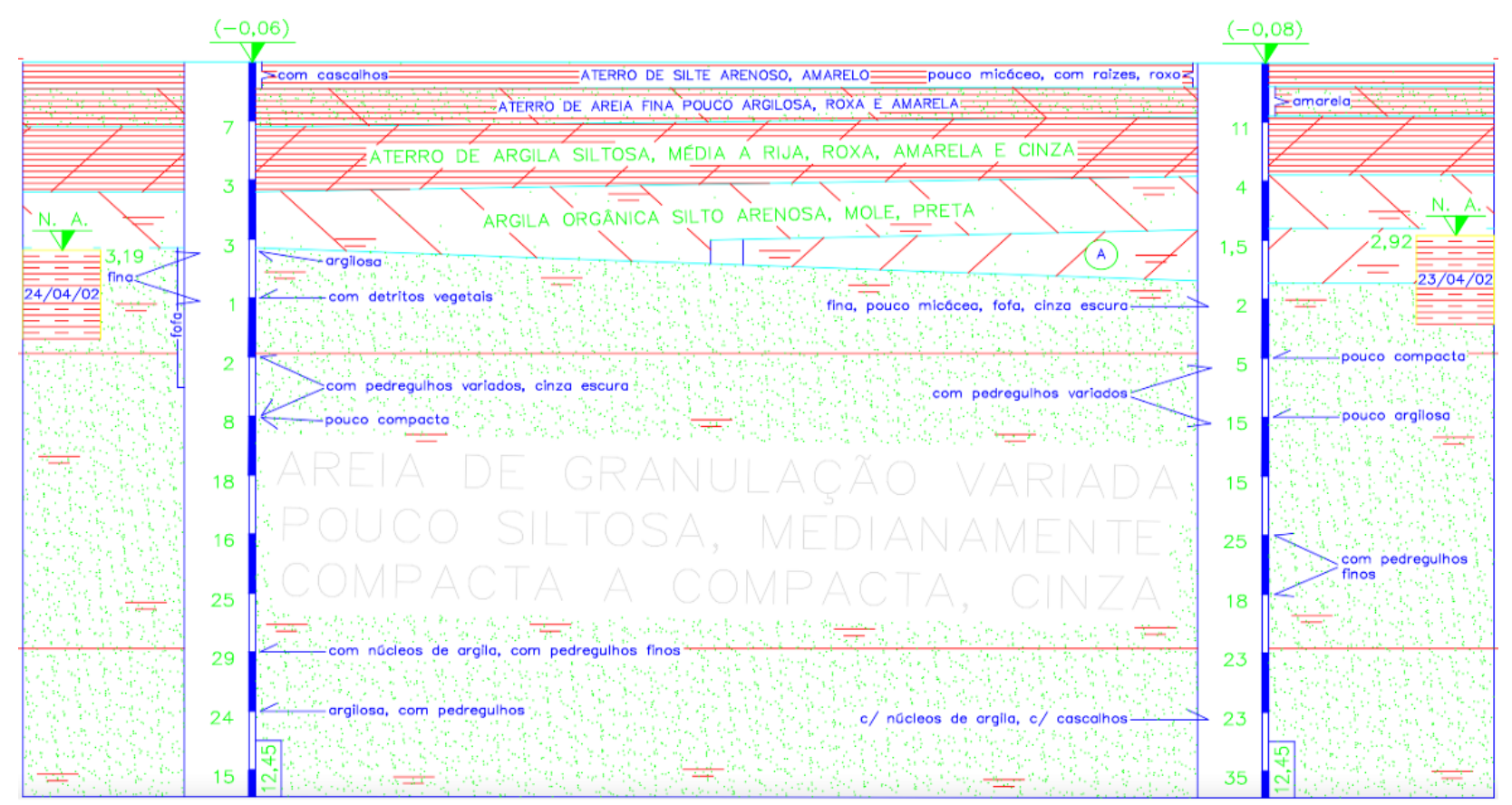

Fonte: Miyashiro (2015)

A Figura 4.4 mostra a locação de três ensaios de resistência à penetração executados nas adjacências do Centro de Técnicas de Construção Civil, no terreno pertencente ao prédio de Engenharia Civil. 
Figura 4.4 - Locação de sondagens nas adjacências do Centro de Técnicas de Construção Civil: (a) plano geral sem escala; (b) esquema com escala

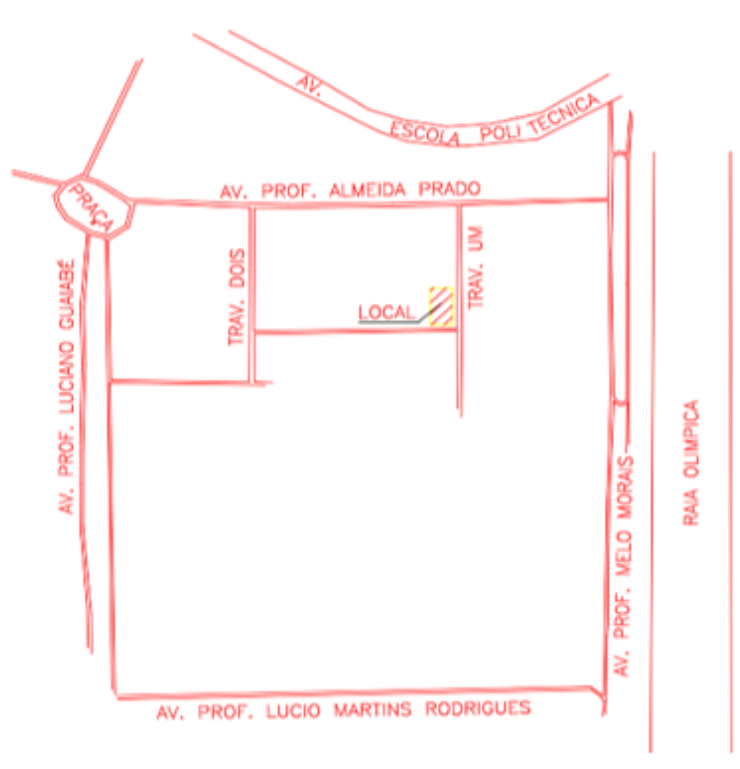

(a)

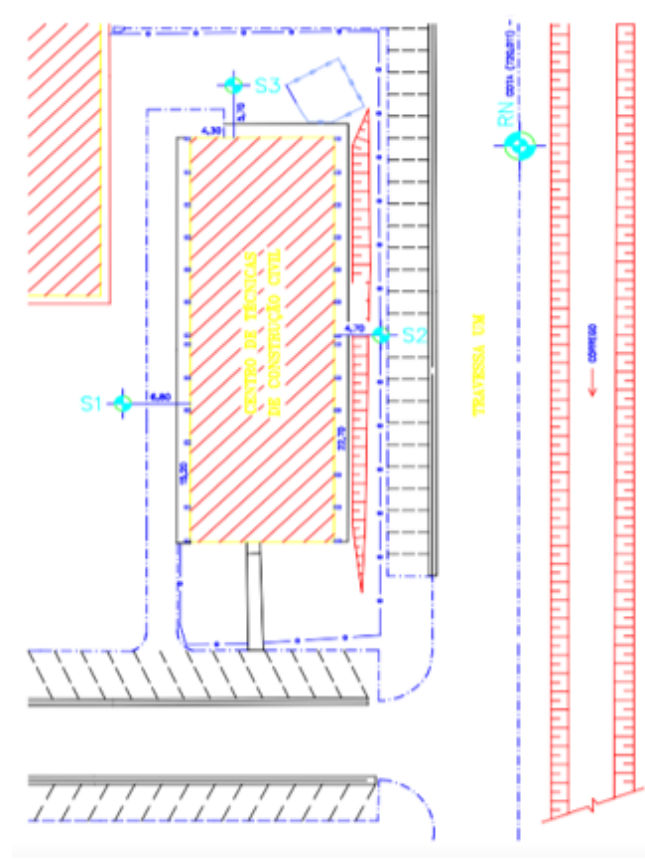

(b)

Fonte: Miyashiro (2015)

A Figura 4.5 expõe o perfil de solo relacionado à sondagem designada como S1 na Figura 4.4. Há um aterro superficial de cerca de $3 \mathrm{~m}$ de espessura de argila silto arenosa, mole a média, vermelha e cinza, seguido de uma camada de 1,5 $\mathrm{m}$ de argila orgânica silto arenosa, muito mole a mole e preta. A maior camada é composta por uma areia de granulação variada e argilosa, medianamente compacta a compacta, de cor cinza. O nível de água está na profundidade $3,42 \mathrm{~m}$. 
Figura 4.5 - Perfil de solo relacionado à sondagem S1

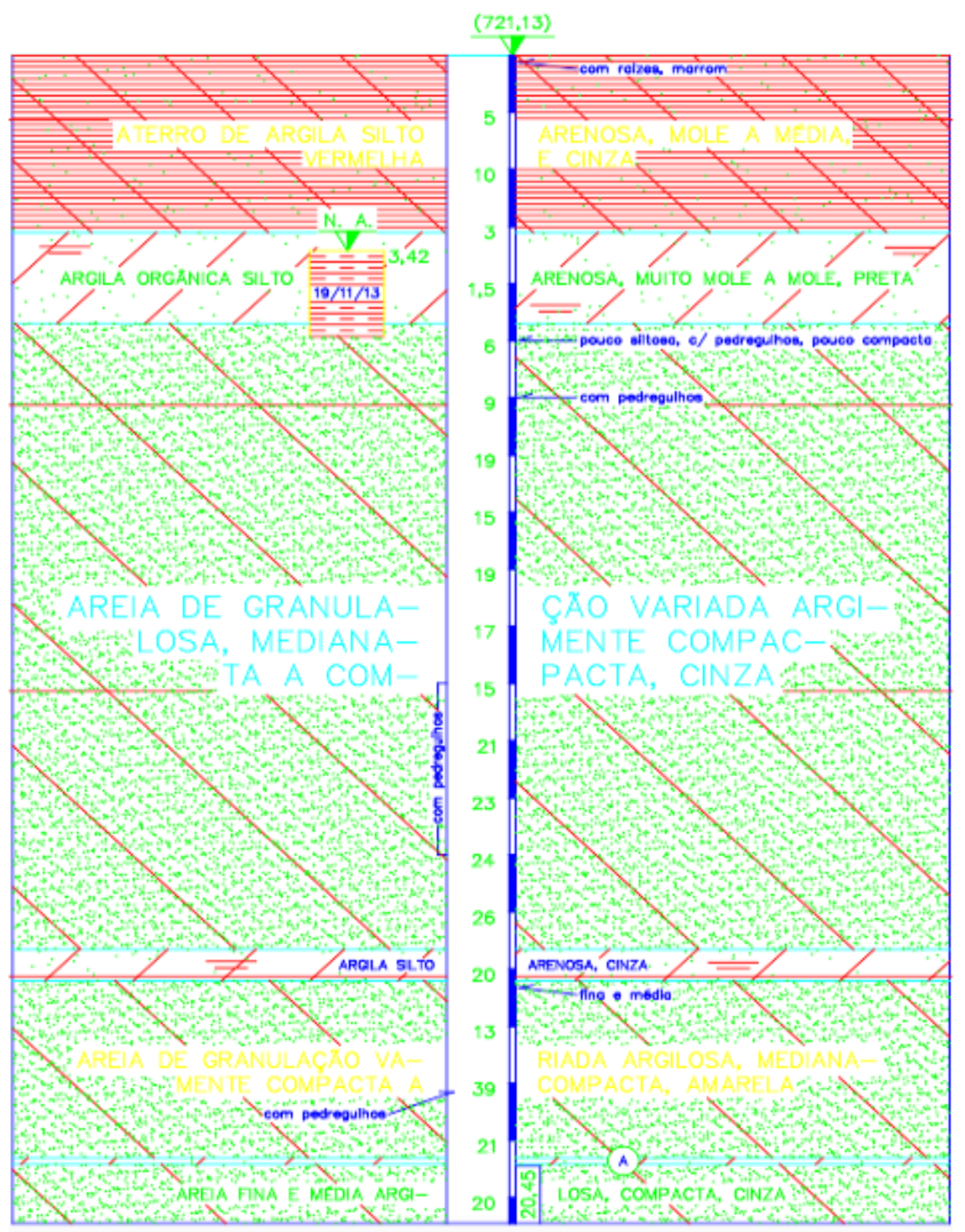

Fonte: Miyashiro (2015)

A Figura 4.6 expõe o perfil de solo relacionado à sondagem designada como S2 na Figura 4.4. O perfil possui um aterro superficial de argila siltosa muito arenosa, mole e marrom de cerca de 1,5 m de espessura, seguido por uma camada de argila silto-arenosa, muito mole, cinza e escura. Diferentemente dos outros perfis apresentados, percebe-se a ocorrência de uma terceira camada, constituída por areia fina e média, argilosa, com matéria orgânica, fofa e cinza escura. Novamente, percebe-se a existência de uma espessa camada de areia de granulação variada pouco argilosa, medianamente compacta a compacta e cinza. O nível de água está situado na profundidade $1,90 \mathrm{~m}$. 
Figura 4.6 - Perfil de solo relacionado à sondagem S2

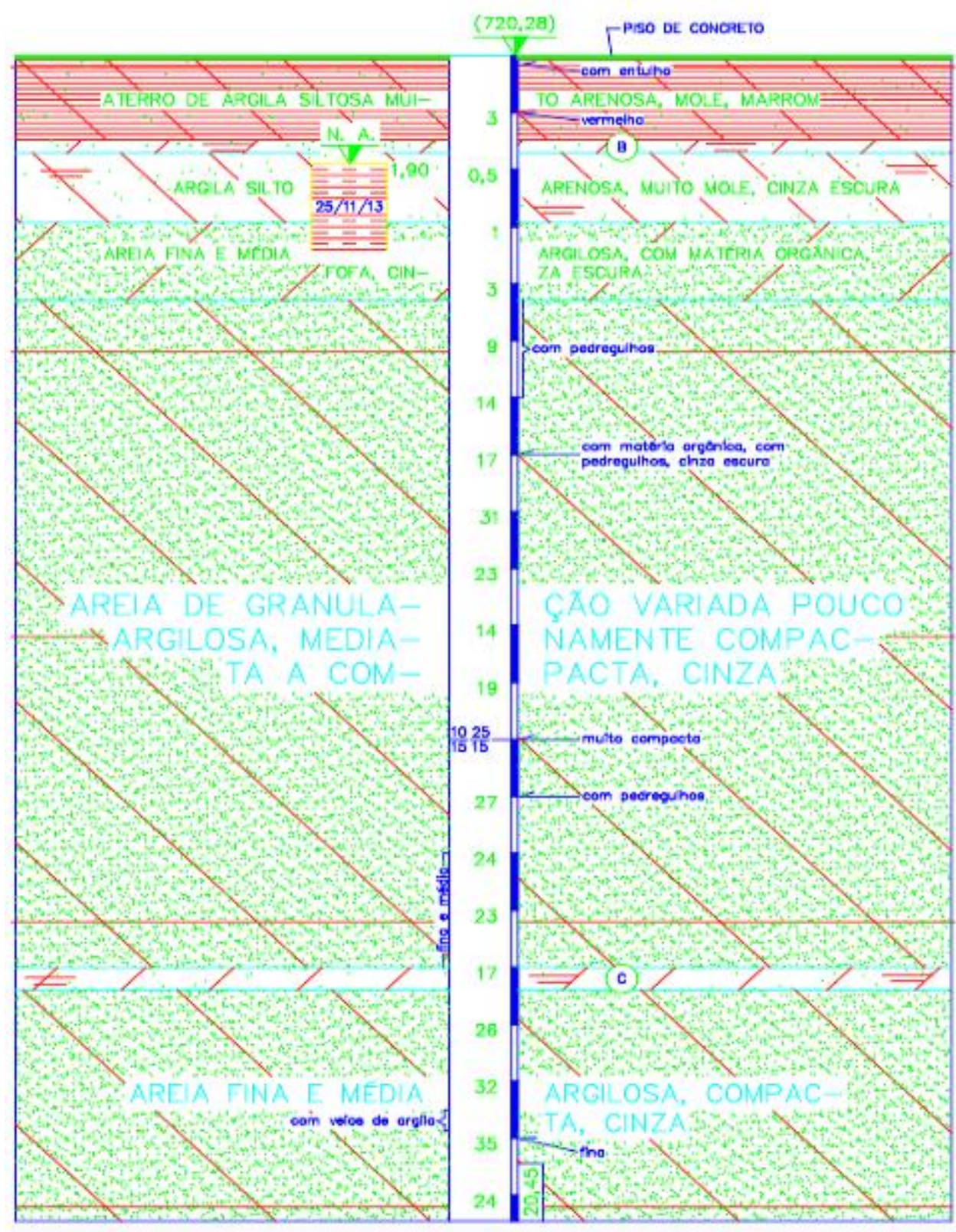

Fonte: Miyashiro (2015)

A Figura 4.7 expõe o perfil de solo relacionado à sondagem designada como S3 na Figura 4.4. Constata-se a existência de um aterro superficial de argila silto-arenosa de cerca de 1,5 m, média e vermelha sobre uma camada de 1,5 m de uma argila silto- arenosa, com matéria orgânica, muito mole e cinza escura, por sua vez sobre uma espessa camada de areia de granulação variada argilosa, medianamente compacta a compacta e cinza. O nível de água está localizado na profundidade 2,56 m. 
Figura 4.7- Perfil de solo relacionado à sondagem S3

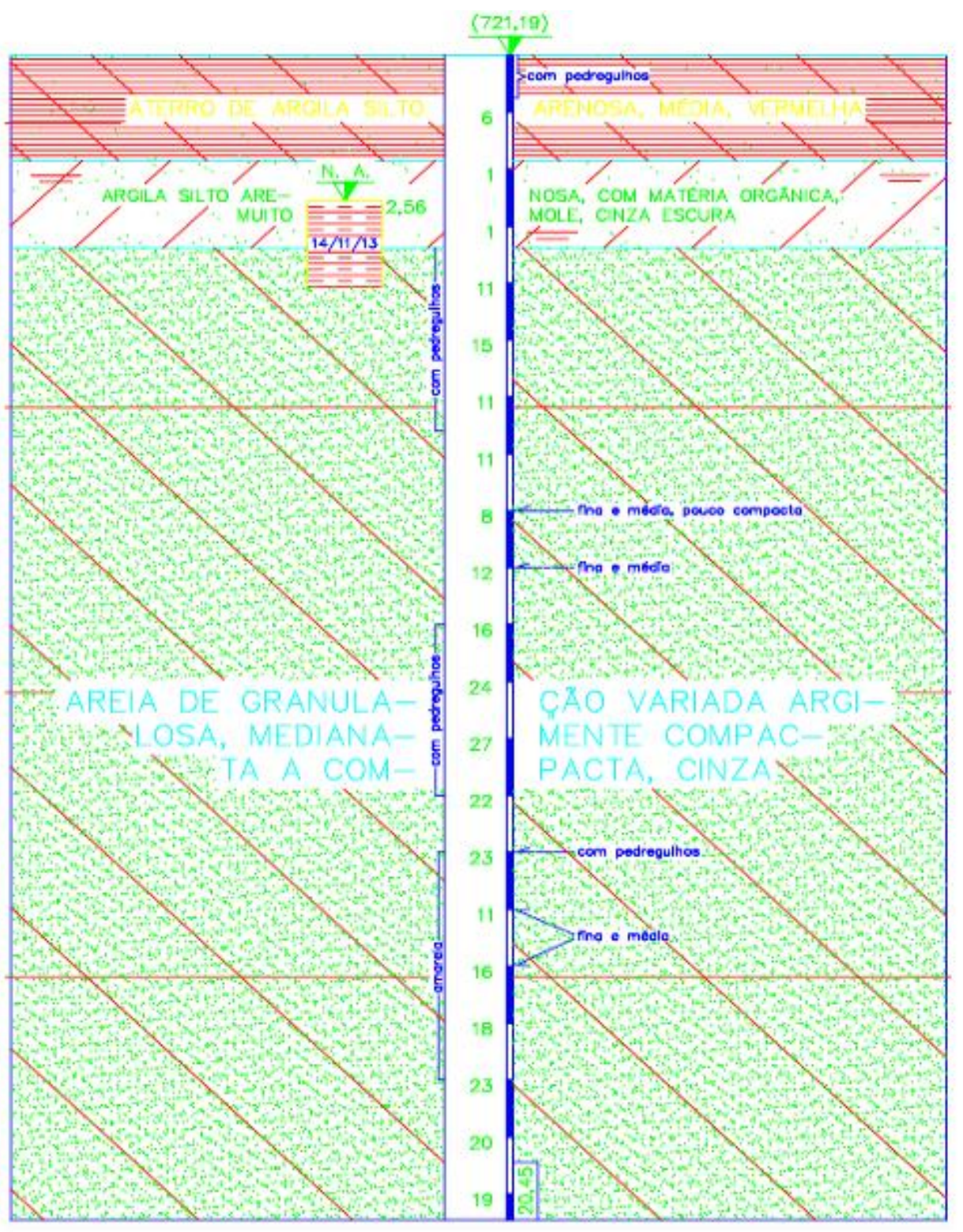

Fonte: Miyashiro (2015)

\subsection{ENSAIO TRT E RESULTADOS EXPERIMENTAIS DISPONÍVEIS PARA MODELAGEM}

Os resultados experimentais disponíveis para modelagem numérica são oriundos de um ensaio TRT realizado nas adjacências da EPUSP (onde está sendo construído o CICS Living Lab), tendo em vista a determinação dos parâmetros: condutividade térmica do solo in situ, resistência térmica da estaca e temperatura não perturbada do solo. $\mathrm{O}$ ensaio TRT foi realizado por estaca (diâmetro $0,35 \mathrm{~m}$ e comprimento $15 \mathrm{~m}$ ), com um 
circuito único de tubos de PEAD em formato de "U" (diâmetro externo de $32 \mathrm{~mm}$ e diâmetro interno 26 mm) (MORAIS e TSUHA, 2018).

A Figura 4.8 ilustra o processo de escavação para a construção da estaca de pequeno diâmetro, sendo: (a) equipamento de perfuração hidráulica e (b) processo de perfuração. Utilizaram-se tubos de revestimento para garantir a estabilidade do conjunto antes da deposição do grout (MORAIS e TSUHA, 2018).

Figura 4.8 - Construção da estaca geotérmica: perfuração

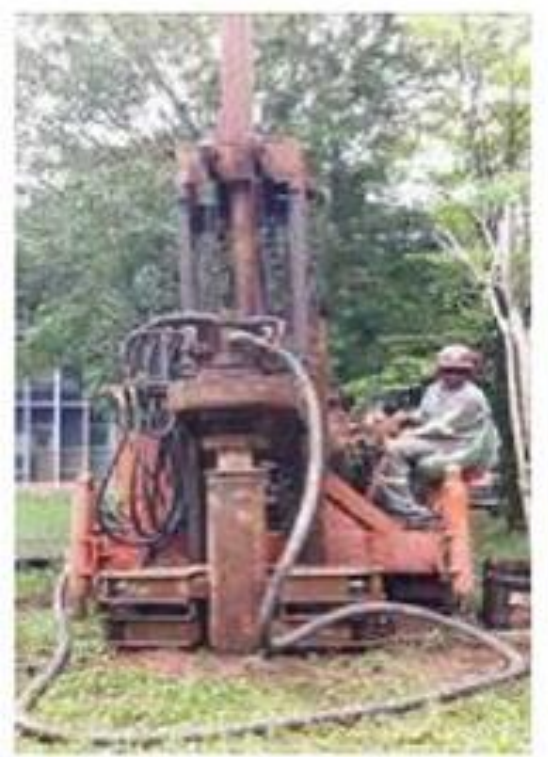

(a)

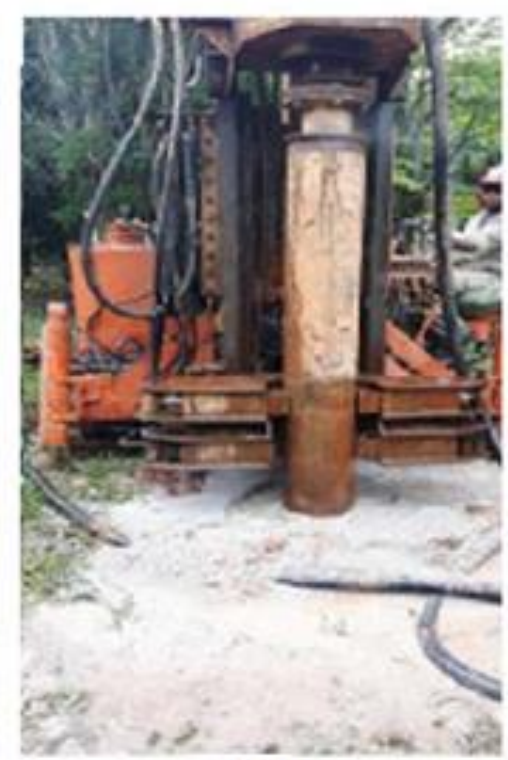

(b)

Fonte: Morais e Tsuha (2018)

Os tubos passaram por um processo de limpeza e foram fixados à armadura, como mostra a Figura 4.9.

Após a execução da perfuração e a instalação da armadura, preencheu-se o furo com grout de proporções cimento/agregado 0,55 e cimento/água 0,50. O processo de preenchimento foi interrompido após a completa remoção da água do interior do furo. A Figura 4.10 apresenta diferentes etapas construtivas do ensaio TRT.

O equipamento utilizado consiste em um reservatório de calor, uma bomba de circulação, um medidor de vazão, três sensores dos tipos PT - 100 e um sistema de aquisição de dados de alta resolução. 
A duração do ensaio TRT executado foi de 10 dias (superior ao valor de 48 horas apontado pela literatura) e seguiu os procedimentos descritos pelo documento de padronização do Comitê Europeu (TC 341 WI 00341067.6) preparado pelo CEN/TC 341.

Figura 4.9 - Construção da estaca geotérmica: armadura e tubos
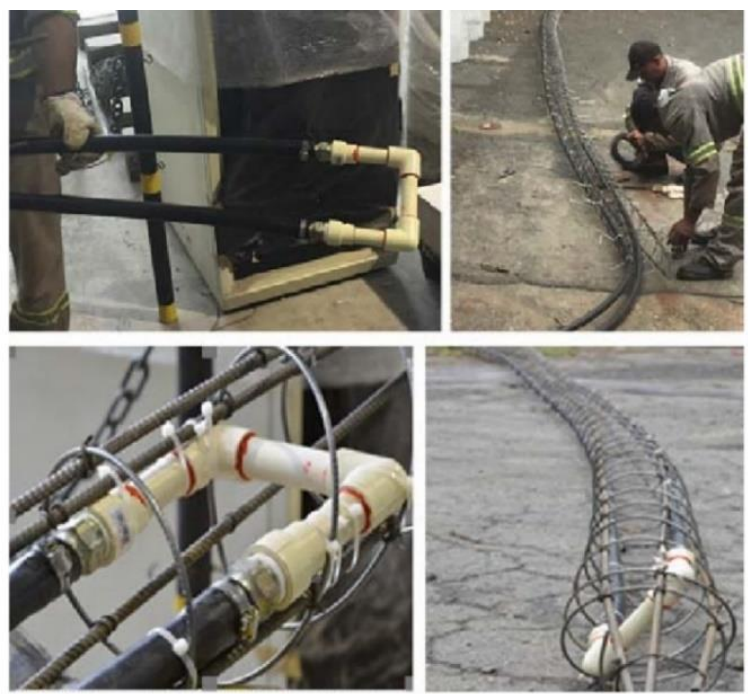

Fonte: Morais e Tsuha (2018)

Figura 4.10 - Construção da estaca geotérmica: concretagem

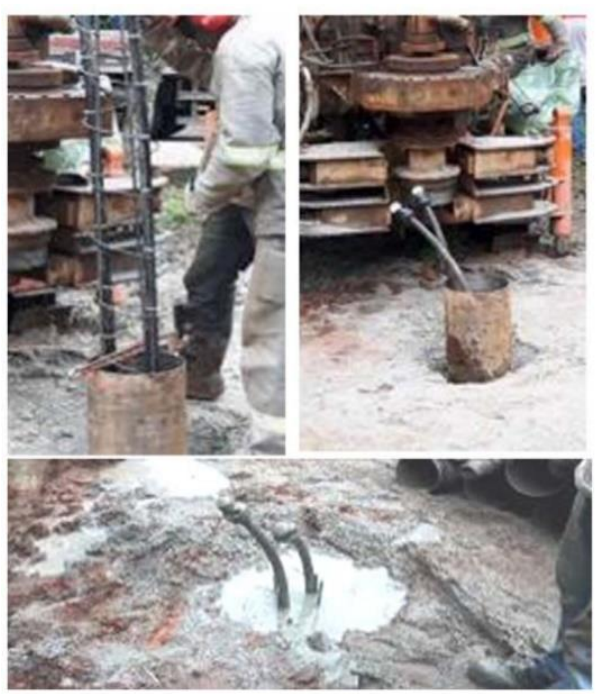

Fonte: Morais e Tsuha (2018)

$\mathrm{Na}$ execução do ensaio, injetou-se uma taxa constante de calor na estaca e monitoraram-se as temperaturas ambiente, de entrada e de saída do fluido nos tubos através de dois sensores de temperatura do tipo PT - 100, que foram conectados a um 
sistema de aquisição de dados de alta resolução (frequência mínima de 0,1 Hz) (MORAIS e TSUHA, 2018).

A Figura 4.11 ilustra a instalação dos sensores de temperatura nos pontos de entrada e saída dos tubos de PEAD.

Figura 4.11 - Instalação dos sensores de temperatura nos pontos de entrada e saída dos tubos de PEAD

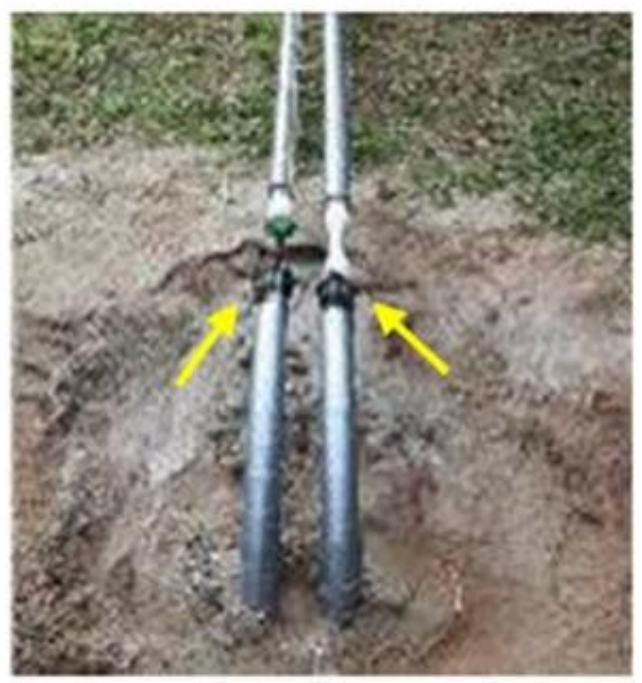

Fonte: Morais e Tsuha (2018)

Utilizou-se um reservatório de calor convencional e elétrico de volume $0,1 \mathrm{~m}^{3} \mathrm{e}$ com taxa de aquecimento de $1 \mathrm{~kW}$, sendo a água o fluido circulante. Tubos e sensores foram isolados termicamente. Para determinar a temperatura não perturbada do solo antes da realização do ensaio TRT, mediram-se as temperaturas de entrada e saída de água pelos tubos de PEAD sem a inserção de calor ao sistema (o que caracteriza o ensaio de circulação de água). Com o objetivo de garantir-se fluxo turbulento, usou-se vazão de $211,2 \mathrm{~L} / \mathrm{min}$ para o fluido circulante, aplicando-se potência de $1061 \mathrm{~W}$, ou $70,8 \mathrm{~W} . \mathrm{m}^{-1}$ (taxa de calor por unidade de comprimento da estaca) (MORAIS e TSUHA, 2018).

Os medidores de vazão tipo turbina série SVT - L/G, de acordo com o fabricante, possuem limite de erro de $\pm 0,6 \%$, a partir da definição de linearidade (capacidade de medir precisamente ao longo da proporção de escoamento completa) para líquidos com viscosidade inferior a 5 cst. A repetibilidade (capacidade de permanecer preciso ao longo de um número de ciclos) é de $\pm 0,05 \%$ da leitura (CONTECH, 2018).

A Figura 4.12 ilustra esquematicamente o arranjo do ensaio TRT. 
Figura 4.12 - Esquema do aparato experimental empregado

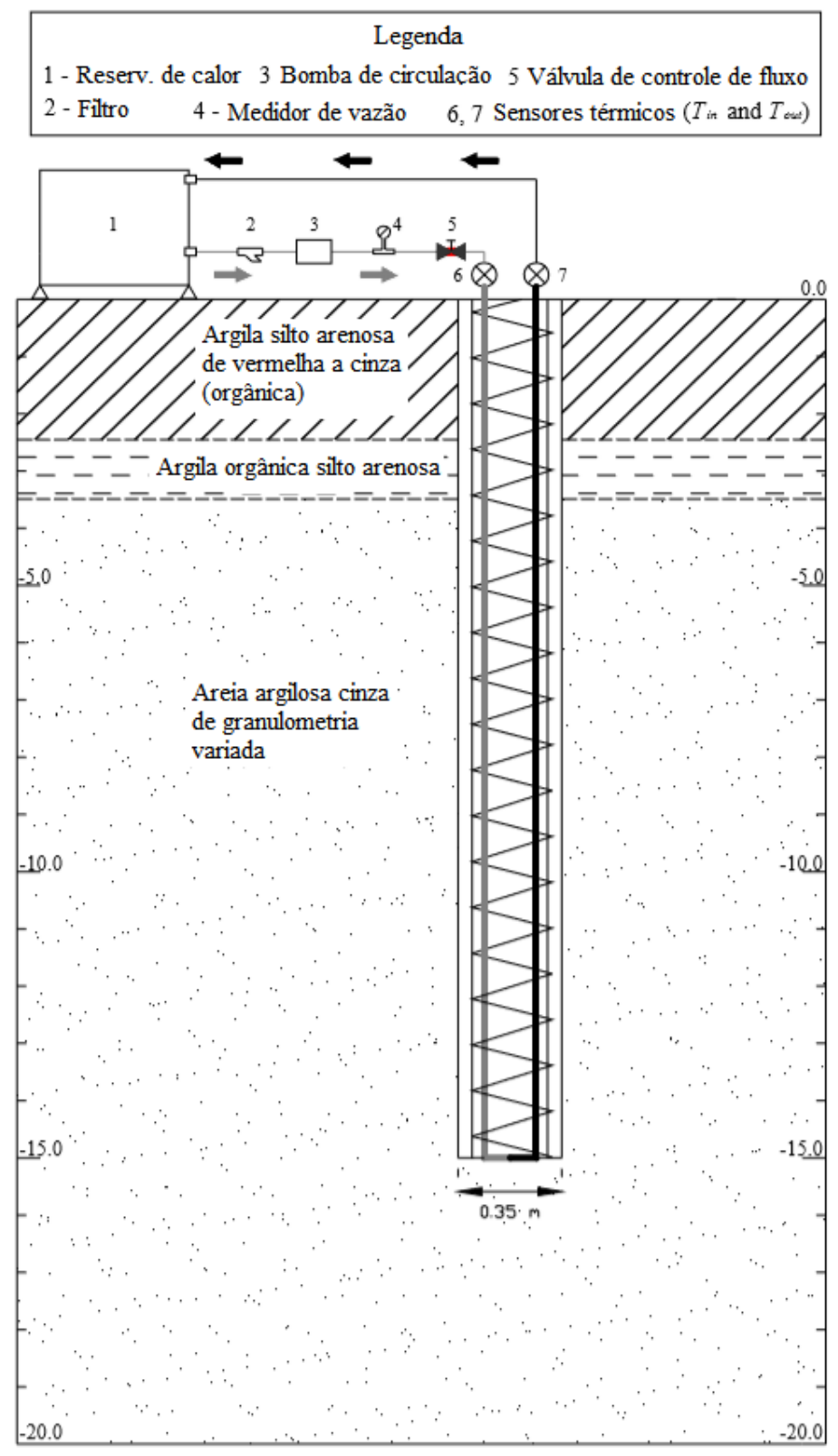

Fonte: Autor, adaptado de Morais e Tsuha (2018)

A interpretação dos resultados fornecidos pelo ensaio TRT foi efetuada com base no teorema da fonte linear de calor de Kelvin. O modelo analítico de cálculo é explorado no item 3.1.5 e os pressupostos teóricos são: a estaca geotérmica é considerada uma fonte linear de calor, o solo é tomado como um meio semi-infinito e homogêneo, a transferência de calor na interface solo-estaca é constante e se propaga na direção radial. O ensaio foi realizado em fevereiro de 2017, durante o verão brasileiro (MORAIS e TSUHA, 2018). 
A Tabela 4.1 apresenta os resultados de temperatura inicial média do solo ao longo do comprimento da estaca (não se determinou um perfil de temperaturas), obtidos por meio do ensaio com circulação de água, sem a introdução de calor ao sistema geotérmico.

Tabela 4.1 - Resultados do ensaio de circulação de água

\begin{tabular}{|c|c|c|c|}
\hline \multirow{2}{*}{ Duração do ensaio (s) } & \multirow{2}{*}{ Posição do nível de água $(\mathrm{m})$} & \multicolumn{2}{|c|}{ Temperatura $(\mathrm{K})$} \\
\cline { 3 - 4 } & & Ambiente & Inicial do solo \\
\hline 1296 & 1,90 & 297,9 & 297,8 \\
\hline
\end{tabular}

Fonte: Morais e Tsuha (2018)

A Figura 4.13 ilustra o comportamento da variação da temperatura ambiente e da temperatura média do fluido circulante (média das temperaturas de entrada e saída) durante o ensaio de circulação de água.

Figura 4.13 - Variação de temperatura com o tempo no ensaio de circulação de água

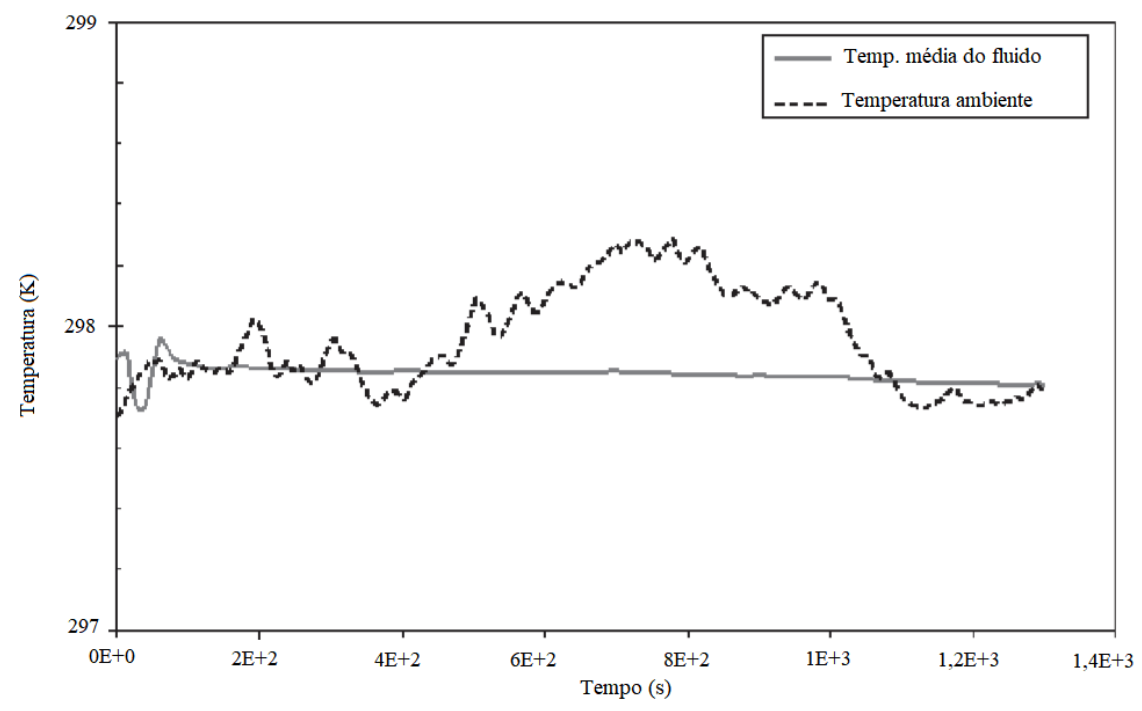

Fonte: Autor, adaptado de Morais e Tsuha (2018)

A seguir, prosseguiu-se ao ensaio TRT propriamente dito, em que a duração de 246 horas garantiu estabilidade às trocas de calor, conforme se verifica na Figura 4.14. Nota-se que a potência fornecida pela bomba de calor e, portanto, a taxa de calor fornecida ao sistema, são aproximadamente constantes. Além disso, percebe-se que a variação da temperatura ambiente possui influência nas temperaturas de entrada e saída do fluido circulante (MORAIS e TSUHA, 2018). A partir da observação das temperaturas de 
entrada e de saída nota-se que, a partir do instante equivalente a 50 horas $\left(1,8 \times 10^{5} \mathrm{~s}\right)$, o sistema geotérmico tende a atingir estabilidade.

Figura 4.14 - Variação das temperaturas do fluido e ambiente durante o ensaio TRT

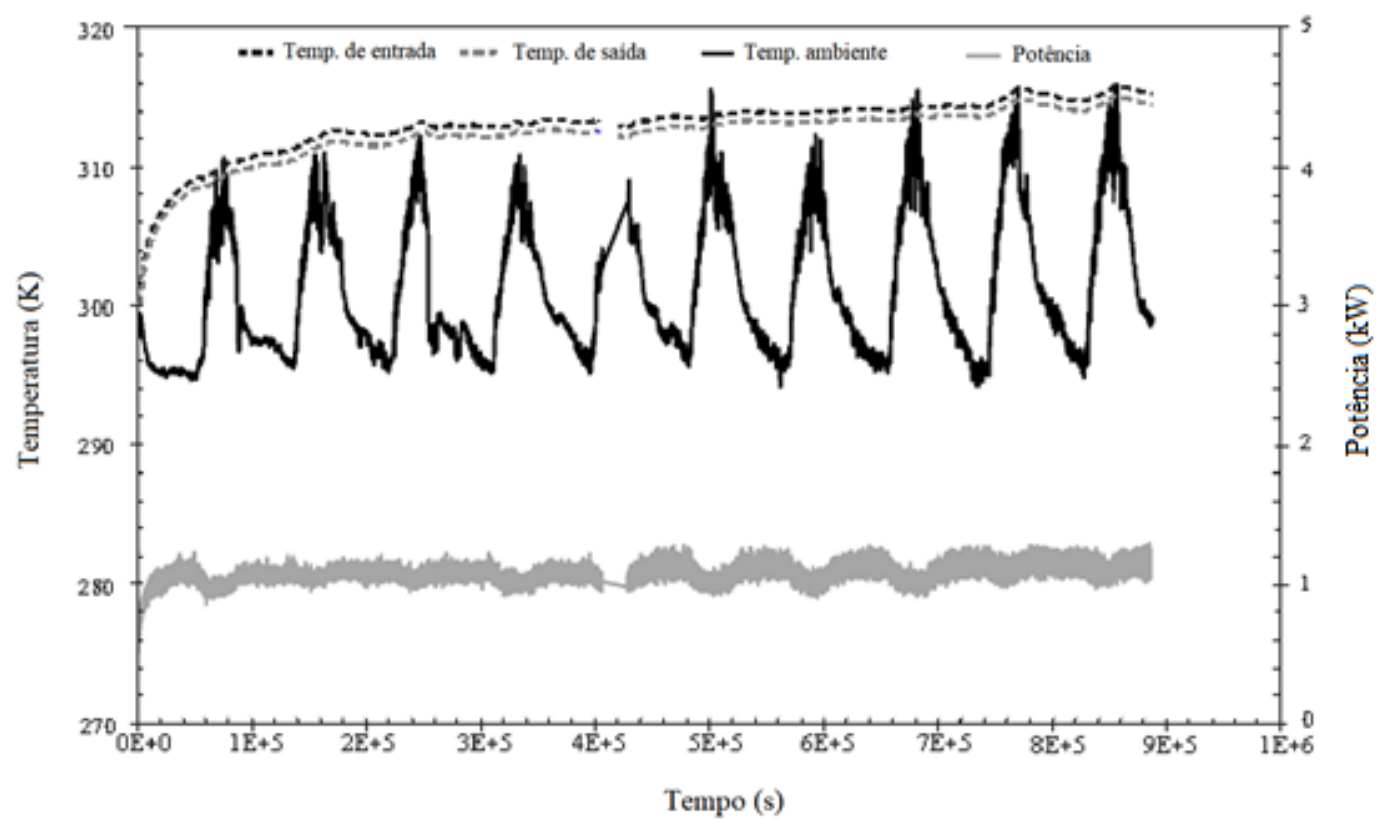

Fonte: Autor, adaptado de Morais e Tsuha (2018)

A estimativa dos parâmetros de condutividade térmica e resistência térmica da estaca foi efetuada com base nas Equações 3.12, 3.13 e 3.14. A Figura 4.15 apresenta a variação da temperatura ambiente e da resistência térmica estimada. Destaca-se que o valor médio de resistência térmica da estaca é de $0,13 \mathrm{~m} . \mathrm{K} . \mathrm{W}^{-1}$. 
Figura 4.15 - Resistência térmica da estaca durante o ensaio TRT

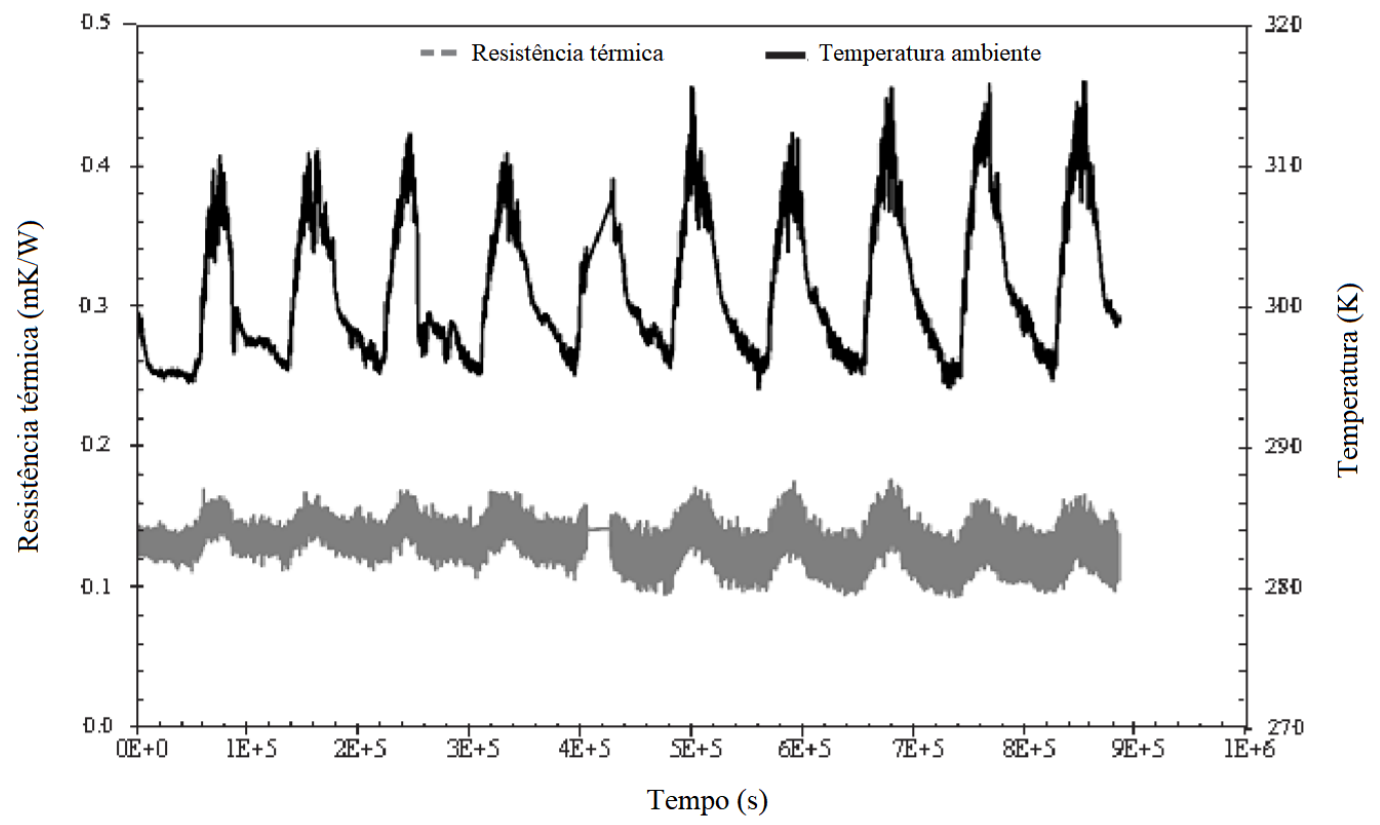

Fonte: Autor, adaptado de Morais e Tsuha (2018)

Com a Equação 3.14, determinou-se o valor de $\lambda$ (coeficiente angular da regressão linear do diagrama de variação da temperatura média do fluido versus o logaritmo do tempo). O ajuste para a regressão linear pode ser encontrado na Figura 4.16.

Figura 4.16 - Temperatura média do fluido circulante x logaritmo do tempo

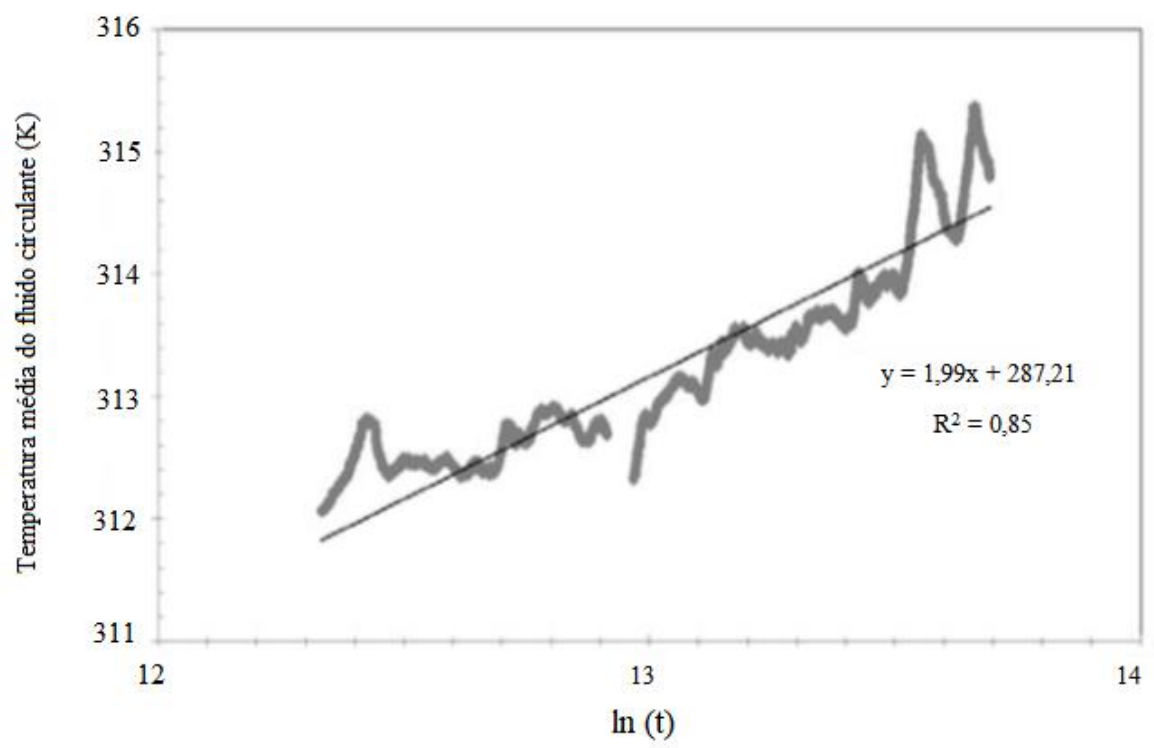

Fonte: Autor, adaptado de Morais e Tsuha (2018) 
A Tabela 4.2 relaciona valores de temperatura medidos a partir do instante 50 horas, em que se estima que houve o início da estabilização do ensaio (quando a diferença entre as temperaturas de entrada e saída do fluido circulante torna-se constante).

Tabela 4.2 - Resumo das temperaturas medidas no ensaio de circulação de água

\begin{tabular}{|c|c|}
\hline Medidas de temperatura & Valor \\
\hline Não perturbada $(\mathrm{K})$ & 297,3 \\
\hline Média ambiente $(\mathrm{K})$ & 301,1 \\
\hline Máxima ambiente $(\mathrm{K})$ & 315,9 \\
\hline Mínima ambiente $(\mathrm{K})$ & 294,1 \\
\hline Entrada do fluido $(50 \mathrm{~h})(\mathrm{K})$ & 312,4 \\
\hline Saída do fluido $(50 \mathrm{~h})(\mathrm{K})$ & 311,7 \\
\hline Entrada do fluido $(100 \mathrm{~h})(\mathrm{K})$ & 313,3 \\
\hline Saída do fluido $(100 \mathrm{~h})(\mathrm{K})$ & 312,5 \\
\hline Entrada do fluido $(200 \mathrm{~h})(\mathrm{K})$ & 314,3 \\
\hline Saída do fluido $(200 \mathrm{~h})(\mathrm{K})$ & 313,6 \\
\hline Velocidade do fluxo $\left(\mathrm{m} . \mathrm{s}^{-1}\right)$ & 0,66 \\
\hline Potência média $(\mathrm{kW})$ & 1,06 \\
\hline
\end{tabular}

Fonte: Autor, adaptado de Morais e Tsuha (2018)

A Tabela 4.3 sintetiza os valores obtidos para os parâmetros de condutividade e resistência térmicas, assim como os coeficientes estimados ao longo do processo experimental.

Tabela 4.3 - Parâmetros obtidos no ensaio de circulação de água

\begin{tabular}{|c|c|c|c|}
\hline $\boldsymbol{\lambda}$ & $\mathbf{R}^{\mathbf{2}}$ & $\mathbf{k}$ & $\mathbf{R}_{\mathbf{b}}$ \\
\hline- & - & $\mathrm{W} \cdot \mathrm{m}^{-} 1 \cdot \mathrm{K}^{-1}$ & $\mathrm{~m} \cdot \mathrm{K}^{-1} \mathrm{~W}^{-1}$ \\
\hline 1,99 & 0,85 & 2,82 & 0,13 \\
\hline
\end{tabular}

$\lambda=$ coeficiente angular da regressão linear do diagrama de variação da temperatura média do fluido versus o logaritmo do tempo, $\mathrm{R}^{2}=$ coeficiente da regressão linear de $\lambda, \mathrm{k}=$ condutividade térmica do solo, $\mathrm{R}_{\mathrm{h}}=$ resistência térmica da estaca

Fonte: Morais e Tsuha (2018)

\subsection{ANÁLISE NUMÉRICA}

A análise numérica desenvolvida nesta pesquisa visa: (i) construir um modelo numérico do ensaio TRT; (ii) validar o modelo numérico pela comparação dos resultados numéricos representativos do ensaio TRT com os resultados experimentais obtidos em 
campo e (iii) realizar um estudo paramétrico que relacione variáveis geométricas, geotécnicas, térmicas e hidráulicas dos materiais constituintes ao comportamento térmico do sistema composto por solo e estaca. É importante assinalar que a estaca geotérmica a ser simulada opera de forma a aquecer o solo, isto é, com o intuito de resfriar ambientes internos de uma edificação.

\subsubsection{Modelo numérico}

A realização das simulações foi desenvolvida por meio do programa ANSYS CFX versão 19.2, ferramenta CFD (Computational Fluid Dynamics - Dinâmica dos Fluidos Computacional) de alto desempenho.

As equações empregadas para a caracterização do escoamento e do fluxo de calor são as equações de massa, energia e quantidade de movimento, em suas formas conservativas (provenientes da análise de um volume de controle fixo no espaço), chamadas de Equações de Navier-Stokes (ANSYS, 2016). As Equações (4.1), (4.2) e (4.3) expressam, respectivamente, a equação de conservação de massa, a equação de conservação de energia e a equação de conservação da quantidade de movimento:

$$
\begin{gathered}
\frac{\partial \rho}{\partial t}+\nabla \cdot(\rho U)=0 \\
\frac{\partial(\rho U)}{\partial t}+\nabla \cdot(\rho U x U)=-\nabla P+\nabla \cdot \tau+S_{m} \\
\frac{\partial\left(\rho h_{o t}\right)}{\partial t}-\frac{\partial P}{\partial t}+\nabla \cdot\left(\rho U h_{o t}\right)=\nabla \cdot\left(k \nabla T_{E}\right)+\nabla \cdot(U \cdot \tau)+U \cdot S_{M}+S_{E}
\end{gathered}
$$

Em que:

- $\quad \rho$ é a massa específica $\left(\mathrm{kg} \cdot \mathrm{m}^{-3}\right)$;

- $U$ é o vetor velocidade $\left(\mathrm{m} . \mathrm{s}^{-1}\right)$;

- $\quad t$ é o tempo (s);

- $\quad P$ é a pressão estática $(\mathrm{Pa})$;

- $S_{m}$ é o termo fonte $\left(\mathrm{kg} \cdot \mathrm{m}^{-2} \cdot \mathrm{s}^{-2}\right)$;

- $\tau$ é o tensor de tensões $(\mathrm{Pa})$; 
- $\quad k$ é a condutividade térmica $\left(\mathrm{W} \cdot \mathrm{m}^{-1} \cdot \mathrm{K}^{-1}\right)$;

- $T_{E}$ é a temperatura estática $(\mathrm{K})$;

- $S_{E}$ é o termo fonte $\left(\mathrm{W} \cdot \mathrm{m}^{-3}\right)$;

- $h_{o t}$ é a entalpia específica total $\left(\mathrm{m}^{2} \cdot \mathrm{s}^{-2}\right)$

O termo $\nabla .(U . \tau)$ se refere ao trabalho devido à tensão viscosa, enquanto o termo U. $S_{M}$ trata do trabalho devido a forças externas.

O tensor de tensões é calculado pela Equação (4.4):

$$
\tau=\mu\left(\nabla U+(\nabla U)^{T}-2 / 3 \delta \nabla \cdot U\right)
$$

A Equação (4.5) exibe o cálculo da entalpia específica total:

$$
h_{o t}=h+1 / 2|U|^{2}
$$

Em que:

- $\delta$ é o delta de Kronecker;

- $\quad h$ é a entalpia específica $\left(\mathrm{m}^{2} \cdot \mathrm{s}^{-2}\right)$.

Nas simulações realizadas, usou-se a opção Thermal Energy (em virtude das velocidades baixas do fluido no interior dos tubos de PEAD), o que permitiu menores custos computacionais. Em casos em que não é possível desprezar a energia cinética, é necessário considerar a parcela relativa à entalpia total na equação de conservação de movimento. As equações apresentadas estão em suas versões completas, em que não se despreza a parcela relacionada à energia cinética.

Soluções analíticas das equações de massa, energia e quantidade de movimento só são possíveis em condições ideais e geometrias simples. É comum a discretização dessas equações para solucionar-se problemas que envolvem configurações geométricas complexas (OLIVEIRA, 2017). O programa empregado utiliza o Método dos Volumes Finitos (MVF) para a realizar a discretização de domínios através de malhas.

O Método dos Volume Finitos fundamenta-se na forma integral da equação de conservação, isto é, divide-se o domínio de solução em um número finito de volumes de controle e aplica-se, a cada um deles, a equação da conservação. No centroide de cada volume de controle situa-se um nó, para o qual são calculados os valores das variáveis. 
Ao final, define-se uma equação algébrica para cada volume de controle, assim como os valores das variáveis em cada nó e nos nós adjacentes (GONÇALVES, 2007). O ANSYS CFX utiliza o método iterativo Multigrid para solucionar o sistema discreto de equações lineares a partir da execução de iterações anteriores em uma malha refinada, além de iterações posteriores em malhas virtuais mais grosseiras. Ao final, os resultados são transportados das malhas menos refinadas para a malha original, de maior refino.

Além disso, o programa ANSYS CFX serve-se, quando possível, de aproximações de segunda ordem. No acoplamento das variáveis pressão e velocidade utiliza-se um arranjo co-localizado, de forma que os volumes de controle são iguais para as equações de transporte. Ou seja, o programa faz uso de resolução acoplada, resolvendo equações de caráter hidrodinâmico em um único sistema (ANSYS, 2016).

No que tange os resíduos e critérios de convergência, o programa ANSYS CFX nomeia um resíduo da solução do sistema linear, para uma variável qualquer $\zeta$, como resíduo bruto $r_{\zeta}$. Todavia, no critério de convergência é empregado um resíduo normalizado $\breve{r}_{\zeta}$ (ANSYS, 2016) segundo a Equação (4.6).

$$
\breve{r}_{\zeta}=\frac{r_{\zeta}}{a_{p} \delta_{\zeta}}
$$

Em que:

- $a_{p}$ é o coeficiente representativo do volume de controle obtido na discretização das equações de conservação;

- $\delta_{\zeta}$ é a variação da variável qualquer.

Frequentemente empregado em simulações CFD, o critério de convergência estipulado foi a raiz do valor quadrático médio (Root Mean Square - RMS), isto é, o monitoramento do valor eficaz. Atinge-se a convergência quando o valor eficaz é inferior a $10^{-4}$ ou, para o caso de simulações em regime transiente, um número máximo de 10 iterações por passo de tempo é atingido para todas as variáveis (ANSYS, 2016).

A discretização do termo transiente foi desenvolvida a partir do esquema Second Order Euler Scheme (método de Euler de segunda ordem), de caráter conservativo e robusto, sem limites em termos de passos de tempo. A aproximação foi feita de acordo com a Equação (4.7): 


$$
\frac{\partial}{\partial t} \int \rho \zeta \mathrm{dV} \approx V \frac{1}{\Delta t}\left[\frac{3}{2}(\rho \zeta)-2(\rho \zeta)^{0}+\frac{1}{2}(\rho \zeta)^{00}\right]
$$

Em que:

- V é o volume de controle;

- $\Delta t$ é o passo de tempo (s);

- 0 é o passo de tempo antecedente.

\subsubsection{Hipóteses para o modelo numérico}

Em Ozudogru e Olgun (2014), Ma et al. (2017), Thompson III (2013), Sánchez et al. (2015), Fare (2015), You et al. (2017), Sousa Júnior (2017) e Orozco (2017) argumentase que são bem fundamentadas as seguintes hipóteses para a modelagem numérica de estacas geotérmicas:

- O solo é um meio semi-infinito, isotrópico e homogêneo. A camada de solo é homogênea, de modo que densidade, peso específico e parâmetros térmicos não variam dentro de seus limites;

- A temperatura inicial do solo (anterior ao fluxo térmico proporcionado pelo sistema geotérmico) é constante ao longo da profundidade. Inicialmente, o perfil de temperaturas é variável ao longo da estaca, todavia, por falta de dados experimentais, considera-se temperatura inicial constante com a profundidade.

- O fenômeno de transferência de calor ocorre predominantemente na direção radial, sendo desprezível a transferência vertical de calor (ao longo do eixo relativo ao comprimento da estaca);

- O mecanismo que governa a transferência de calor nos solos é a condução, governada pela Lei de Fourier, de forma que os processos de convecção e radiação são desprezíveis;

- Existe troca de calor entre as superfícies dos domínios de solo e concreto e o ar;

- No início do ensaio, as temperaturas do fluido e concreto são dependentes da temperatura do solo;

- O fluido circulante é incompressível; 
- Com a variação de temperatura não se alteram: a saturação e, consequentemente, a condutividade térmica do solo; parâmetros de densidade, capacidade térmica e condutividade térmica do fluido, tubos de PEAD, concreto e solo; e a viscosidade do fluido circulante;

Na presente pesquisa, essas hipóteses foram adotadas para o modelo numérico, com uma exceção: considerou-se transferência vertical de calor pela estaca. Em Sousa Júnior (2017), a operação de uma estaca geotérmica provocou o surgimento de uma região, em formato de bulbo, influenciada pelo aquecimento da estaca, indicando que a transferência de calor não ocorre em condição unicamente radial.

\subsubsection{Geometria}

Para a criação da geometria do modelo numérico foi utilizado o modo Space Claim do software ANSYS CFX. A estaca modelada tem diâmetro de 0,35 $\mathrm{m}$ e comprimento de $15 \mathrm{~m}$. Os tubos em formato de U possuem diâmetro interno de $26 \mathrm{~mm}$ e externo de $32 \mathrm{~mm}$. A curva em U dista $10 \mathrm{~cm}$ da face inferior da estaca. Por ter pequena relevância nos processos de troca de calor, desprezou-se a armadura (no ensaio TRT executado a armadura não possuía função estrutural), hipótese também adotada por Ozudogru e Olgun (2014), Orozco (2016), Sousa Júnior (2017) e You et al. (2017).

O maciço de solo foi modelado como um meio contínuo, de formato cilíndrico e raio de $3 \mathrm{~m}$, distância suficientemente grande para que a influência do aquecimento da estaca no solo seja desprezível. A distância do centro da estaca a partir da qual as temperaturas no solo têm valor equivalente ao estado não perturbado foi estimada como $3 \mathrm{~m}$ por Morais e Tsuha (2016), $3 \mathrm{~m}$ por Bandeira Neto (2015) e 2,5 m por Ozudogru e Olgun (2014). Também abaixo da face inferior da estaca atribuiu-se uma distância de $3 \mathrm{~m}$.

As simulações foram executadas em uma metade simétrica do problema, tendo em vista diminuir o custo computacional. A Figura 4.17 ilustra a geometria do problema analisado e a Figura 4.18 mostra em detalhe a face superior da estaca, juntamente às superfícies de entrada e saída do fluido circulante. 
Figura 4.17 - Geometria representativa do ensaio TRT

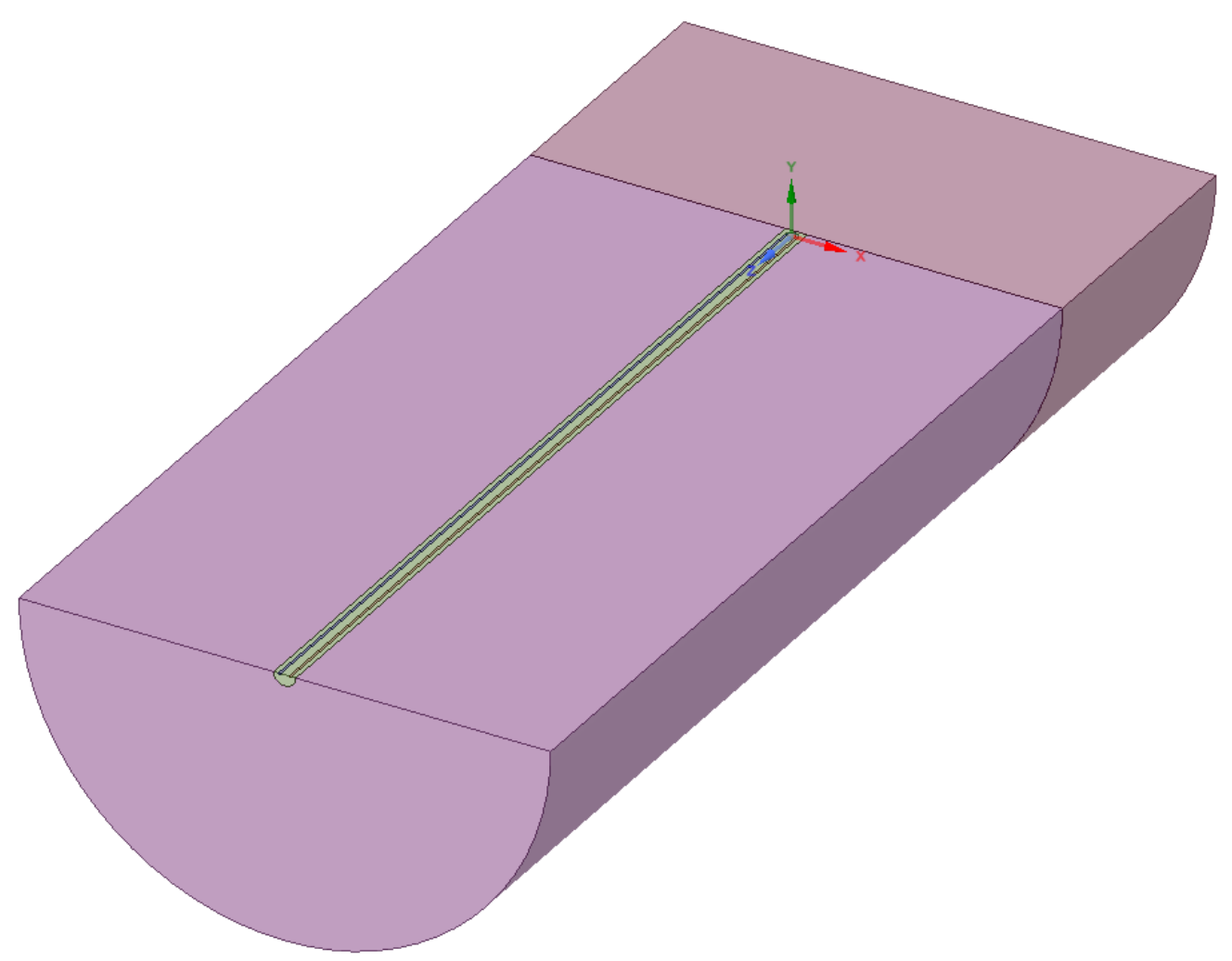

Figura 4.18 - Detalhe da geometria da face superior da estaca

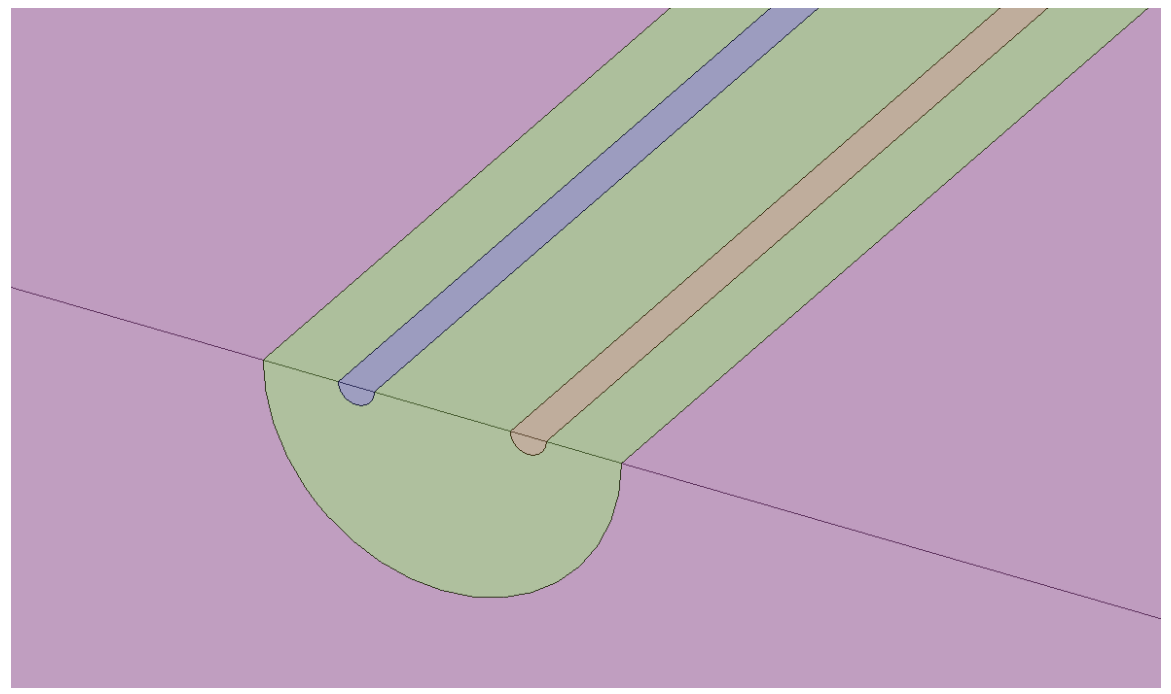

A Figura 4.19 exibe os detalhes da curva da tubulação em formato em "U", situada a $10 \mathrm{~cm}$ do fundo da estaca. 
Figura 4.19 - Detalhe da geometria curva da tubulação em formato em "U"

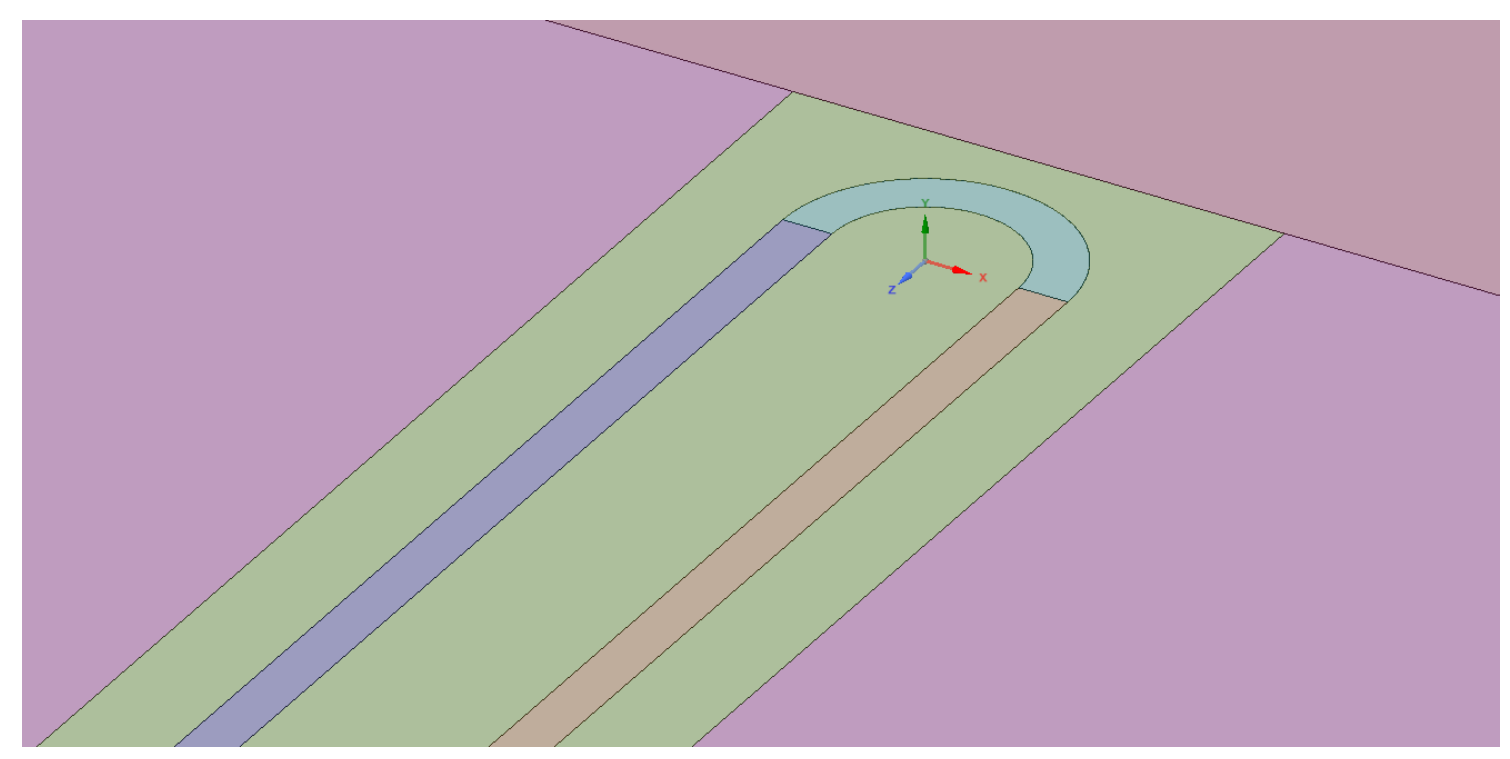

\subsubsection{Malha}

A criação da malha foi realizada através do módulo Meshing, presente no software ANSYS CFX. A precisão da solução é bastante dependente do número de elementos e da sua distribuição na malha. Melhores resultados são obtidos à medida que o refinamento e o custo computacional aumentam. Outro ponto relevante é a escolha do tipo de elemento, fator que impacta diretamente a eficiência da geração da malha (MALISKA, 2004).

Optou-se pelo maior refinamento da malha na região onde há fluido circulante, uma vez que os fenômenos de movimento da água em regime turbulento e convecção forçada tornam a modelagem mais complexa. A partir das trocas térmicas com o fluido circulante é que o fluxo de calor se dissipa para outros materiais do sistema geotérmico, de modo que erros ou menor precisão na simulação do comportamento do fluido acarretariam danos para toda a modelagem.

No domínio do fluido, a complexidade dos fenômenos envolvidos torna difícil a aplicação de hipóteses simplificadoras como a ocorrência de fluxo de energia térmica em direções preferenciais, condição fundamental para a escolha de malhas baseadas em elementos hexaédricos. Portanto, empregaram-se elementos tetraédricos para a malha do fluido circulante, que permitem a obtenção de malhas em configurações geométricas de maior complexidade (a exemplo da curva em "U" na região do fundo da estaca).

Outra vantagem dos elementos tetraédricos é a maior facilidade para a composição de malhas em zonas de transição, onde elementos hexaédricos usualmente apresentam 
problemas. Todavia, o encontro de elementos tetraédricos, de diferentes dimensões, provenientes da geometria da estaca e do fluido, deve ser compatibilizado para que se mantenham apropriadas conectividade e qualidade da malha. Para isso, emprega-se o comando inflation, que gera elementos na forma de prismas para solucionar problemas de conexão e para melhor representar a proximidade com as paredes. Assim, é possível que elementos tetraédricos previamente existentes sejam reestruturados para a obtenção de adequadas transições.

O espaço delimitado pelas superfícies dos tubos de PEAD, por onde circula o fluido, possui 258.400 nós e 551.765 elementos. A Figura 4.20 mostra a malha na região da curva em "U”, com disposição de elementos tetraédricos no interior do volume do fluido e suas conexões com a malha da estaca.

Figura 4.20 - Distribuição de elementos na malha do fluido na região da curva em "U"

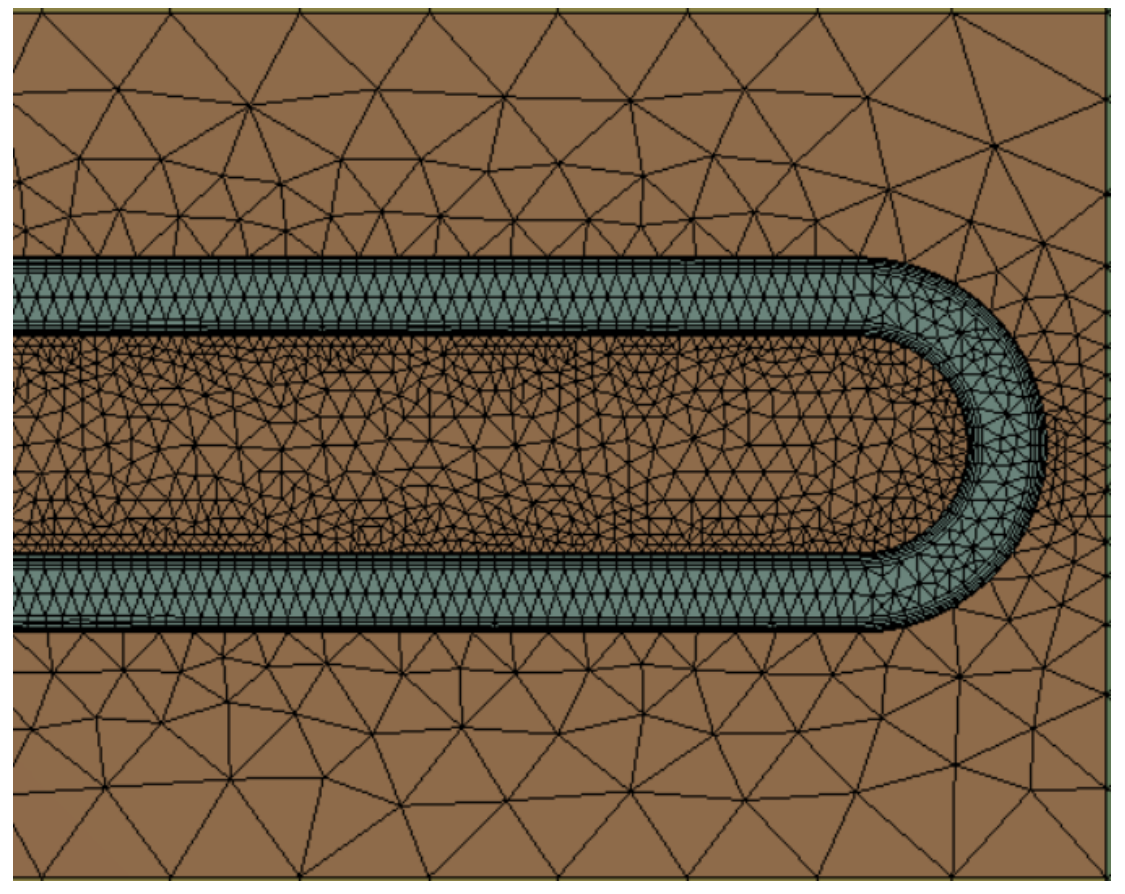

A Figura 4.21 mostra em detalhe os elementos de prisma na transição entre as malhas tetraédricas do concreto e do fluido. 
Figura 4.21 - Disposição de elementos tetraédricos e prismáticos no encontro das malhas do concreto e fluido

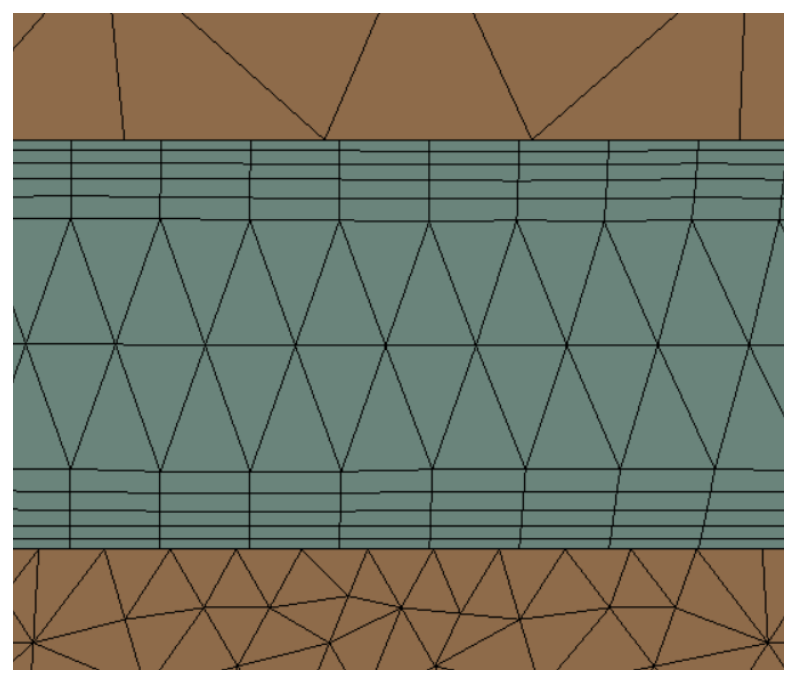

Para a modelagem do solo que circunda a estaca optou-se pelo uso de elementos hexaédricos, que têm a vantagem de formar uma malha com menor número de elementos (para um dado número de nós são necessários menos elementos hexaédricos do que tetraédricos). Consequentemente, obtêm-se soluções mais rápidas e com menor custo computacional. A escolha deste tipo de elemento só é coerente porque os elementos estão alinhados na direção do fluxo de térmico, além de que a geometria do entorno é bastante simples. Nesta geometria foram empregados 692.640 nós e 661.248 elementos.

A Figura 4.22 ilustra a malha elaborada para o solo do entorno da estaca com relação ao eixo XY. A Figura 4.23 detalha o encontro entre as malhas do solo e da estaca.

Figura 4.22 - Malha do solo do entorno da estaca com relação ao eixo XY

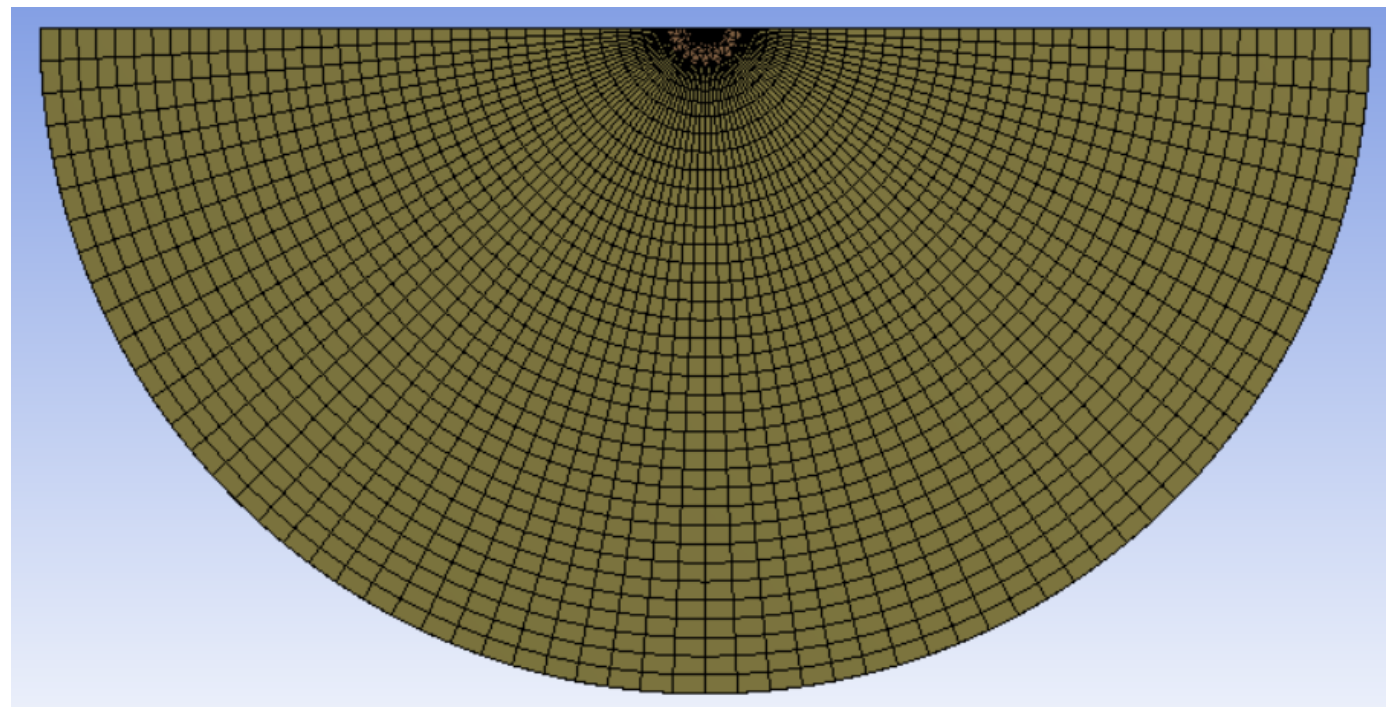


Figura 4.23 - Detalhe da malha de solo no encontro com a malha da estaca com relação ao eixo $\mathrm{XY}$

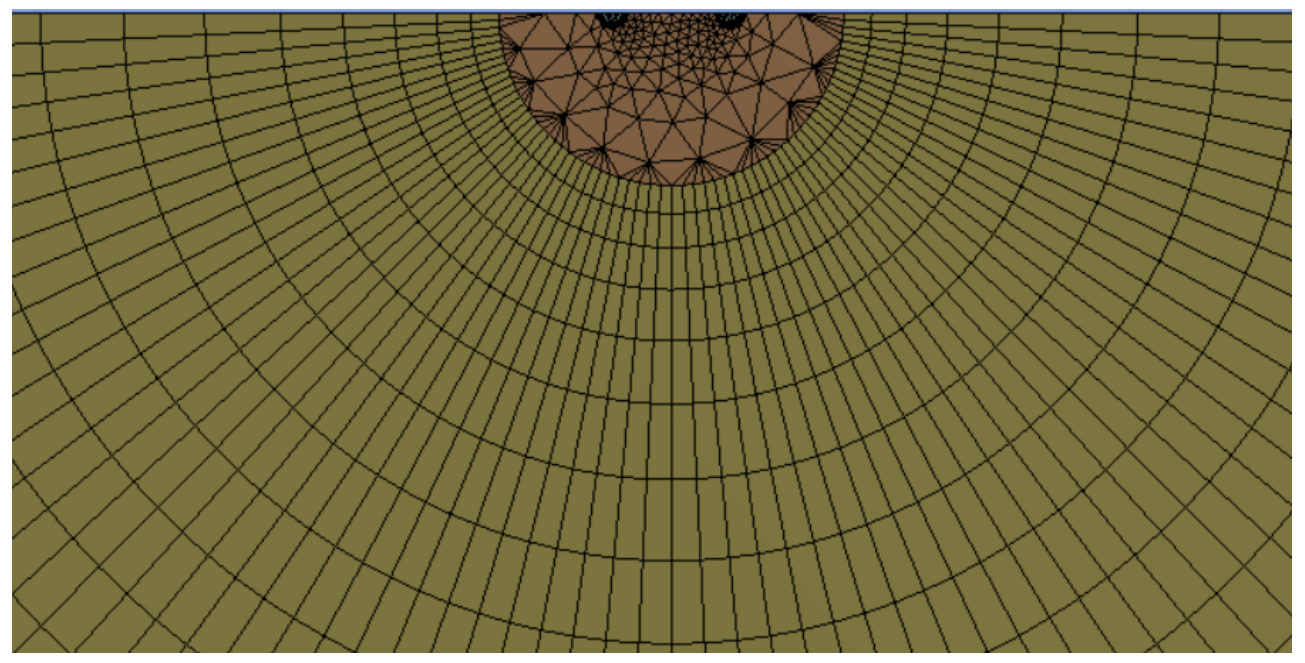

A Figura 4.24 exibe a malha para o solo do entorno da estaca com relação ao eixo XZ. A Figura 4.25 detalha essa malha na face limite do material.

Figura 4.24 - Malha do solo do entorno com relação ao eixo XZ

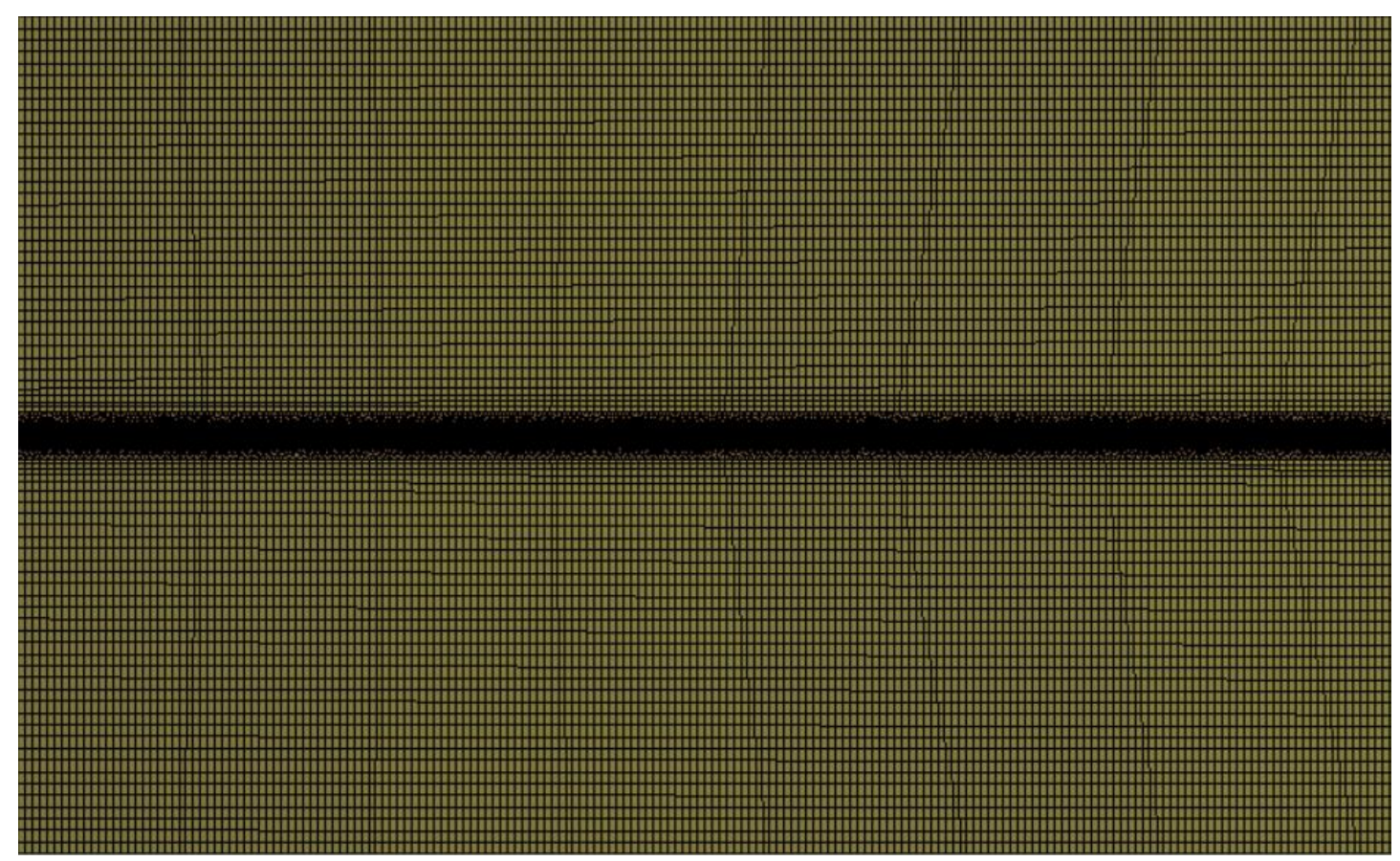


Figura 4.25 - Malha do solo do entorno em vista tridimensional

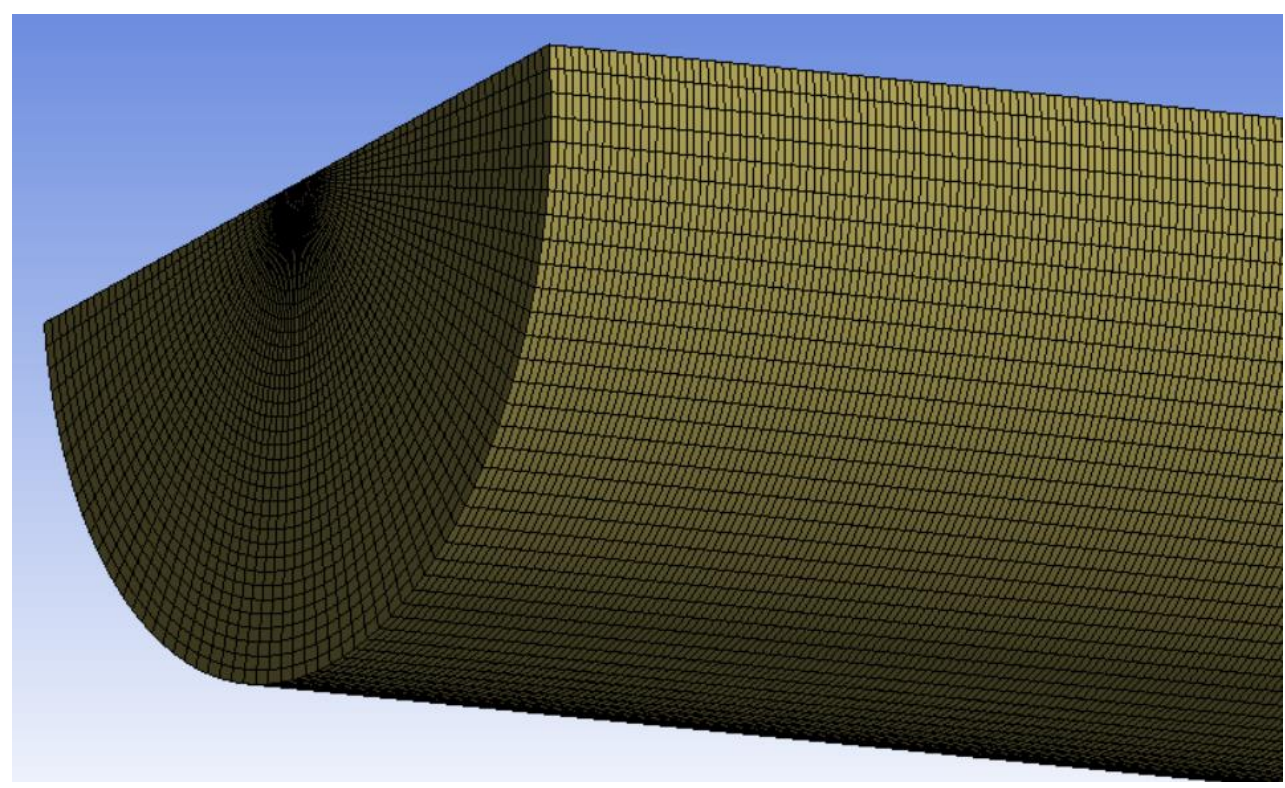

Conforme a malha do solo do entorno se aproxima da região em que ocorrem os fenômenos relacionados ao fluxo de água, é necessário que os elementos se tornem cada vez menores, de modo que ocorra um refinamento progressivo do solo para o concreto e, finalmente, para os volumes interiores aos tubos de PEAD. Assim, surge o desafio particular de se promover o encontro e a harmonização de elementos que obedecem a diferentes necessidades de refinamento.

A atribuição de elementos tetraédricos para a geometria representativa do material de concreto da estaca constituiu a melhor configuração para que fossem atendidos os critérios de maior refinamento da estaca (em comparação ao solo do entorno), ao mesmo tempo em que foi possível obter uma adequada transição entre a malha do solo do entorno (mais grosseira) e a malha do fluido (de maior refinamento). A região entre os tubos de PEAD passou a possuir maior refinamento quando comparada aos elementos que se encontram entre o solo e os limites dos tubos, visto que o volume entre os tubos constitui uma transição entre regiões bastante refinadas.

Para a estaca de concreto foram utilizados 270.148 nós e 1349.839 elementos. A Figura 4.26 ilustra a malha da estaca de concreto em vista tridimensional. A Figura 4.27 exibe a malha da estaca de concreto com relação ao eixo XZ. 
Figura 4.26 - Malha da estaca de concreto em vista tridimensional

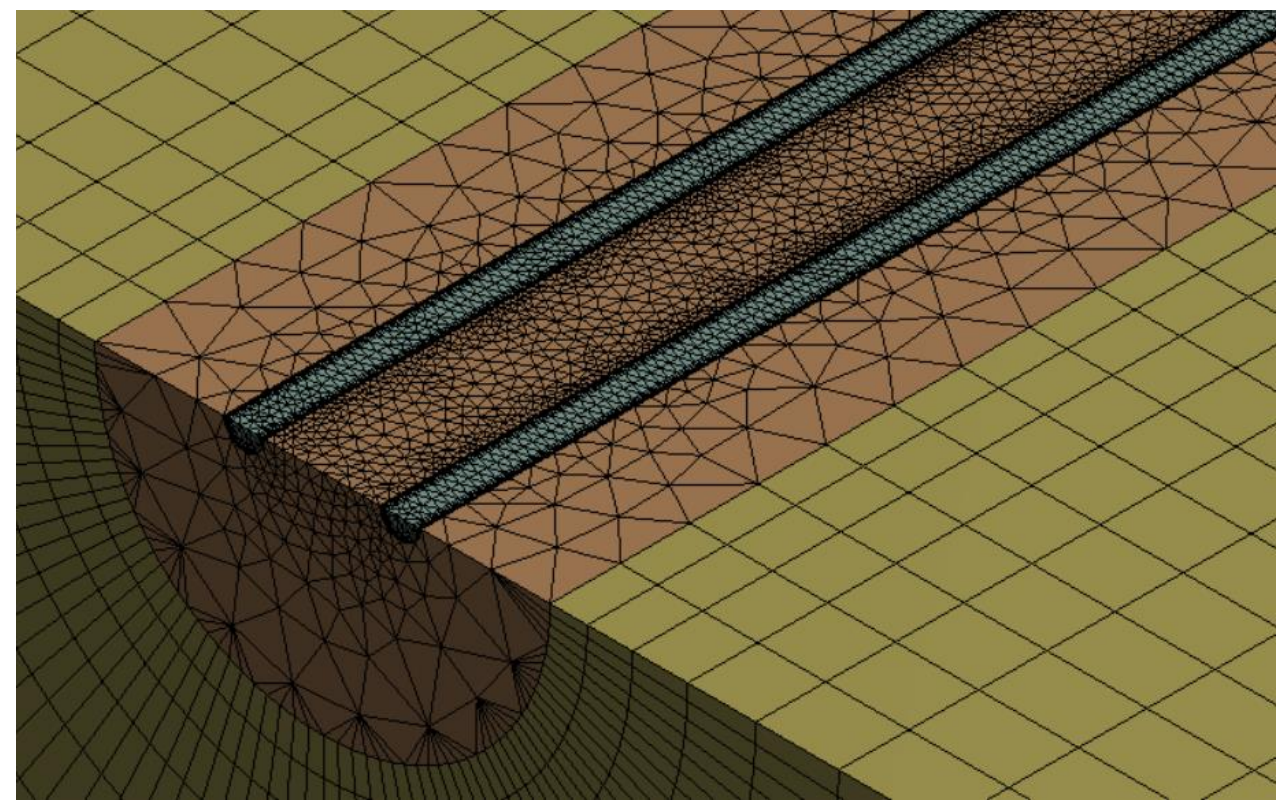

Figura 4.27 - Malha da estaca de concreto em relação ao eixo XZ

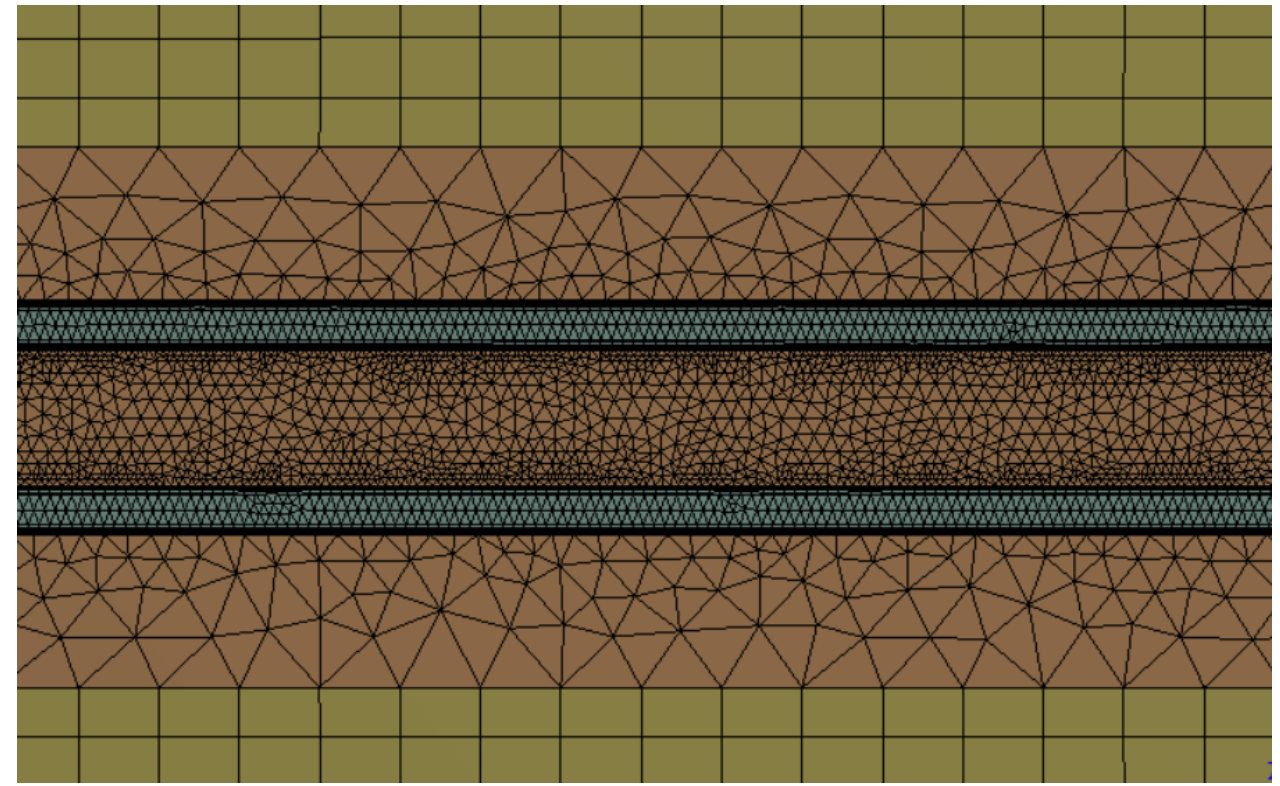

A geometria equivalente ao solo do fundo da estaca permite menor refinamento porque o único fenômeno que ocorre é a transmissão de calor por condução. Entretanto, a malha deve harmonizar-se com os elementos do solo que circunda a estaca (relativamente grosseira) e da estaca de concreto (de maior refinamento). Portanto, a melhor solução encontrada para a malha do solo do fundo da estaca foi utilizar elementos tetraédricos. Além disso, nesta região, o fluxo de energia não ocorre predominantemente na direção radial, o que descarta o uso de elementos hexaédricos, pois eles devem estar 
alinhados com a direção preferencial de dissipação de calor. O solo do fundo da estaca possui 50.042 nós e 260.957 elementos.

A Figura 4.28 mostra a distribuição de elementos tetraédricos para o solo do fundo da estaca, em visão tridimensional. A Figura 4.29 apresenta o detalhe do encontro da malha do solo do fundo da estaca (tetraédrica) com a malha da geometria da estaca de concreto (tetraédrica) e com a malha da geometria do solo circundante (hexaédrica).

Figura 4.28 - Malha do solo do fundo da estaca em vista tridimensional

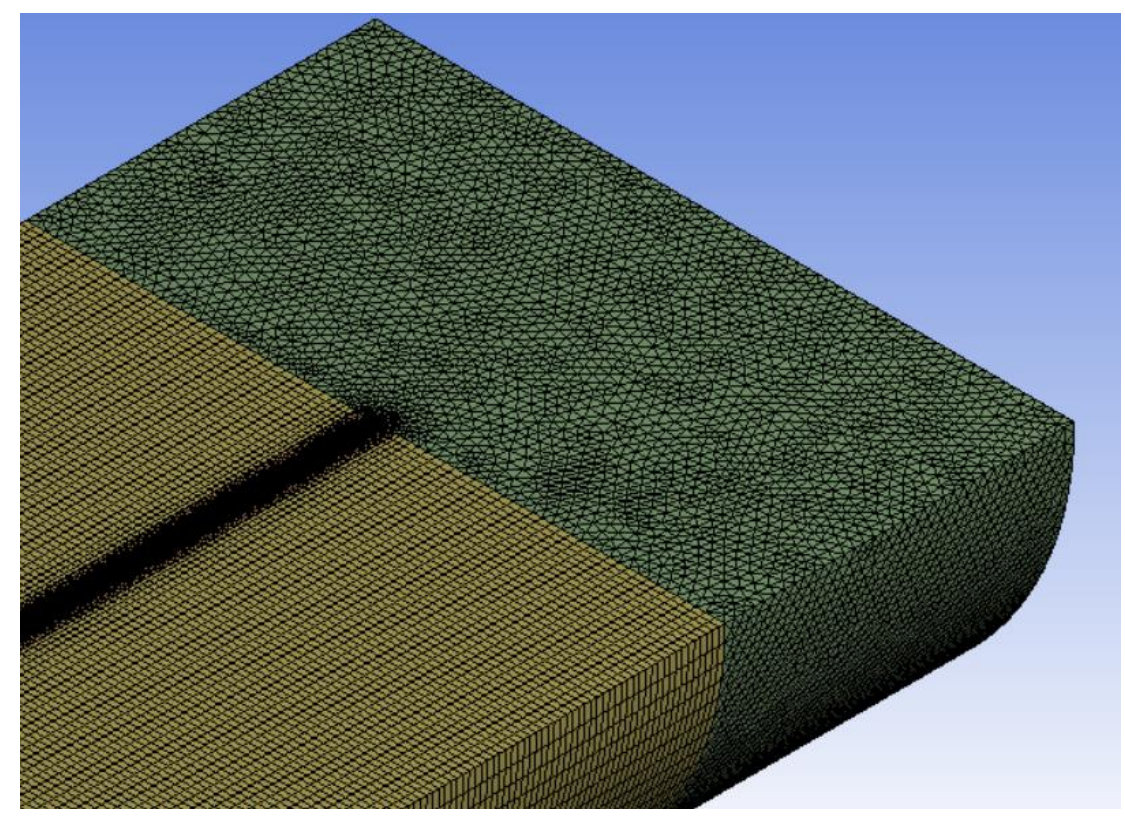

Figura 4.29 - Detalhe do encontro das malhas do solo circundante, solo de fundo e estaca de concreto

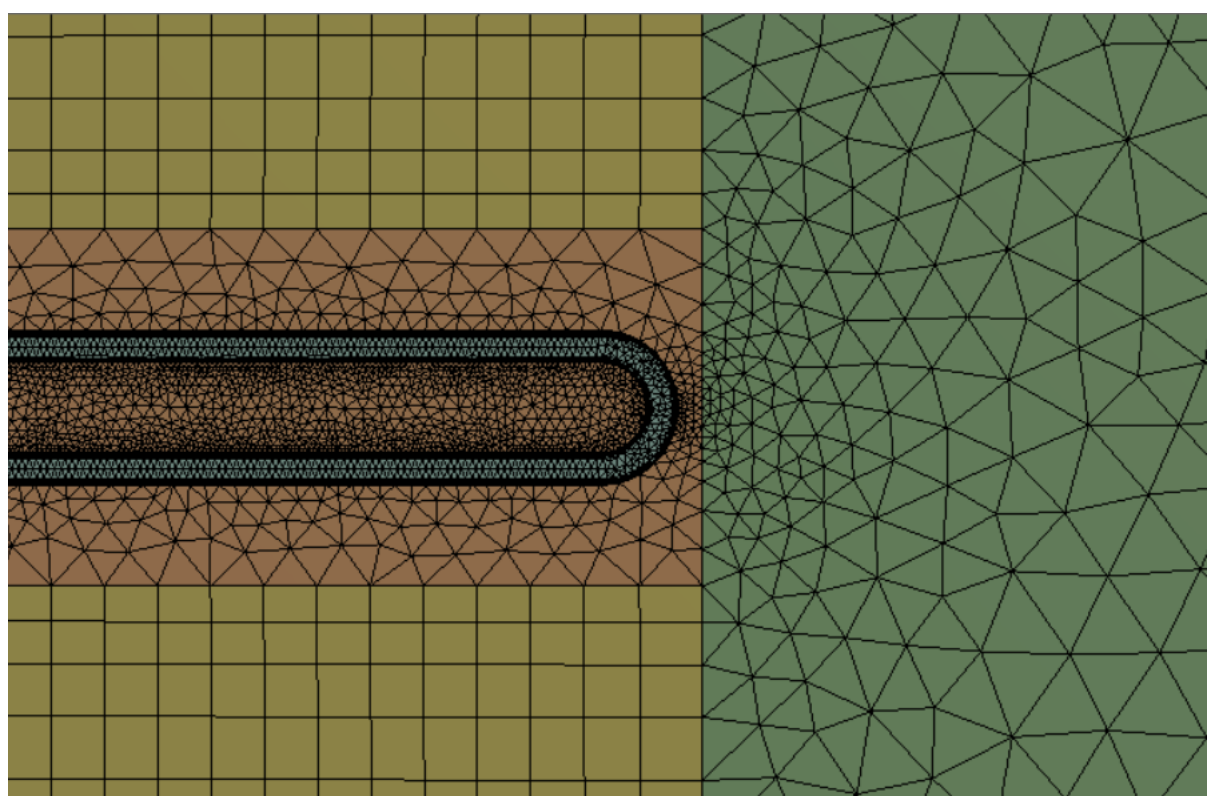




\subsubsection{Modelo de turbulência}

O modelo de turbulência empregado no módulo Setup foi $(k-\varepsilon)$, corriqueiramente empregado em simulações CFD. Este modelo está fundamentado em duas equações que representam as propriedades turbulentas do escoamento: a energia cinética turbulenta $(k)$ e a dissipação de energia turbulenta $(\varepsilon)$ responsável por determinar a escala de turbulência. Também em Thompson III (2013) encontra-se a utilização do modelo ( $k-$ $\varepsilon)$ para a modelagem do fluido circulante de estacas geotérmicas no programa ANSYS CFX.

A Equação (4.8) exprime como o modelo de turbulência $(k-\varepsilon)$ leva em consideração a variável energia cinética turbulenta (HARLOW e NAKAYAMA, 1968):

$$
k_{t}=\alpha\left(\frac{k^{2}}{\varepsilon} k_{x}\right)_{x}-\varepsilon
$$

A Equação (4.9) apresenta a formulação da dissipação de energia turbulenta: (HARLOW e NAKAYAMA, 1968)

$$
\varepsilon_{t}=\beta\left(\frac{k^{2}}{\varepsilon} \varepsilon_{x}\right)_{x}-\gamma \frac{\varepsilon^{2}}{k}
$$

Em que:

- $\quad k$ é a energia cinética turbulenta;

- $\varepsilon$ é a dissipação de energia turbulenta;

- $\alpha, \beta, \gamma$ são constantes positivas.

\subsubsection{Validação do modelo numérico do ensaio TRT}

Nesta etapa, simulou-se o comportamento do ensaio TRT realizado por Morais e Tsuha (2018) nas adjacências da EPUSP, para comparar os resultados experimentais com os fornecidos pelo modelo numérico. A obtenção de resultados adequados na fase de validação torna o modelo numérico confiável para estudos paramétricos.

Intenciona-se entender o comportamento do sistema geotérmico em regime estacionário, quando as trocas térmicas entre fluido, tubos, concreto e solo atingiram condições de estabilidade. 
Para a simulação em regime estacionário e 3D escolheram-se os instantes de tempo equivalente a $50 \mathrm{~h}$ (quando se considerou que o ensaio TRT atingiu estabilidade), $100 \mathrm{~h}$ e $200 \mathrm{~h}$.

\subsubsection{Parâmetros dos materiais e condições de contorno}

Os parâmetros dos materiais e condições de contorno são inseridos no módulo Setup do software ANSYS CFX. Prevê-se fluxo térmico entre o fluido circulante (onde ocorre convecção forçada), tubos de PEAD, estaca de concreto e solo.

Os valores utilizados para o concreto da estaca, de acordo com o ensaio TRT realizado, foram: densidade $2400 \mathrm{~kg} \cdot \mathrm{m}^{-3}$, capacidade térmica específica $1000 \mathrm{~J} \cdot \mathrm{kg}^{-1} \cdot \mathrm{K}^{-1} \mathrm{e}$ condutividade térmica 2,0 W.m ${ }^{-1} \cdot \mathrm{K}^{-1}$ (OROZCO, 2017). Brandl (2006) e Asadi et al. (2018) destacam que o concreto é um material de reduzida condutividade térmica, pois os materiais cimentícios possuem elevado teor de minerais calcários, mas que possui bons valores de capacidade térmica.

Os tubos de PEAD foram simulados por uma superfície de resistência térmica de $0,012 \mathrm{~m}^{2} \cdot \mathrm{K} \cdot \mathrm{W}^{-1}$, calculada a partir da espessura de $6 \mathrm{~mm}$ e condutividade térmica de 0,5 W. $\mathrm{m}^{-1} \cdot \mathrm{K}^{-1}$ (valor retirado da ABNT - NBR 15220/2003, conforme a Equação (4.10):

$$
R=\frac{L}{k}
$$

Em que:

- $R$ é a resistência térmica dos tubos de PEAD $\left(\mathrm{m}^{2} . \mathrm{K} \cdot \mathrm{W}^{-1}\right)$;

- $\quad L$ é a espessura da parede dos tubos de PEAD (m).

O fluido circulante é água, com suas propriedades referidas à temperatura $25^{\circ} \mathrm{C}$ : densidade $997 \mathrm{~kg} \cdot \mathrm{m}^{-3}$, capacidade térmica específica 4181,7 J.kg-1 $\cdot \mathrm{K}^{-1}$, condutividade térmica $0,6069 \mathrm{~W} \cdot \mathrm{m}^{-1} \cdot \mathrm{K}^{-1}$.

Para o parâmetro de entrada condutividade térmica do maciço de solo utilizou-se o valor estimado por Morais e Tsuha (2018) a partir do ensaio TRT: $2,82 \mathrm{~W} \cdot \mathrm{m}^{-1} \cdot \mathrm{K}^{-1}$. Como em Morais e Tsuha (2018) não se determinou a capacidade térmica específica do solo, atribuiu-se o valor de $1578,9 \mathrm{~J} . \mathrm{kg}^{-1} \cdot \mathrm{K}^{-1}$ com base em Lhendup et al. (2014), que 
indicaram valores no intervalo de $1315,8-1578,9 \mathrm{~J} \cdot \mathrm{kg}^{-1} \cdot \mathrm{K}^{-1}$ para solos arenosos. Na etapa relativa ao estudo paramétrico tal hipótese será adequadamente avaliada.

Foram simulados três instantes de tempo apresentados por Morais e Tsuha (2018), uma vez que neles o ensaio TRT por estaca operava em condições estáveis. A cada um deles, foram aplicadas as condições de contorno:

- Para o instante equivalente a 50 horas de ensaio: temperatura de entrada do fluido $312,4 \mathrm{~K}$, vazão mássica $0,3363 \mathrm{~kg} . \mathrm{s}^{-1}$, temperatura ambiente $310,7 \mathrm{~K}$, potência de aquecimento $1031,20 \mathrm{~W}$, temperatura não perturbada do solo $297,3 \mathrm{~K}$;

- Para o instante equivalente a 100 horas de ensaio: temperatura de entrada do fluido $313,3 \mathrm{~K}$, vazão mássica $0,3366 \mathrm{~kg} \cdot \mathrm{s}^{-1}$, temperatura ambiente $311,2 \mathrm{~K}$, potência de aquecimento 1083,44 W, temperatura não perturbada do solo $297,3 \mathrm{~K}$;

- Para o instante equivalente a 200 horas de ensaio: temperatura de entrada do fluido $314,3 \mathrm{~K}$, vazão mássica $0,3663 \mathrm{~kg} . \mathrm{s}^{-1}$, temperatura ambiente $313,1 \mathrm{~K}$, potência de aquecimento $1107,29 \mathrm{~W}$, temperatura não perturbada do solo $297,3 \mathrm{~K}$;

Supõe-se que o topo da estaca e o solo realizam troca térmica por convecção natural com o ambiente. Na saída, assumiu-se que o fluido escoa à pressão atmosférica. Adotouse temperatura do solo de $297,3 \mathrm{~K}$ para a distância radial de $3 \mathrm{~m}$ e também a $3 \mathrm{~m}$ abaixo da face inferior da estaca. Inicialmente, a temperatura da estaca e do solo são iguais.

Além disso, o domínio de solo é adiabático, isto é, não há entrada ou saída de calor para fora dos limites do solo. Assim, todos os fenômenos ocorrem no interior do sistema composto pelo fluido, tubos, concreto e solo.

A água circula no interior dos tubos em regime turbulento (número de Reynolds superior a 2400) com número de Reynolds igual a 17.109, obtido pela Equação (4.11):

$$
R_{e}=\frac{\rho \cdot v \cdot D}{\mu}
$$

Em que:

- $R_{e}$ é o número de Reynolds;

- $\rho$ é a massa específica do fluido $\left(\mathrm{kg} \cdot \mathrm{m}^{-3}\right)$;

- $v$ é a velocidade do fluido $\left(\mathrm{m} . \mathrm{s}^{-1}\right)$;

- $\quad D$ é o diâmetro da tubulação $(\mathrm{m})$;

- $\mu$ é a viscosidade dinâmica do fluido (N.s.m $\left.{ }^{-2}\right)$.

Os parâmetros de entrada e condições de contorno empregados para a validação do modelo numérico são apresentados na Tabela 4.4: 
Tabela 4.4 - Parâmetros de entrada e condições de contorno empregados

\begin{tabular}{|c|c|c|}
\hline- & Parâmetro & Valor \\
\hline \multirow{7}{*}{ Geometria } & Diâmetro da estaca (m) & 0,35 \\
\hline & Comprimento da estaca $(\mathrm{m})$ & 15 \\
\hline & Diâmetro interno dos tubos (m) & 0,026 \\
\hline & Diâmetro externo dos tubos $(\mathrm{m})$ & 0,032 \\
\hline & Resistência térmica resultante dos tubos $\left(\mathrm{m}^{2} . \mathrm{K} . \mathrm{W}^{-1}\right)$ & 0,012 \\
\hline & Raio do volume cilíndrico de solo (m) & 3 \\
\hline & Altura do volume cilíndrico de solo (m) & 18 \\
\hline \multirow{10}{*}{$\begin{array}{l}\text { Geotérmicos } \\
\text { e estruturais }\end{array}$} & Temperatura a 3 m do centro da estaca $(\mathrm{K})$ & 297,3 \\
\hline & Condutividade térmica do solo $\left(\mathrm{W} \cdot \mathrm{m}^{-1} \cdot \mathrm{K}^{-1}\right)$ & 2,82 \\
\hline & Capacidade térmica específica do solo $\left(\mathrm{J} \cdot \mathrm{kg}^{-1} \cdot \mathrm{K}^{-1}\right)$ & 1578,9 \\
\hline & Condutividade térmica do concreto $\left(\mathrm{W} \cdot \mathrm{m}^{-1} \cdot \mathrm{K}^{-1}\right)$ & 2 \\
\hline & Capacidade térmica específica do concreto $\left(\mathrm{J} \cdot \mathrm{kg}^{-1} \cdot \mathrm{K}^{-1}\right)$ & 1000 \\
\hline & Densidade do concreto $\left(\mathrm{kg} \cdot \mathrm{m}^{-3}\right)$ & 2400 \\
\hline & Capacidade térmica específica da água $\left(\mathrm{J} \cdot \mathrm{kg}^{-1} \cdot \mathrm{K}^{-1}\right)$ & 1487,7 \\
\hline & Condutividade térmica da água $\left(\mathrm{W} \cdot \mathrm{m}^{-1} \cdot \mathrm{K}^{-1}\right)$ & 0,6069 \\
\hline & Vazão mássica (kg/s) & 0,3363 \\
\hline & Temperatura não perturbada do solo (K) & 297,3 \\
\hline \multicolumn{3}{|c|}{ Parâmetros variáveis ao longo do tempo (Etapa de validação) } \\
\hline \multirow{2}{*}{$50 \mathrm{~h}$} & Temperatura de entrada $(\mathrm{K})$ & 312,4 \\
\hline & Temperatura ambiente $(\mathrm{K})$ & 310,7 \\
\hline \multirow{2}{*}{$100 \mathrm{~h}$} & Temperatura de entrada $(\mathrm{K})$ & 313,3 \\
\hline & Temperatura ambiente $(\mathrm{K})$ & 311,2 \\
\hline \multirow{2}{*}{$200 \mathrm{~h}$} & Temperatura de entrada $(\mathrm{K})$ & 314,3 \\
\hline & Temperatura ambiente $(\mathrm{K})$ & 313,1 \\
\hline \multirow{5}{*}{$\begin{array}{l}\text { Condições } \\
\text { de contorno }\end{array}$} & Superfície solo limite & Adiabática \\
\hline & Superfície solo topo & Convecção natural \\
\hline & Interior dos tubos & Convecção forçada \\
\hline & Interface tubo-concreto & Condução \\
\hline & Interface solo-tubo & Condução \\
\hline
\end{tabular}




\subsubsection{Estudo paramétrico em modelo numérico do ensaio TRT}

Nesta etapa são analisadas a troca de calor na estaca geotérmica e a distribuição de temperaturas nos materiais e regiões afetados pela operação do sistema geotérmico em relação às seguintes variáveis de projeto e de operação: parâmetros geométricos (comprimento e diâmetro da estaca), material dos tubos, velocidade do fluido circulante, tipo de concreto, tipo de solo e saturação do solo.

Utilizou-se o modelo numérico calibrado para o ensaio TRT em operação no instante de tempo equivalente a $200 \mathrm{~h}$. A escolha desse tempo do ensaio para o estudo paramétrico deve-se ao fato de que, nestas condições, observa-se maior estabilidade na operação da estaca geotérmica, conforme ilustra a Figura 4.16, e menor diferença entre as temperaturas de entrada e saída do fluido que circula pelos tubos $(0,7 \mathrm{~K})$.

\subsubsection{Variação dos parâmetros de entrada}

A revisão da literatura evidencia que não há análises que busquem explicar como variações de parâmetros geotérmicos, hidráulicos, estruturais e geométricos afetam o desempenho térmico de estacas geotérmicas. Tendo em vista o preenchimento desta lacuna este trabalho partiu de parâmetros usuais de projeto para relacionar variações paramétricas ao desempenho térmico do sistema.

Os parâmetros geométricos investigados foram comprimento da estaca (L) e diâmetro da estaca (D). Utilizaram-se como valores de L: 5 m, 10 m, 15 m (comprimento original da estaca), 20 m, $30 \mathrm{~m}$ e $50 \mathrm{~m}$, e como valores de D: 0,2 m, 0,35 m (diâmetro original da estaca), 0,50 m, 0,70 m, 0,90 m e 1,1m.

Variou-se também o material que compõe os tubos. Foram selecionados, na literatura, materiais cujo uso em aplicações hidráulicas é comum. Mantendo-se a espessura de $6 \mathrm{~mm}$ (segundo a configuração original do ensaio TRT), calcularam-se diferentes valores de resistência térmica para diferentes materiais (Equação 4.10). Além disso, atribuíram-se diferentes espessuras de tubo para o material PEAD, originalmente utilizado no ensaio TRT. Simulou-se também a operação da estaca sem resistência térmica na interface entre tubos e concreto, a fim de se obter os valores ideais de trocas térmicas caso a resistência do material que compõe o tubo pudesse ser suprimida. A Tabela 4.5 sintetiza os materiais, espessuras (e), condutividades térmicas (k) e resistências térmicas $(\mathrm{R})$ empregadas nas simulações. 
Outra variável estudada foi a velocidade do fluido que circula pelo interior dos tubos de PEAD. Valores usuais de velocidade de fluido circulante encontram-se no intervalo de $0,5 \mathrm{~m} . \mathrm{s}^{-1}$ a $0,9 \mathrm{~m} \cdot \mathrm{s}^{-1}$, segundo Fare (2015). Entretanto, atribuiu-se à velocidade do fluido circulante valores inferiores e superiores a essa faixa com vistas a possíveis ganhos em termos de troca térmica. A Tabela 4.6 sintetiza os valores de velocidade do fluido circulante utilizados nas simulações, bem como os valores de vazão, número de Reynolds ( $\mathrm{Re}$ ) e tipo de regime (turbulento, transitório ou laminar) decorrentes de cada variável. Recorda-se que a velocidade de $0,66 \mathrm{~m} \cdot \mathrm{s}^{-1}$ foi a usada no ensaio TRT executado.

Tabela 4.5 - Materiais, espessuras (e), condutividades térmicas (k) e resistências térmicas $(\mathrm{R})$ empregadas no estudo paramétrico

\begin{tabular}{|c|c|c|c|c|}
\hline Material & $k\left(\mathbf{W} \cdot \mathrm{m}^{-1} \cdot \mathrm{K}^{-1}\right)$ & e $(\mathbf{m m})$ & $R\left(\mathbf{m}^{2} \cdot \mathbf{K} \cdot \mathbf{W}^{-1}\right)$ & Fonte \\
\hline Policloreto de vinila (PVC) & 0,17 & 6 & 0,0353 & Patterson e Miers, 2015 \\
\hline Polietileno de alta densidade (PEAD) & 0,50 & 6 & 0,0120 & NBR 15220/2003 \\
\hline Polietileno de alta densidade (PEAD) & 0,50 & 3 & 0,0060 & NBR 15220/2003 \\
\hline Polietileno de alta densidade (PEAD) & 0,50 & 24 & 0,0480 & NBR 15220/2003 \\
\hline Polietileno de alta densidade (PEAD) & 0,50 & 12 & 0,0240 & NBR 15220/2003 \\
\hline Cobre & 380,00 & 6 & $1,57895 \mathrm{E}-05$ & Patterson e Miers, 2015 \\
\hline Aço & 50,00 & 6 & 0,00012 & Patterson e Miers, 2015 \\
\hline Policloreto de vinila clorado (CPVC) & 0,139 & 6 & 0,04317 & Patterson e Miers, 2015 \\
\hline Polietileno monocamada (PEX) & 0,51 & 6 & 0,01176 & Patterson e Miers, 2015 \\
\hline Polietileno de baixa densidade & 0,33 & 6 & 0,01818 & Patterson e Miers, 2015 \\
\hline Polipropileno & 0,22 & 6 & 0,02727 & Patterson e Miers, 2015 \\
\hline
\end{tabular}


Tabela 4.6 - Valores de velocidade do fluido circulante (juntamente à vazão, número de Reynolds e tipo de regime) utilizados no estudo paramétrico

\begin{tabular}{|c|c|c|c|}
\hline Velocidade $\left(\mathrm{m} \mathrm{s}^{-1}\right)$ & Vazão (L.min-1) & $\operatorname{Re}$ & Tipo de regime \\
\hline 3,1392 & 100 & 81375,43 & Turbulento \\
\hline 2,3544 & 75 & 61031,57 & Turbulento \\
\hline 1,5696 & 50 & 40687,71 & Turbulento \\
\hline 0,7848 & 25 & 20343,86 & Turbulento \\
\hline 0,6600 & 21 & 17088,84 & Turbulento \\
\hline 0,6278 & 20 & 16275,09 & Turbulento \\
\hline 0,4709 & 15 & 12206,31 & Turbulento \\
\hline 0,3139 & 10 & 8137,54 & Turbulento \\
\hline 0,1256 & 4 & 3255,02 & Transição \\
\hline 0,0314 & 1 & 813,75 & Laminar \\
\hline 0,0157 & 0,5 & 406,88 & Laminar \\
\hline 0,0031 & 0,1 & 81,38 & Laminar \\
\hline
\end{tabular}

Variaram-se também os parâmetros térmicos do concreto, obedecendo a dois critérios: a seleção de materiais cujo uso seja comum em Engenharia e a de materiais cujos parâmetros térmicos resultem em cenários extremos, até então não abordados em pesquisas envolvendo estacas geotérmicas. Os tipos de concretos analisados e seus parâmetros térmicos são apresentados na Tabela 4.7.

Segundo Orozco (2016) e Fare (2015), valores usuais de condutividade térmica para o concreto em aplicações geotérmicas encontram-se no intervalo de $1,0 \mathrm{~W} \cdot \mathrm{m}^{-1} \cdot \mathrm{K}^{-1} \mathrm{a}$ $3,0 \mathrm{~W} \cdot \mathrm{m}^{-1} \cdot \mathrm{K}^{-1}$. Regulamentos europeus limitam a condutividade térmica de estacas geotérmicas a $1,5 \mathrm{~W} \cdot \mathrm{m}^{-1} \cdot \mathrm{K}^{-1}$.

Para analisar efeitos acoplados em termos de estudo paramétrico, foram realizadas simulações para o concreto com condutividade térmica de $2 \mathrm{~W} \cdot \mathrm{m}^{-1} \cdot \mathrm{K}^{-1} \mathrm{e} 3,85 \mathrm{~W} \cdot \mathrm{m}^{-1} \cdot \mathrm{K}^{-1}$, em duas situações: com e sem a resistência térmica de contato de $0,012 \mathrm{~m}^{2} . \mathrm{K}^{\mathrm{W}} \mathrm{W}^{-1}$ na interface entre tubos e concreto. 
Tabela 4.7 - Tipos de concretos analisados e seus parâmetros térmicos

\begin{tabular}{|c|c|c|c|c|}
\hline Tipo de concreto & $\rho\left(\mathbf{k g} \cdot \mathbf{m}^{-3}\right)$ & $k\left(\mathbf{W} \cdot \mathbf{m}^{-1} \cdot \mathbf{K}^{-1}\right)$ & $c_{e}\left(J_{. k g}{ }^{-1} K^{-1}\right)$ & Fonte \\
\hline Celular autoclavado & 450 & 0,17 & 1000 & NBR 15220 \\
\hline Dosagem cimento/areia 1:3 & 750 & 0,29 & 1000 & NBR 15220 \\
\hline Com pozolana ou escória expandida & 1400 & 0,52 & 1000 & NBR 15220 \\
\hline Com argila expandida $\left(i>350 \mathrm{~kg} / \mathrm{m}^{3}\right)$ & 1500 & 0,85 & 1000 & NBR 15220 \\
\hline Com argila expandida $\left(c>300 \mathrm{~kg} / \mathrm{m}^{3}\right)$ & 1700 & 1,05 & 1000 & NBR 15220 \\
\hline \multirow{3}{*}{ Média densidade } & 1800 & 1,15 & 1000 & ISO (2007) \\
\hline & 2000 & 1,35 & 1000 & ISO (2007) \\
\hline & 2200 & 1,65 & 1000 & ISO (2007) \\
\hline Concreto com agregados de pedra & 2300 & 1,75 & 1000 & NBR 15220 \\
\hline Alta densidade & 2400 & 2,00 & 1000 & ISO (2007) \\
\hline Reforçado (1\% de aço) & 2300 & 2,30 & 1000 & ISO (2007) \\
\hline Reforçado ( $2 \%$ de aço) & 2400 & 2,50 & 1000 & ISO (2007) \\
\hline ST2 - com micro PCM & 2441 & 2,95 & 1000 & Asadi et al. (2018) \\
\hline GRA - Concreto com fibras de aço & 1890 & 3,52 & 1000 & Asadi et al. (2018) \\
\hline GAM - com rebarbas de latão & 2810 & 3,85 & 1000 & Asadi et al. (2018) \\
\hline
\end{tabular}

$i$ : dosagem dos inertes; $c$ : dosagem do cimento; $\rho$ : massa específica do concreto; $k$ : condutividade térmica do concreto; ce: calor específico do concreto.

Para a análise do tipo de solo reuniram-se parâmetros publicados em Lhendup et al. (2014) e sintetizados na Tabela 4.8. Nas simulações foram considerados os cenários com e sem a resistência térmica $0,012 \mathrm{~m}^{2} . \mathrm{K} \cdot \mathrm{W}^{-1}$ na interface entre tubos e concreto. $\mathrm{O}$ material designado por solo real se refere ao solo investigado no ensaio TRT.

Tabela 4.8 - Tipos de solos analisados e seus parâmetros térmicos

\begin{tabular}{|c|c|c|c|}
\hline Material & $\boldsymbol{k}\left(\mathbf{W} \cdot \mathbf{m}^{-\mathbf{1}} \cdot \mathbf{K}^{-\mathbf{1}}\right)$ & $\mathbf{c}_{\mathbf{e}}\left(\mathbf{J} . \mathbf{k g}^{-\mathbf{1}} \cdot \mathbf{K}^{\mathbf{- 1}}\right)$ & $\left.\boldsymbol{\rho} \mathbf{~ k g . m}^{-\mathbf{3}}\right)$ \\
\hline Pedregulho & 2,65 & 942,35 & 2600 \\
\hline Areia & 2,00 & 1447,35 & 1900 \\
\hline Silte & 1,70 & 1556,05 & 1800 \\
\hline Argila & 0,90 & 1588,25 & 1700 \\
\hline Argilito & 2,85 & 1061,05 & 2210 \\
\hline Arenito & 3,70 & 997,75 & 2200 \\
\hline Solo real & 2,82 & 1578,9 & 2400 \\
\hline
\end{tabular}

$\rho$ : massa específica do solo; $k$ : condutividade térmica do solo; $\mathrm{c}_{\mathrm{e}}$ : calor específico do solo.

De forma adicional, realizaram-se simulações variando-se isoladamente os parâmetros condutividade térmica e calor específico segundo os valores apresentados nas 
Tabelas 4.9 e 4.10. Essa análise paramétrica se destina apenas à verificação da influência isolada dos parâmetros térmicos do solo sobre as trocas térmicas, sem a preocupação de representarem materiais geotécnicos reais.

Tabela 4.9 - Variação da condutividade térmica do solo

\begin{tabular}{|c|c|c|c|}
\hline Material & $k\left(\mathbf{W} \cdot \mathbf{m}^{-1} \cdot \mathbf{K}^{-1}\right)$ & $c_{e}\left(J^{\prime} \cdot k^{-1} \cdot K^{-1}\right)$ & $\rho\left(\right.$ kg.m $\left.^{-3}\right)$ \\
\hline $\mathrm{A}$ & 1 & 1000 & 1000 \\
\hline $\mathrm{B}$ & 4 & 1000 & 1000 \\
\hline $\mathrm{C}$ & 8 & 1000 & 1000 \\
\hline $\mathrm{D}$ & 20 & 1000 & 1000 \\
\hline
\end{tabular}

Tabela 4.10 - Variação do calor específico do solo

\begin{tabular}{|c|c|c|c|}
\hline Material & $\boldsymbol{k}\left(\mathbf{W} \cdot \mathbf{m}^{-\mathbf{1}} \cdot \mathbf{K}^{\mathbf{- 1}}\right)$ & $\boldsymbol{c}_{\mathbf{e}}\left(\mathbf{J} \cdot \mathbf{k g}^{-\mathbf{1}} \cdot \mathbf{K}^{\mathbf{- 1}}\right)$ & $\boldsymbol{\rho}\left(\mathbf{k g . m ^ { - 3 }}\right)$ \\
\hline $\mathrm{A}$ & 2,82 & 100 & 1800 \\
\hline $\mathrm{B}$ & 2,82 & 500 & 1800 \\
\hline $\mathrm{C}$ & 2,82 & 1000 & 1800 \\
\hline $\mathrm{D}$ & 2,82 & 4000 & 1800 \\
\hline
\end{tabular}

Para a análise da influência do grau de saturação, partiu-se do estudo experimental efetuado por Sánchez et al. (2015), em que se relacionam diferentes graus de saturação (juntamente à porosidade e índice de vazios) de amostras de uma areia a seus respectivos valores de condutividade térmica. Assim, os valores de grau de saturação foram introduzidos indiretamente nas simulações numéricas, uma vez que foram utilizados como dados de entrada para o programa os dados de condutividade térmica provenientes de diferentes graus de saturação. Foram considerados os cenários com e sem a resistência térmica $0,012 \mathrm{~m}^{2} . \mathrm{K} . \mathrm{W}^{-1}$ na interface entre tubos e concreto. Os valores simulados variam do estado quase seco até a saturação completa e são apresentados na Tabela 4.11. 
Tabela 4.11 - Variação da condutividade térmica com o grau de saturação, porosidade e índice de vazios de uma areia

\begin{tabular}{|c|c|c|c|c|}
\hline Material & Índice de vazios & Porosidade & Grau de saturação & $\boldsymbol{k}\left(\mathbf{W} \cdot \mathbf{m}^{-\mathbf{1}} \cdot \mathbf{K}^{-\mathbf{1}}\right)$ \\
\hline \multirow{4}{*}{ Areia } & 0,80 & 0,45 & 0,015 & 0,90 \\
\cline { 2 - 5 } & 0,87 & 0,47 & 0,188 & 1,35 \\
\cline { 2 - 5 } & 0,78 & 0,44 & 0,311 & 1,75 \\
\cline { 2 - 5 } & 0,81 & 0,45 & 0,480 & 2,10 \\
\cline { 2 - 5 } & 0,79 & 0,44 & 0,715 & 2,40 \\
\cline { 2 - 5 } & 0,81 & 0,45 & 1,000 & 2,65 \\
\hline
\end{tabular}

Fonte: Autor, adaptado de Sánchez et al., 2015

Variaram-se também os valores de temperatura do fluido circulante na entrada dos tubos de PEAD. Dado que a escolha de tal parâmetro em situações de projeto depende do sistema de bomba de calor e de condições climáticas, foram simulados os seguintes valores: $293,1 \mathrm{~K}\left(20{ }^{\circ} \mathrm{C}\right), 303,1 \mathrm{~K}\left(30{ }^{\circ} \mathrm{C}\right), 313,1 \mathrm{~K}\left(40{ }^{\circ} \mathrm{C}\right), 323,1 \mathrm{~K}\left(50{ }^{\circ} \mathrm{C}\right), 333,1 \mathrm{~K}(60$ $\left.{ }^{\circ} \mathrm{C}\right), 343,1 \mathrm{~K}\left(70{ }^{\circ} \mathrm{C}\right), 353,1 \mathrm{~K}\left(80{ }^{\circ} \mathrm{C}\right), 363,1 \mathrm{~K}\left(90{ }^{\circ} \mathrm{C}\right)$ e $373,1 \mathrm{~K}\left(100{ }^{\circ} \mathrm{C}\right)$. Vale ressaltar que, para o ensaio TRT, no instante equivalente a $200 \mathrm{~h}$, a temperatura de entrada era de $314,3 \mathrm{~K}\left(41,1^{\circ} \mathrm{C}\right)$. 


\section{RESULTADOS E DISCUSSÕES}

Nesta seção são apresentados e discutidos os resultados obtidos pelas simulações numéricas e, quando possível, são feitas comparações com resultados experimentais. A partir das simulações foram computados os valores de taxa de transferência de calor total e temperatura média por interface, além do diâmetro de influência térmico, isto é, a distância medida a partir do centro da estaca, na metade de seu comprimento, até o ponto do solo cuja temperatura é alterada em $1 \mathrm{~K}$ com relação à sua temperatura na condição não perturbada

\subsection{VALIDAÇÃO}

As simulações desenvolvidas com os parâmetros e condições explicitados na Tabela 4.4 (que definem o cenário base), visando a validação do modelo numérico proposto, forneceram resultados coerentes com os experimentais, com diferenças entre as temperaturas de saída medidas no experimento e obtidas numericamente inferiores a 0,3 K. Em Sánchez et al. (2015) tal diferença foi de 0,5 K. A Tabela 5.1 compara os valores experimentais e numéricos de temperatura de saída nos instantes simulados em regime estacionário. As diferenças entre as temperaturas de saída experimental e numérica referentes aos instantes $50 \mathrm{~h}, 100 \mathrm{~h}$ e $200 \mathrm{~h}$ foram inferiores ao limite de erro dos sensores PT $-100( \pm 0,5 \mathrm{~K})$. Os valores de desvio padrão para as temperaturas experimentais foram calculados considerando-se, em intervalo de 1 minuto, as temperaturas anteriores e posteriores às temperaturas medidas em ensaio TRT para os instantes $50 \mathrm{~h}, 100 \mathrm{~h}$ e 200

h. A Tabela A.1 (Apêndice A) apresenta todas as etapas dos cálculos desenvolvidos.

Tabela 5.1 - Comparação dos valores experimentais e numéricos de temperatura de saída do fluido

\begin{tabular}{|c|c|c|c|c|}
\hline Instante (h) & Ts,exp (K) & Ts,num (K) & Desvio (K) & Incerteza combinada (K)* \\
\hline 50 & 311,7 & 311,6 & 0,1 & $\pm 0,3$ \\
\hline 100 & 312,5 & 312,7 & $-0,2$ & $\pm 0,3$ \\
\hline 200 & 313,6 & 313,8 & $-0,2$ & $\pm 0,3$ \\
\hline \multicolumn{5}{r}{ Ts,exp = temperatura de saída do fluido medida no experimento, Ts,num = temperatura de saída }
\end{tabular}

do fluido calculada numericamente. *O cálculo de incerteza combinada encontra-se no Apêndice A1. 
A Figura 5.1 apresenta os valores de taxa de transferência de calor total $(\dot{q})$ obtidos numericamente para os instantes de tempo simulados nas interfaces: tubo/concreto, concreto/solo, solo/topo e superfície solo limite (raio de $3 \mathrm{~m}$ medido a partir do centro da estaca). As taxas na interface concreto/solo aumentaram do instante $50 \mathrm{~h}(420,042 \mathrm{~W})$ até o instante 200 h (474,632 W), mostrando que o sistema geotérmico ainda não tinha atingido totalmente as condições de estabilidade às $50 \mathrm{~h}$ de ensaio. Espera-se que as trocas de calor em tempos maiores que $200 \mathrm{~h}$ tendam a valores constantes, o que poderia ser confirmado por uma simulação com tempo maior do que $200 \mathrm{~h}$ ou com simulações em regime transiente.

As taxas de transferência de calor na interface tubo/concreto são ligeiramente superiores às da interface concreto/solo (no instante $200 \mathrm{~h}$ a taxa de transferência de calor na interface tubo/concreto é de 479,148 W e na interface concreto/solo é de 474,632 W). A superfície solo limite apresenta taxas muito superiores (723,336 W no instante $200 \mathrm{~h}$ ), devido ao calor absorvido do ambiente acima do sistema solo-estaca, onde a temperatura do ar é 313,1 K. Essa hipótese é comprovada pelas taxas de transferência de calor total da interface solo topo, que são equivalentes à diferença entre as taxas das interfaces tubo/concreto e solo limite. Este fenômeno foi observado em todas as etapas do estudo paramétrico. Em Ferreira (2017) observa-se também a influência da temperatura ambiente nos ensaios, uma vez que se registram de picos nas temperaturas de entrada e saída do fluido.

Figura 5.1 -Taxa de transferência de calor por interface em função do tempo

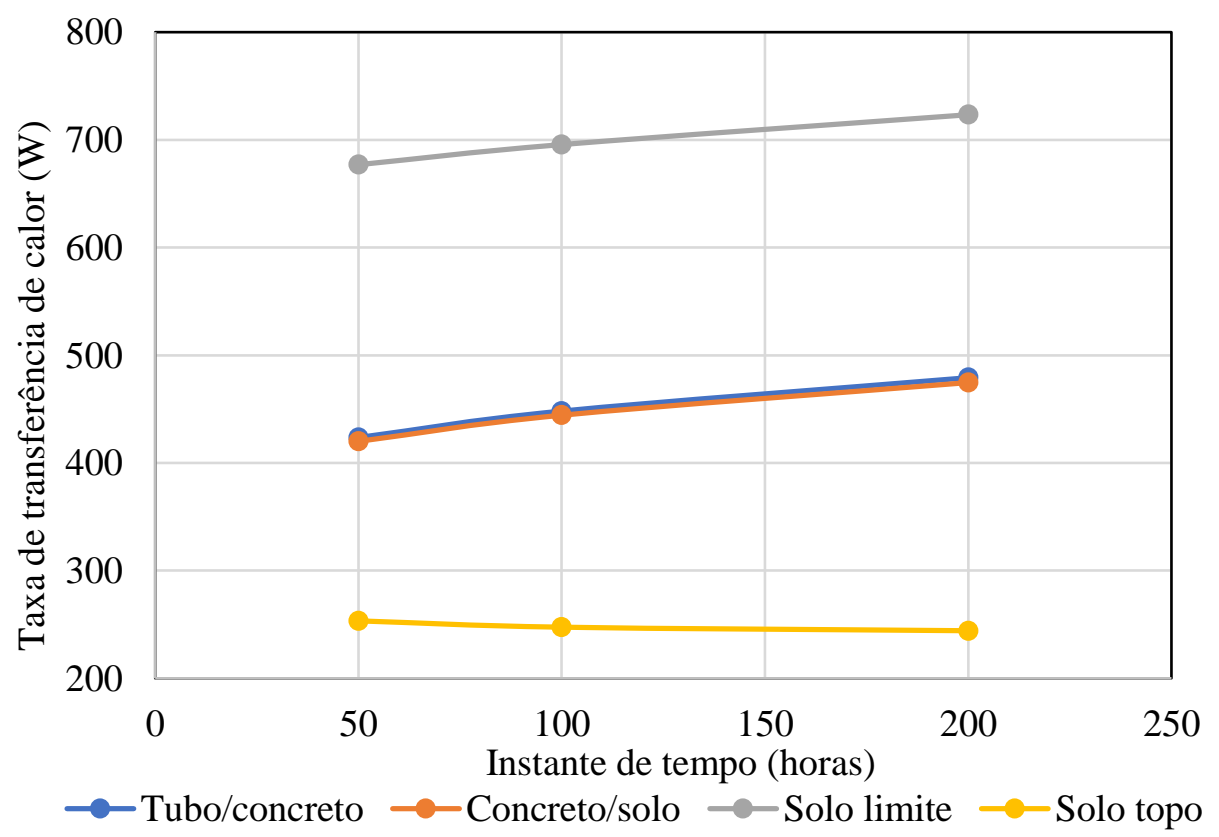


A distribuição de temperaturas médias ao longo do tempo nas interfaces do sistema geotérmico é apresentada na Figura 5.2. Em cada interface, as temperaturas apresentaram um pequeno aumento do instante $50 \mathrm{~h}$ até o instante $200 \mathrm{~h}$ (na interface concreto/solo, respectivamente, de 304,7 K para 305,6 K). A temperatura na superfície solo limite é imposta pela condição de contorno apresentada no item 4.3.6.1, constante e igual a $297,3 \mathrm{~K}$.

Figura 5.2 - Variação da temperatura média por interface em função do tempo

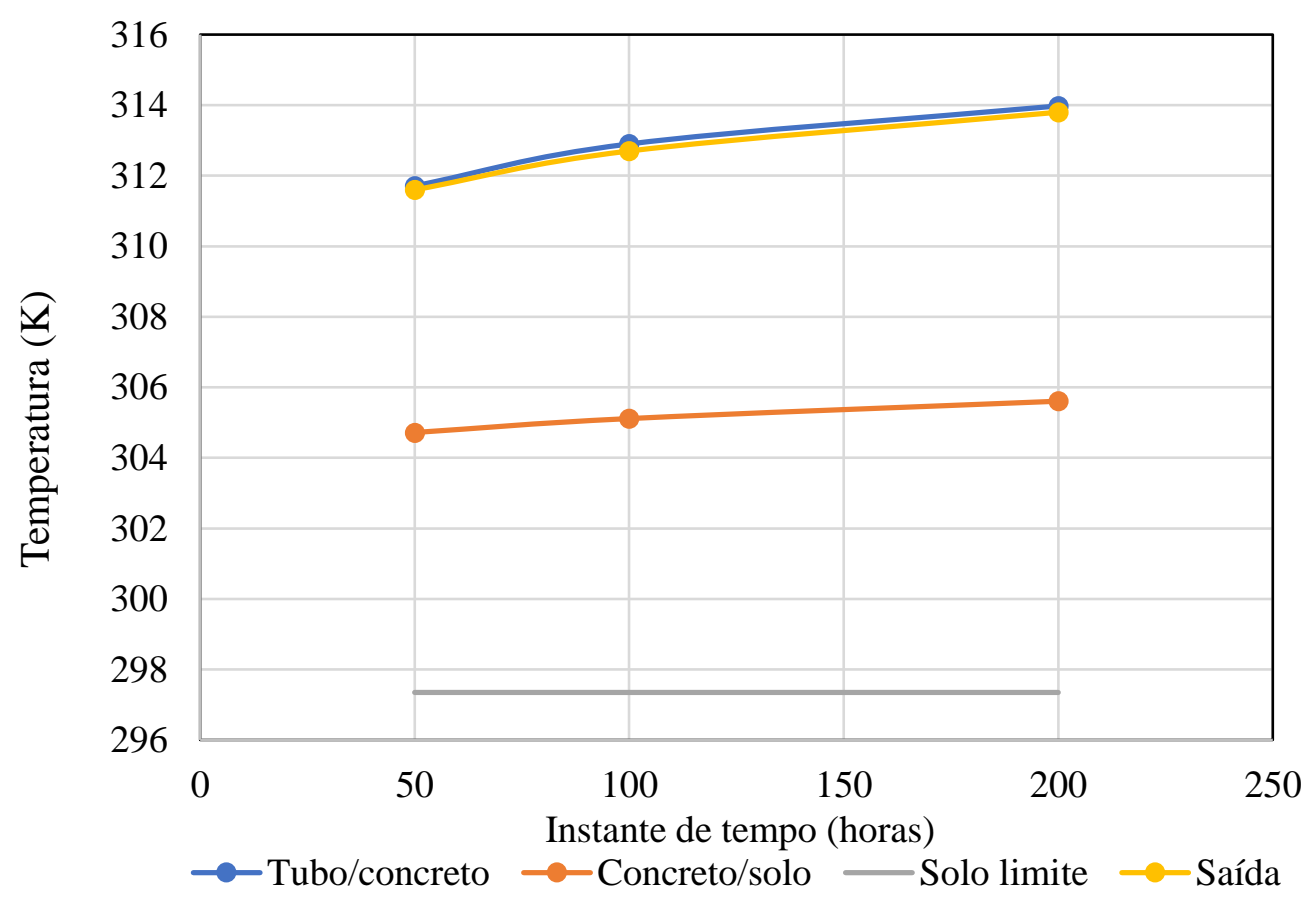

Observa-se que a temperatura inicial de todo o sistema era igual a $297,3 \mathrm{~K}$. Portanto, nas primeiras $50 \mathrm{~h}$ a temperatura subiu desse valor a 312,0 K na saída do tubo e na interface tubo-concreto, e a $304,7 \mathrm{~K}$ na interface solo-concreto.

A Figura 5.3 mostra, a partir de um plano XY localizado na profundidade de 7,5 m, a distribuição radial de temperaturas no sistema geotérmico para o instante $200 \mathrm{~h}$. Nota-se a diminuição das temperaturas conforme aumenta-se a distância radial a partir do centro da estaca até que, na superfície solo limite, a temperatura média é igual à temperatura não perturbada do solo (297,3 K).

A Figura 5.4 ilustra, a partir da distribuição de temperaturas no plano XZ (situado no centro da estaca), a zona de influência térmica para o instante $200 \mathrm{~h}$, quando o diâmetro de influência térmica é de 4,55 m. Ensaios TRT de diâmetro 0,45 m e comprimento $20 \mathrm{~m}$ 
(estaca) reportados por Ozudogru e Olgun (2014) em solo arenoso mostram, de forma analítica, raio de influência térmica de 2,5 $\mathrm{m}$ a partir da parede.

Finalmente, a Figura 5.5 apresenta a variação do diâmetro de influência térmica ao longo do tempo. Percebe-se um pequeno aumento das zonas de influência térmica (de $4,45 \mathrm{~m}$ no instante $50 \mathrm{~h}$ a 4,55 m no instante $200 \mathrm{~h}$ ), indicador de que o sistema geotérmico tende a atingir condições de equilíbrio. Mais uma vez, seria interessante comprovar essa percepção simulando-se um tempo maior ou com simulações em regime transiente.

Figura 5.3 - Distribuição de temperaturas no plano XY e na profundidade de 7,5 $\mathrm{m}$ do sistema geotérmico para o instante $200 \mathrm{~h}$

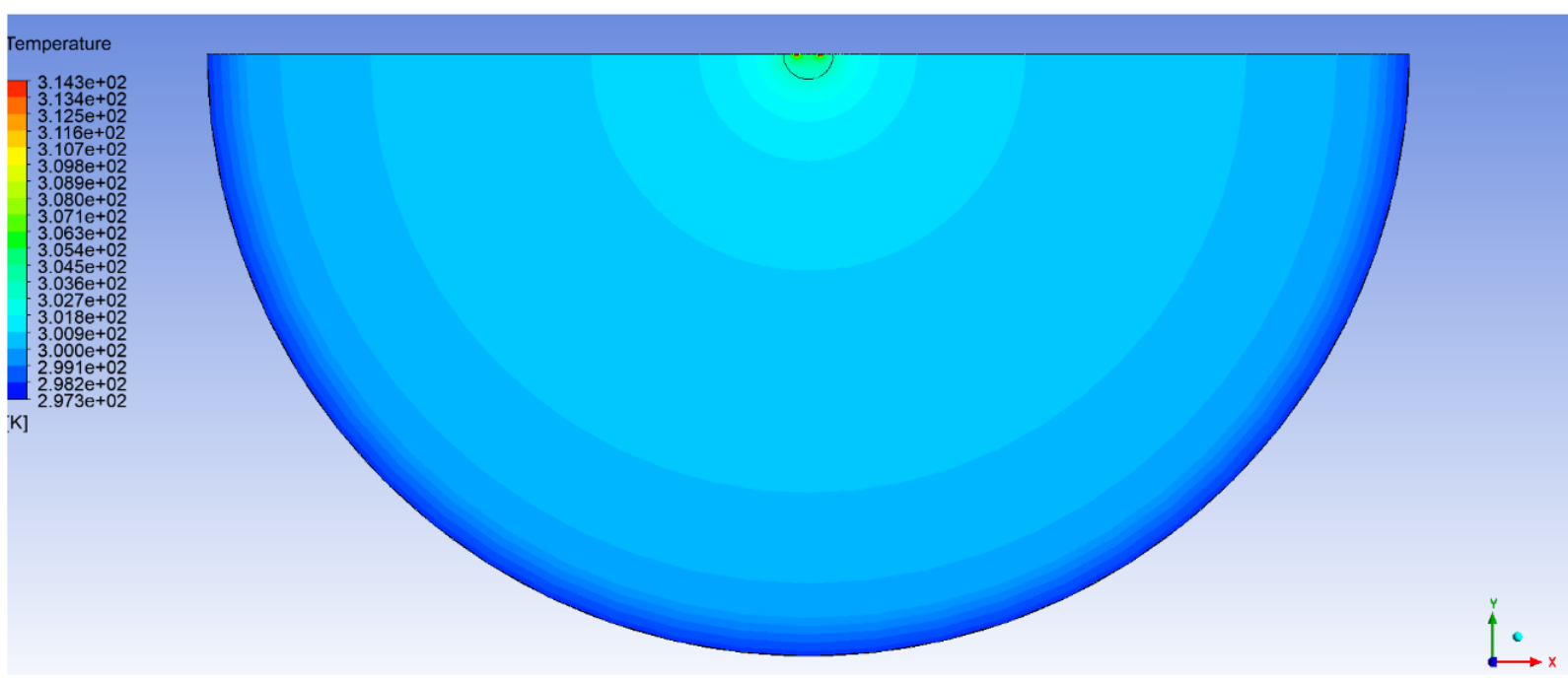

Figura 5. 4 - Zona de influência térmica no instante 200 h
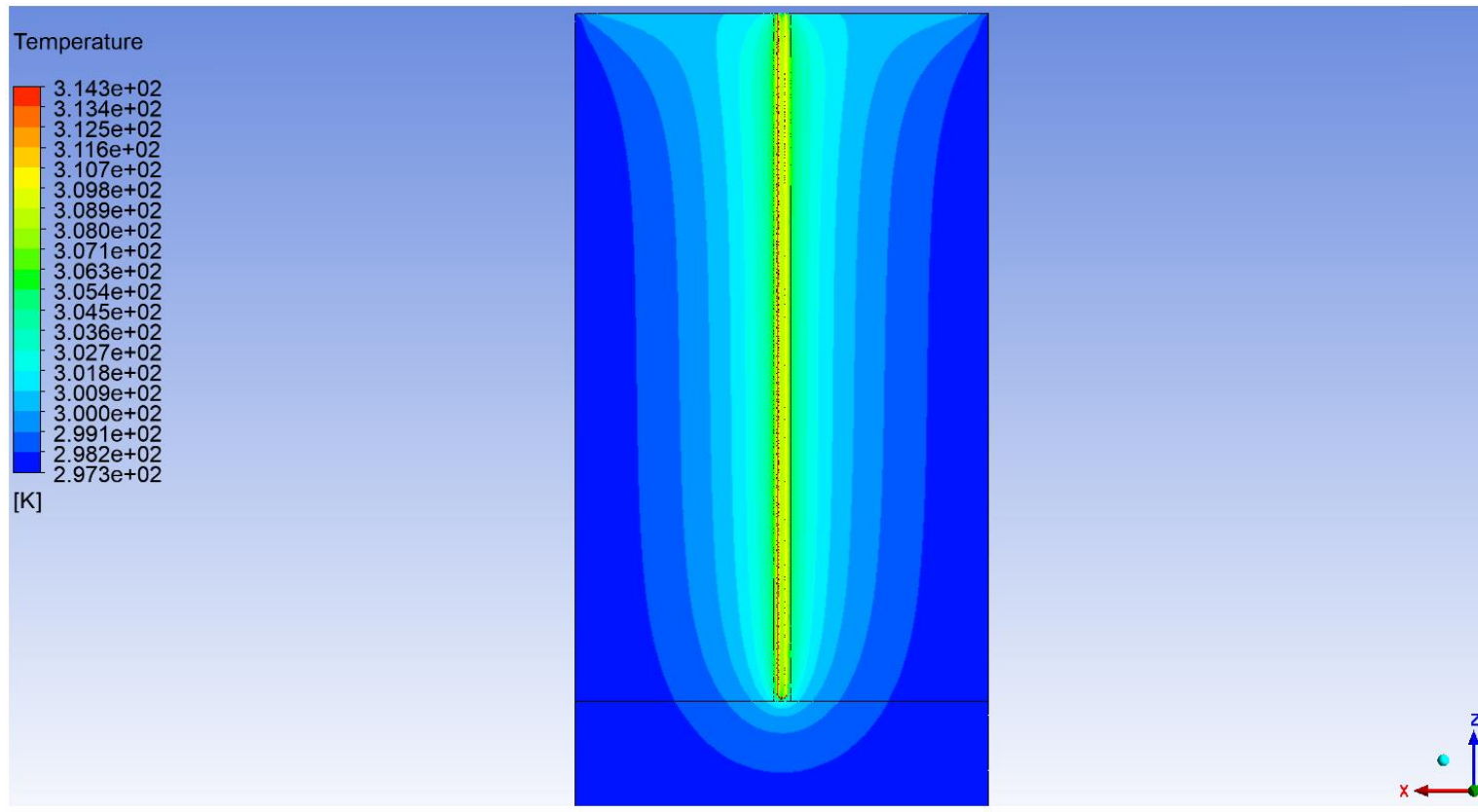
Figura 5.5 - Diâmetro de influência térmica em função do tempo

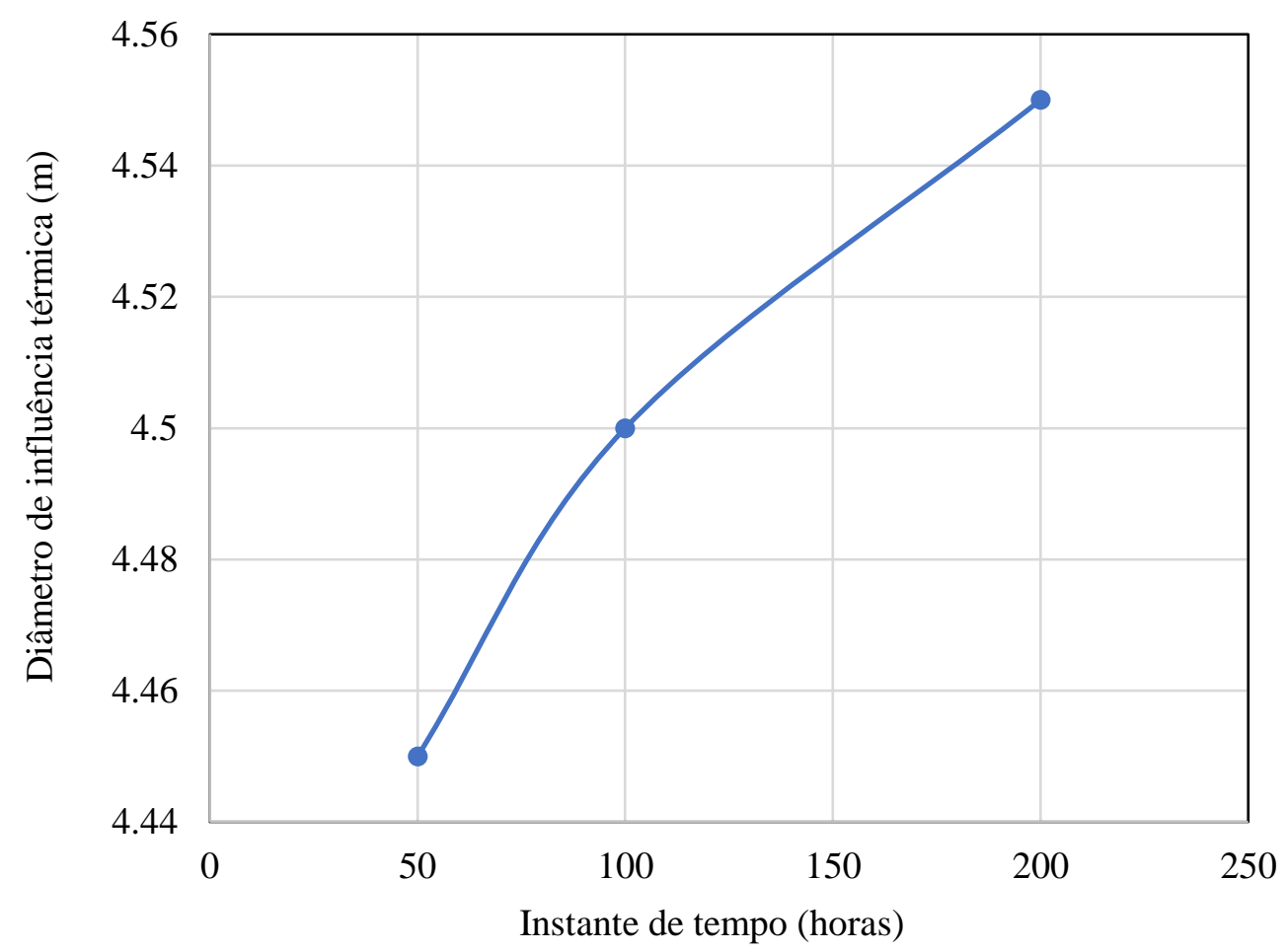

Os resultados apresentados permitem concluir que as simulações numéricas realizadas refletem o comportamento do fenômeno físico experimental. Portanto, a etapa de validação evidencia que o modelo numérico elaborado é confiável para a realização de estudos paramétricos.

\subsection{ESTUDO DE CONVERGÊNCIA DE MALHA}

Realizou-se um estudo de convergência de malha na região interna dos tubos, por onde circula o fluido, a fim de verificar-se a influência do refinamento progressivo da malha na precisão dos resultados. Esta região, onde os fenômenos envolvidos são mais complexos, determina a dissipação de calor em todo o sistema geotérmico.

Para isso, foram usadas as condições de contorno referentes ao instante $200 \mathrm{~h}$, em regime estacionário. Foram desprezadas as demais geometrias, atribuindo-se à interface tubo/concreto a temperatura 314,0 K (obtida nas simulações de validação para o instante 200 h), representativa da interação dos tubos e fluido circulante com o restante do sistema geotérmico.

A Figura 5.6 apresenta os resultados obtidos no estudo de convergência de malha. Nota-se que, ao aumentar o número de elementos tetraédricos na região do fluido de 
551.765 para 7.854.123, há um erro percentual de $0,07 \%$ na temperatura. Portanto, a realização de simulações menos refinadas, com 551.765 elementos, garante resultados confiáveis ao mesmo tempo em que reduz consideravelmente o custo computacional. Um diagrama que exibisse temperaturas correspondentes a malhas ainda menos refinadas evidenciaria a tendência de estabilização da curva.

Figura 5.6 - Estudo de convergência de malha para a região do fluido circulante

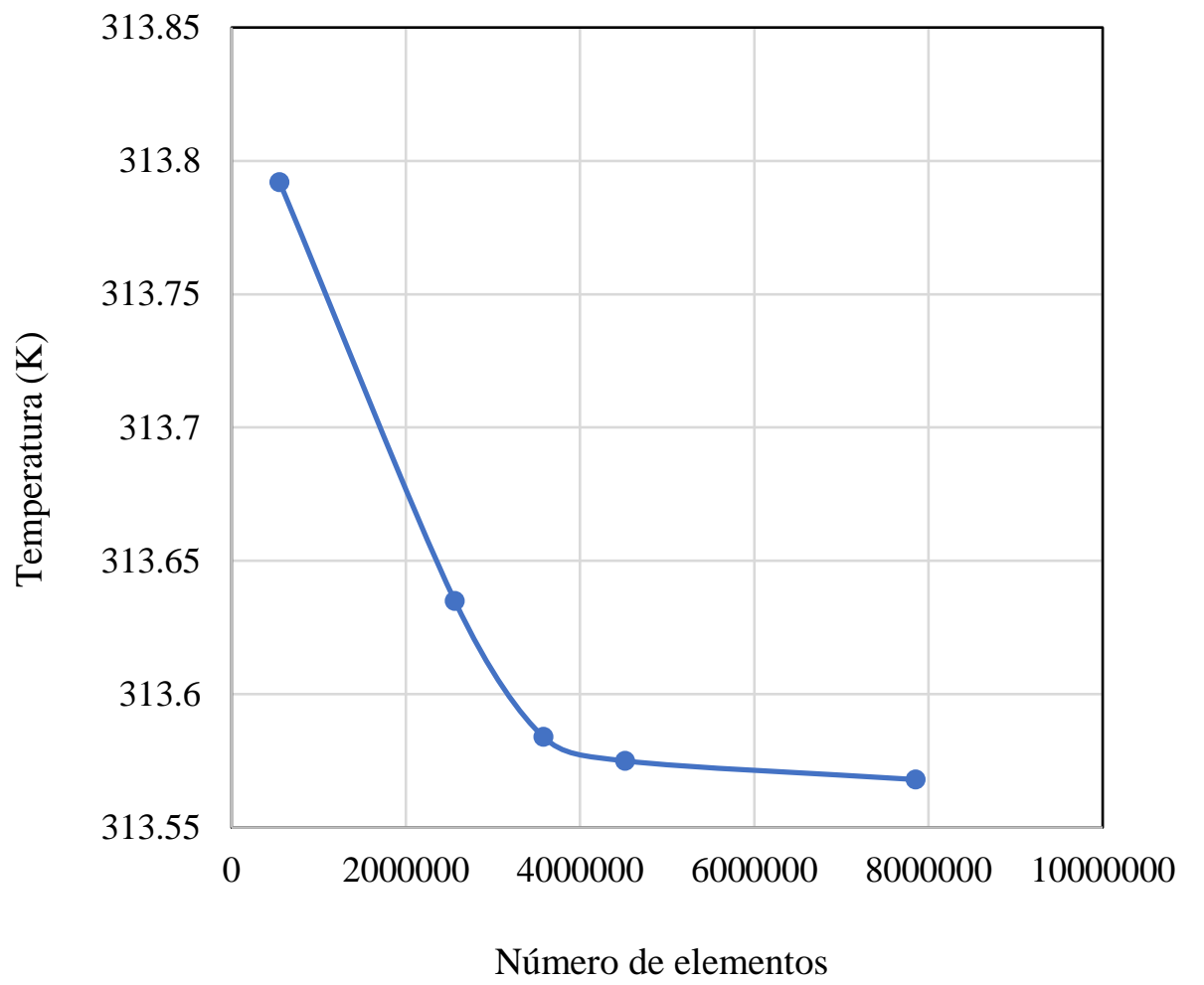

\subsection{VARIAÇÃO DO COMPRIMENTO DA ESTACA}

Foram simulados os comprimentos (L) de estaca $5 \mathrm{~m}, 10 \mathrm{~m}, 15 \mathrm{~m}$ (comprimento original da estaca), $20 \mathrm{~m}, 30 \mathrm{~m}$ e $50 \mathrm{~m}$. Inicialmente, observa-se que o aumento da área trocadora de calor entre a estaca e o solo ocasiona o aumento dos valores de taxas de transferência de calor total nas interfaces tubo/concreto, concreto/solo e solo limite. A Figura 5.7 mostra os valores totais de taxas de transferência de calor total por interface do sistema geotérmico. Percebe-se o crescimento linear das taxas de transferência de calor em função do comprimento da estaca. Destacam-se, para a interface concreto/solo, os valores de comprimento de estaca extremos $(5 \mathrm{~m}$ e $50 \mathrm{~m})$ e intermediário (15 m, que é o 
comprimento original da estaca geotérmica) e suas respectivas taxas de transferência de calor: $151,63 \mathrm{~W}(\mathrm{~L}=5 \mathrm{~m}), 479 \mathrm{~W}(\mathrm{~L}=10 \mathrm{~m}), 148 \mathrm{~W}(\mathrm{~L}=15 \mathrm{~m})$ e $1646,29 \mathrm{~W}(\mathrm{~L}=50$ m). Em Thompson III (2013) observa-se também incrementos lineares das taxas de transferência de calor total em função do comprimento da estaca.

Figura 5.7 - Taxa de transferência de calor em função do comprimento da estaca geotérmica, por interface

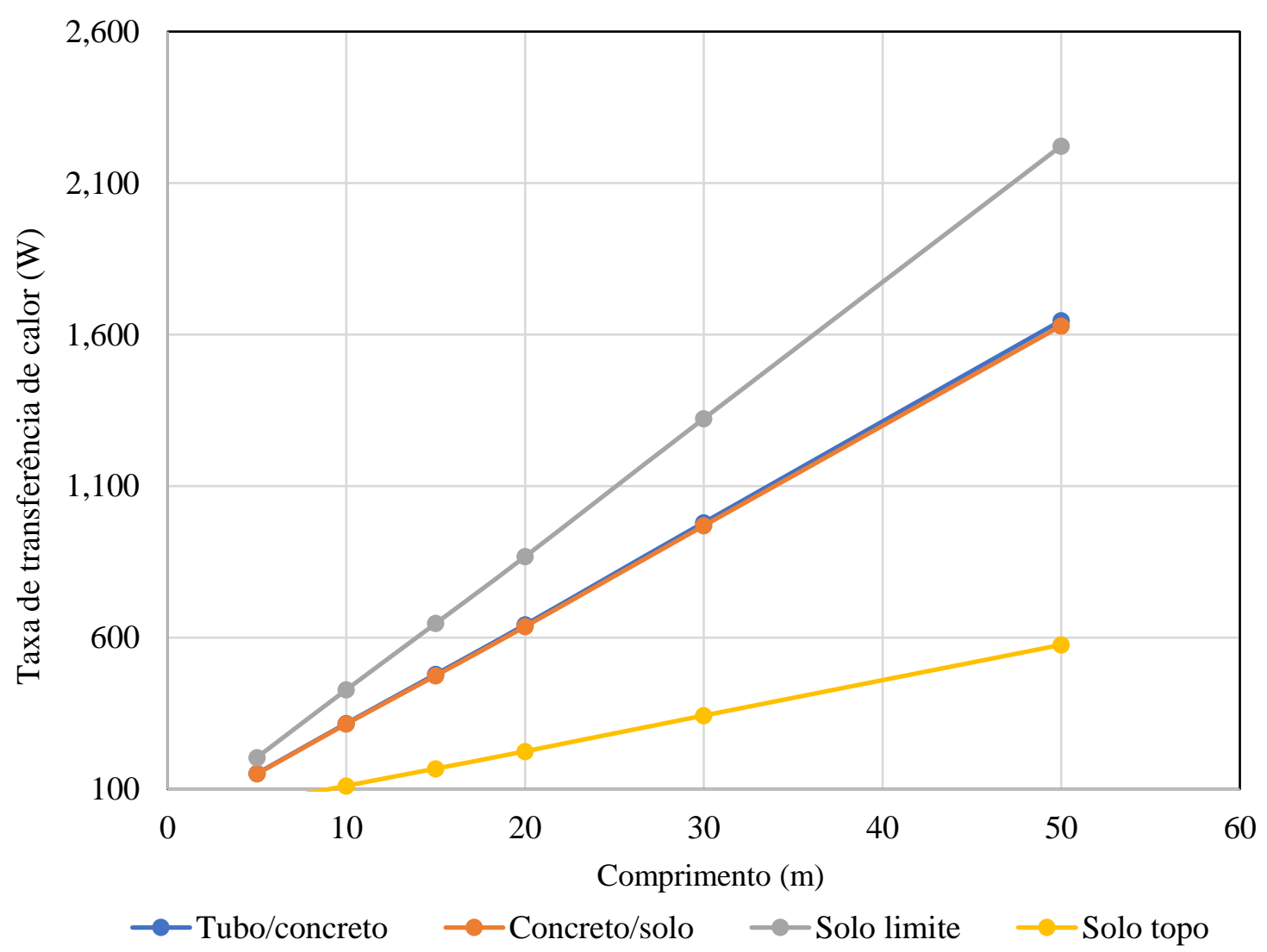

A variação do comprimento da estaca pouco afeta os valores de taxa de transferência de calor normalizados pelo comprimento da estaca geotérmica $\left(\dot{Q}_{L}\right)$, que são aproximadamente constantes, como se nota na Figura 5.8. Portanto, o aumento do comprimento da estaca propicia maiores trocas de calor totais, mas melhora a eficiência térmica da estaca por unidade de comprimento em apenas $8 \%$ quando o comprimento da estaca aumenta de $5 \mathrm{~m}$ para $50 \mathrm{~m}$. Destacam-se os valores de troca de calor normalizada para os comprimentos $5 \mathrm{~m}, 15 \mathrm{~m}$ e $50 \mathrm{~m}$ na interface concreto/solo: 30,08 W/m, 31,65 $\mathrm{W} / \mathrm{m}$ e $32,57 \mathrm{~W} / \mathrm{m}$, respectivamente. Orozco (2016) apresenta comportamentos similares ao normalizar as taxas de transferência de calor total pelo comprimento da estaca. 
Figura 5.8 - Taxa de transferência de calor normalizada pelo comprimento da estaca em função do comprimento da estaca geotérmica, por interface

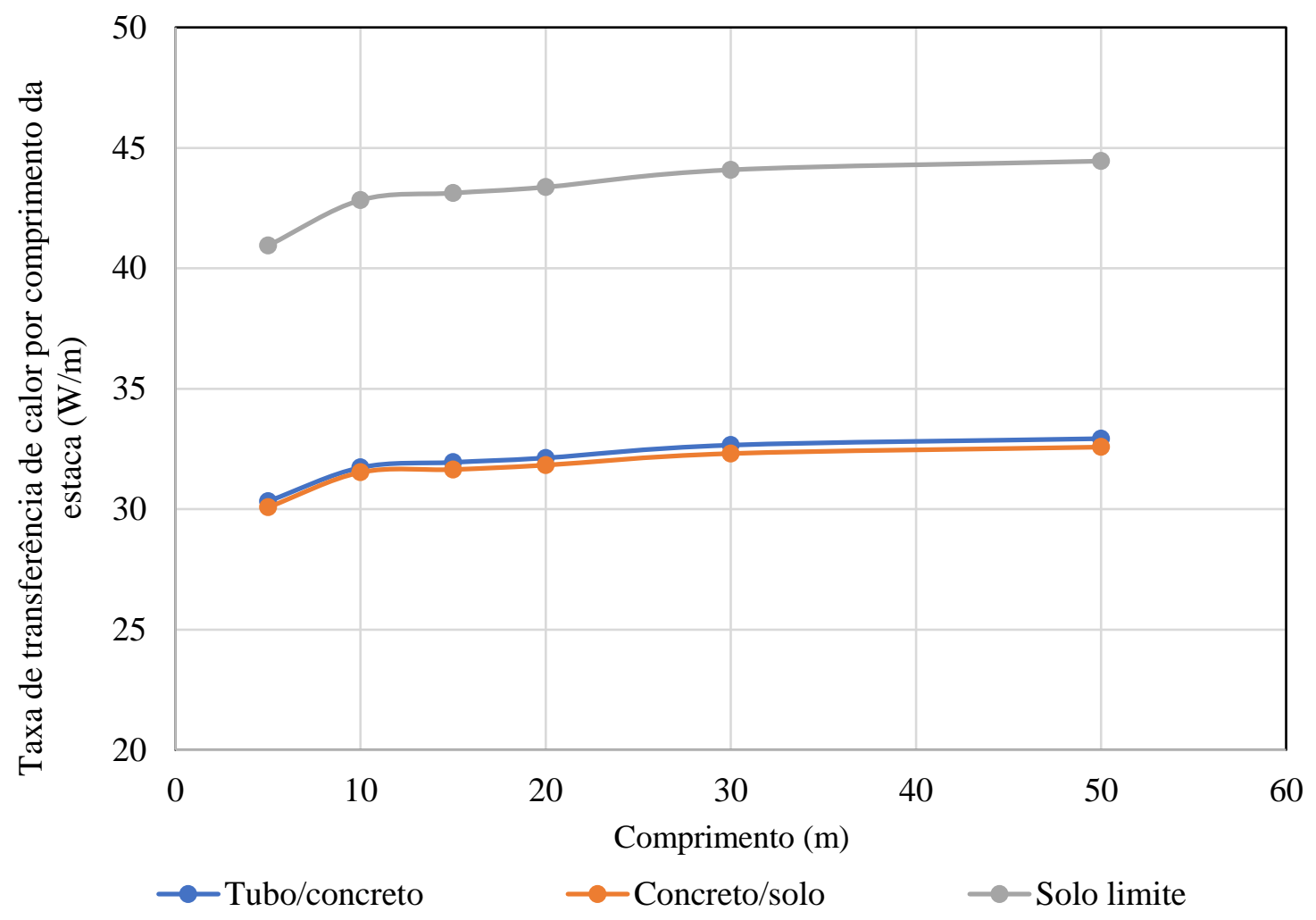

Um comportamento similar pode ser observado ao se normalizarem as taxas de transferência de calor pela área da superfície da estaca (área da superfície lateral somada à área de sua base) $\left(\dot{Q}_{S}\right)$. A Figura 5.9 denota que a taxa de transferência de calor normalizada pela área da superfície da estaca aumenta em cerca de $10 \%$ quando o comprimento da estaca aumenta de $5 \mathrm{~m}$ para $50 \mathrm{~m}$. O aumento do comprimento da estaca e, consequentemente da área de sua superfície lateral, propicia maiores trocas de calor totais, mas não melhora significativamente a eficiência térmica da estaca por unidade de área. Destacam-se os valores de troca de calor normalizada por unidade de área da superfície da estaca considerando os comprimentos $5 \mathrm{~m}, 15 \mathrm{~m}$ e $50 \mathrm{~m}$ na interface concreto/solo: $26,88 \mathrm{~W} / \mathrm{m}^{2}, 28,42 \mathrm{~W} / \mathrm{m}^{2}$ e $29,57 \mathrm{~W} / \mathrm{m}^{2}$, respectivamente. 
Figura 5.9 - Taxa de transferência de calor normalizada pela área da superfície da estaca em função do comprimento da estaca geotérmica, por interface

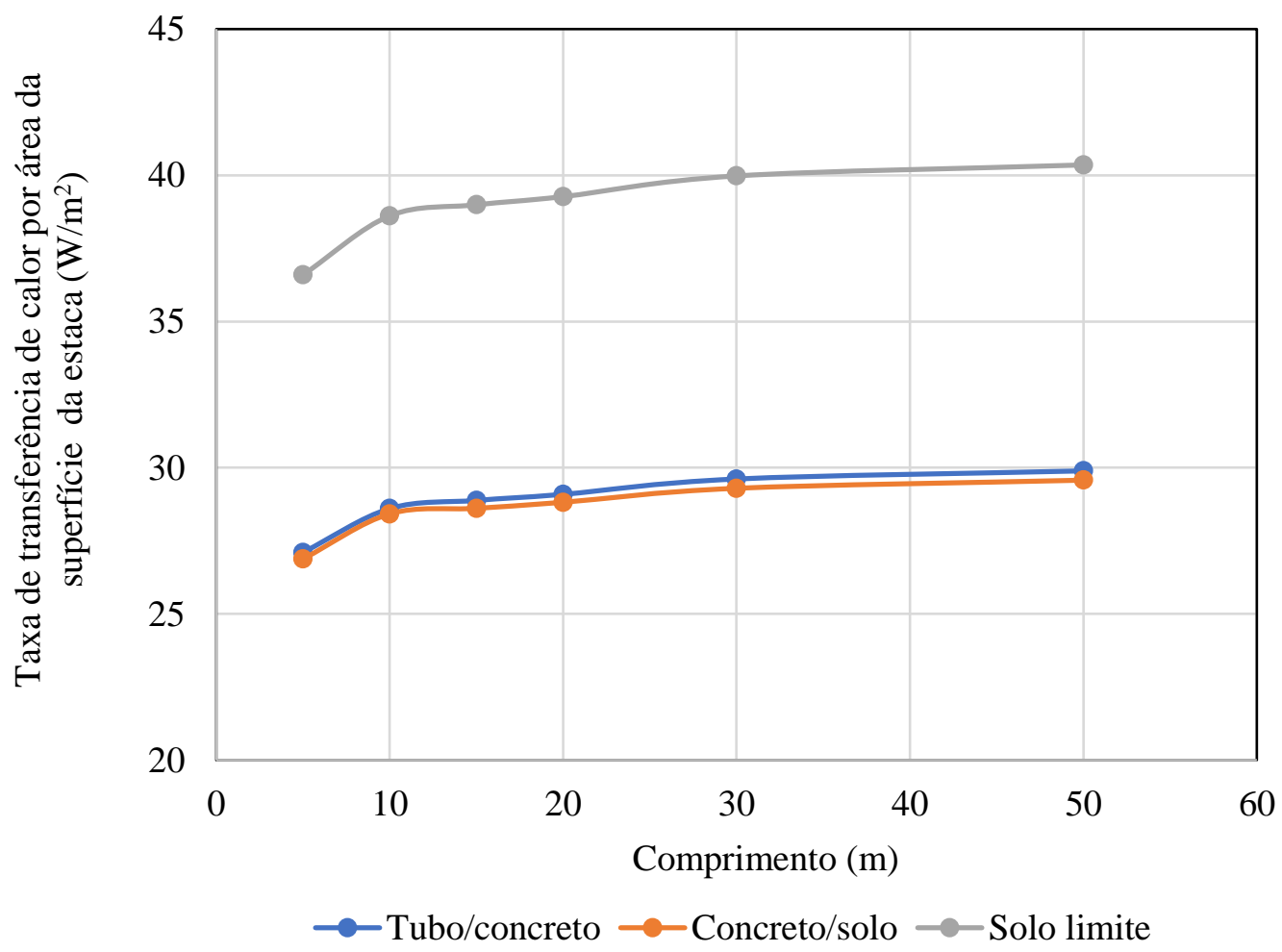

A distribuição de temperaturas médias nas superfícies do sistema geotérmico em função do comprimento da estaca é apresentada na Figura 5.10. As temperaturas não variam com o comprimento da estaca, com exceção da interface concreto/solo, onde se observa ligeiro aumento de temperatura com o aumento do comprimento. Na superfície concreto/solo são observados os valores de temperatura, para os comprimentos $5 \mathrm{~m}, 15$ m e 50 m: 304,9 K, 305,3 K e 305,8 K, respectivamente. Além disso, as temperaturas diminuem conforme a distância radial a partir do centro da estaca aumenta até que, na superfície solo limite, a temperatura média é igual à temperatura não perturbada do solo (297,33 K).

A diferença entre as temperaturas médias do fluido circulante nas posições de entrada e saída dos tubos de PEAD para os comprimentos 5 m, 15 m e 50 m é desprezível. 
Figura 5.10 - Temperatura média em função do comprimento da estaca, por interface

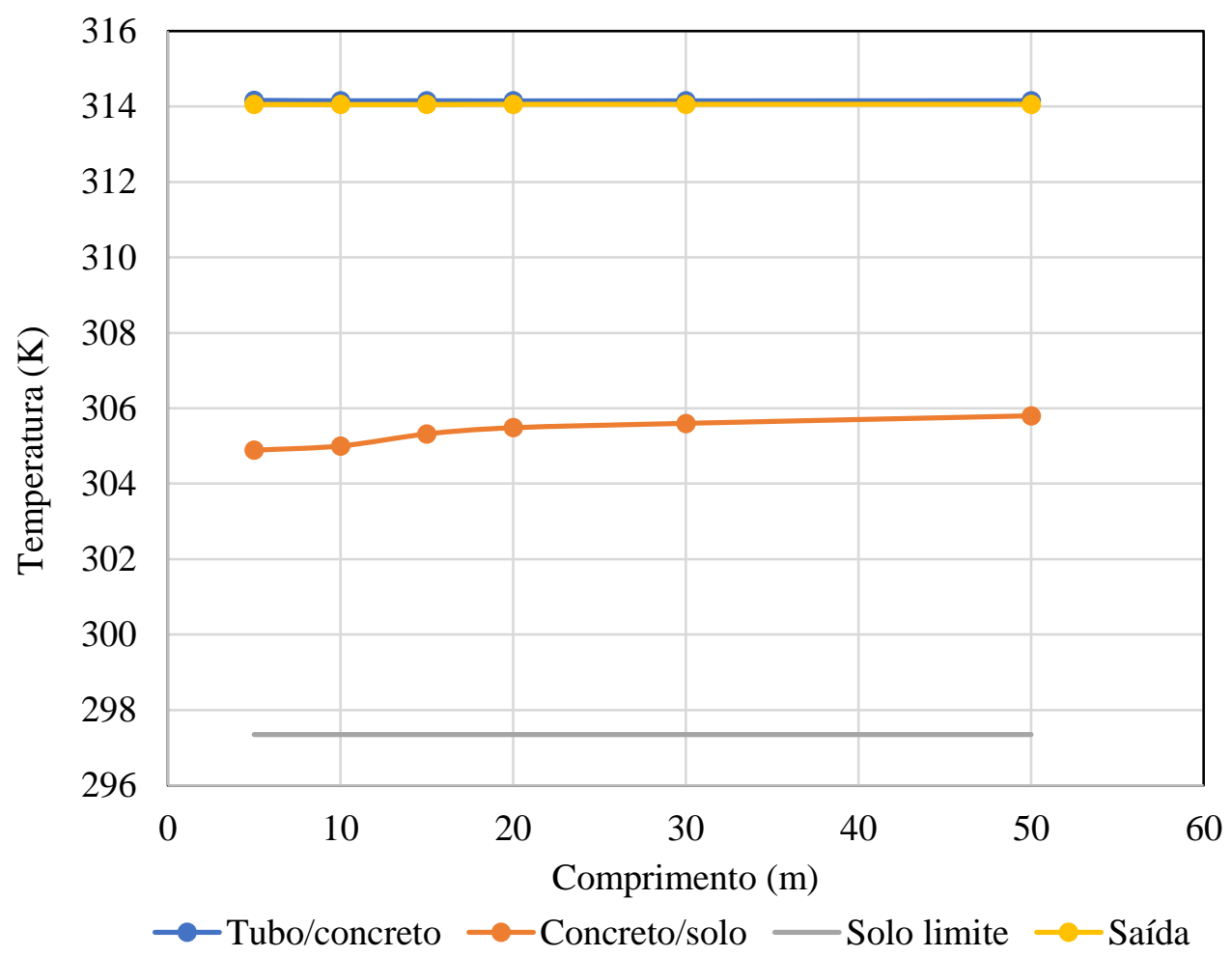

\subsection{VARIAÇÃO DO DIÂMETRO DA ESTACA}

Foram simulados os diâmetros (D) de estaca 0,20 m, 0,35 m (diâmetro original da estaca), 0,50 m, 0,70 m, 0,90 m e 1,10 m. Notou-se que o aumento do diâmetro, portanto da área trocadora de calor entre estaca e solo, permite o aumento da taxa de transferência de calor nas interfaces tubo/concreto, concreto/solo e solo limite. A Figura 5.11 mostra o crescimento linear da taxa de transferência de calor em função do diâmetro da estaca. Na interface concreto/solo, para os diâmetros $0,20 \mathrm{~m}, 0,35 \mathrm{~m}$ e 1,10 m, os valores de taxa de transferência de calor são: 256,74 W, 474,65 W e 1533,45 W, respectivamente.

Ao se normalizar a taxa de transferência de calor pelo comprimento da estaca, observa-se que o comportamento linear em função do diâmetro se mantém, conforme a Figura 5.12. Isso se deve ao fato de que, por unidade de comprimento, há aumento da área disponível para trocas térmicas com o aumento do diâmetro, apesar do comprimento ser mantido constante. Para os diâmetros 0,20 m, 0,35 m e 1,10 m, na interface concreto/solo, destacam-se os valores de taxa de transferência de calor normalizada pelo comprimento da estaca: $17,12 \mathrm{~W} / \mathrm{m}, 31,64 \mathrm{~W} / \mathrm{m}$ e $102,23 \mathrm{~W} / \mathrm{m}$, respectivamente. 
Figura 5.11 - Taxa de transferência de calor em função do diâmetro da estaca geotérmica, por interface

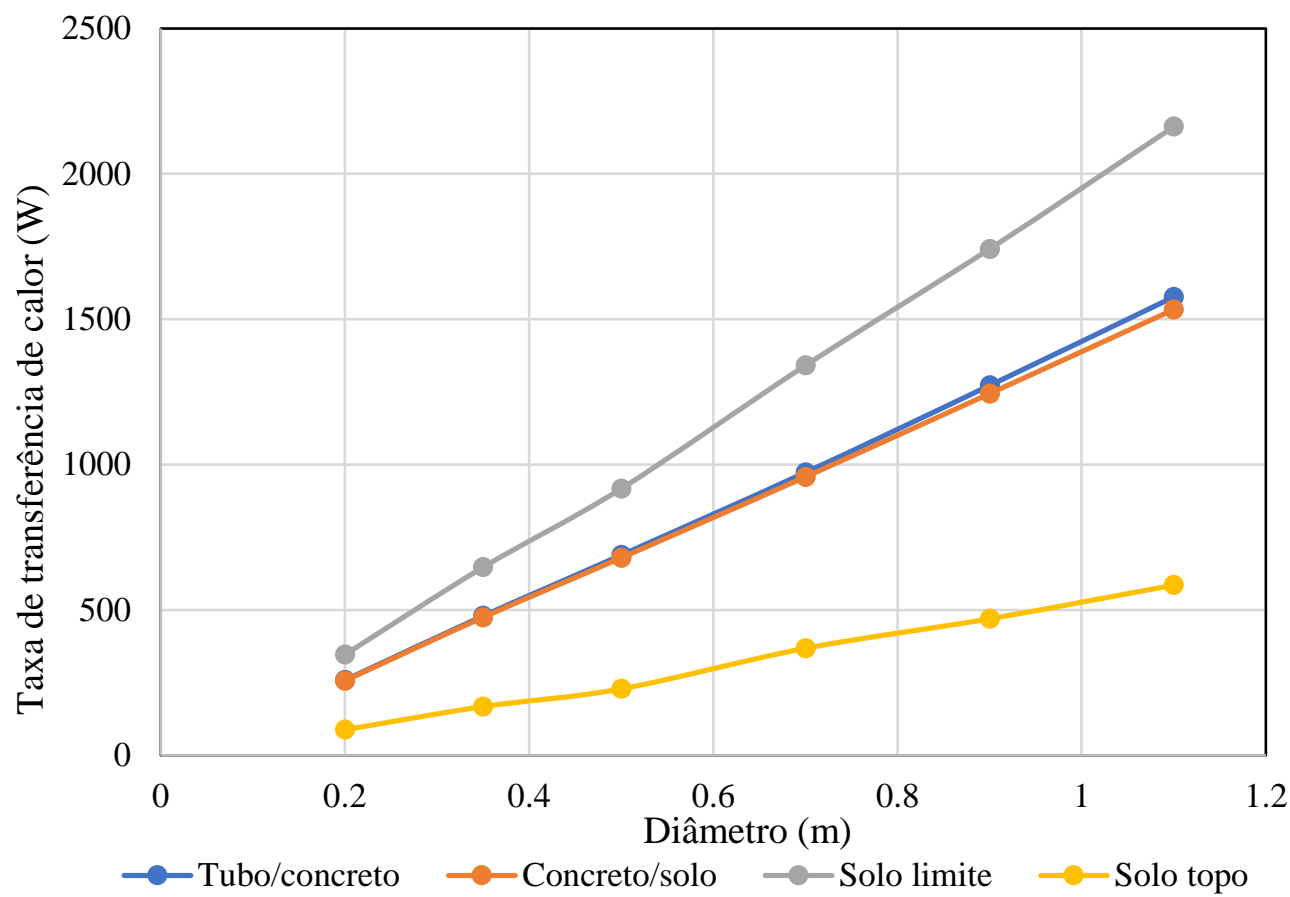

Figura 5.12 - Taxa de transferência de calor normalizada pelo comprimento em função do diâmetro da estaca geotérmica, por interface

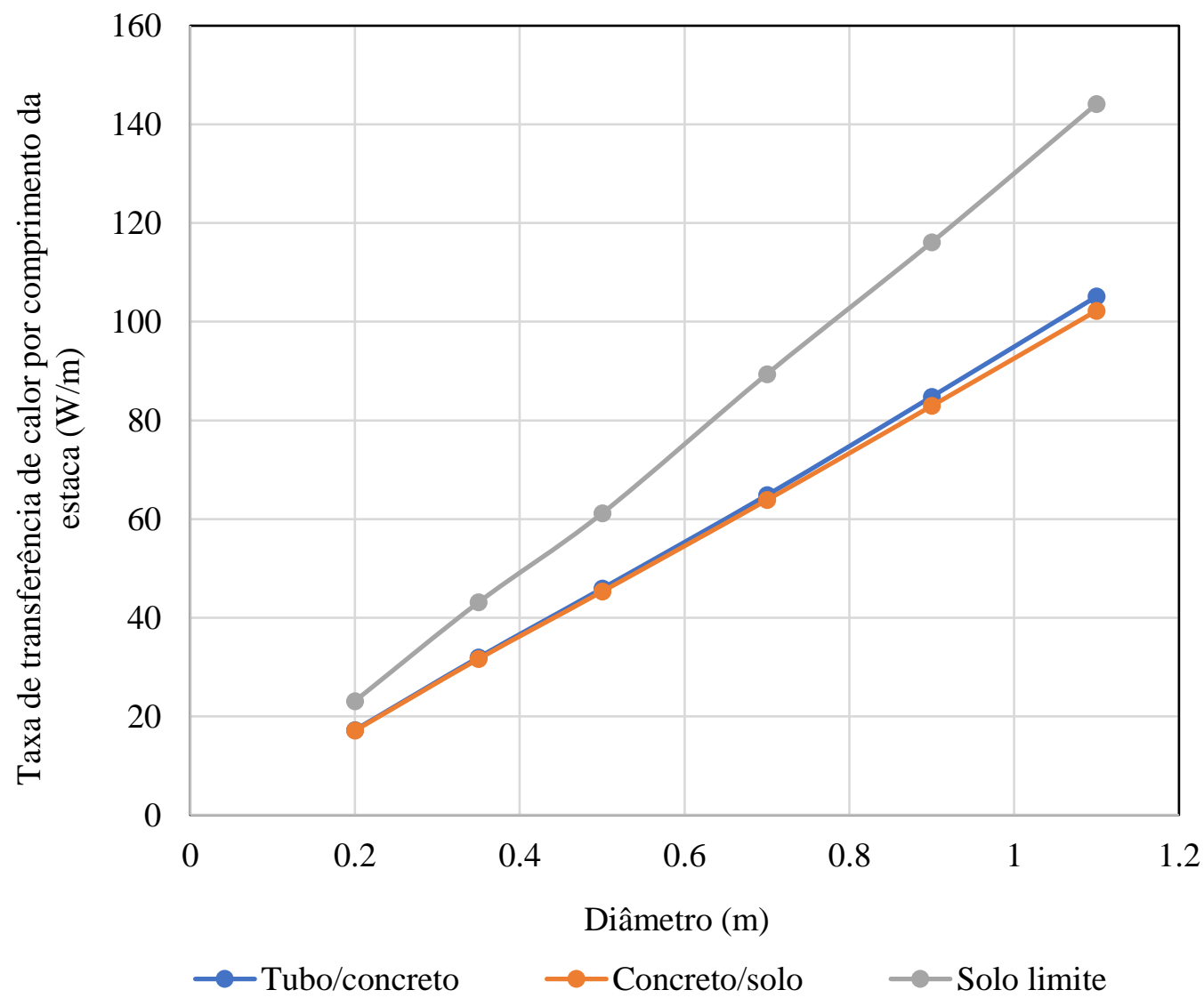


A Figura 5.13 apresenta os valores de taxa de transferência de calor normalizados pela área da superfície da estaca (área da superfície lateral somada à área de sua base) em função de seu diâmetro. Na interface concreto/solo, a taxa de transferência de calor normalizada pela área da superfície da estaca aumenta em 7 \% quando o diâmetro aumenta de 0,20 m a 1,10 m. Portanto, o aumento do diâmetro da estaca propicia maiores trocas de calor totais, mas a eficiência térmica da estaca por unidade de área de sua superfície é pouco alterada. Destacam-se os valores de troca de calor normalizada pela área da superfície da estaca para os diâmetros $0,20 \mathrm{~m}, 0,35 \mathrm{~m}$ e $1,10 \mathrm{~m}$ na interface concreto/solo: $27,15 \mathrm{~W} / \mathrm{m}^{2}, 28,61 \mathrm{~W} / \mathrm{m}^{2}$ e $29,05 \mathrm{~W} / \mathrm{m}^{2}$, respectivamente. Percebe-se um progressivo aumento na distância entre as curvas referentes às interfaces tubo/concreto e concreto/solo, resultado do aumento da resistência térmica do concreto ocasionado pelo aumento de sua espessura.

Figura 5.13 - Taxa de transferência de calor normalizada pela área da superfície da estaca em função do diâmetro da estaca geotérmica, por interface

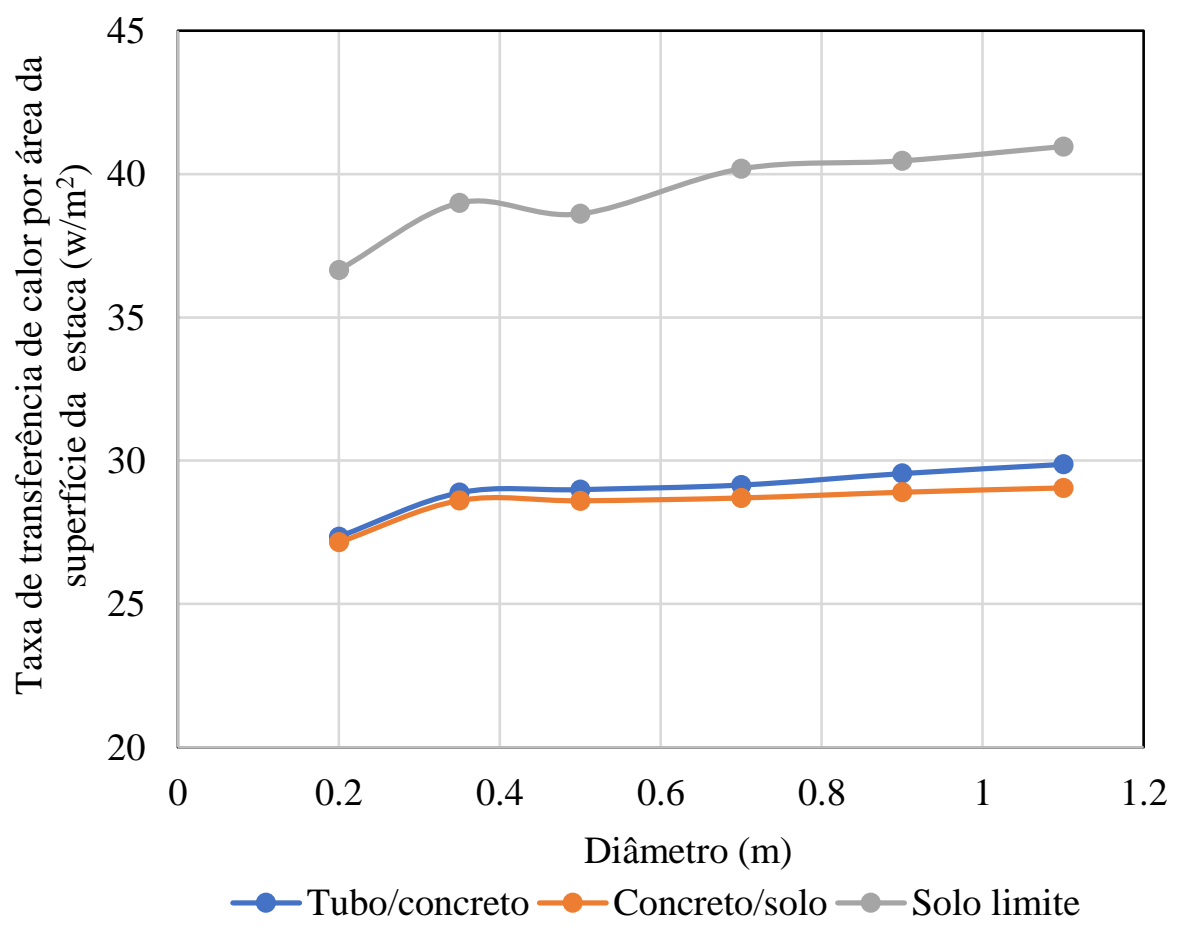

A distribuição de temperaturas médias nas superfícies do sistema geotérmico em função do diâmetro da estaca é apresentada na Figura 5.14. As temperaturas na saída do tubo e na interface tubo/concreto praticamente independem do diâmetro da estaca, porém na interface concreto/solo a temperatura diminui com o aumento da espessura do concreto e, consequentemente, de sua resistência térmica. Nota-se que as temperaturas diminuem 
conforme aumenta a distância radial a partir do centro da estaca até que, na superfície solo limite, a temperatura média é igual à temperatura não perturbada do solo (297,3 K). $\mathrm{Na}$ superfície concreto/solo são observados os valores, para os diâmetros $0,20 \mathrm{~m}, 0,35 \mathrm{~m}$ e 1,10 m: 306, $0 \mathrm{~K}, 305,2 \mathrm{~K}$ e $302,2 \mathrm{~K}$, respectivamente.

Figura 5.14 - Temperatura média em função do diâmetro da estaca geotérmica, por interface

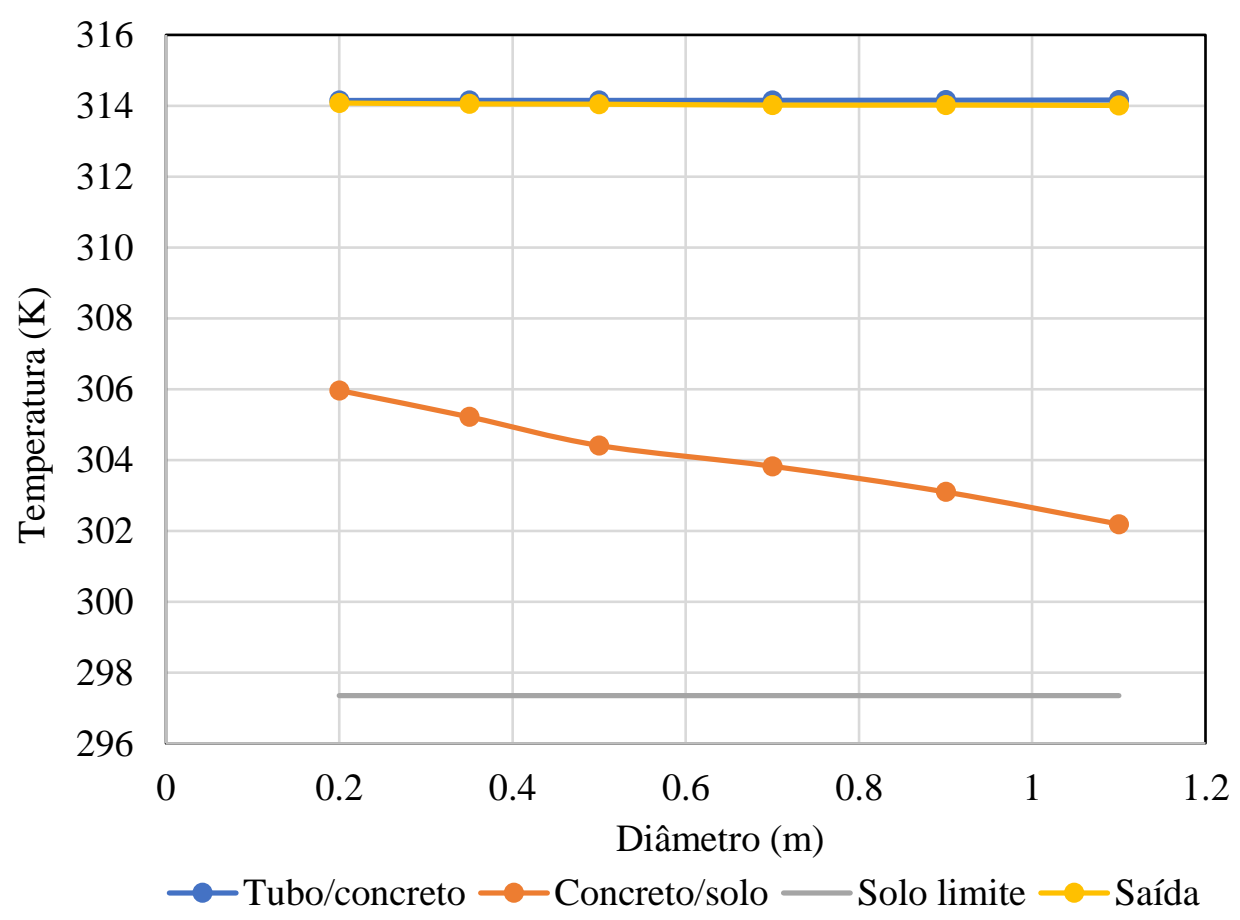

A diferença entre as temperaturas médias do fluido circulante nas posições de entrada e saída do tubo de PEAD foram, para os diâmetros 0,20 m, 0,35 m e 1,10 m: 0,2 $\mathrm{K}, 0,2 \mathrm{~K}$ e $0,3 \mathrm{~K}$. Tal ordem de grandeza pode ser considerada desprezível, indicando que a diferença de temperaturas no fluido circulante nas posições de entrada e saída do tubo de PEAD praticamente não varia com a variação do diâmetro da estaca.

\subsection{VARIAÇÃO DO ÍNDICE DE ESBELTEZ DA ESTACA}

O índice de esbeltez em estacas geotérmicas é definido pela relação L/D (ROTTA LORIA e LALOUI, 2016). Simularam-se duas séries de dados variando-se o índice de esbeltez: na primeira aumentou-se o comprimento de uma estaca de diâmetro 0,35 m (item 5.3) e na segunda aumentou-se o diâmetro de uma estaca de comprimento $15 \mathrm{~m}$ (item 5.4). 
Na primeira série, foram simulados os índices de esbeltez de estaca de 14,3; 28,6; 42,$9 ; 57,1 ; 85,7$ e 142,9, que aumentam de forma diretamente proporcional ao aumento do comprimento da estaca. Como resultado, percebe-se que o aumento da área trocadora de calor entre a estaca e o solo ocasiona o aumento dos valores de taxas de transferência de calor total nas interfaces tubo/concreto, concreto/solo, solo limite e solo topo. A Figura 5.15 mostra os valores totais de taxas de transferência de calor total por interface do sistema geotérmico. Percebe-se o crescimento linear das taxas de transferência de calor em função índice de esbeltez. Destaca-se, para a interface concreto/solo, para os valores de índice de esbeltez 14,3; 42,9 e 142,9 e suas respectivas taxas de transferência de calor: $151,63 \mathrm{~W}, 479 \mathrm{~W}, 148 \mathrm{~W}$ e $1646,29 \mathrm{~W}$.

Figura 5.15 - Taxa de transferência de calor em função do índice de esbeltez da estaca geotérmica, por interface, série 1

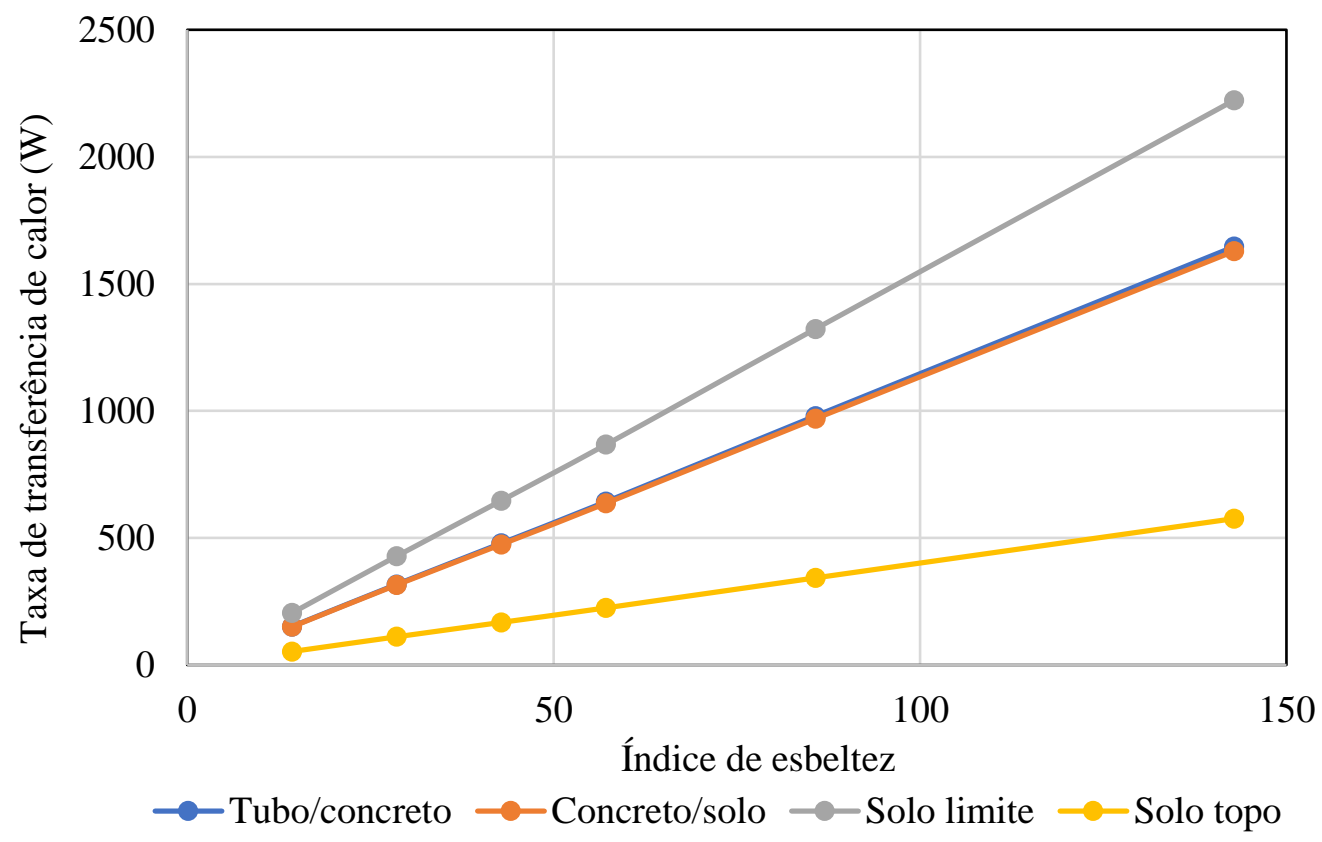

Na segunda série, foram simulados os índices de esbeltez de estaca de 11,8; 14,4; 18,$6 ; 26,0 ; 37,1$ e 65,0, que aumentam de forma inversamente proporcional ao diâmetro da estaca. Como resultado, percebe-se o aumento do índice de esbeltez é reflexo da redução do diâmetro da estaca e da diminuição da área trocadora de calor entre a estaca e o solo, o que ocasiona a redução dos valores de taxas de transferência de calor total nas interfaces do sistema geotérmico. A Figura 5.16 mostra os valores totais de taxas de transferência de calor total por interface do sistema geotérmico. Percebe-se a redução das taxas de transferência de calor em função índice de esbeltez em curvas que tendem a assíntotas. Destaca-se, para a interface concreto/solo, para os valores de índice de esbeltez 
11,8; 42,9 e 65,0 e suas respectivas taxas de transferência de calor: 1533,45 W, 474,65 W e $256,74 \mathrm{~W}$.

Figura 5.16 - Taxa de transferência de calor em função do índice de esbeltez da estaca geotérmica, por interface, série 2

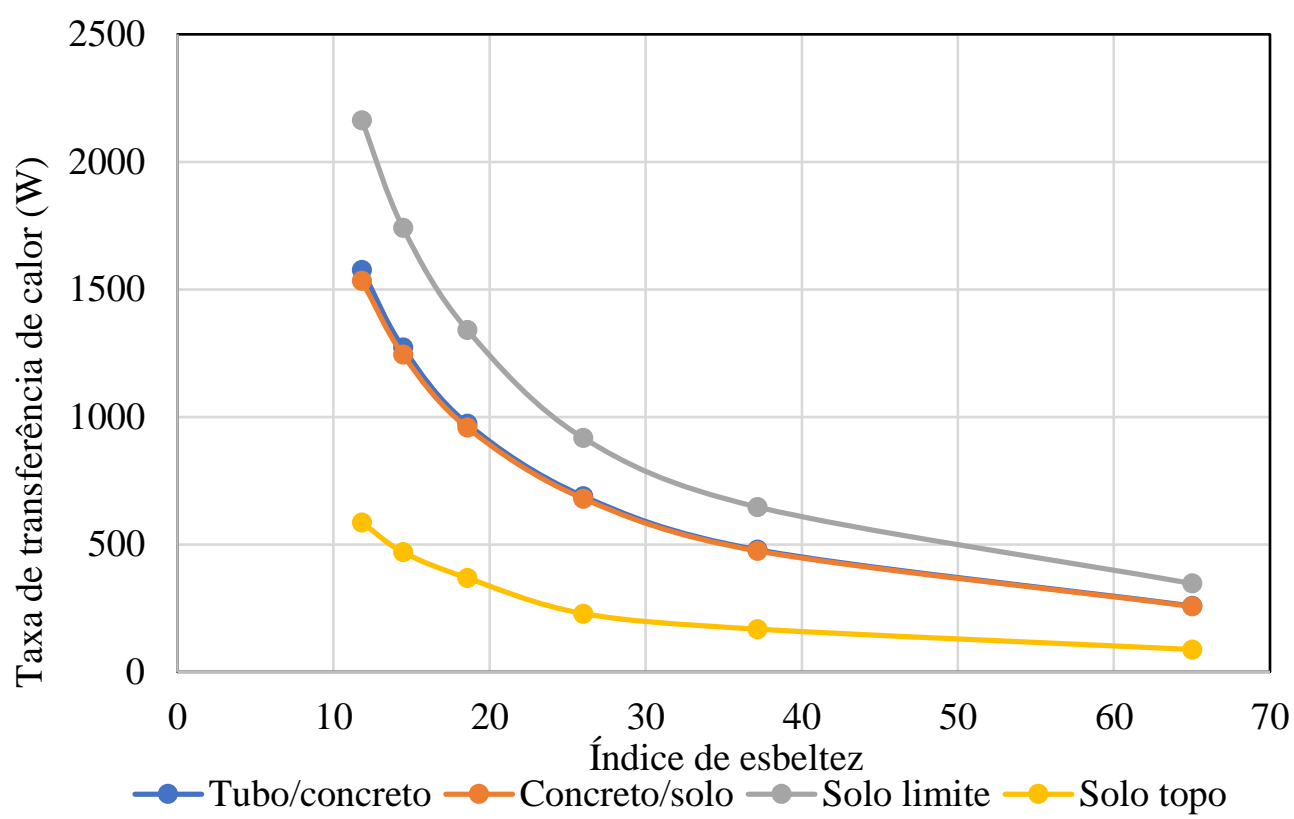

O índice de esbeltez individualmente, portanto, não define a taxa de transferência de calor. Comparem-se, por exemplo, as taxas de transferência de calor na interface concreto/solo para o índice de esbeltez igual a 50. Para $\mathrm{D}=0,35 \mathrm{~m}$ e $\mathrm{L}=17,5 \mathrm{~m}$, a taxa é aproximadamente $550 \mathrm{~W}$, enquanto para $\mathrm{L}=15 \mathrm{~m}$ e D $=0,30 \mathrm{~m}$, a taxa é cerca de 400 W. Também, não há uma tendência única de variação da taxa de transferência de calor em função do aumento do índice de esbeltez, como se vê da comparação entre as Figuras 5.15 e 5.16 .

Em termos de fatores geométricos, é a área da estaca disponível para trocas térmicas que determina a magnitude das taxas de transferência de calor total (quanto maiores as áreas para trocas térmicas maiores serão as taxas de transferência de calor). Um mesmo índice de esbeltez pode estar relacionado a diferentes valores de área da superfície da estaca, o que resulta em diferentes taxas de transferência de calor total.

\subsection{VARIAÇÃO DA CONDUTIVIDADE TÉRMICA DO CONCRETO}

Foram simulados os valores de condutividade térmica do concreto: $0,17 \mathrm{~W} \cdot \mathrm{m}^{-1} \cdot \mathrm{K}^{-1}$, 0,29 W.m $\mathrm{m}^{-1} \cdot \mathrm{K}^{-1}, 0,52 \mathrm{~W} \cdot \mathrm{m}^{-1} \cdot \mathrm{K}^{-1}, 0,85 \mathrm{~W} \cdot \mathrm{m}^{-1} \cdot \mathrm{K}^{-1}, 1,05 \mathrm{~W} \cdot \mathrm{m}^{-1} \cdot \mathrm{K}^{-1}, 1,15 \mathrm{~W} \cdot \mathrm{m}^{-1} \cdot \mathrm{K}^{-1}$, 
$1,35 \mathrm{~W} \cdot \mathrm{m}^{-1} \cdot \mathrm{K}^{-1}, 1,65 \mathrm{~W} \cdot \mathrm{m}^{-1} \cdot \mathrm{K}^{-1}, 1,75 \mathrm{~W} \cdot \mathrm{m}^{-1} \cdot \mathrm{K}^{-1}, 2,00 \mathrm{~W} \cdot \mathrm{m}^{-1} \cdot \mathrm{K}^{-1}, 2,30 \mathrm{~W} \cdot \mathrm{m}^{-1} \cdot \mathrm{K}^{-1}, 2,50$ $\mathrm{W} \cdot \mathrm{m}^{-1} \cdot \mathrm{K}^{-1}, 2,95 \mathrm{~W} \cdot \mathrm{m}^{-1} \cdot \mathrm{K}^{-1}, 3,52 \mathrm{~W} \cdot \mathrm{m}^{-1} \cdot \mathrm{K}^{-1} \mathrm{e} 3,85 \mathrm{~W} \cdot \mathrm{m}^{-1} \cdot \mathrm{K}^{-1}$. Mais dados acerca de cada tipo de concreto podem ser encontrados na Tabela 4.7 .

A Figura 5.17 mostra o comportamento da taxa de transferência de calor em função da condutividade térmica do concreto nas interfaces tubo/concreto, concreto/solo, solo topo e solo limite. As curvas de cada interface apresentam formato similar e indicam o aumento da taxa de transferência de calor com o aumento da condutividade térmica do concreto, em até 4,6 vezes na interface concreto/solo quando a condutividade térmica do concreto aumenta de $0,17 \mathrm{~W} \cdot \mathrm{m}^{-1} \cdot \mathrm{K}^{-1} \mathrm{a} 3,85 \mathrm{~W} \cdot \mathrm{m}^{-1} \cdot \mathrm{K}^{-1}$. Todavia, as curvas parecem tender a assíntotas, que representariam o máximo valor de taxa de transferência de calor que pode ser obtida em cada interface aumentando-se a condutividade térmica do concreto. Para os valores de condutividade térmica do concreto de $0,17 \mathrm{~W} \cdot \mathrm{m}^{-1} \cdot \mathrm{K}^{-1}, 2,00 \mathrm{~W} \cdot \mathrm{m}^{-1} \cdot \mathrm{K}^{-1}$ (variável oriunda do cenário base) e $3,85 \mathrm{~W} \cdot \mathrm{m}^{-1} \cdot \mathrm{K}^{-1}$, na interface concreto/solo, destacamse os valores de taxa de transferência de calor total: 114,8 W, 476,398 W e 531,336 W, respectivamente.

Figura 5.17 - Taxa de transferência de calor em função da condutividade térmica do concreto, por interface

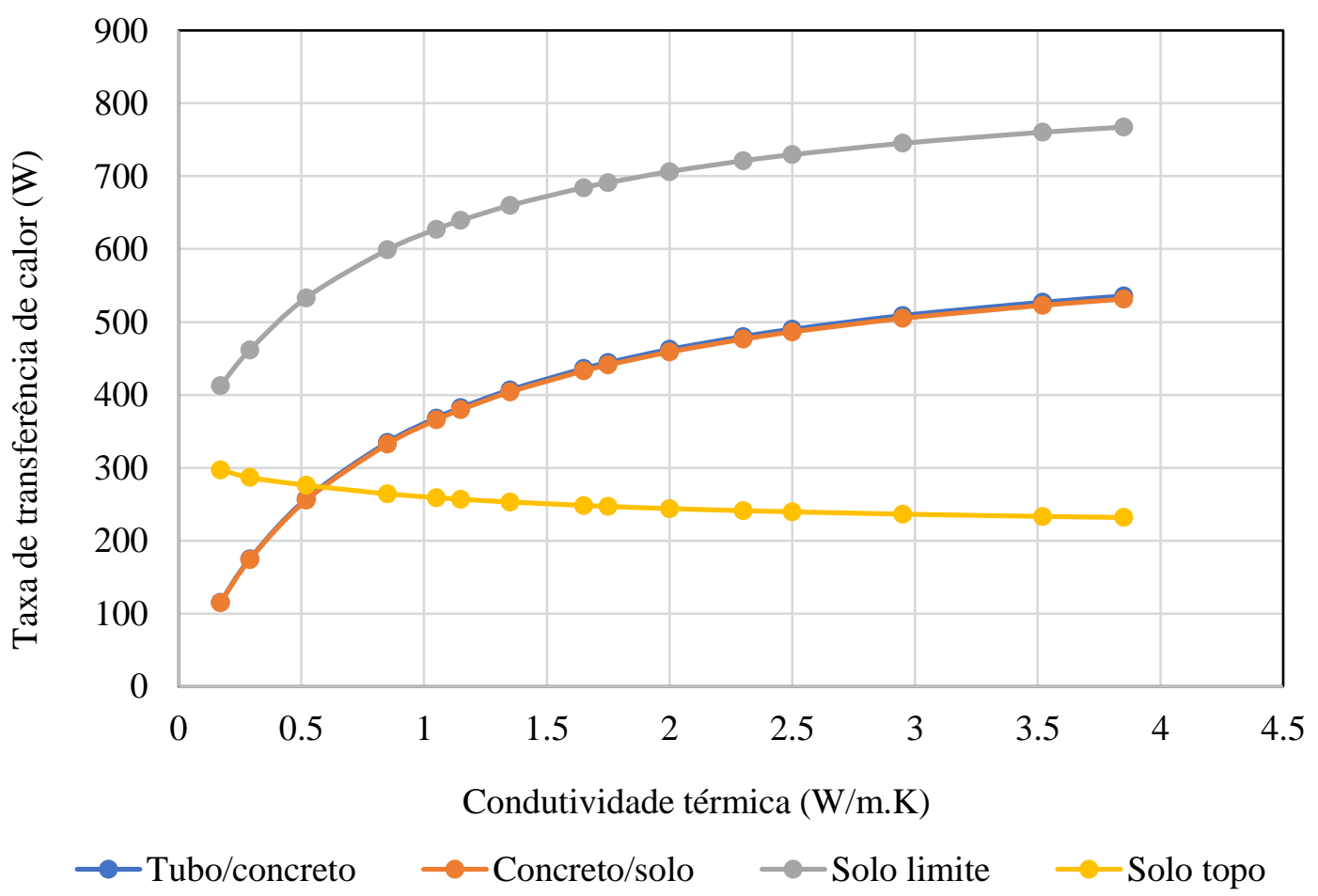

A distribuição de temperaturas médias nas superfícies do sistema geotérmico em função da condutividade térmica do concreto da estaca é apresentada na Figura 5.18. As 
temperaturas praticamente independem da condutividade térmica do concreto na saída do tubo e na interface tubo/concreto, porém na interface concreto/solo a temperatura aumenta de 299,6 K a 306,5 K quando a condutividade térmica do concreto aumenta de $0,17 \mathrm{~W} \cdot \mathrm{m}^{-1} \cdot \mathrm{K}^{-1}$ a $3,85 \mathrm{~W} \cdot \mathrm{m}^{-1} \cdot \mathrm{K}^{-1}$. A curva apresenta uma tendência assintótica, portanto os acréscimos de temperatura vão diminuindo com o aumento da condutividade térmica do concreto. Nota-se a diminuição das temperaturas conforme a distância radial a partir do centro da estaca aumenta até que, na superfície solo limite, a temperatura média é igual à temperatura não perturbada do solo $(297,33 \mathrm{~K})$. Na superfície concreto/solo são observados os valores, para as condutividades térmicas do concreto de $0,17 \mathrm{~W} \cdot \mathrm{m}^{-1} \cdot \mathrm{K}^{-1}$, $2,00 \mathrm{~W} \cdot \mathrm{m}^{-1} \cdot \mathrm{K}^{-1}$ e $3,85 \mathrm{~W} \cdot \mathrm{m}^{-1} \cdot \mathrm{K}^{-1}: 299,594 \mathrm{~K}, 305,317 \mathrm{~K}$ e 306,507 K, respectivamente.

A diferença entre as temperaturas médias do fluido circulante nas posições de entrada e saída do tubo de PEAD foram, para as condutividades térmicas do concreto de $0,17 \mathrm{~W} \cdot \mathrm{m}^{-1} \cdot \mathrm{K}^{-1}, 2,00 \mathrm{~W} \cdot \mathrm{m}^{-1} \cdot \mathrm{K}^{-1} \mathrm{e} 3,85 \mathrm{~W} \cdot \mathrm{m}^{-1} \cdot \mathrm{K}^{-1}: 0,1 \mathrm{~K}, 0,2 \mathrm{~K}$ e $0,3 \mathrm{~K}$. Não se conhece a precisão da aproximação numérica, mas pode-se afirmar que é desprezível a diferença de temperaturas do fluido circulante nas posições de entrada e saída do tubo em função da condutividade térmica do concreto.

Figura 5.18 - Temperatura média em função da condutividade térmica do concreto da estaca geotérmica, por interface

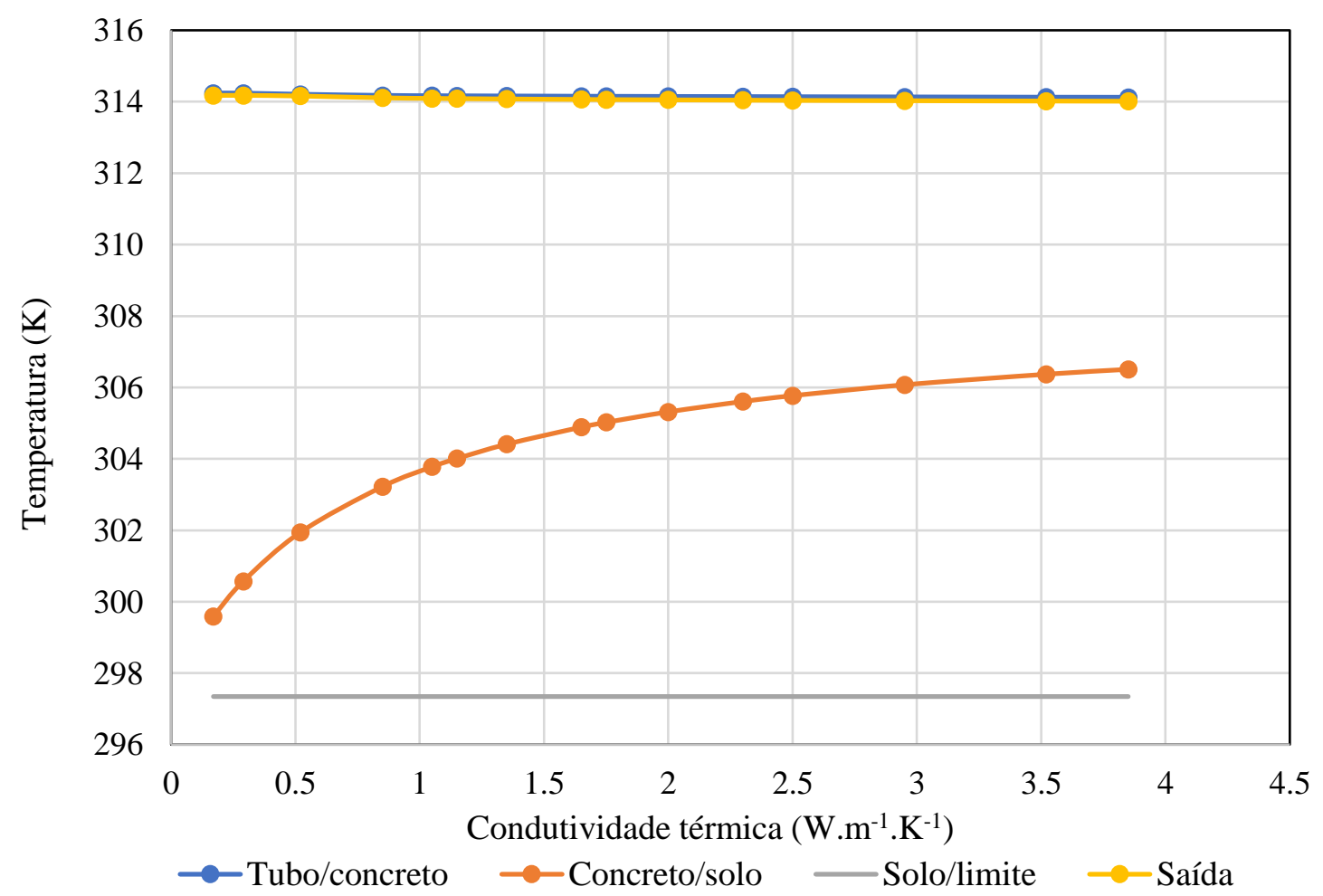


À medida que se aumentou a condutividade térmica do concreto, reduziu-se a influência térmica entre os tubos de entrada e de saída, como ilustram as distribuições de temperaturas na porção superior da estrutura de concreto no plano XZ, situado no centro da estaca, nas Figuras 5.19 (referente à condutividade térmica do concreto de $0,17 \mathrm{~W} \cdot \mathrm{m}^{-1} \cdot \mathrm{K}^{-1}$ ) e 5.20 (referente a condutividade térmica do concreto de $\left.3,85 \mathrm{~W} \cdot \mathrm{m}^{-1} \cdot \mathrm{K}^{-1}\right)$.

Figura 5.19 - Distribuição de temperaturas na estrutura de concreto da estaca, no plano $\mathrm{XZ}$, com condutividade térmica do concreto de $0,17 \mathrm{~W} \cdot \mathrm{m}^{-1} \cdot \mathrm{K}^{-1}$

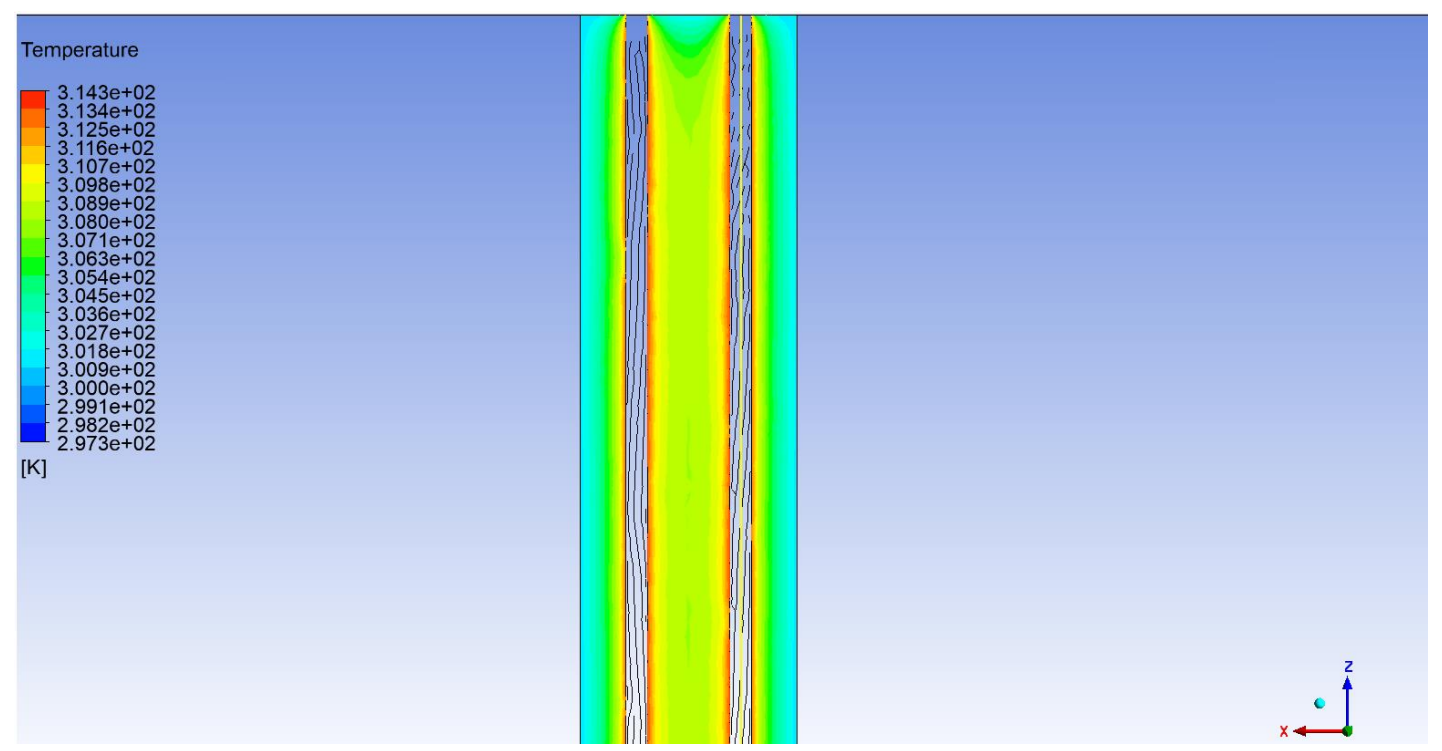

Figura 5.20 - Distribuição de temperaturas na estrutura de concreto da estaca, no plano $\mathrm{XZ}$, com condutividade térmica do concreto de $3,85 \mathrm{~W} \cdot \mathrm{m}^{-1} \cdot \mathrm{K}^{-1}$

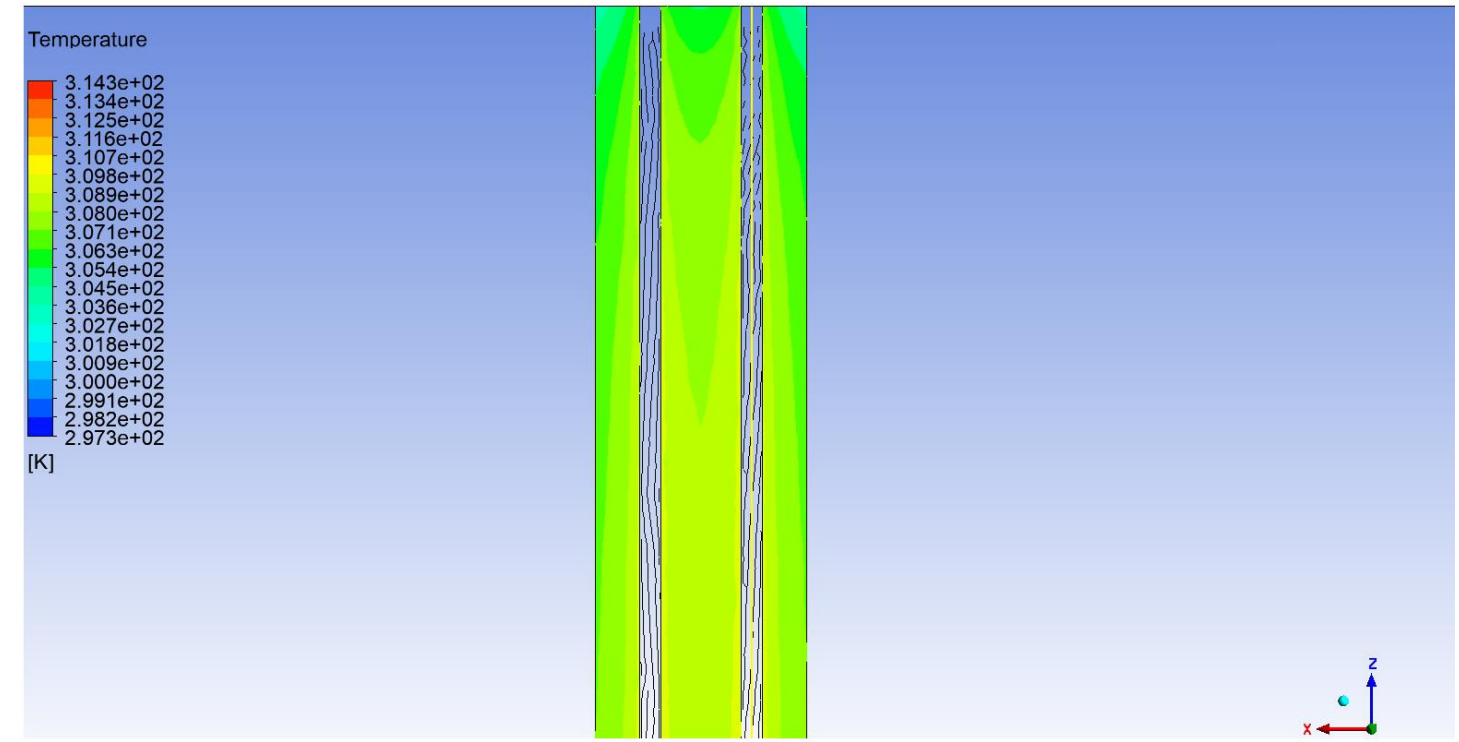


Compararam-se as simulações do cenário base, onde a resistência térmica de contato entre fluido e concreto era $0,012 \mathrm{~m}^{2} . \mathrm{K} . \mathrm{W}^{-1}$ (cenário 1), representativa dos tubos de PEAD, com as simulações em que se considerou resistência térmica de contato nula entre fluido e concreto (cenário 2).

A Figura 5.21 mostra a taxa de transferência de calor na interface concreto/solo em função da condutividade térmica do concreto para os dois cenários. Observa-se que, para a interface concreto/solo, a taxa de transferência de calor aumenta em função da condutividade térmica do concreto nos dois cenários, todavia a existência de uma resistência térmica de contato provoca diferenças consideráveis em termos de troca de calor. Para a condutividade térmica do concreto de $3,85 \mathrm{~W} \cdot \mathrm{m}^{-1} \cdot \mathrm{K}^{-1}$ a diferença de taxa de transferência de calor entre os cenários 1 e 2 é de 209,82 W. Esse aumento representa 39 $\%$ da taxa de calor transferida ao solo no cenário 1 pela interface concreto/solo. Isto evidencia que pequenos valores de resistência térmica na interface tubo/concreto acarretam relevantes reduções em termos de desempenho do sistema geotérmico.

Figura 5.21 - Transferência de calor em função da condutividade térmica do concreto considerando os cenários 1 e 2 na interface concreto/solo

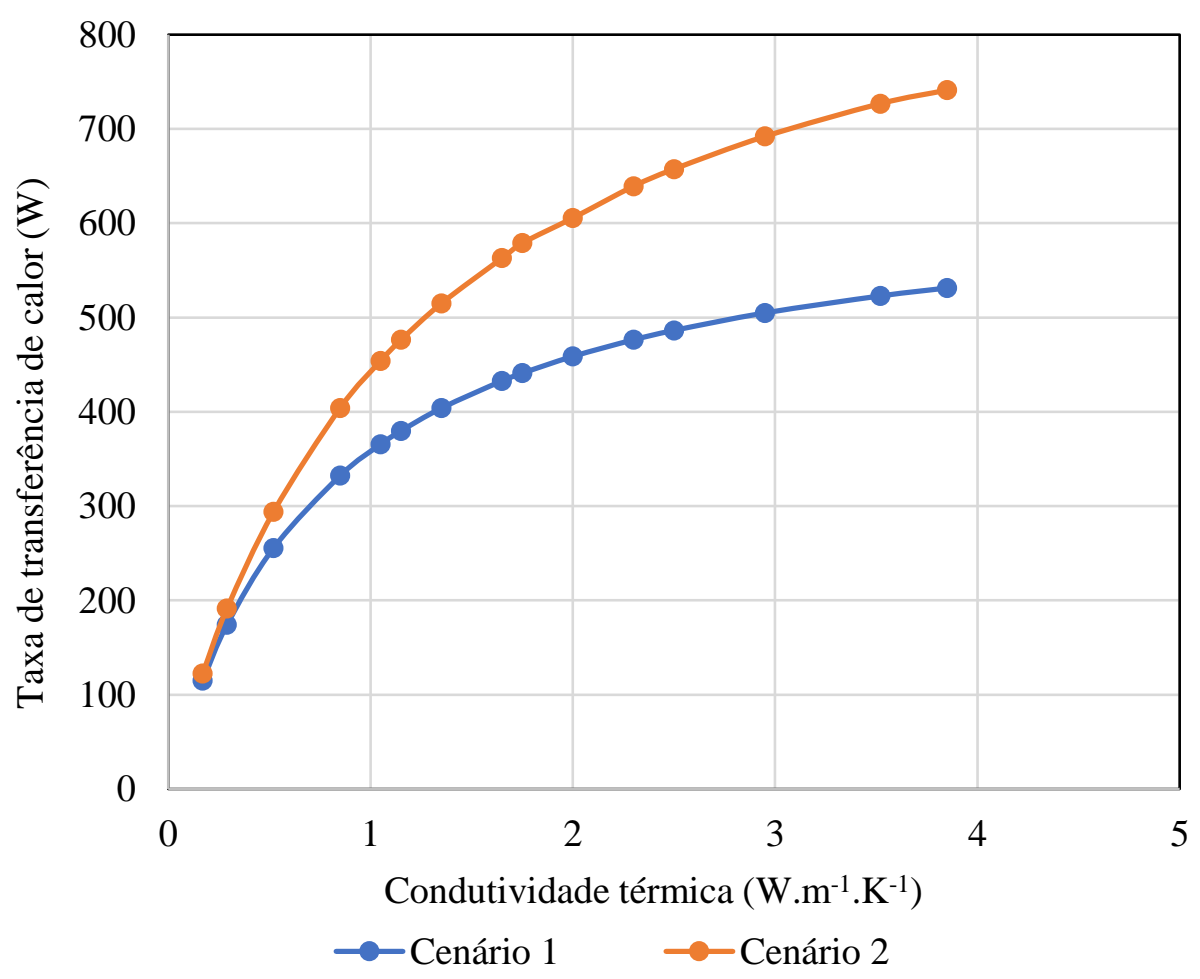

A Figura 5.22 apresenta uma comparação da distribuição de temperaturas médias na interface concreto/solo considerando-se os cenários 1 e 2 . O comportamento das curvas 
seguiu o padrão apresentado para a interface concreto/solo na Figura 5.18, porém no cenário 1 as temperaturas médias são menores do que no cenário 2. Para condutividade térmica do concreto de $3,85 \mathrm{~W} \cdot \mathrm{m}^{-1} \cdot \mathrm{K}^{-1}$, a diferença de temperatura na interface concreto/solo entre os dois cenários é de 3,3 K.

Figura 5.22 - Temperatura média na interface concreto-solo em função da condutividade térmica do concreto considerando os cenários 1 e 2

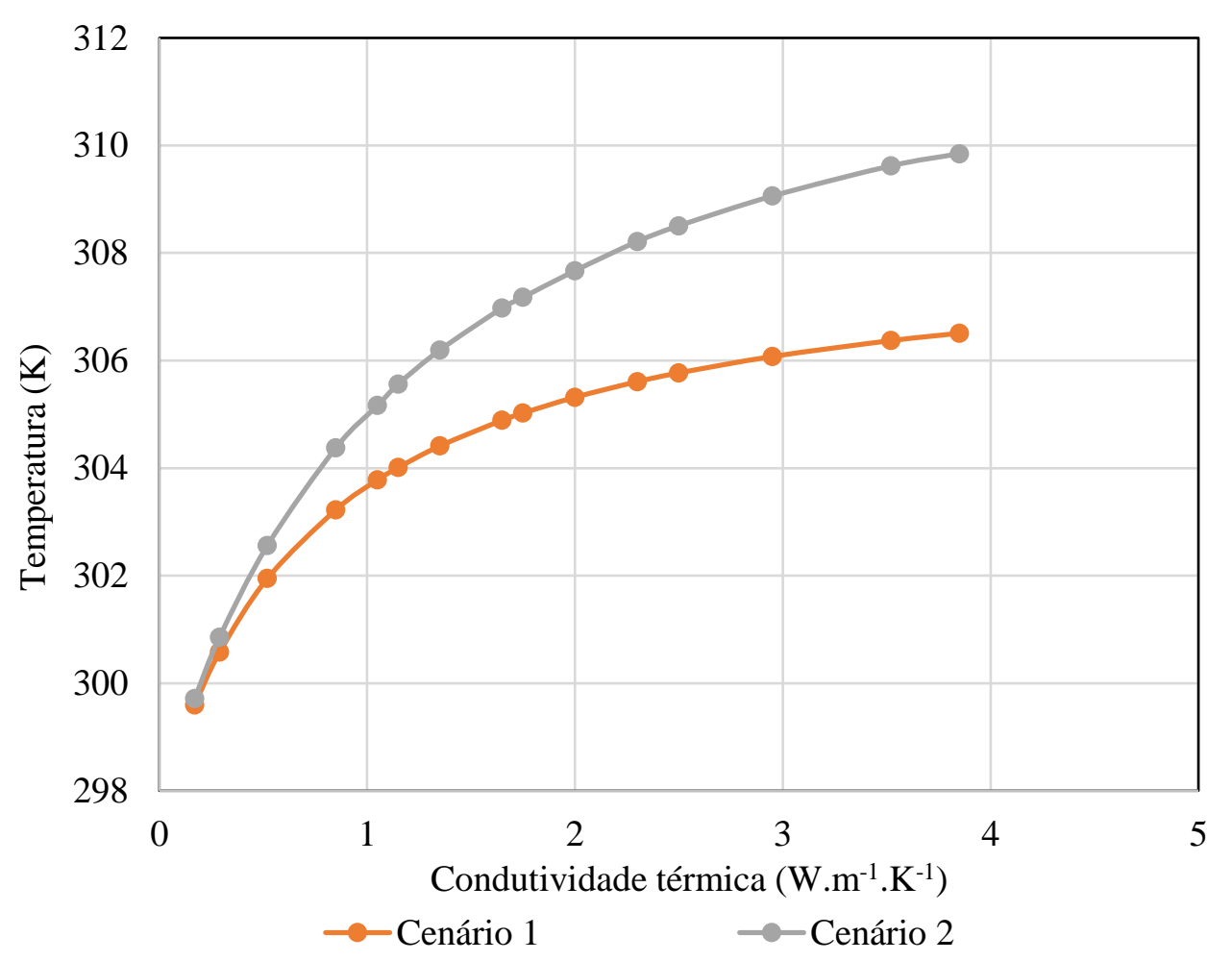

A Figura 5.23 mostra, para os cenários 1 e 2, o aumento do diâmetro de influência térmica com o aumento da condutividade térmica do concreto. As curvas parecem tender a assíntotas, atingindo para a máxima condutividade térmica do concreto investigada

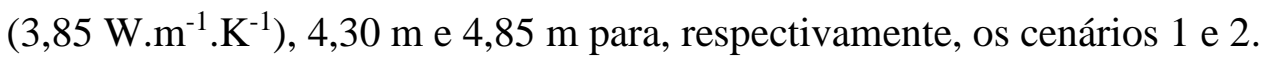

Primeiramente, percebe-se que tanto a temperatura média na interface concreto/solo (Figura 5.22) quanto o diâmetro de influência (Figura 5.22) dependem da taxa de calor transferida do concreto para o solo: conforme aumenta-se a condutividade térmica do concreto, aumentam-se as trocas térmicas no sistema geotérmico, bem como a temperatura média na interface concreto/solo e o diâmetro de influência térmica. Assim, explica-se a diferença de distribuição de temperaturas nas Figuras 5.19 e 5.20: o aumento da condutividade térmica do concreto (e a consequente diminuição de sua resistência térmica) aumenta a facilidade com a qual o fluxo de calor atravessa a estrutura de 
concreto, reduzindo as temperaturas no interior da estaca. Entretanto, na interface concreto/solo, a taxa de transferência de calor também tende a aumentar (Figura 5.17), uma vez que nesta região ocorre a mudança da condutividade térmica do meio (do concreto para o solo).

Em segundo lugar, considerando-se a diferença entre as curvas de diâmetro de influência nos cenários 1 e 2 da Figura 5.23: maior resistência térmica de contato na interface tubo/concreto resulta na diminuição do diâmetro de influência térmica. Assim, a resistência térmica de contato nula atribuída à interface tubo/concreto no cenário 2 aumenta o diâmetro de influência térmica em $0,55 \mathrm{~m}$ em relação a resistência térmica de contato de $0,012 \mathrm{~m}^{2} . \mathrm{K} \cdot \mathrm{W}^{-1}$ para condutividade térmica do concreto de $3,85 \mathrm{~W} \cdot \mathrm{m}^{-1} \cdot \mathrm{K}^{-1}$.

Figura 5.23 - Diâmetro de influência térmica em função da condutividade térmica do concreto considerando os cenários 1 e 2

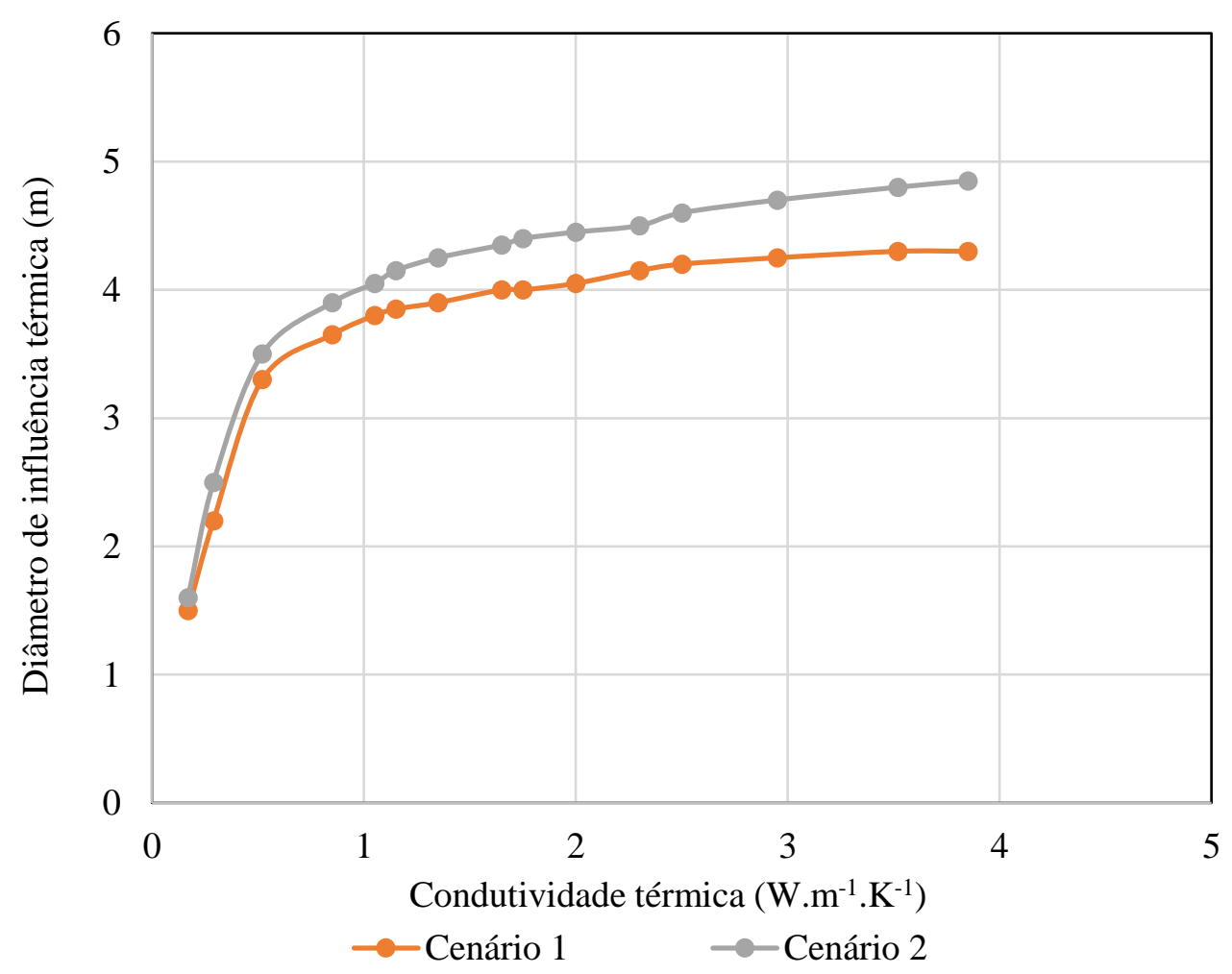

A Figura 5.24 ilustra, no plano XZ situado no centro da estaca, a zona de influência térmica de diâmetro $1,5 \mathrm{~m}$, considerando-se o cenário base e a condutividade térmica do concreto como $0,17 \mathrm{~W} \cdot \mathrm{m}^{-1} \cdot \mathrm{K}^{-1}$, enquanto a Figura 5.25 mostra a zona de influência térmica de diâmetro $4,3 \mathrm{~m}$, considerando-se o cenário base e a condutividade térmica do concreto de $3,85 \mathrm{~W} \cdot \mathrm{m}^{-1} \cdot \mathrm{K}^{-1}$. 
Figura 5.24 - Zona de influência térmica condutividade do concreto $0,17 \mathrm{~W} \cdot \mathrm{m}^{-1} \cdot \mathrm{K}^{-1}$

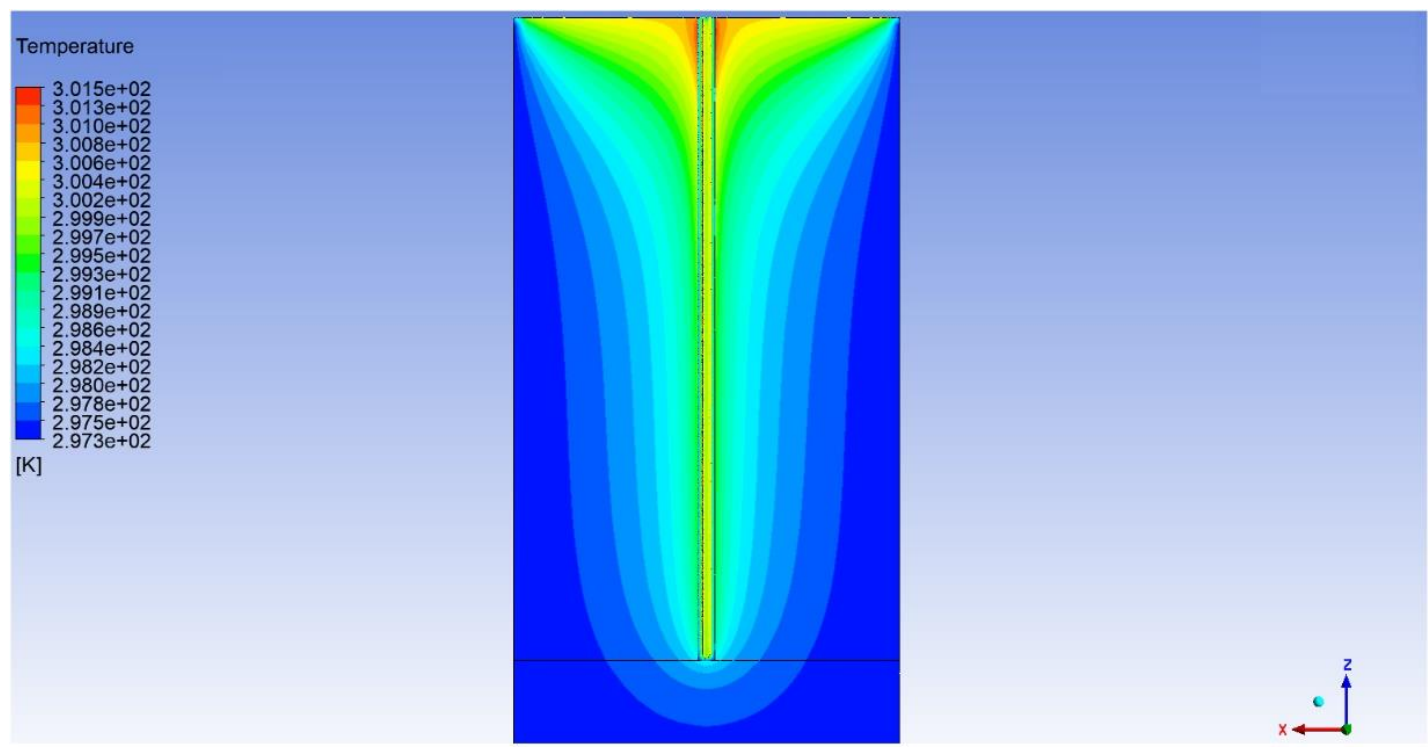

Figura 5.25 - Zona de influência térmica condutividade do concreto $3,85 \mathrm{~W} \cdot \mathrm{m}^{-1} \cdot \mathrm{K}^{-1}$
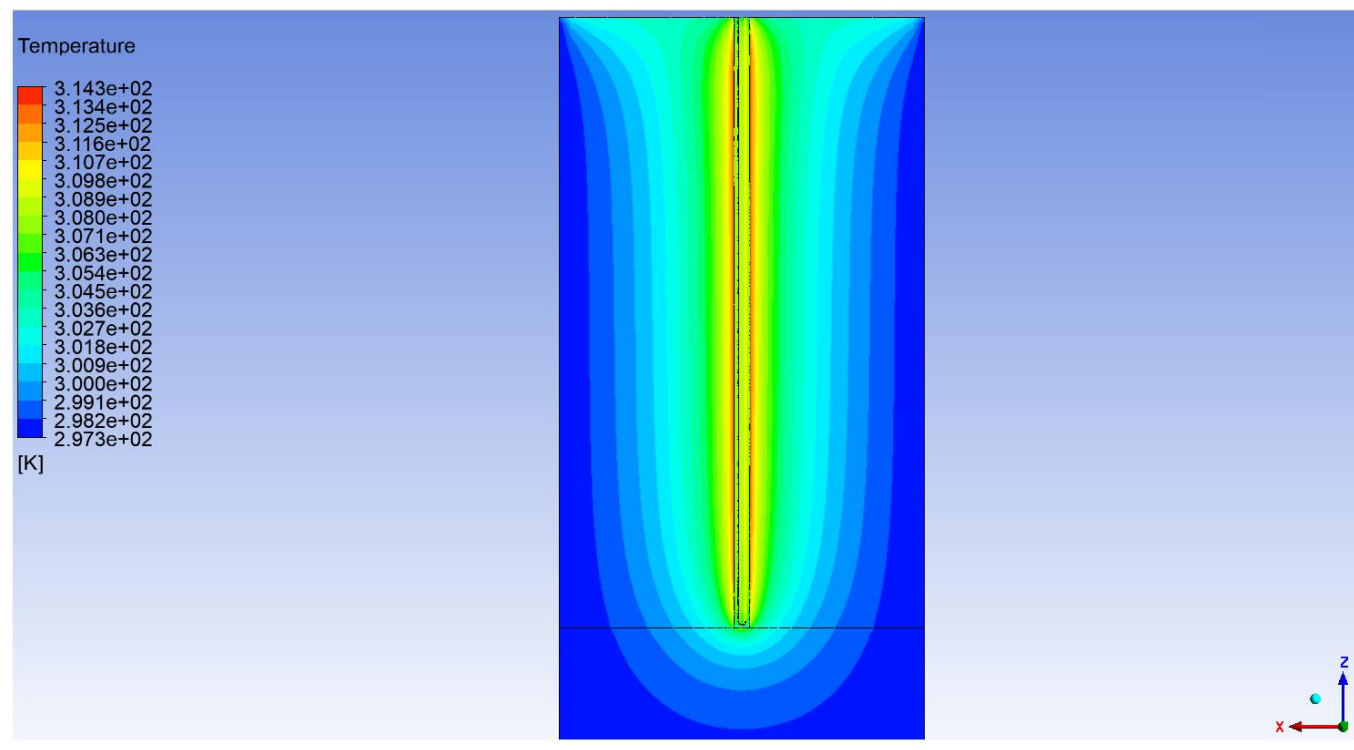

\subsection{VARIAÇÃO DA CONDUTIVIDADE TÉRMICA DO SOLO}

Foram simulados os seguintes tipos de solo e suas respectivas condutividades térmicas: pedregulho $\left(2,65 \mathrm{~W} \cdot \mathrm{m}^{-1} \cdot \mathrm{K}^{-1}\right)$, areia $\left(2,00 \mathrm{~W} \cdot \mathrm{m}^{-1} \cdot \mathrm{K}^{-1}\right)$, silte $\left(1,70 \mathrm{~W} \cdot \mathrm{m}^{-1} \cdot \mathrm{K}^{-1}\right)$, argila $\left(0,90 \mathrm{~W} \cdot \mathrm{m}^{-1} \cdot \mathrm{K}^{-1}\right)$, argilito $\left(2,85 \mathrm{~W} \cdot \mathrm{m}^{-1} \cdot \mathrm{K}^{-1}\right)$, arenito $\left(3,70 \mathrm{~W} \cdot \mathrm{m}^{-1} \cdot \mathrm{K}^{-1}\right)$ e solo real $\left(2,82 \mathrm{~W} \cdot \mathrm{m}^{-1} \cdot \mathrm{K}^{-1}\right)$. Mais dados acerca de cada tipo de solo podem ser encontrados na Tabela 4.8. 
A Figura 5.26 mostra a variação da taxa de transferência de calor total em função dos valores de condutividade térmica do solo nas interfaces tubo/concreto, concreto/solo e solo limite, simulados a partir do cenário base. As curvas obtidas indicam que a taxa de transferência de calor aumenta com o aumento da condutividade térmica do solo, sendo que esse acréscimo diminui com o aumento da condutividade térmica do solo. A interface solo limite apresenta maiores taxas de transferência de calor e aumento mais acentuado da taxa de transferência de calor em função da condutividade térmica do solo do que as interfaces tubo/concreto e concreto/solo, essas praticamente coincidentes. Para os valores de condutividade térmica do solo de $0,90 \mathrm{~W} \cdot \mathrm{m}^{-1} \cdot \mathrm{K}^{-1}, 2,82 \mathrm{~W} \cdot \mathrm{m}^{-1} \cdot \mathrm{K}^{-1}$ (variável oriunda do cenário base) e $3,70 \mathrm{~W} \cdot \mathrm{m}^{-1} \cdot \mathrm{K}^{-1}$, na interface concreto/solo, destacam-se os valores de taxa de transferência de calor total: 233,116 W, 458,462 W e 511,280 W, respectivamente.

Figura 5.26 - Taxa de transferência de calor total em função da condutividade térmica do solo, por interface

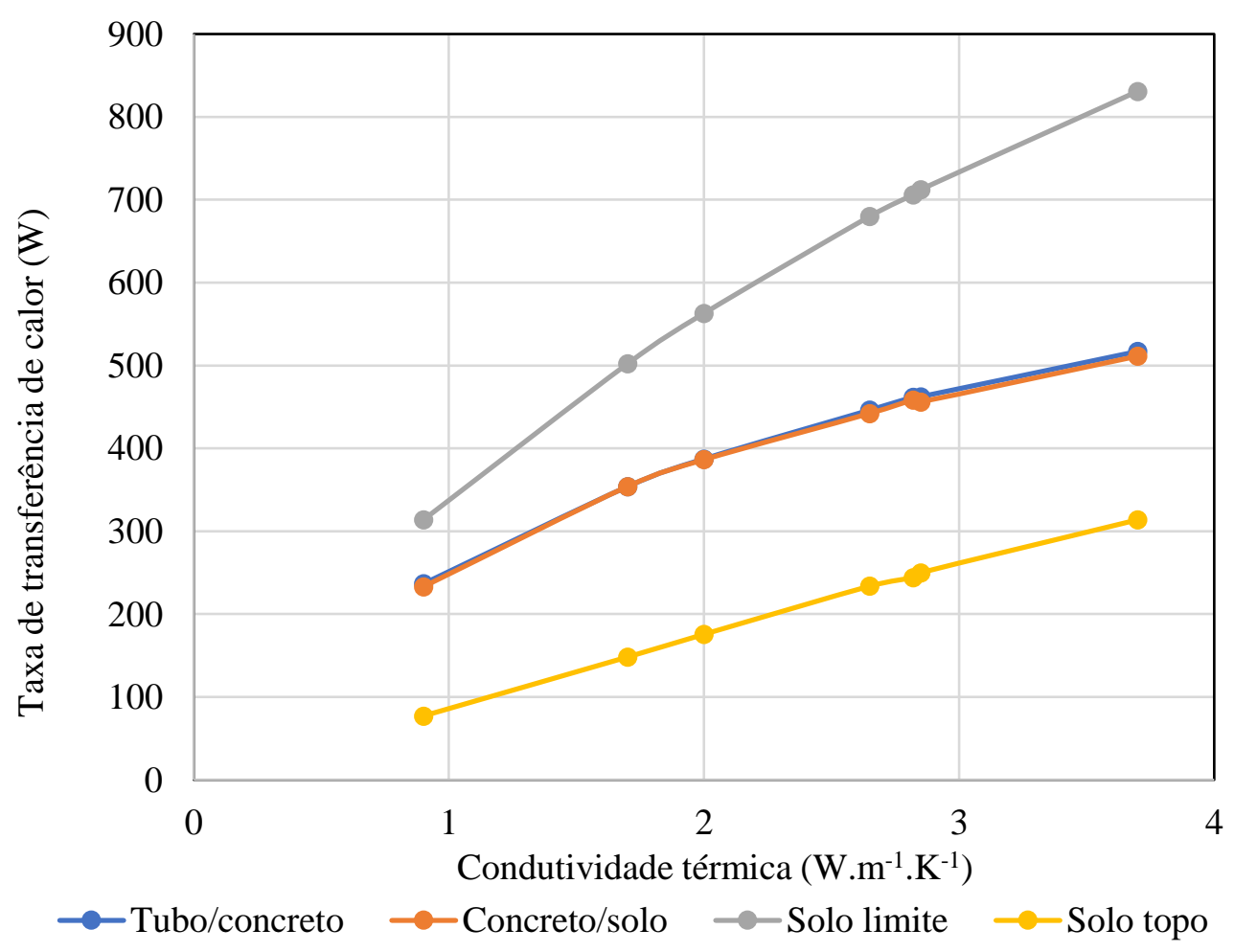

A Figura 5.27 mostra a distribuição de temperaturas médias nas superfícies do sistema geotérmico em função da condutividade térmica do solo, simulada a partir do cenário base. As temperaturas praticamente não variam na saída do fluido e na interface tubo/concreto em função da condutividade térmica do solo. Na interface concreto/solo, as temperaturas diminuem conforme a condutividade térmica do solo aumenta e sua 
resistência térmica diminui, pois à medida que a condutividade térmica do solo aumenta, maior é a facilidade com a qual o fluxo de calor deixa a interface concreto/solo para ser transferido radialmente ao maciço de solo. Na superfície concreto/solo são observadas as temperaturas, para as condutividades térmicas do solo de $0,90 \mathrm{~W} \cdot \mathrm{m}^{-1} \cdot \mathrm{K}^{-1}, 2,82 \mathrm{~W} \cdot \mathrm{m}^{-1} \cdot \mathrm{K}^{-}$ ${ }^{1}$ e $3,70 \mathrm{~W} \cdot \mathrm{m}^{-1} \cdot \mathrm{K}^{-1}: 309,6 \mathrm{~K}, 305,3 \mathrm{~K}$ e $304,2 \mathrm{~K}$, respectivamente.

Figura 5.27 - Temperatura média em função da condutividade térmica do solo, por interface

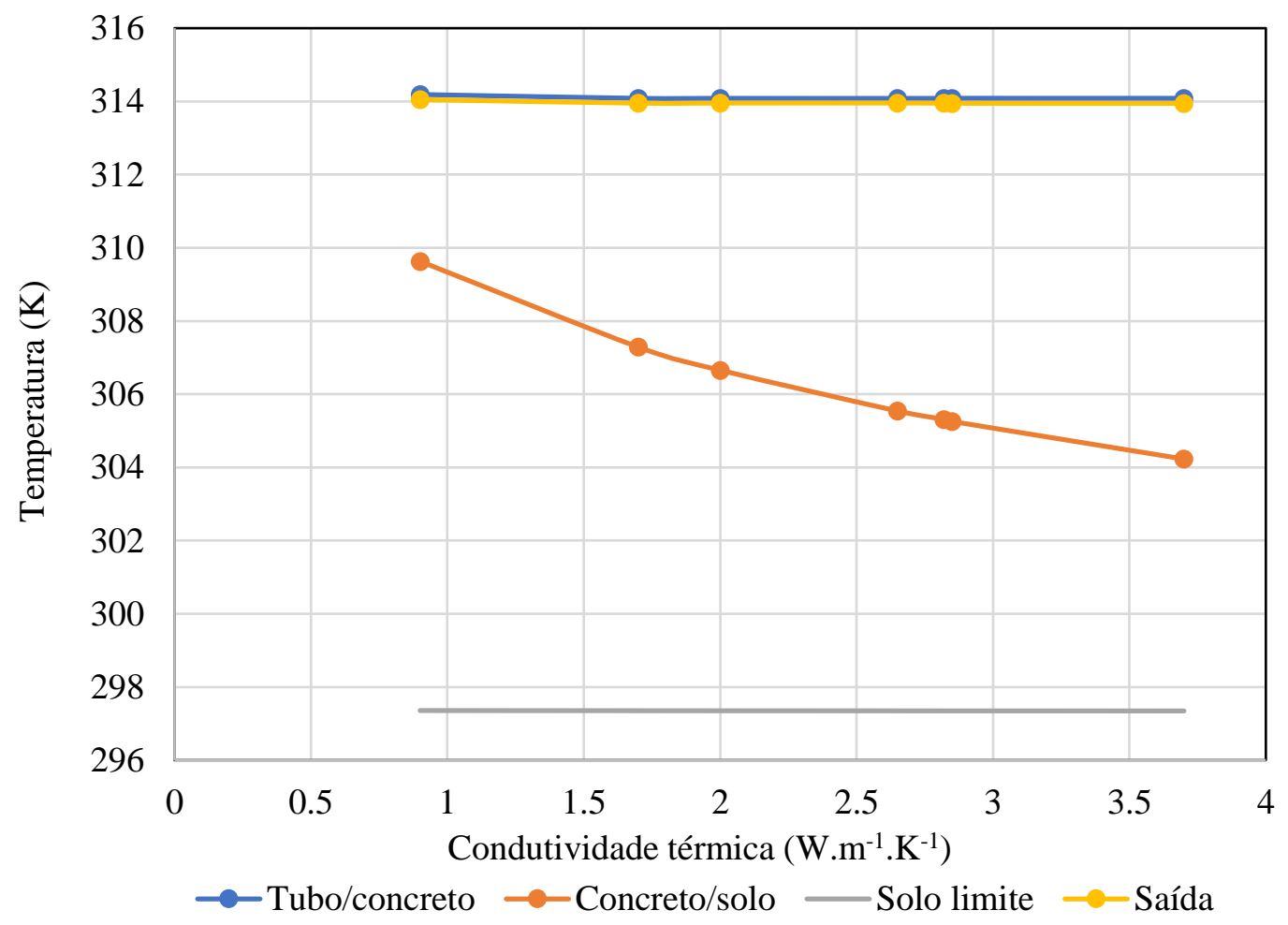

A diferença entre as temperaturas médias do fluido circulante nas posições de entrada e saída do tubo foram, para as condutividades térmicas do solo $0,90 \mathrm{~W} \cdot \mathrm{m}^{-1} \cdot \mathrm{K}^{-1}$, 2,82 W.m. ${ }^{-1} \cdot \mathrm{K}^{-1}$ e $3,70 \mathrm{~W} \cdot \mathrm{m}^{-1} \cdot \mathrm{K}^{-1}: 0,2 \mathrm{~K}, 0,3 \mathrm{~K}$ e 0,3 K, respectivamente. Não se conhece a precisão da aproximação numérica, mas pode-se afirmar que é desprezível a diferença de temperaturas do fluido circulante nas posições de entrada e saída do tubo em função da variação da condutividade térmica do concreto.

Todavia, a comparação entre as Figuras 5.28 e 5.29, que mostram a distribuição de temperaturas na porção superior da estaca geotérmica, no plano XZ situado no centro da estaca, indica que o aumento da condutividade térmica do solo diminui as trocas térmicas entre os tubos de entrada e saída de fluido circulante. A Figura 5.28 resulta da simulação para condutividade térmica do solo $0,9 \mathrm{~W} \cdot \mathrm{m}^{-1} \cdot \mathrm{K}^{-1}$ e a Figura 5.29 , para 
condutividade térmica do solo de $3,70 \mathrm{~W} \cdot \mathrm{m}^{-1} \cdot \mathrm{K}^{-1}$. O aumento da condutividade e redução da resistência térmica do solo aumentam a facilidade com a qual o fluxo de calor deixa radialmente a estrutura de concreto em direção ao maciço de solo. Por isso, a concentração de calor na estaca diminui com o aumento da condutividade térmica do solo, reduzindo também a magnitude das temperaturas distribuídas no concreto.

Figura 5.28 - Distribuição de temperaturas na estrutura de concreto da estaca, no plano $\mathrm{XZ}$, com condutividade térmica do solo de $0,90 \mathrm{~W} \cdot \mathrm{m}^{-1} \cdot \mathrm{K}^{-1}$

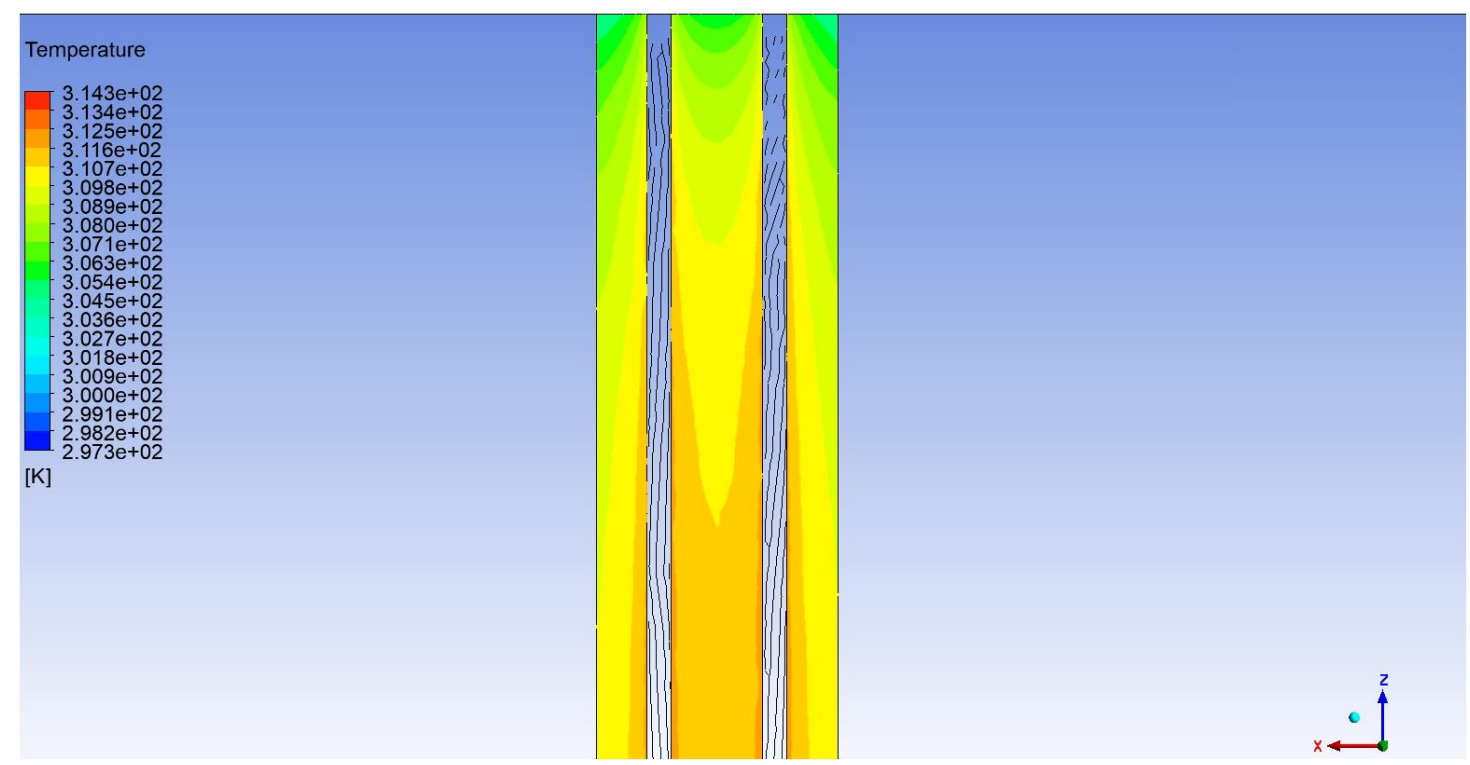

Figura 5.29 - Distribuição de temperaturas na estrutura de concreto da estaca, no plano $\mathrm{XZ}$, com condutividade térmica do solo de $3,70 \mathrm{~W} \cdot \mathrm{m}^{-1} \cdot \mathrm{K}^{-1}$

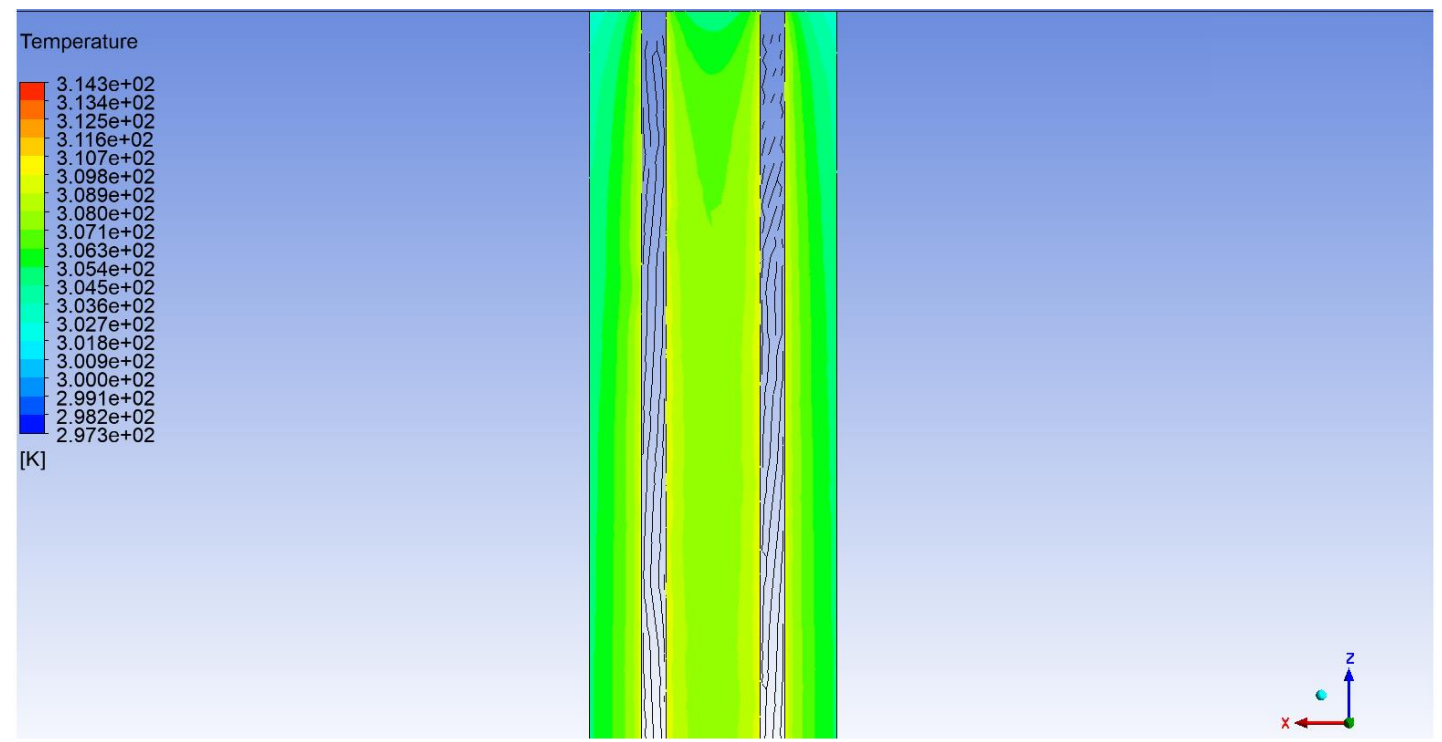

A Figura 5.30 apresenta a variação da taxa de transferência de calor em função da condutividade térmica do solo na interface concreto/solo nos cenários 1 e 2 . A resistência 
térmica de contato reduz as taxas de transferência de calor. Para a condutividade térmica do solo de $3,70 \mathrm{~W} \cdot \mathrm{m}^{-1} \cdot \mathrm{K}^{-1}$, a diferença de taxa de transferência de calor entre os cenários 1 e 2 é de 198,54 W, igual a $39 \%$ da taxa de calor transferida ao solo pela interface concreto/solo no cenário 1.

Figura 5.30 - Taxa de transferência de calor total função da condutividade térmica do concreto considerando os cenários 1 e 2 na interface concreto/solo

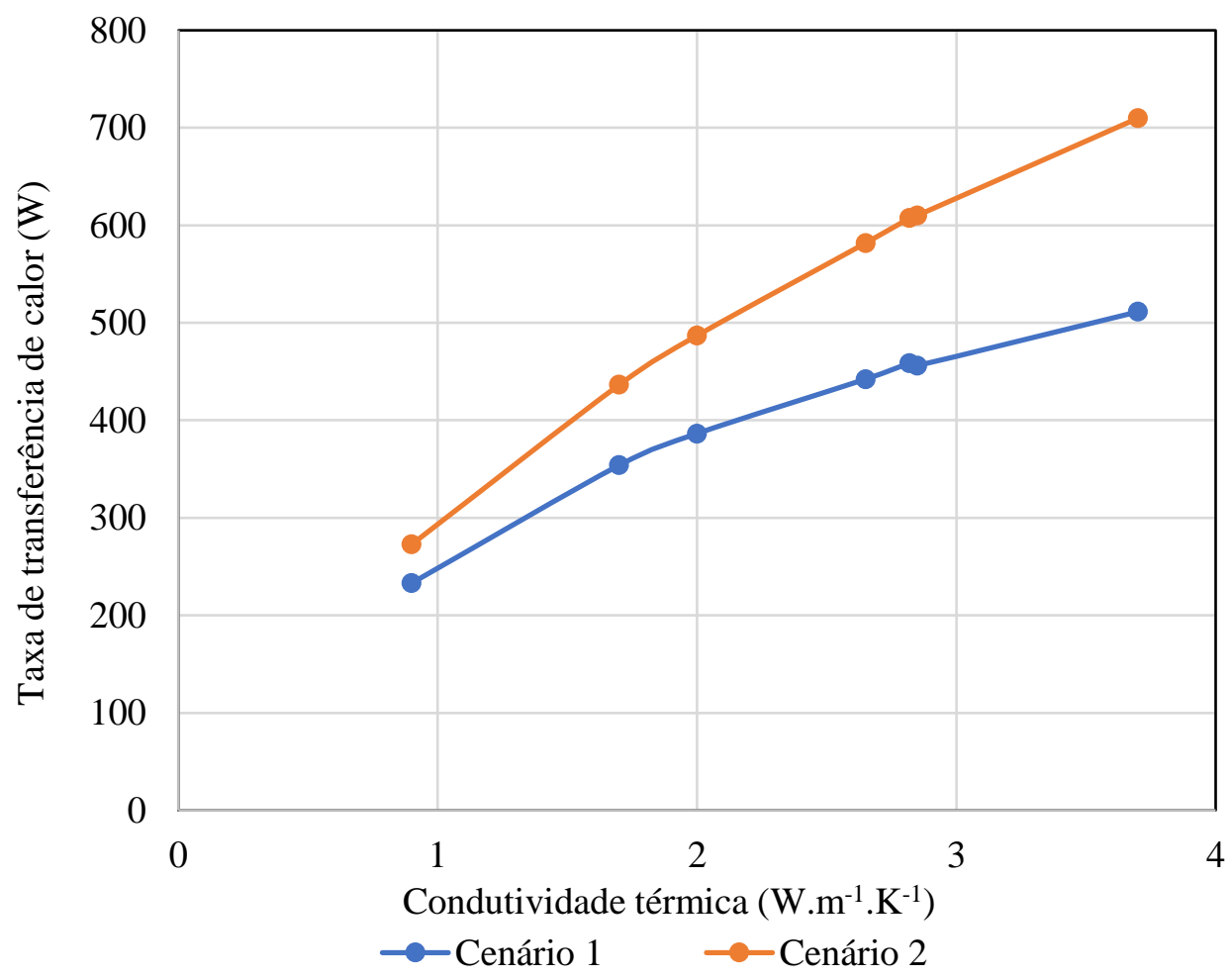

A Figura 5.31 apresenta uma comparação da distribuição de temperaturas médias na interface concreto/solo nos cenários 1 e 2 . O cenário 1 (resistência térmica de contato de $0,012 \mathrm{~m}^{2} . \mathrm{K} . \mathrm{W}^{-1}$ ), apresenta menores valores de temperaturas médias em comparação ao cenário 2, em que não há resistência térmica de contato. A diferença de temperaturas entre os cenários é de 2,4 K para condutividade térmica do solo de $3,7 \mathrm{~W} \cdot \mathrm{m}^{-1} \cdot \mathrm{K}^{-1}$.

O diâmetro de influência térmica, por sua vez, diminui com o aumento da condutividade térmica do solo, como mostra a Figura 5.32. A diferença entre diâmetros de influência térmica dos cenários 1 e 2 é de 0,3 m para as simulações com condutividade térmica do solo de $3,7 \mathrm{~W} \cdot \mathrm{m}^{-1} \cdot \mathrm{K}^{-1}$. 
Figura 5.31 - Temperatura média em função da condutividade térmica do solo considerando os cenários 1 e 2

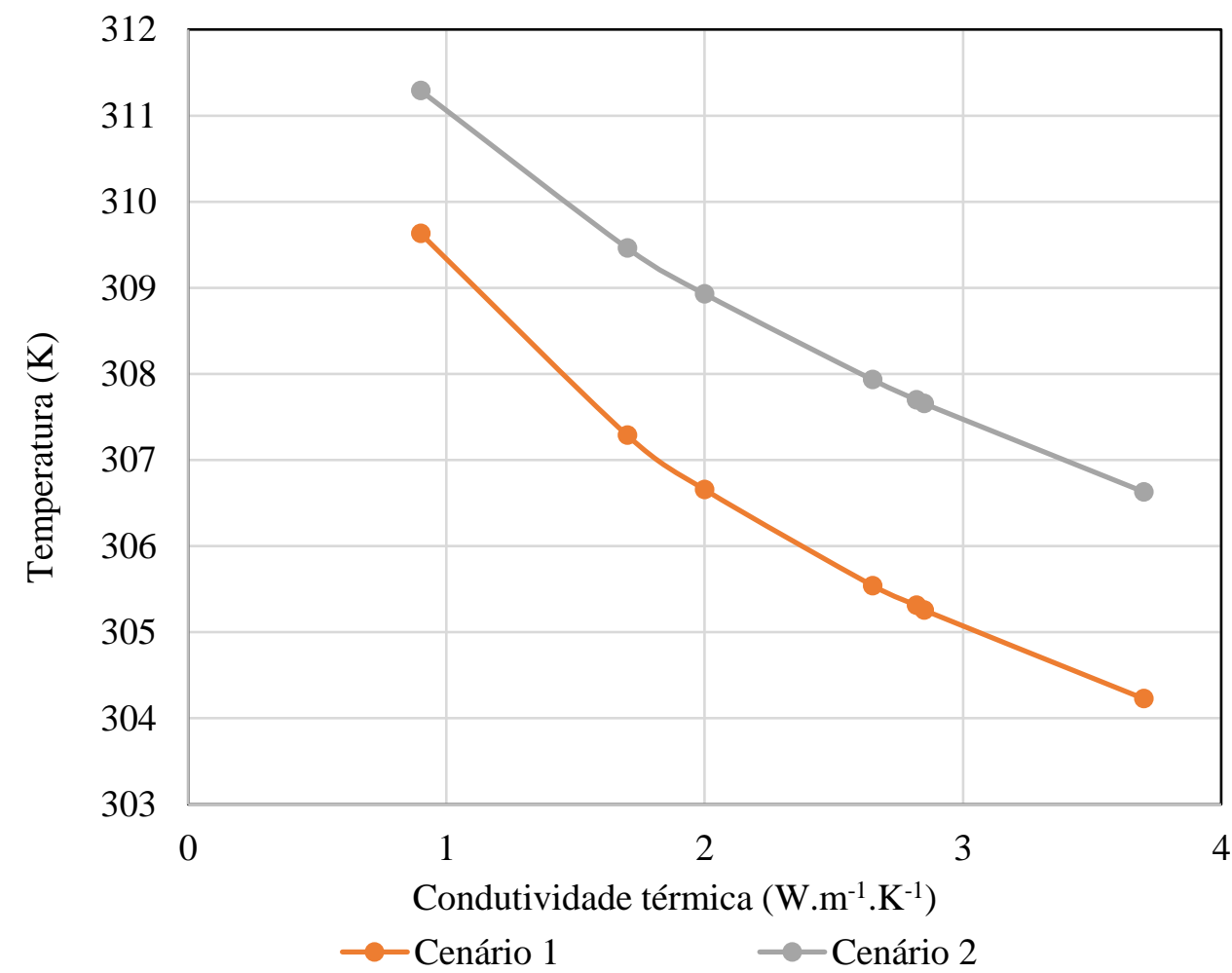

Figura 5.32 - Diâmetro de influência térmica em função da condutividade térmica do solo considerando os cenários 1 e 2

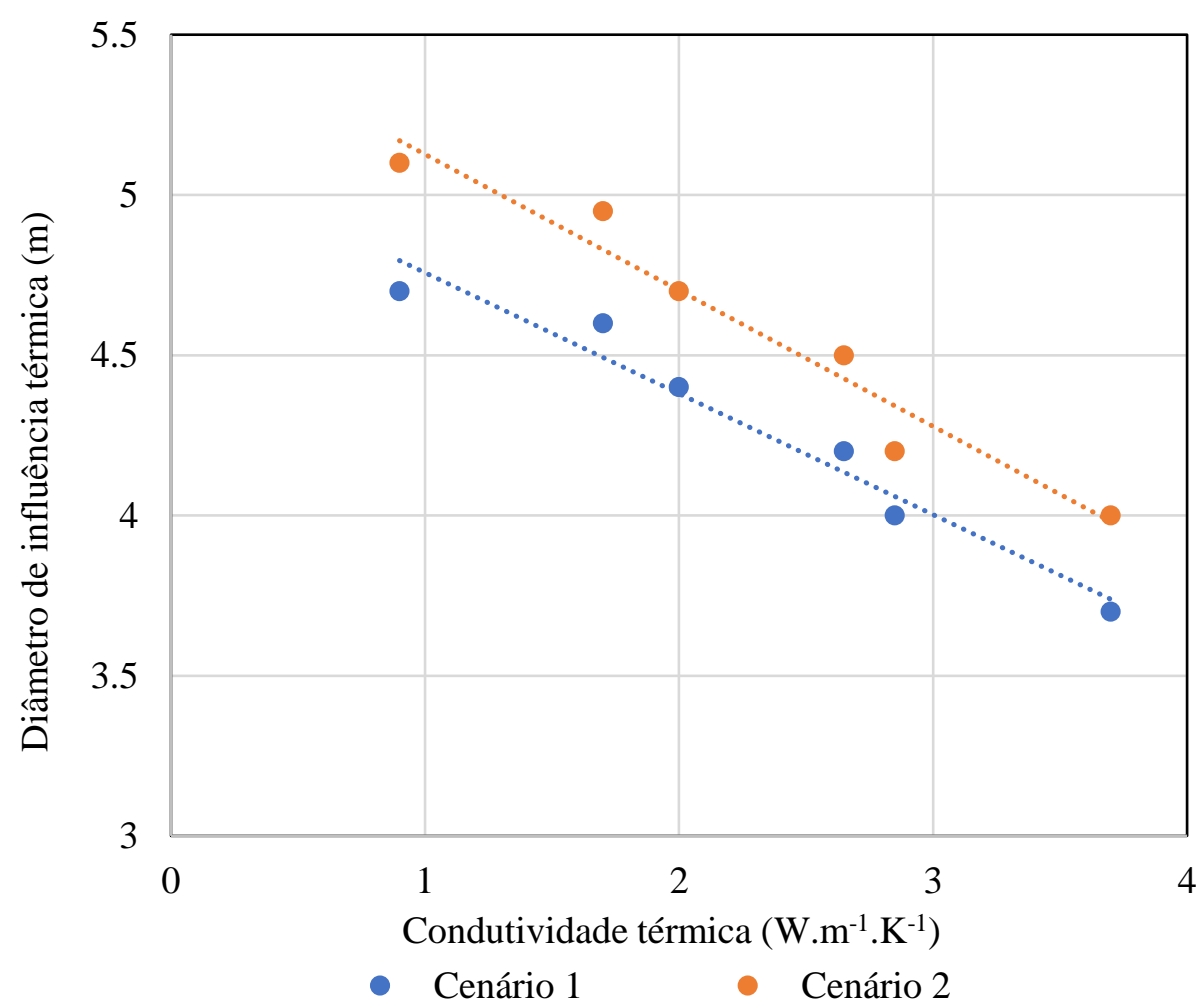


A redução dos valores de diâmetro de influência com o aumento da condutividade térmica do solo pode ser verificada a partir da comparação das Figuras 5.33 e 5.34, que ilustram a distribuição de temperaturas no plano XZ situado no centro da estaca, considerando-se o cenário base. Na Figura 5.33, a condutividade térmica do solo é 0,9 $\mathrm{W} \cdot \mathrm{m}^{-1} \cdot \mathrm{K}^{-1}$ e o diâmetro da zona de influência térmica é 4,7 m. Na Figura 5.34, para solo com condutividade térmica de $3,7 \mathrm{~W} \cdot \mathrm{m}^{-1} \cdot \mathrm{K}^{-1}$, o diâmetro da zona de influência é $3,7 \mathrm{~m}$.

Figura 5.33 - Zona de influência térmica - condutividade térmica do solo $0,9 \mathrm{~W} \cdot \mathrm{m}^{-1} \cdot \mathrm{K}^{-1}$

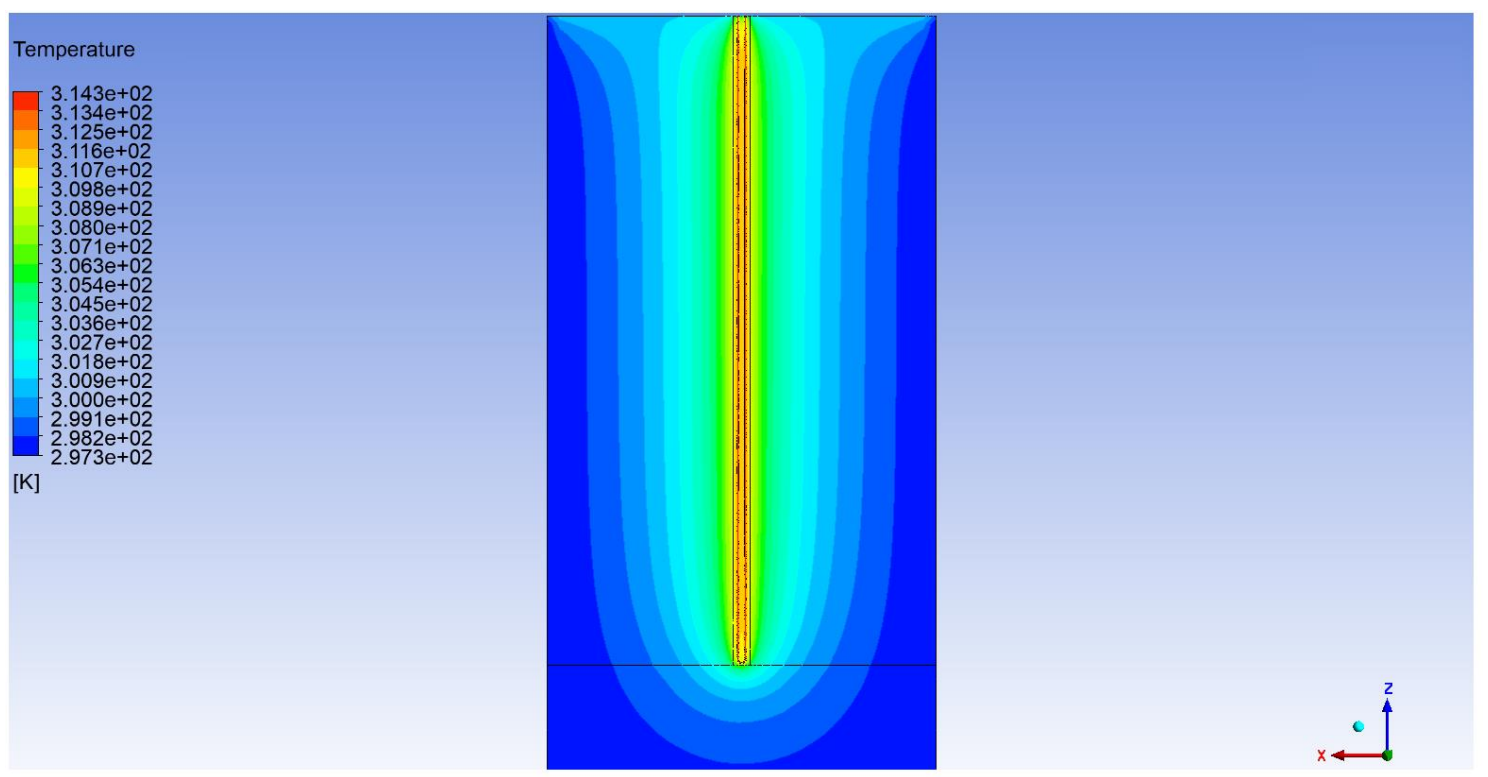

Figura 5.34 - Zona de influência térmica - condutividade térmica do solo $3,7 \mathrm{~W} \cdot \mathrm{m}^{-1} \cdot \mathrm{K}^{-1}$
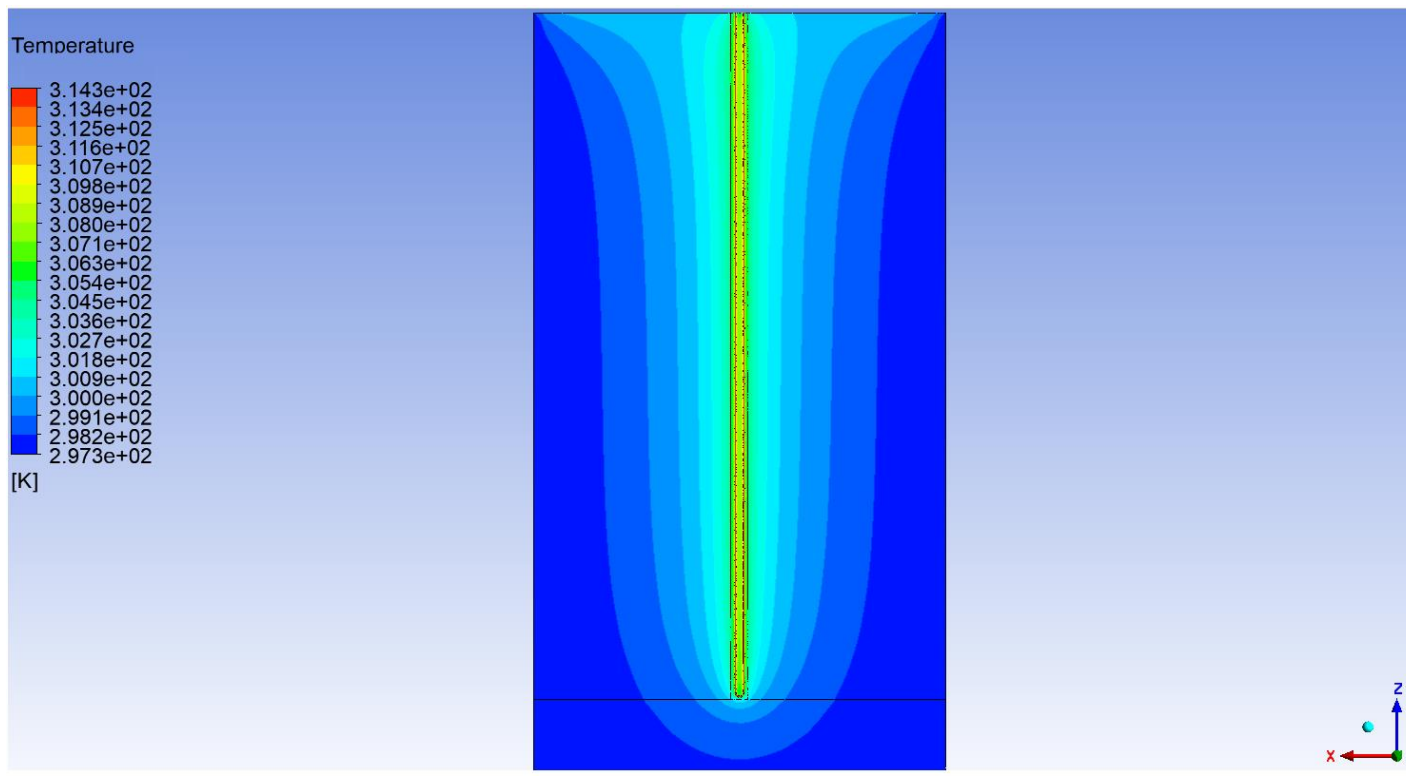
A justificativa para a redução dos valores de diâmetro de influência térmica é embasada na Lei de Fourier (Equação 3.3): conforme aumentam-se a taxa de transferência de calor e a condutividade térmica do solo, são reduzidos os valores de gradiente térmico ao longo do maciço de solo, o que afeta a distribuição de temperaturas no material. Nas simulações em se que variou a condutividade térmica do concreto observou-se o contrário, uma vez que o aumento da taxa de transferência de calor devido ao aumento da condutividade térmica do concreto ocorreu com valores fixos de condutividade térmica do solo $\left(2,82 \mathrm{~W} \cdot \mathrm{m}^{-1} \cdot \mathrm{K}^{-1}\right)$. Consequentemente, houve aumento dos gradientes térmicos no solo conforme aumentaram-se as taxas de transferência de calor.

Realizaram-se simulações para determinar a influência isolada dos parâmetros condutividade térmica e calor específico do solo nas trocas térmicas do sistema em regime estacionário. Fixando-se o calor específico do solo em $1000 \mathrm{~J} \cdot \mathrm{kg}^{-1} \cdot \mathrm{K}^{-1}$, o aumento da condutividade térmica do solo ocasionou o aumento da taxa de transferência de calor nas interfaces do sistema, como mostra a Figura 5.35. Para os valores de condutividade térmica do solo de $1,0 \mathrm{~W} \cdot \mathrm{m}^{-1} \cdot \mathrm{K}^{-1}$ e $20,0 \mathrm{~W} \cdot \mathrm{m}^{-1} \cdot \mathrm{K}^{-1}$, na interface concreto/solo, destacamse os valores de taxa de transferência de calor total: 250,98 W e 770,79 W, respectivamente.

Figura 5.35 - Taxa de transferência de calor total em função da condutividade térmica do solo para calor específico constante, por interface

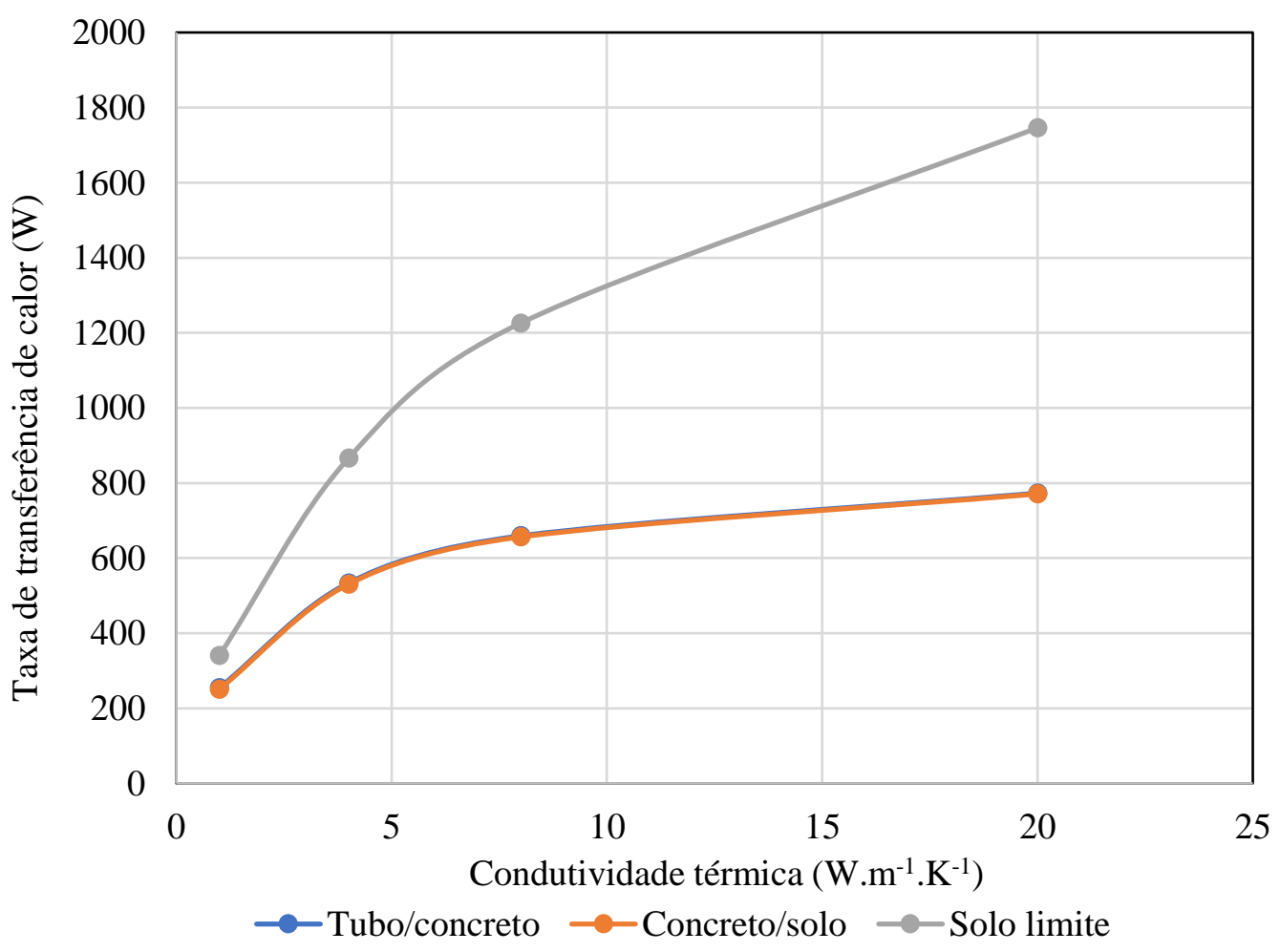


Esses resultados foram coerentes com as conclusões anteriores, assim como a distribuição de temperaturas médias nas interfaces do sistema geotérmico, como mostra a Figura 5.36. Na interface concreto/solo, para condutividade térmica do solo de 1,0 W.m. $\mathrm{m}^{-1} \cdot \mathrm{K}^{-1}$ e $20,0 \mathrm{~W} \cdot \mathrm{m}^{-1} \cdot \mathrm{K}^{-1}$, as temperaturas são $309,3 \mathrm{~K}$ e $299,4 \mathrm{~K}$, respectivamente.

Figura 5.36 - Temperatura média em função da condutividade térmica do solo para calor específico constante, por interface

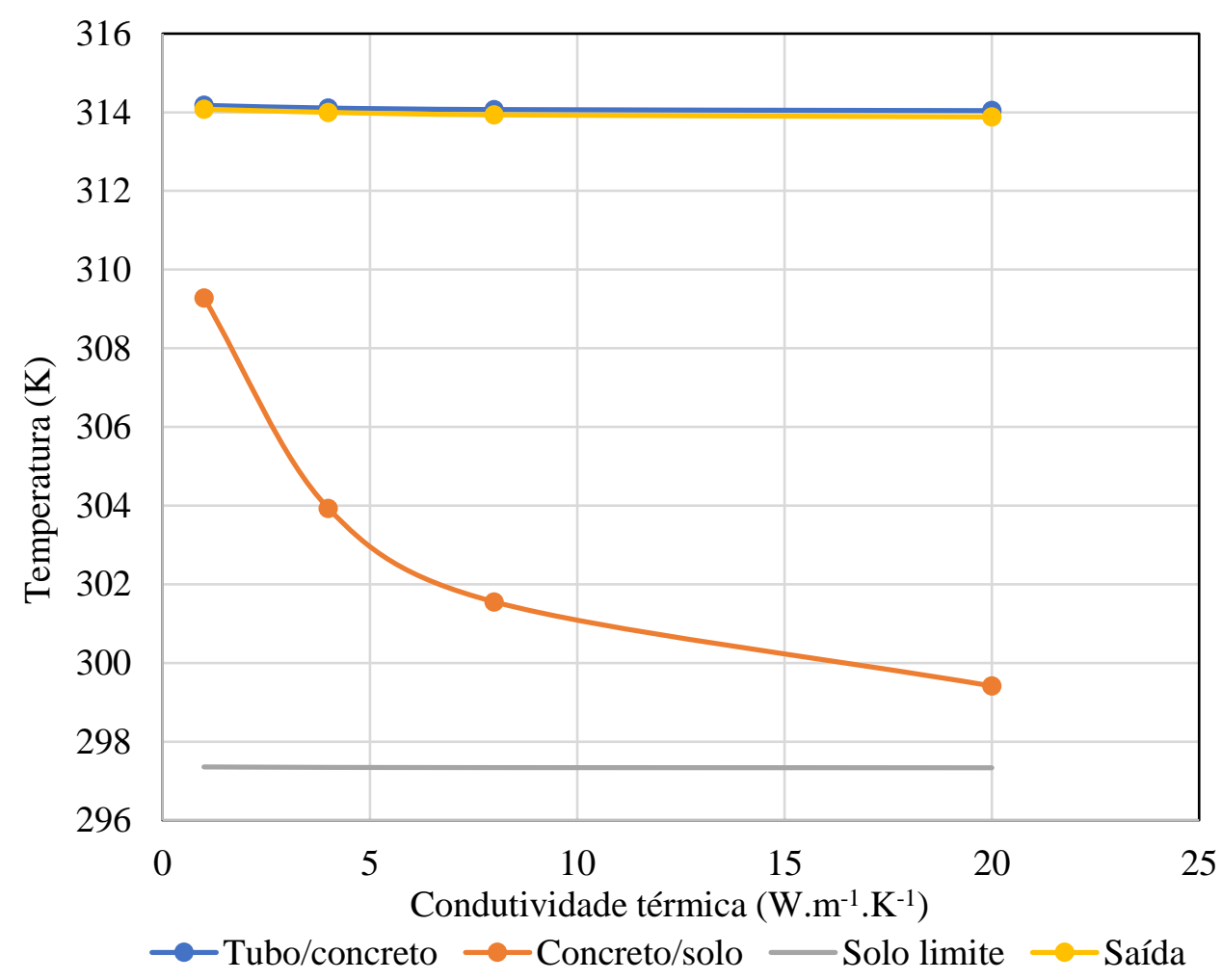

Por outro lado, ao fixar-se a condutividade térmica do solo em $2,82 \mathrm{~W} \cdot \mathrm{m}^{-1} \cdot \mathrm{K}^{-1} \mathrm{e}$ variar-se o calor específico do solo, verificou-se que os valores de taxa de transferência de calor e temperatura por interface permanecem constantes. A constância observada está em conformidade com o conhecimento de que, em regime permanente, a transferência de calor não depende do calor específico dos materiais. Na interface concreto/solo a taxa de transferência de calor foi constante e igual a 457,78 W, como ilustra a Figura 5.37. A distribuição de temperaturas nas interfaces do sistema geotérmico não é afetada pela variação do calor específico do solo, como mostra a Figura 5.38. Na interface concreto/solo verificou-se a temperatura constante de 305,3 K. 
Figura 5.37 - Taxa de transferência de calor total em função do calor específico do solo para condutividade térmica do solo constante, por interface

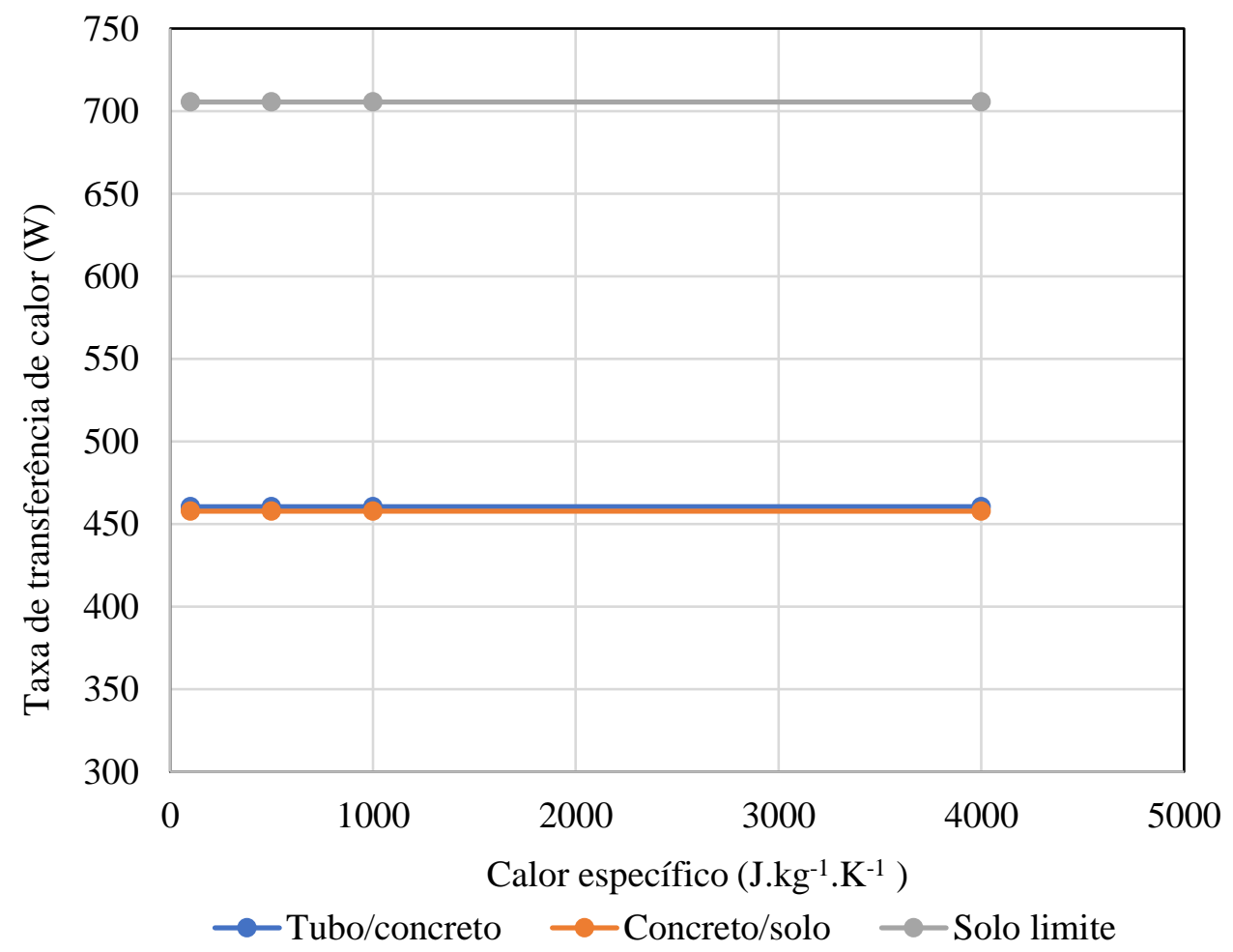

Figura 5.38 - Temperatura média por interface em função do calor específico do solo para condutividade térmica do solo constante, por interface

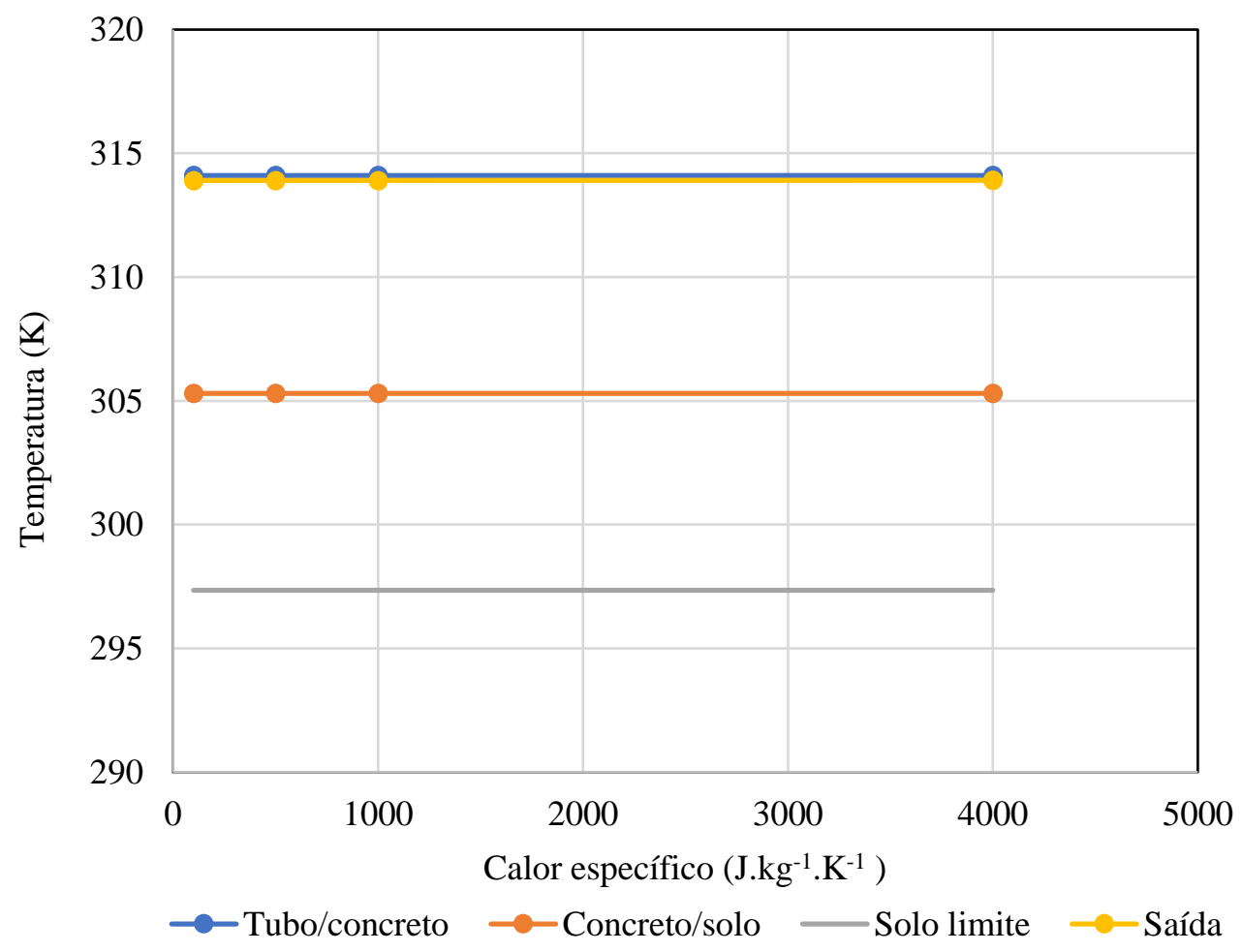




\subsection{VARIAÇÃO DO GRAU DE SATURAÇÃO DO SOLO}

Atribuiu-se ao material solo os seguintes valores de condutividade térmica, relacionados a respectivos valores de grau de saturação (s), conforme estudo experimental apresentado em Sánchez et al. (2015): $0,90 \mathrm{~W} \cdot \mathrm{m}^{-1} \cdot \mathrm{K}^{-1}(\mathrm{~s}=1,5 \%), 1,35 \mathrm{~W} \cdot \mathrm{m}^{-1} \cdot \mathrm{K}^{-1}(\mathrm{~s}=$ $18,8 \%), 1,75 \mathrm{~W} \cdot \mathrm{m}^{-1} \cdot \mathrm{K}^{-1}(\mathrm{~s}=31,1 \%), 2,10 \mathrm{~W} \cdot \mathrm{m}^{-1} \cdot \mathrm{K}^{-1}(\mathrm{~s}=48,0 \%), 2,40 \mathrm{~W} \cdot \mathrm{m}^{-1} \cdot \mathrm{K}^{-1}(\mathrm{~s}=$ $71,5 \%)$ e $2,65 \mathrm{~W} \cdot \mathrm{m}^{-1} \cdot \mathrm{K}^{-1}(\mathrm{~s}=100,0 \%)$. Mais dados podem ser encontrados na Tabela 4.11 .

A variação da taxa de transferência de calor em função do grau de saturação do solo, nas interfaces do sistema geotérmico, é apresentada na Figura 5.39. As curvas exibem padrões similares aos obtidos para a variação de taxa de transferência de calor em função da condutividade térmica do solo (item 5.7), porém o aumento do grau de saturação ocasiona pequenos aumentos de condutividade térmica. Como resultado, ocorrem reduzidos incrementos de taxa de transferência de calor à medida que o solo se satura. $\mathrm{Na}$ interface concreto/solo, para os graus de saturação de 1,5 \% e 100,0 \%, destacam-se os valores de taxa de transferência de calor: 233,12 W e 441,04 W, respectivamente. As taxas de transferência de calor apresentam tendência à estabilidade a partir de graus de saturação da ordem de $20 \%$.

Figura 5.39 - Taxa de transferência de calor em função grau de saturação do solo, por interface

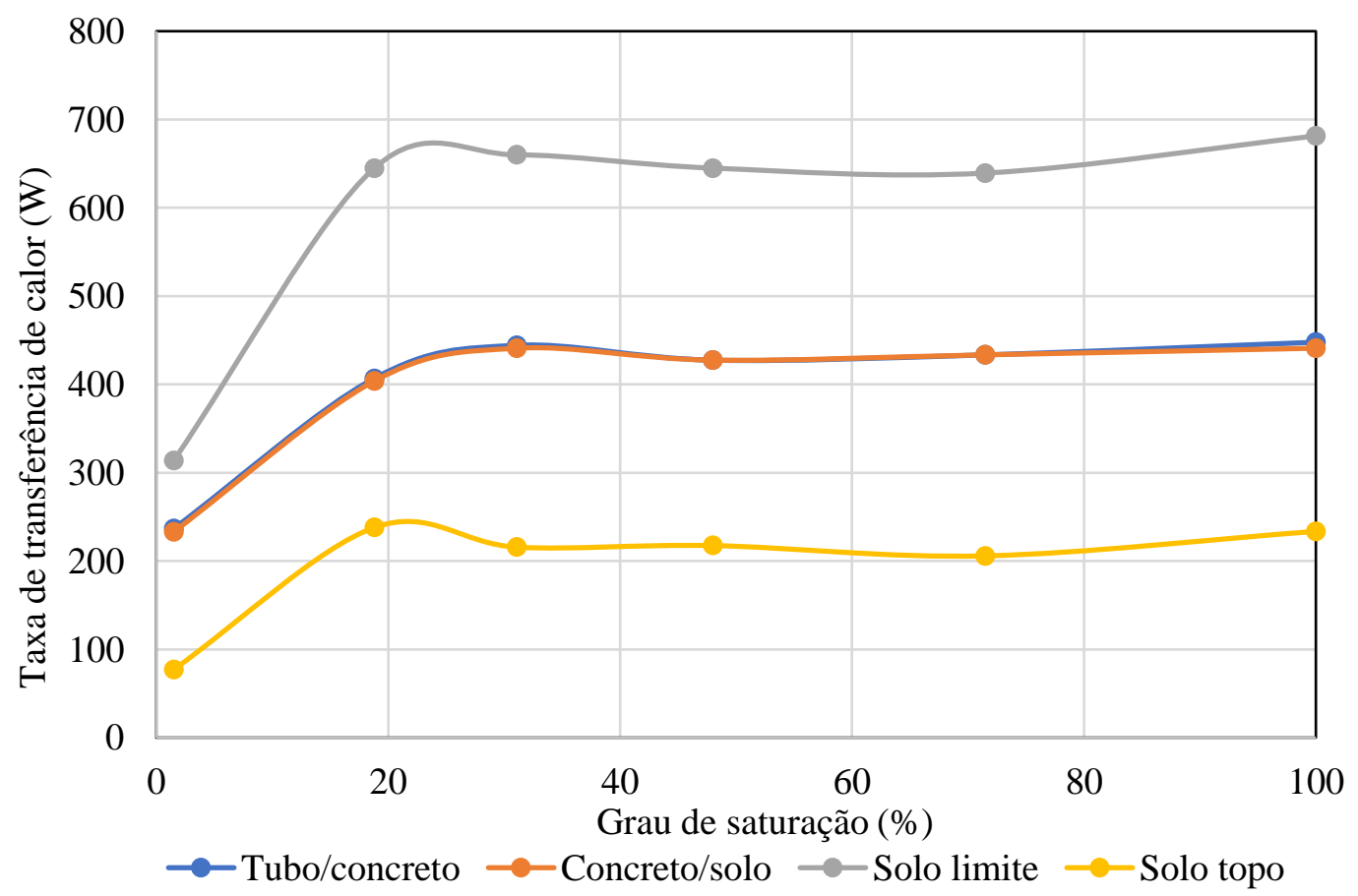


Sánchez et al. (2015) mostraram que, entre máxima e mínima saturação, o desempenho do sistema geotérmico em areias pode cair em até $40 \%$. Nas simulações aqui desenvolvidas estima-se que essa redução seja de $53 \%$.

A Figura 5.40 exibe a distribuição de temperaturas médias nas superfícies do sistema geotérmico em função do grau de saturação para o cenário base. Os resultados são semelhantes aos observados para a variação de temperatura em função da condutividade térmica do solo (item 5.6). A redução de temperaturas não é tão acentuada quanto na Figura 5.24, porque os incrementos de condutividade térmica provocados pelo crescimento grau de saturação são relativamente pequenos. A partir do grau de saturação de $18,8 \%$, as temperaturas nessa interface não diminuem mais em função do aumento do grau de saturação. Na superfície concreto/solo são observadas as temperaturas, para os graus de saturação de 1,5 \% e 100,0 \%: 309,6 K e 305,6 K, respectivamente.

Figura 5.40 - Temperatura média em função do grau de saturação do solo, por interface

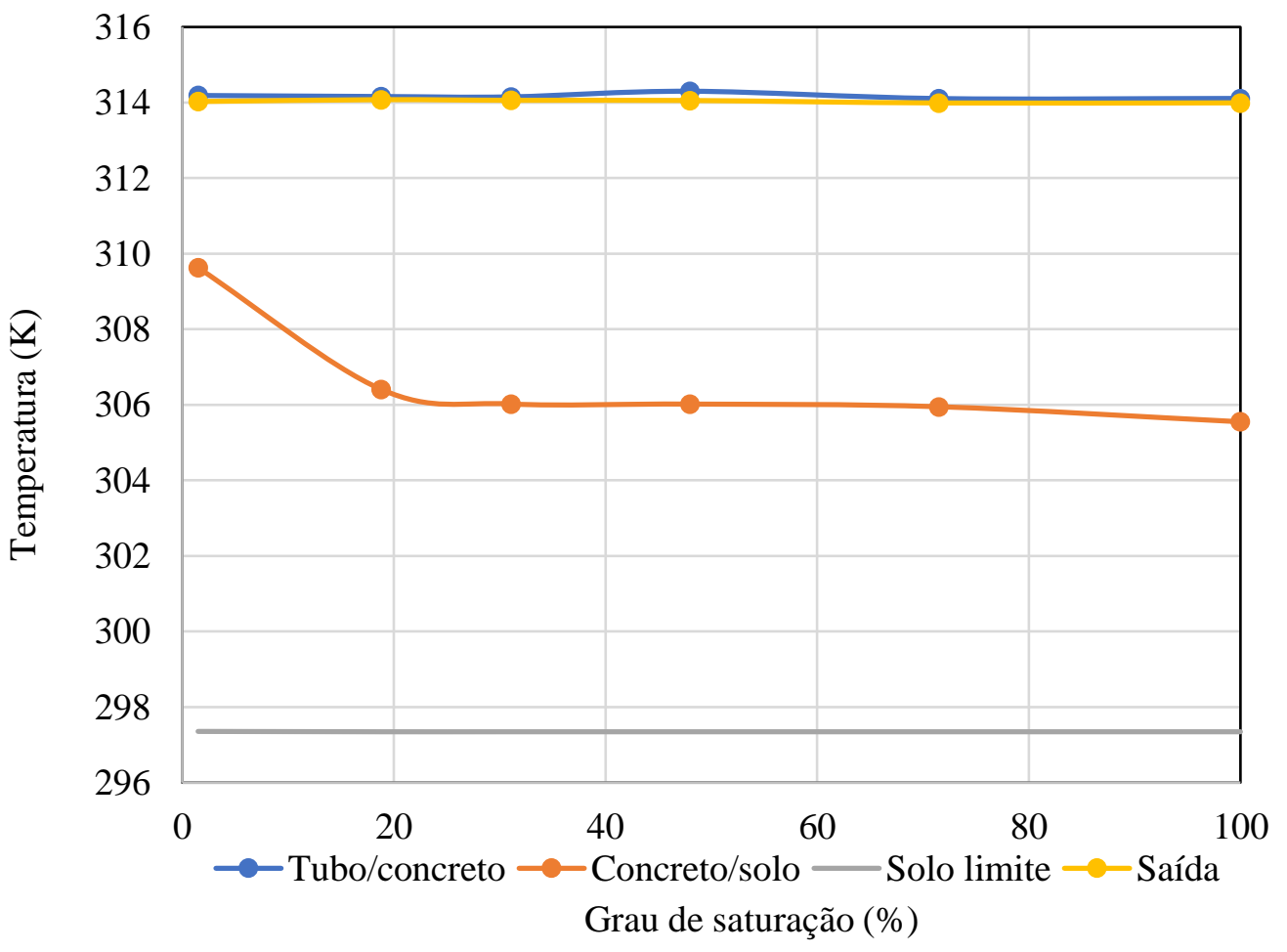

A Figura 5.41 apresenta os valores de taxa de transferência de calor em função do grau de saturação para a interface concreto/solo nos cenários 1 e 2 . As curvas obtidas são coerentes com as discussões no item 5.7. Para o grau de saturação de $100 \%$, a diferença de taxa de transferência de calor entre os cenários 1 e 2 é de 143,67 W. A diferença de 
143,67 W representa aumento de 32,6 \% da taxa de calor transferida ao solo em relação ao cenário 1 pela interface concreto/solo.

Figura 5.41 - Taxa de transferência de calor total em função do grau de saturação considerando os cenários 1 e 2

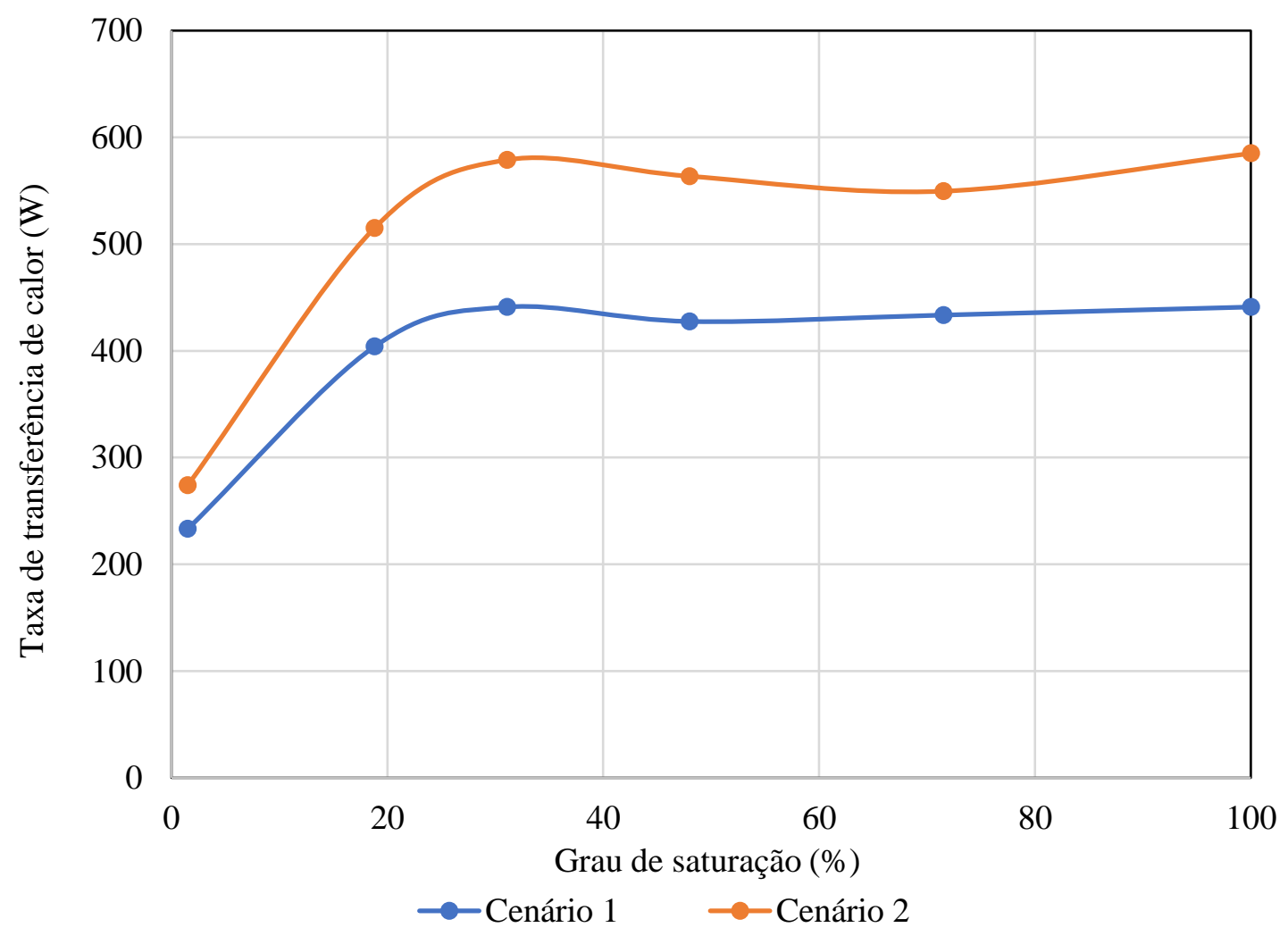

A Figura 5.42 apresenta uma comparação da distribuição de temperaturas médias na interface concreto/solo considerando-se os cenários 1 e 2 . Nota-se que a temperatura diminui conforme o grau de saturação aumenta. Porém, no cenário 1 (que apresenta menores valores de temperaturas médias em comparação com o cenário 2, em que não há resistência térmica de contato), a partir do grau de saturação de $30 \%$, o grau de saturação pouco influencia a temperatura nessa interface. A diferença de temperaturas entre os cenários é de 2,4 K para grau de saturação de $100 \%$.

O diâmetro de influência térmica diminui com o aumento do grau de saturação, como mostra a Figura 5.43. Esse fenômeno é similar aos resultados observados no item 5.7 e pode igualmente ser explicado através da Lei de Fourier: conforme aumenta-se a taxa de transferência de calor total e o grau de saturação do solo (que provoca o aumento de sua condutividade térmica), são reduzidos os gradientes térmicos ao longo do maciço de solo, alterando a distribuição de temperaturas no material. A diferença entre diâmetros de influência térmica nos cenários 1 e 2 é de 0,3 m para grau de saturação igual a $100 \%$. 
Figura 5.42 - Temperatura média em função do grau de saturação do solo considerando os cenários 1 e 2

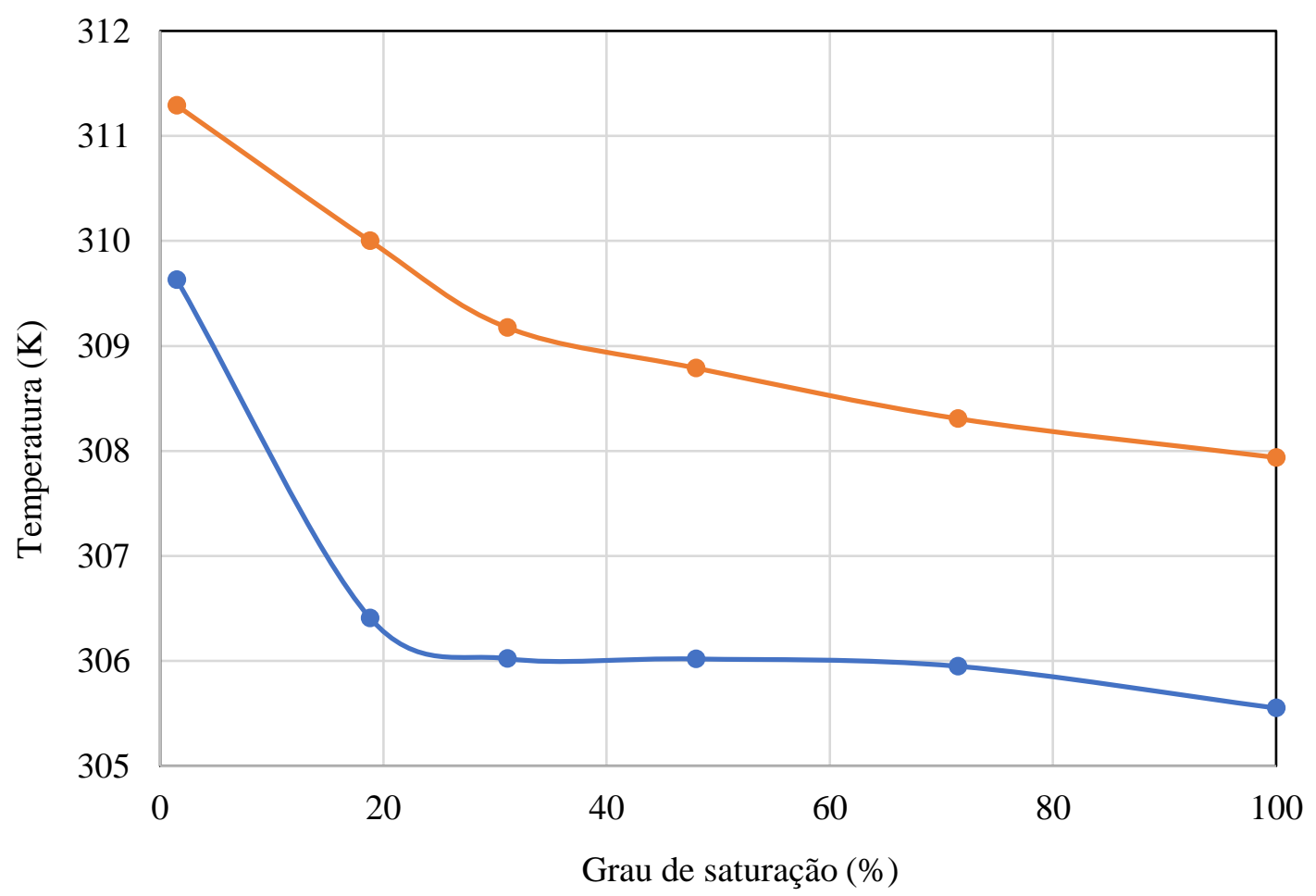

$\rightarrow$ Cenário $1 \rightarrow$ Cenário 2

Figura 5.43 - Diâmetro de influência térmica em função do grau de saturação solo considerando os cenários 1 e 2

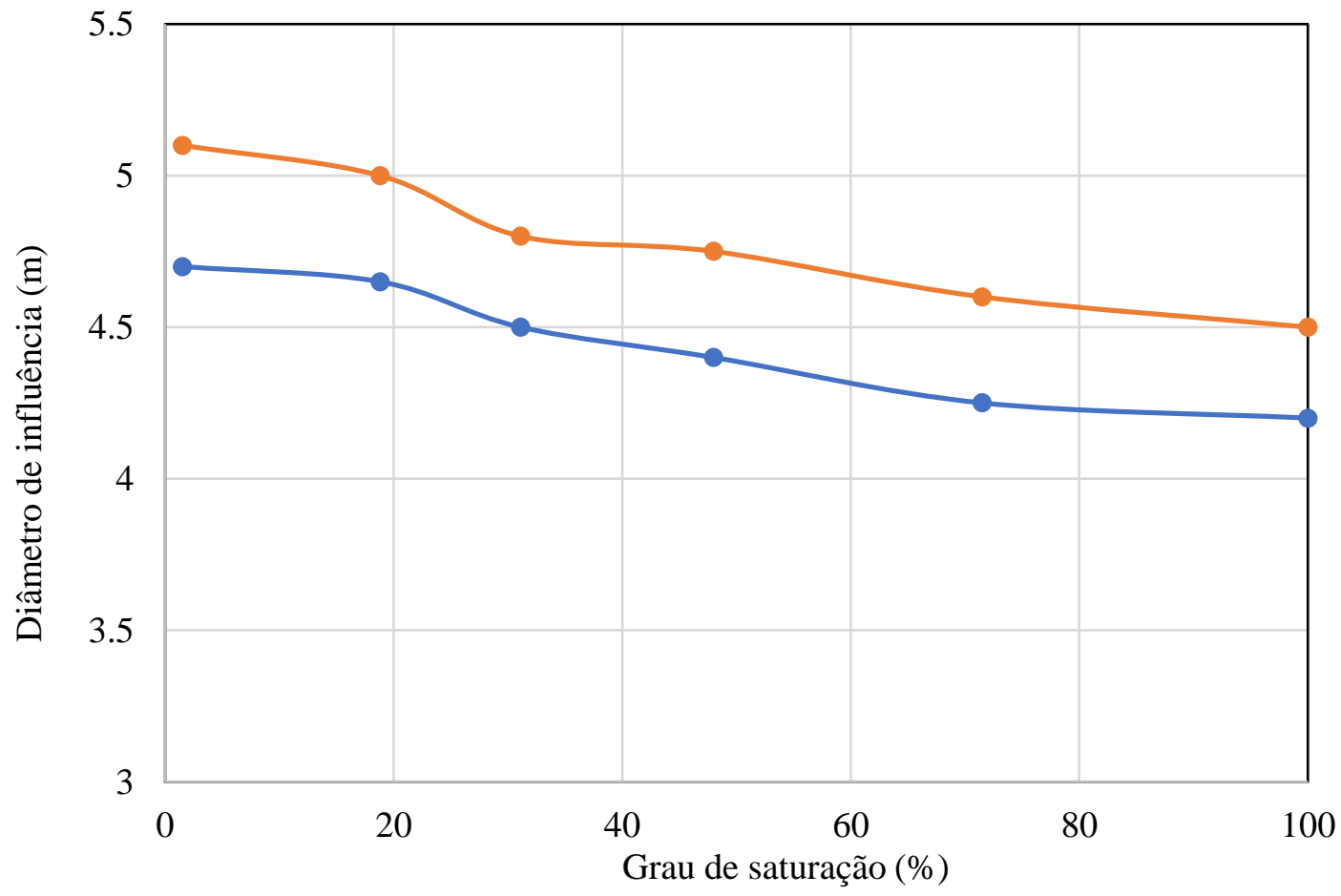

$\multimap$ Cenário $1 \quad \longrightarrow$ Cenário 2 


\subsection{VARIAÇÃO DA TEMPERATURA DE ENTRADA DO FLUIDO CIRCULANTE} NA ESTACA

Foram simulados os seguintes valores para a temperatura de entrada na estaca do fluido circulante: $293,1 \mathrm{~K}\left(20{ }^{\circ} \mathrm{C}\right), 303,1 \mathrm{~K}\left(30{ }^{\circ} \mathrm{C}\right), 313,1 \mathrm{~K}\left(40{ }^{\circ} \mathrm{C}\right), 323,1 \mathrm{~K}\left(50{ }^{\circ} \mathrm{C}\right)$, $333,1 \mathrm{~K}\left(60{ }^{\circ} \mathrm{C}\right), 343,1 \mathrm{~K}\left(70{ }^{\circ} \mathrm{C}\right), 353,1 \mathrm{~K}\left(80{ }^{\circ} \mathrm{C}\right), 363,1 \mathrm{~K}\left(90{ }^{\circ} \mathrm{C}\right)$ e $373,1 \mathrm{~K}\left(100{ }^{\circ} \mathrm{C}\right)$. Para o ensaio TRT, no instante equivalente a 200 h, a temperatura de entrada era de 314,3 $\mathrm{K}\left(41,14^{\circ} \mathrm{C}\right)$.

A Figura 5.44 mostra a variação da taxa de transferência de calor em função da temperatura de entrada do fluido no tubo, nas diferentes interfaces do sistema, simuladas a partir do cenário base. É nítido o aumento linear da taxa de transferência de calor com a temperatura de entrada do fluido, coerente com o fenômeno físico relacionado: à medida que a temperatura de entrada do fluido aumenta a quantidade de energia na forma de calor inserida no sistema geotérmico, o gradiente de temperatura entre o fluido e o restante do sistema aumenta. Essa energia dissipa-se nas diferentes interfaces e a diferença entre as taxas de transferência de calor das diferentes interfaces diminui com o aumento da temperatura de entrada. A partir de temperaturas de entrada de cerca de $360 \mathrm{~K}$, tais diferenças são inferiores a $50 \mathrm{~K}$. A proximidade entre as retas correspondentes a cada interface, com o aumento da temperatura de entrada do fluido, evidencia que as trocas térmicas com o ar em temperatura ambiente são cada vez menos relevantes.

Para os valores de temperatura de entrada do fluido de 293,1 K, 333,1 K e 373,1 $\mathrm{K}$, na interface concreto/solo, destacam-se os valores de taxa de transferência de calor total: $-131,34 \mathrm{~W}, 979,05 \mathrm{~W}$ e 2090,20 W, respectivamente. Para a temperatura de entrada de 293,1 K, inferior à temperatura não perturbada do solo (na qual o sistema geotérmico se encontra antes do início das simulações), a estaca absorve calor do solo para o fluido circulante e aquece a estrutura do edifício. Nessas simulações escolheu-se esse valor extremo para que se desenvolvesse sensibilidade com relação ao funcionamento do modelo numérico. 
Figura 5.44 - Variação da taxa de transferência de calor total por interface em função da temperatura de entrada do fluido circulante

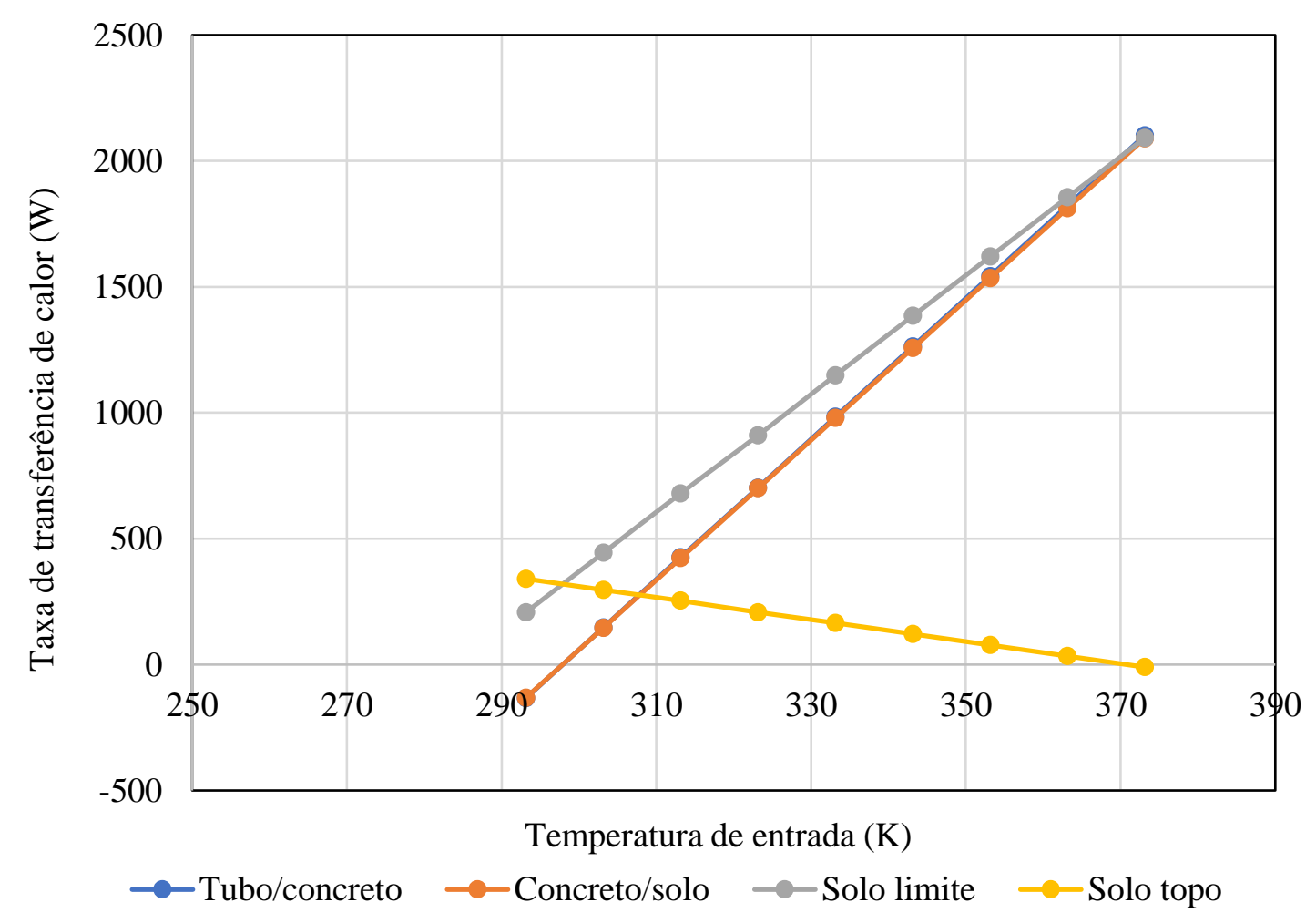

A Figura 5.45 mostra a distribuição de temperaturas médias nas superfícies do sistema geotérmico em função da temperatura de entrada do fluido, para o cenário base. Em todas as interfaces (exceto a solo limite) a temperatura aumenta linearmente com a temperatura de entrada do fluido, ao mesmo tempo em que as temperaturas diminuem conforme a distância radial a partir do centro da estaca aumenta. Na superfície concreto/solo são observadas as temperaturas $295,7 \mathrm{~K}, 313,7 \mathrm{~K}$ e $331,8 \mathrm{~K}$, para as temperaturas de entrada do fluido de $293,1 \mathrm{~K}, 333,1 \mathrm{~K}$ e $373,1 \mathrm{~K}$, respectivamente.

Como exibe a Figura 5.46, a diferença de temperatura do fluido circulante nos pontos de entrada e de saída dos tubos aumenta conforme a temperatura de entrada sofre acréscimos. Nota-se que, mesmo com consideráveis trocas térmicas entre os tubos de entrada e saída, o aumento da temperatura de entrada propicia maiores trocas térmicas da estrutura de concreto da estaca com o solo do que entre os tubos em que circula o fluido. Como resultado das maiores taxas de calor transferidas ao solo, ocorrem maiores diferenças de temperatura entre os pontos de entrada e saída do fluido circulante. A diferença entre as temperaturas médias do fluido circulante nas posições de entrada e saída do tubo foram - 0,2 K, 1,1 K e 2,3 K, para as temperaturas de entrada 293,1 K, 333,1 $\mathrm{K}$ e $373,1 \mathrm{~K}$, respectivamente. 
Figura 5.45 - Temperatura média em função da temperatura de entrada do fluido circulante, por interface

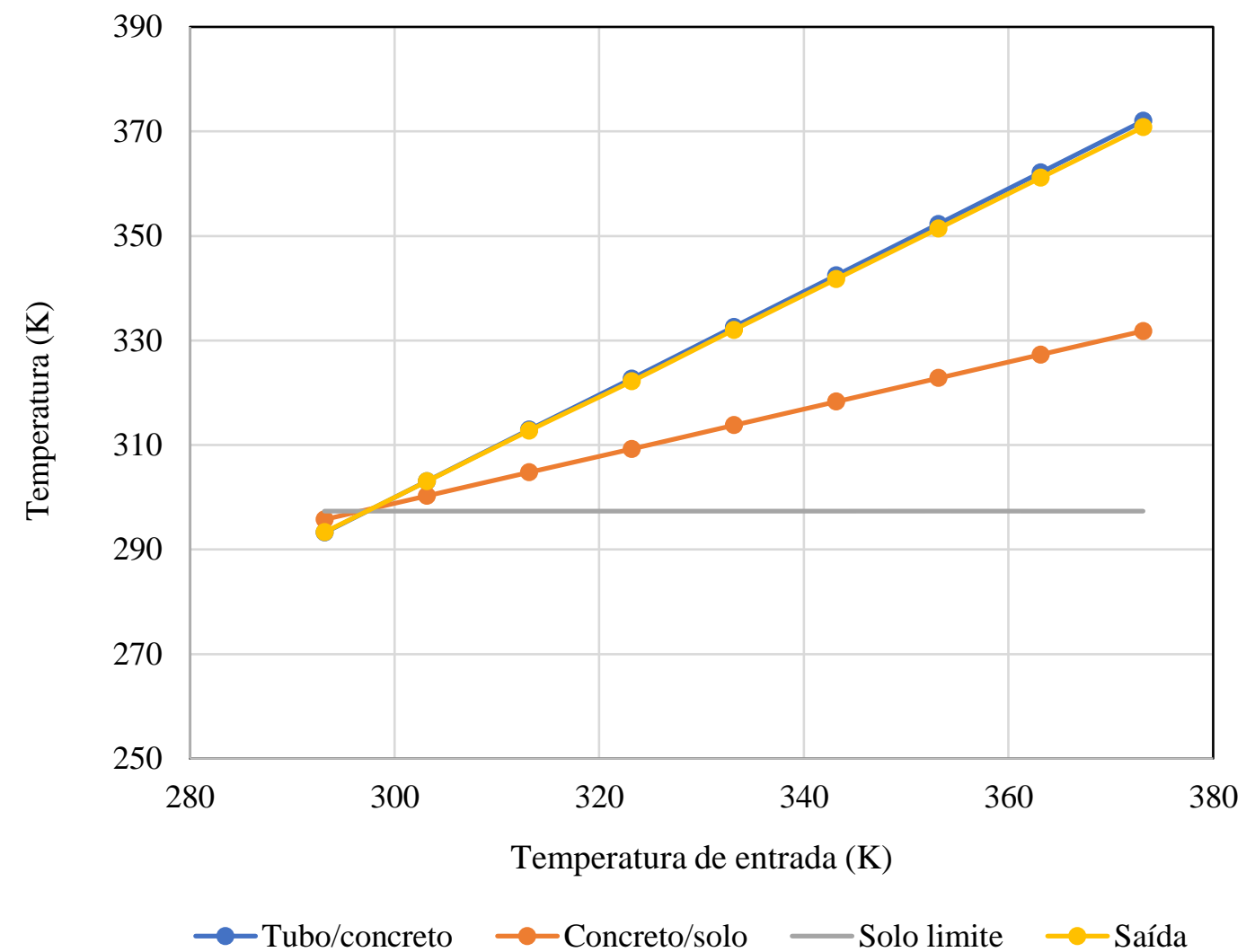

Figura 5.46 - Diferença de temperatura do fluido circulante nos pontos de entrada e de saída dos tubos em função da temperatura de entrada do fluido circulante

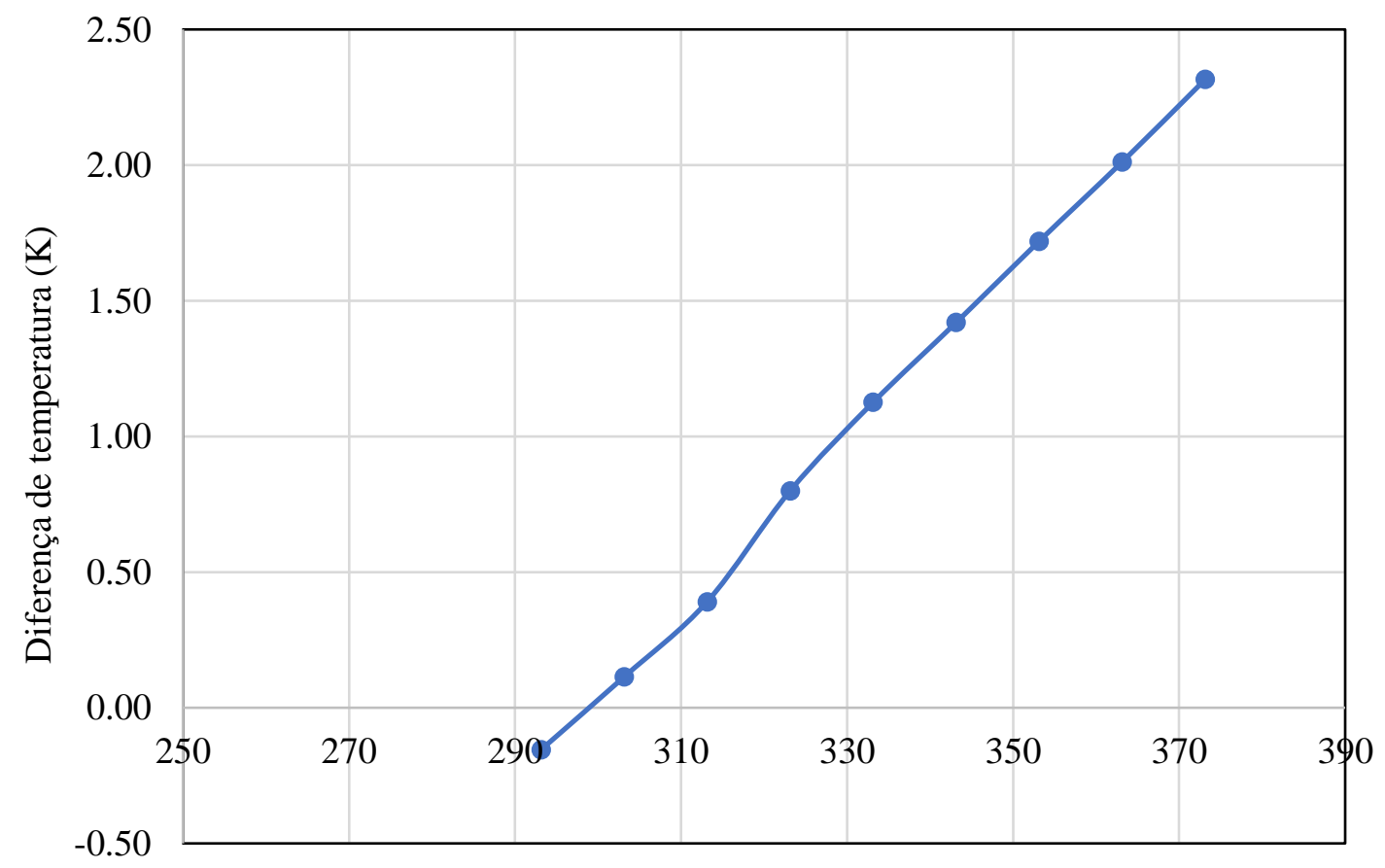

Temperatura de entrada (K) 
A Figura 5.47 apresenta a variação da taxa de transferência de calor em função da temperatura de entrada do fluido na interface concreto/solo nos cenários 1 e 2 . Nota-se o crescimento linear da taxa de transferência de calor em função da temperatura de entrada do fluido. Conforme esperado, a reta correspondente ao cenário 1 apresenta valores inferiores aos do cenário 2. Para a temperatura de entrada de $373,1 \mathrm{~K}$, a diferença de taxa de transferência de calor entre os cenários 1 e 2 é igual a 688,24 W. Ou seja, se não houvesse resistência térmica de contato, aumentaria em $33 \%$ a taxa de transferência de calor para a temperatura de entrada de fluido igual a $373,1 \mathrm{~K}$.

Figura 5.47 - Taxa de transferência de calor total em função da temperatura de entrada do fluido circulante considerando os cenários 1 e 2

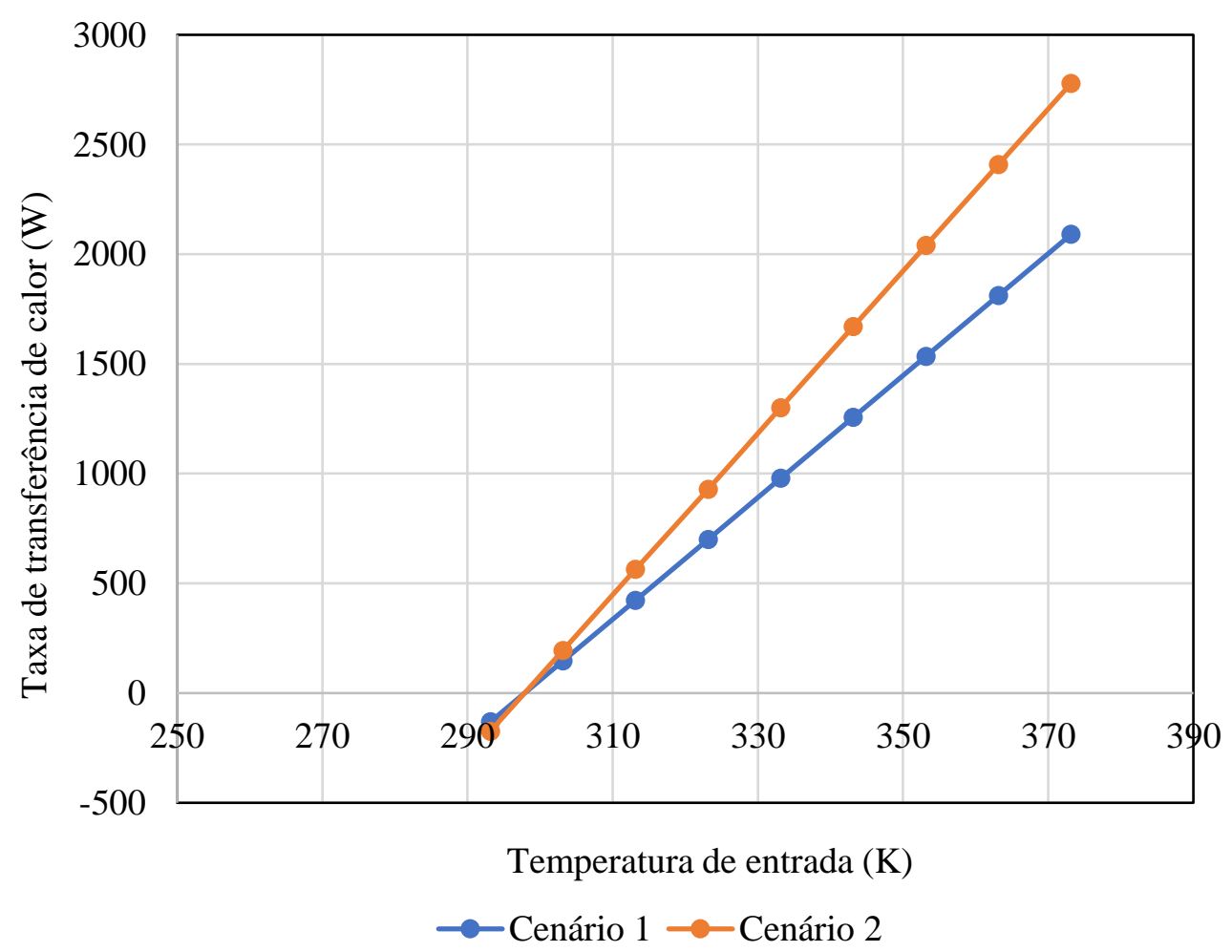

A Figura 5.48 compara a distribuição de temperaturas médias na interface concreto/solo considerando-se os cenários 1 e 2 . Nota-se que a temperatura nas interfaces aumenta linearmente conforme a temperatura de entrada do fluido aumenta. Devido à resistência de contato de $0,012 \mathrm{~m}^{2} . \mathrm{K} . \mathrm{W}^{-1}$ na interface tubo/concreto, os valores no cenário 1 são inferiores aos do cenário 2 . A diferença de temperaturas entre os cenários é de 10,9 K para a temperatura de entrada de $373,1 \mathrm{~K}$. 
Figura 5.48 - Temperatura média em função da temperatura de entrada do fluido circulante considerando os cenários 1 e 2

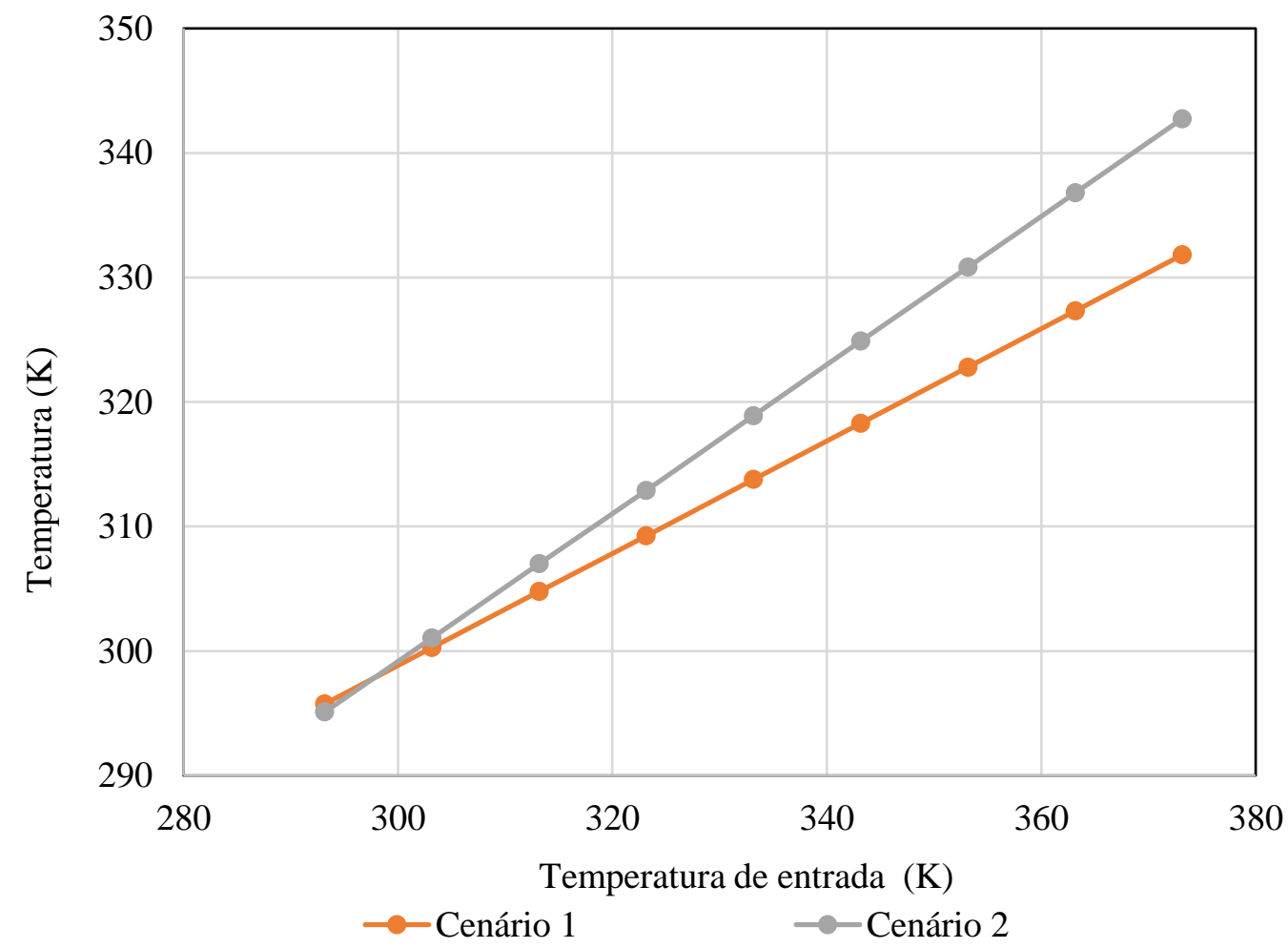

O diâmetro de influência térmica aumentou com a temperatura de entrada do fluido circulante, como mostra a Figura 5.49. O crescimento foi aproximadamente linear até a temperatura de entrada de 313,1 K. Para temperaturas mais elevadas do que $340 \mathrm{~K}$, o diâmetro de influência térmica pouco varia em função da temperatura de entrada do fluido. Esse fato pode ser justificado pelo efeito da capacidade térmica do solo, parâmetro que relaciona a quantidade de energia na forma de calor fornecida a um corpo à sua variação de temperatura: à medida que se aproxima da capacidade térmica do solo, menores são as variações de temperatura experimentadas pelo material, ainda que seja aumentada a taxa de transferência de calor. Conforme os gradientes térmicos se estabilizam, o diâmetro de influência térmica tende a ficar constante.

Atribuindo-se valores de resistência térmica de contato de $0,012 \mathrm{~m}^{2} . \mathrm{K} \mathrm{W}^{-1}$ à interface tubo/concreto no cenário 1 e nula no cenário 2 , a diferença entre diâmetros de influência térmica dos cenários é de 0,35 m para a temperatura de entrada de 373,1 K. 
Figura 5.49 - Diâmetro de influência térmica em função da temperatura de entrada do fluido circulante considerando os cenários 1 e 2

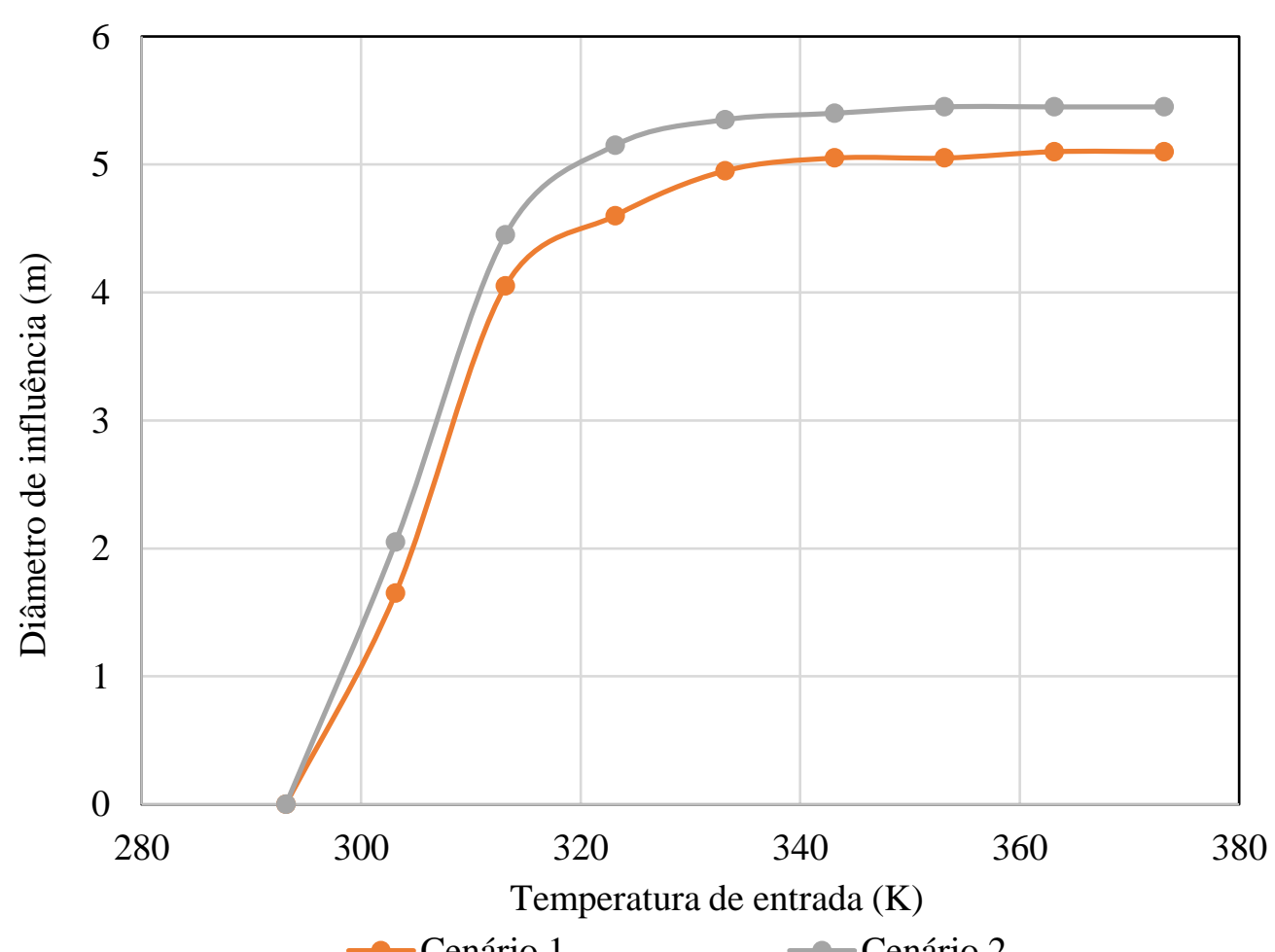

\subsection{VARIAÇÃO DA VELOCIDADE/VAZÃO DO FLUIDO CIRCULANTE}

As simulações em que se variou a velocidade/vazão do fluido que circula pelo interior dos tubos revelaram que o aumento da vazão implica no aumento da taxa de transferência de calor trocada entre a estaca e o solo, conforme esperado. A Figura 5.50 apresenta, para o cenário-base, a variação da taxa de transferência de calor em função da vazão do fluido circulante nas interfaces: tubo/concreto, concreto/solo e superfície solo limite. Os valores de taxa de transferência de calor aumentam acentuadamente e tendem à estabilidade a partir de vazões de $10 \mathrm{~L} / \mathrm{min}$. Para esta vazão, são observadas as taxas de transferência de calor de 453,04 W, 448,63 W e 702,07 W para as interfaces tubo/concreto, concreto/solo e solo limite, respectivamente. 
Figura 5.50 - Taxa de transferência de calor em função da variação da velocidade do fluido circulante, por interface

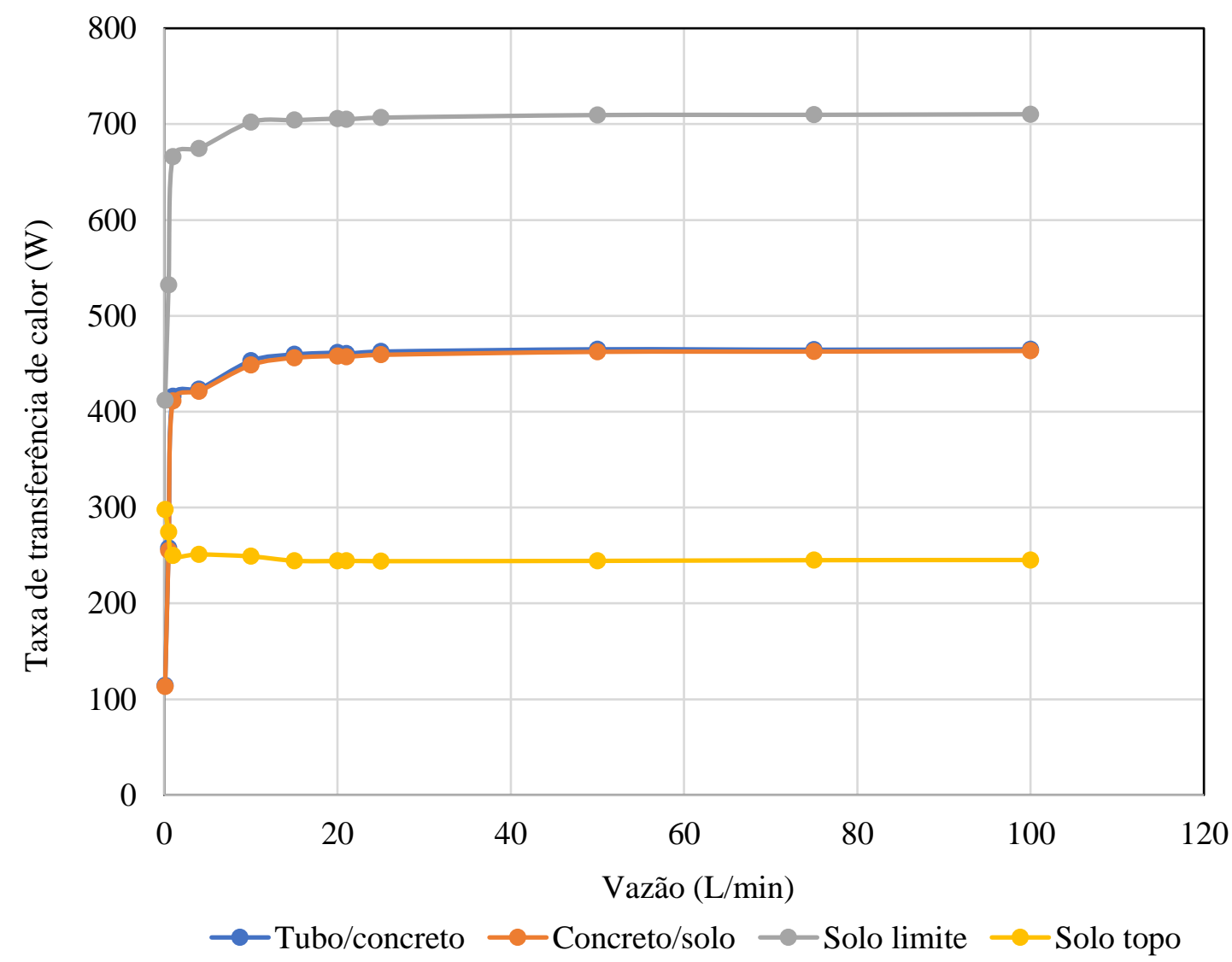

O aumento da taxa de transferência de calor da estaca com o aumento da velocidade/vazão do fluido circulante pode ser justificado a partir da interpretação das Equações 3.6 e 3.8, que relacionam o número de Nusselt ao número de Reynolds. O aumento da velocidade do fluido circulante provoca o aumento do número de Reynolds, que resulta em acréscimos no número de Nusselt. Assim, maior é a efetividade da troca de calor por convecção, processo que culmina no aumento dos valores totais de taxa de transferência de calor. Por outro lado, maiores valores de vazão diminuem o intervalo de tempo em que ocorrem as trocas térmicas entre fluido e tubos ao ponto que, em regime turbulento, as elevadas velocidades resultam em taxas de transferência de calor constantes (como se nota na Figura 5.50), resultantes da combinação de dois efeitos antagônicos: o aumento do número de Nusselt e a diminuição do intervalo de tempo em que as trocas térmicas ocorrem.

Apesar de o aumento dos valores de velocidade de fluido circulante provocar maiores trocas de calor, as diferenças entre as temperaturas de entrada e saída do fluido circulante diminuem, conforme evidencia a Figura 5.51. 
Figura 5.51 - Diferença entre as temperaturas de entrada e saída do fluido circulante em função da variação da velocidade/vazão do fluido circulante

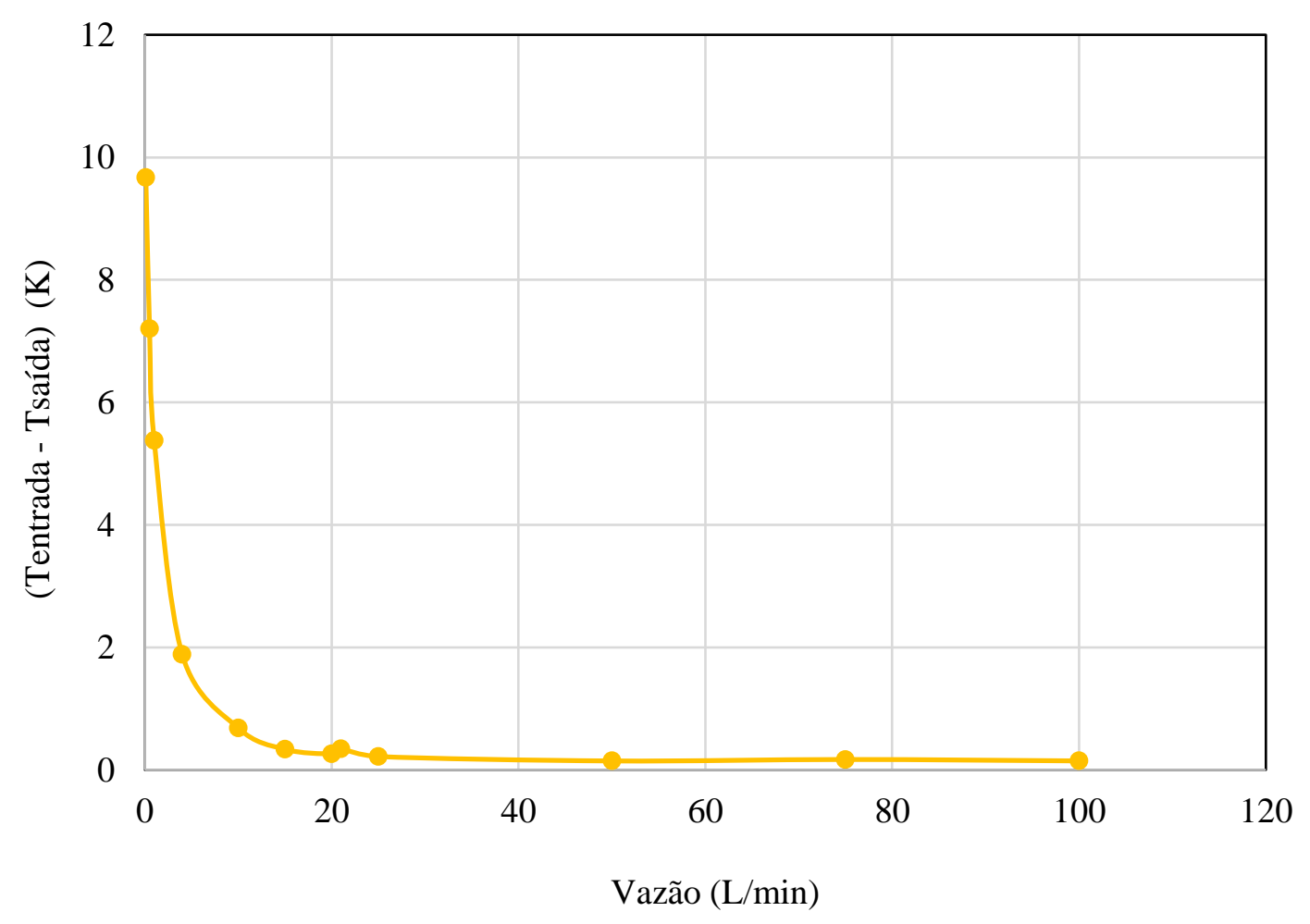

A explicação está nas trocas de calor entre os tubos em que o fluido circula: a água entra na estaca com maior temperatura e desce pelos tubos dissipando calor; ao subir de volta ao topo da estaca a água deveria estar com temperatura menor em comparação à descida. Entretanto, as zonas de influência térmicas provocadas pelo fluido nos tubos de descida e de subida se interpõem e ocorrem trocas de calor entre os tubos. À medida que a velocidade do fluido circulante aumenta, a taxa de transferência de calor nas interfaces aumenta e a diferença de temperatura entre os tubos de descida e subida diminui; até a velocidade atingir determinado valor a partir do qual a taxa de transferência de calor e a diferença de temperatura entre tubos ficam constantes.

Assim, o aumento da velocidade do fluido circulante e, consequentemente, da quantidade de calor transferida ao solo, torna cada vez mais homogêneas as temperaturas no interior da estaca. Em condições extremas, a estaca passaria a operar como uma haste cilíndrica em temperatura uniforme que transfere calor ao solo. A diferença entre as temperaturas de entrada e de saída não mais seria preponderante para determinar as trocas térmicas. A Figura 5.52 ilustra as trocas térmicas, no plano $\mathrm{XZ}$ situado no centro da estaca, entre as regiões próximas aos tubos em que circula o fluido, considerando a 
simulação com vazão de 100 L/min e desenvolvida a partir do cenário base. Observamse temperaturas de $308,4 \mathrm{~K}$ a $308,9 \mathrm{~K}$ na zona de calor que está em contato entre os tubos.

Figura 5.52 - Distribuição de temperaturas próximas aos tubos na porção superior da estaca (vazão de $100 \mathrm{~L} / \mathrm{min}$ ), no plano XZ no centro da estaca

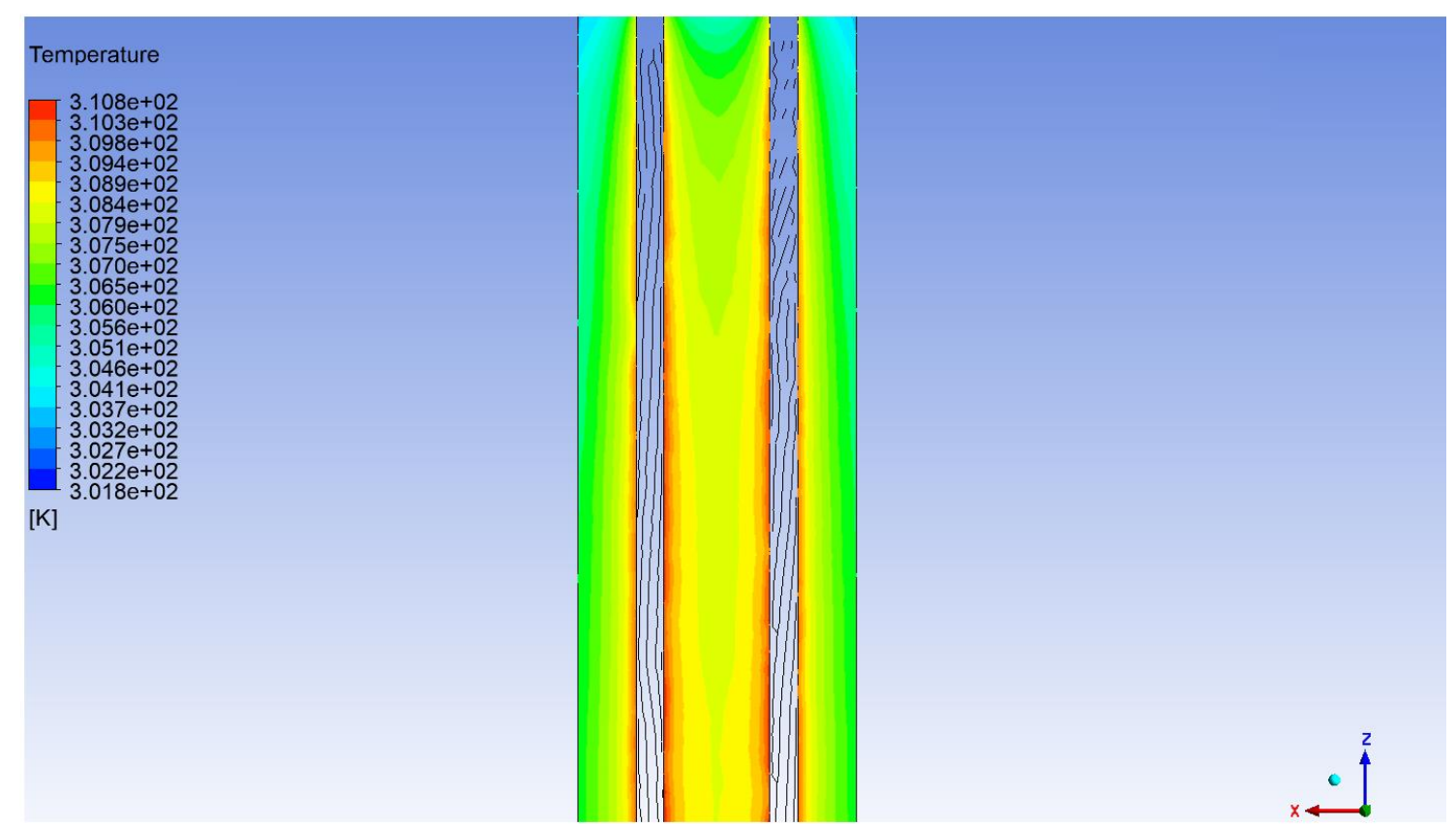

A distribuição de temperaturas em função de valores crescentes de vazão do fluido circulante pode ser observada na Figura 5.53, obtida a partir do cenário base. Em cada interface, as temperaturas aumentam com a vazão até determinado valor de vazão, a partir do qual tornam-se constantes. Além disso, as temperaturas de saída do fluido são similares às temperaturas na interface tubo/concreto (da ordem de $314 \mathrm{~K}$ ). Na interface concreto/solo, por sua vez, as temperaturas estabilizam-se em cerca de 305,3 K.

A Figura 5.54 mostra, a partir da distribuição de temperaturas na superfície do plano XY e na profundidade de 7,5 m, a tendência de diminuição de temperaturas com o aumento da distância radial medida a partir do centro da estaca, considerando a simulação com vazão de 100 L/min a partir do cenário base. Observa-se a confirmação da hipótese de que a dissipação de calor ocorre preferencialmente na direção radial. 
Figura 5.53 - Distribuição de temperaturas em função da vazão, por interface

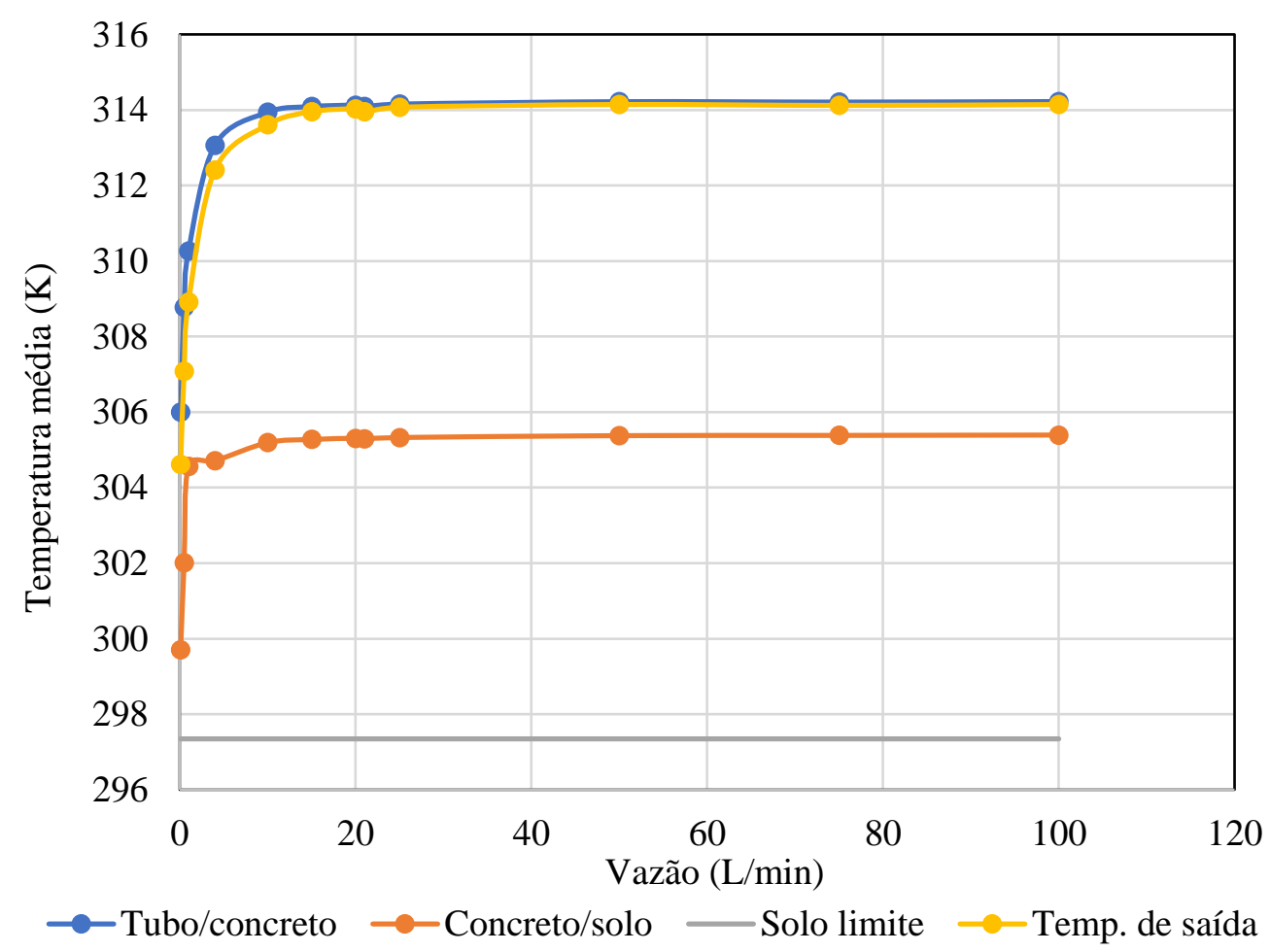

Figura 5.54 - Distribuição de temperaturas no plano XY e na profundidade de 7,5 m (vazão de $100 \mathrm{~L} / \mathrm{min}$ ) do sistema geotérmico

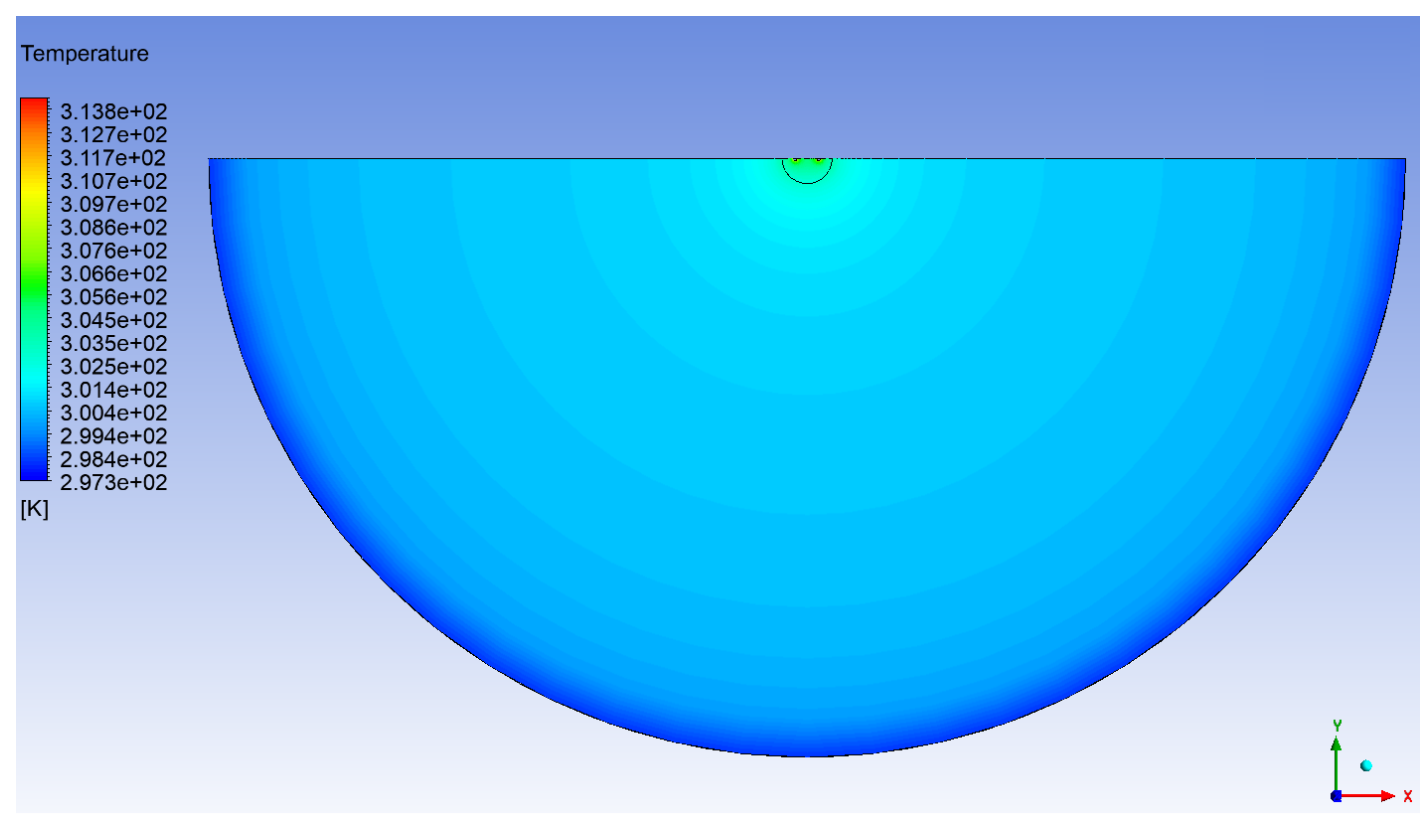

As Figuras 5.55 e 5.56 ilustram as zonas de influência térmicas para as vazões de fluido circulante de $0,1 \mathrm{~L} / \mathrm{min}$ e $100 \mathrm{~L} / \mathrm{min}$, respectivamente, modeladas a partir do cenário base. Observa-se o aumento das zonas de influência térmica com o aumento da 
vazão. Os diâmetros de influência térmica para as vazões de $0,1 \mathrm{~L} / \mathrm{min}$ e $100 \mathrm{~L} / \mathrm{min}$ são de $1,50 \mathrm{~m}$ e $4,35 \mathrm{~m}$, respectivamente.

Figura 5.55 - Zona de influência térmica considerando a vazão de $0,1 \mathrm{~L} / \mathrm{min}$
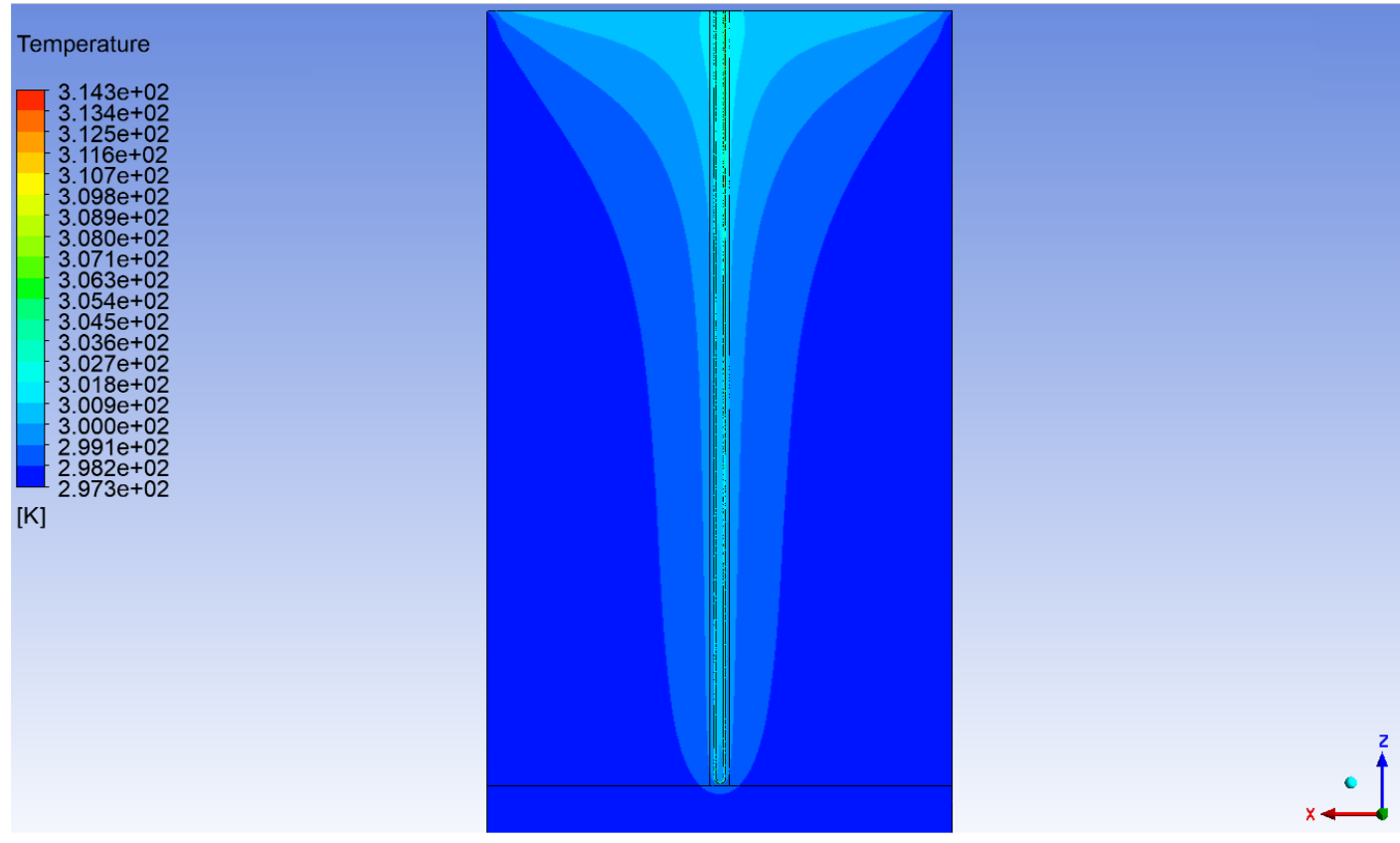

Figura 5.56 - Zona de influência térmica considerando a vazão de 100 L/min
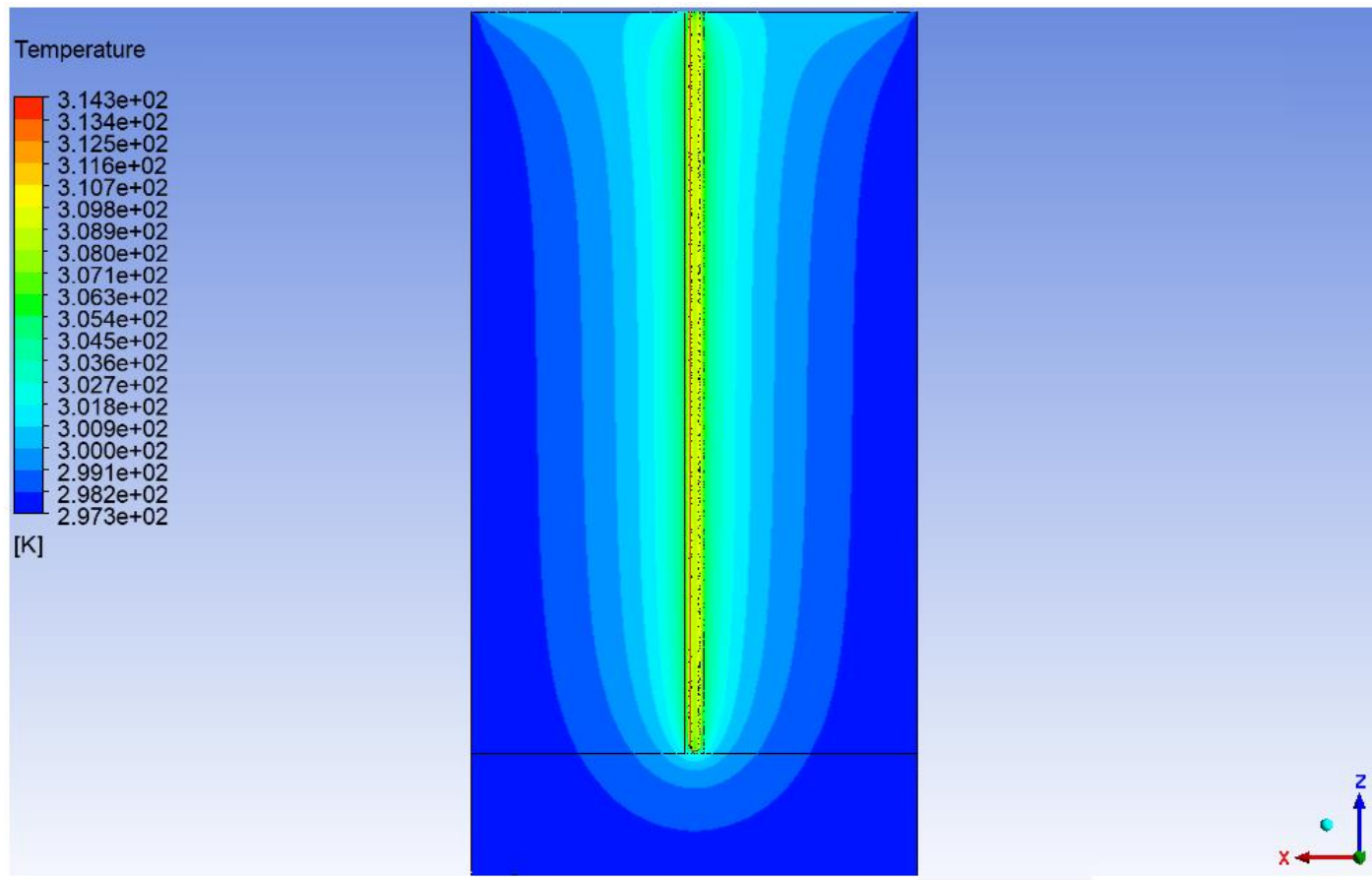
A Figura 5.57 apresenta o comportamento do diâmetro de influência térmica em função da vazão para três cenários: condutividade térmica do concreto $2 \mathrm{~W} \cdot \mathrm{m}^{-1} \cdot \mathrm{K}^{-1} \mathrm{e}$ resistência térmica $0,012 \mathrm{~m}^{2} \cdot \mathrm{K} \cdot \mathrm{W}^{-1}$ (cenário 1 ), condutividade térmica de $2 \mathrm{~W} \cdot \mathrm{m}^{-1} \cdot \mathrm{K}^{-1} \mathrm{e}$ resistência térmica $0 \mathrm{~m}^{2} \cdot \mathrm{K} \cdot \mathrm{W}^{-1}$ (cenário 2), condutividade térmica de $3,85 \mathrm{~W} \cdot \mathrm{m}^{-1} \cdot \mathrm{K}^{-1} \mathrm{e}$ resistência térmica $0 \mathrm{~m}^{2} . \mathrm{K} \cdot \mathrm{W}^{-1}$ (cenário 3 ).

Figura 5.57 - Diâmetro de influência térmica em função da velocidade do fluido circulante em diferentes cenários

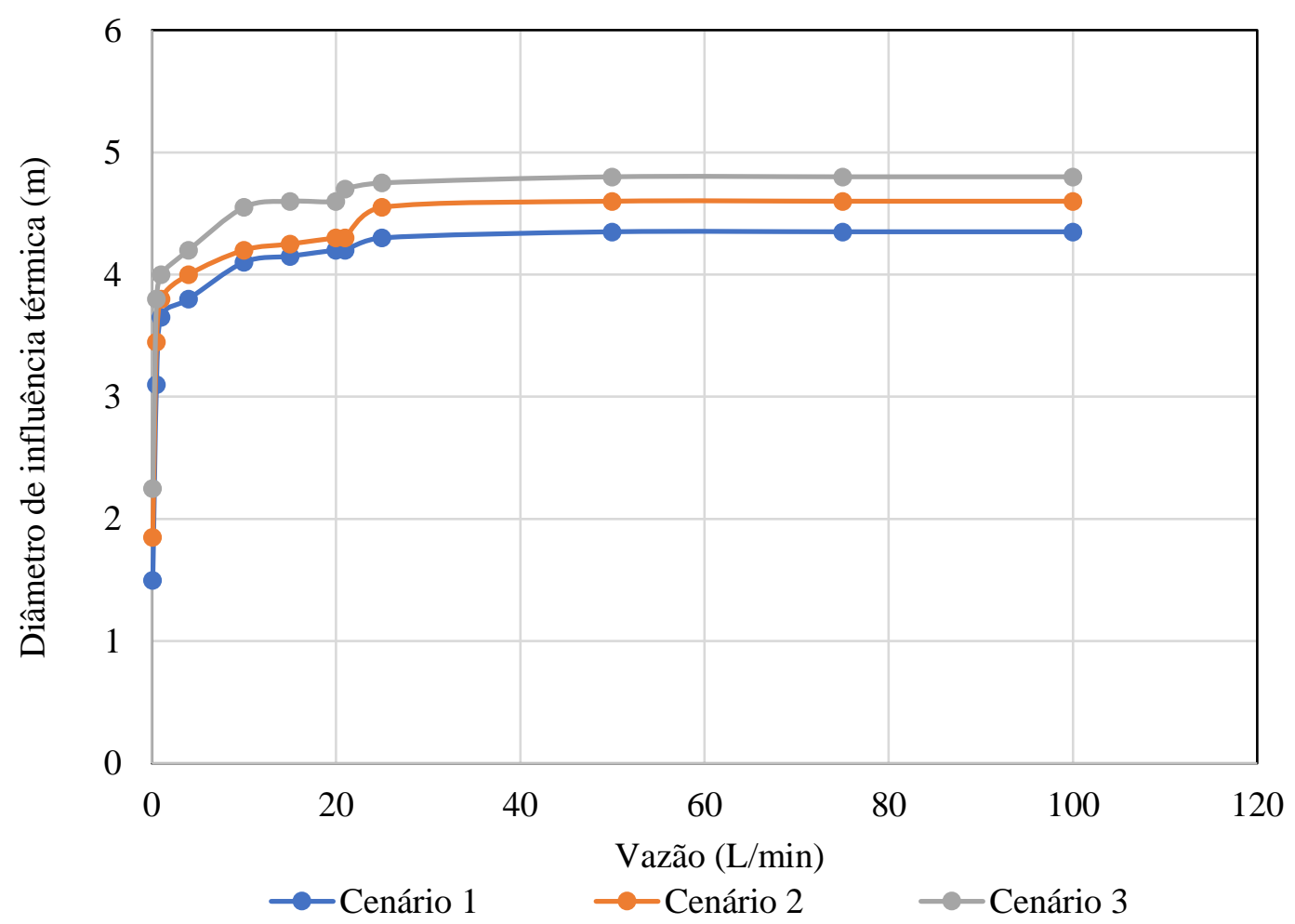

Nota-se que os valores de diâmetro de influência tendem a crescer com o aumento da vazão e a se estabilizar para vazões maiores do que cerca $25 \mathrm{~L} / \mathrm{min}$. No cenário 3, em que não é atribuída resistência térmica à interface tubo/concreto e onde há maior condutividade térmica do concreto, ocorrem maiores valores de diâmetro de influência térmica, que se estabilizam em torno de $4,80 \mathrm{~m}$. Conforme a condutividade térmica do concreto diminui ou impõe-se resistência térmica à interface tubo/concreto, observa-se a diminuição do diâmetro da zona de influência térmica. Para os cenários 1 e 2, os diâmetros para vazões maiores do que $25 \mathrm{~L} / \mathrm{min}$ são de $4,35 \mathrm{~m}$ e 4,60 m, respectivamente.

O aumento das zonas de influência térmica é diretamente proporcional ao aumento das trocas de calor entre a estaca e solo (processo que é intensificado com o aumento da condutividade térmica e redução da resistência térmica dos materiais): quanto 
maiores as taxas de transferência de calor da estaca para o solo maior será o diâmetro da zona que sofrerá variação de temperatura.

A Figura 5.58 mostra a relação entre a taxa de transferência de calor na interface concreto/solo e a vazão do fluido circulante nos cenários 1, 2 e 3. O aumento da condutividade térmica do concreto e a diminuição da resistência térmica da interface tubo/concreto propiciam maiores trocas térmicas no sistema geotérmico. As taxas de transferência de calor aumentam com acréscimos de vazão e estabilizam-se a partir de valores de vazão de cerca de $15 \mathrm{~L} / \mathrm{min}$. Para os cenários 1,2 e 3 os valores de taxa de transferência de calor são de 456,22 W, 600,57 W e 735,03 W, respectivamente.

Figura 5.58 - Taxa de transferência de calor em função da velocidade do fluido circulante em diferentes cenários

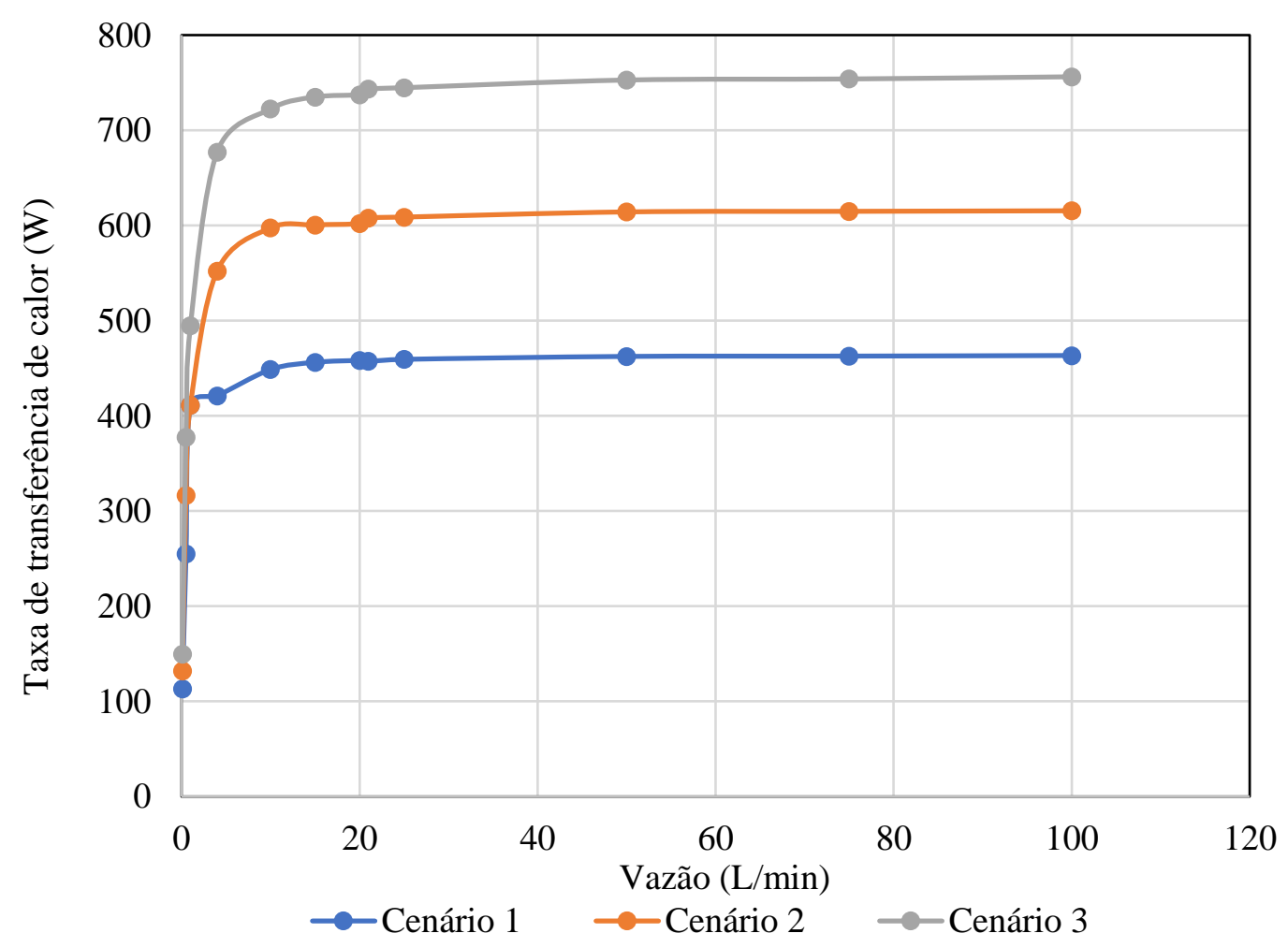

A Figura 5.59 mostra a evolução dos valores de temperatura média na interface concreto/solo em função da vazão do fluido circulante. Observa-se que a temperatura média aumenta com o aumento da vazão e estabiliza-se para vazões acima de $15 \mathrm{~L} / \mathrm{min}$, com valores de 305,3 K, 307, 6 K e 309,8 K para os cenários 1, 2 e 3, respectivamente. 
Figura 5.59 - Distribuição de temperaturas na interface concreto/solo em diferentes cenários

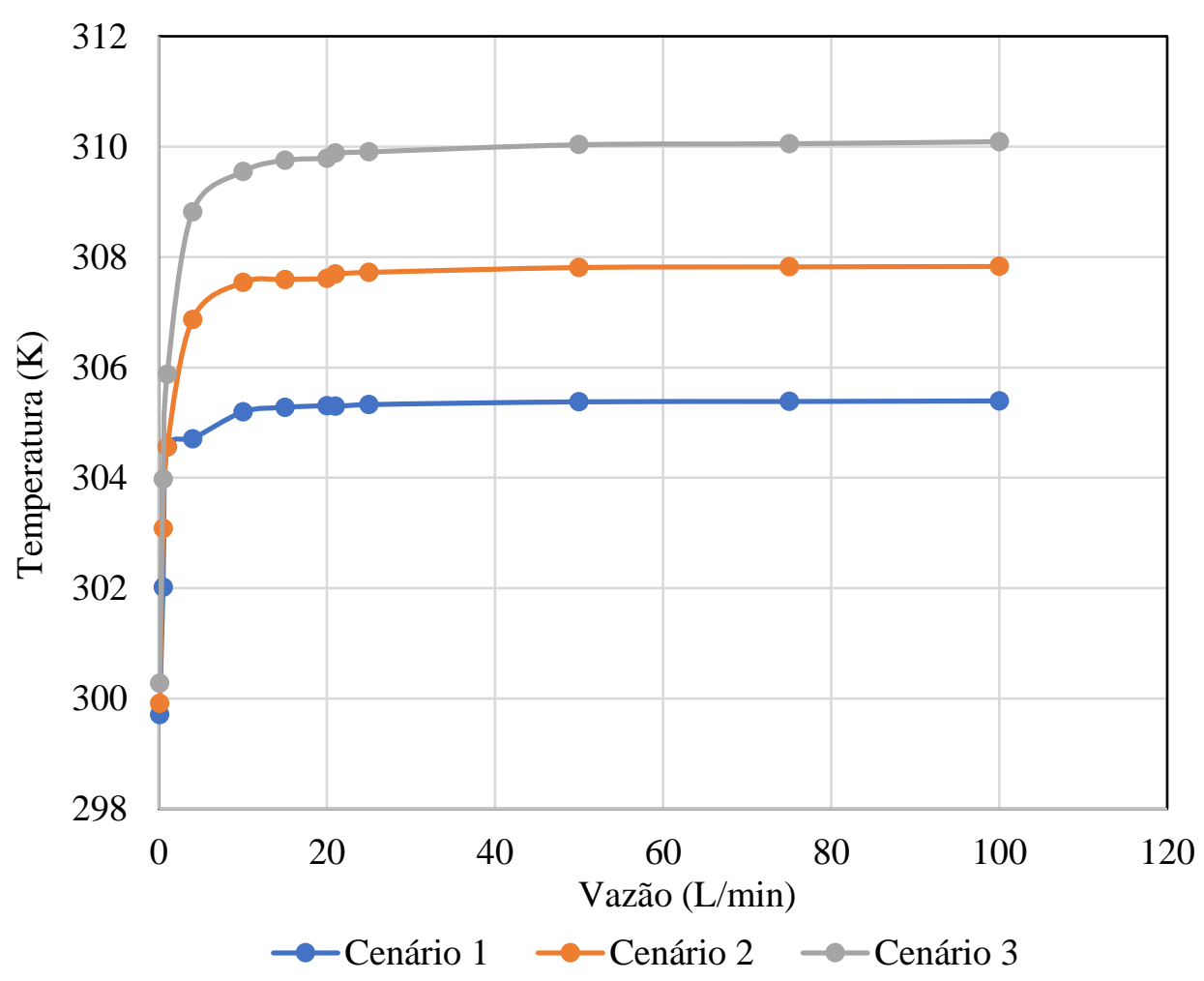

\subsection{VARIAÇÃO DA RESISTÊNCIA TÉRMICA DOS MATERIAIS DOS TUBOS}

A variação do tipo de material que compõe os tubos por onde circula o fluido trocador de calor, bem como a espessura dos tubos, foi simulada por meio da resistência térmica de contato atribuída à interface tubo/concreto, conforme mostra a Tabela 4.5. Foram simulados os seguintes valores de resistência térmica de contato, representativos de diferentes tipos de materiais e espessuras: $0 \mathrm{~m}^{2} . \mathrm{K} / \mathrm{W}, 1,57895.10^{-5} \mathrm{~m}^{2} . \mathrm{K} / \mathrm{W}, 0,00012$ $\mathrm{m}^{2} . \mathrm{K} / \mathrm{W}, 0,0006 \mathrm{~m}^{2} . \mathrm{K} / \mathrm{W}, 0,01176 \mathrm{~m}^{2} . \mathrm{K} / \mathrm{W}, 0,012 \mathrm{~m}^{2} . \mathrm{K} / \mathrm{W}, 0,01818 \mathrm{~m}^{2} . \mathrm{K} / \mathrm{W}, 0,024$ $\mathrm{m}^{2} . \mathrm{K} / \mathrm{W}, 0,02727 \mathrm{~m}^{2} . \mathrm{K} / \mathrm{W}, 0,03529 \mathrm{~m}^{2} . \mathrm{K} / \mathrm{W}, 0,04316 \mathrm{~m}^{2} . \mathrm{K} / \mathrm{W}$ e $0,048 \mathrm{~m}^{2} . \mathrm{K} / \mathrm{W}$.

A Figura 5.60 mostra a variação da taxa de transferência de calor nas diferentes interfaces do sistema geotérmico em função da resistência térmica de contato na interface tubo/concreto para o cenário base. $\mathrm{O}$ aumento da resistência térmica de contato provoca a redução dos valores de taxa de transferência de calor, pois quanto maior a resistência térmica de contato, maior é a dificuldade imposta ao fluxo de calor, o que ocasiona redução nas taxas de transferência de calor. Materiais com maior condutividade térmica (e consequentemente com menor resistência térmica de contato) propiciaram maiores taxas de transferência de calor, a exemplo do aço $\left(R=0,00012 \mathrm{~m}^{2} . \mathrm{K} / \mathrm{W}\right.$ e $\left.e=6 \mathrm{~mm}\right)$, caso 
que apresentou taxa de transferência de calor de 605,10 W na interface concreto/solo. Por outro lado, materiais com maior resistência térmica de contato ocasionaram menores taxa de transferência de calor, como o polietileno de alta densidade $\left(R=0,048 \mathrm{~m}^{2} . \mathrm{K} / \mathrm{W}\right.$ e $e=$ $24 \mathrm{~mm}$ ), com taxa de transferência de calor de 265,51 W na interface concreto/solo. Para resistência térmica de contato nula, obteve-se taxa de transferência de calor de 607,01 W.

Figura 5.60 - Taxa de transferência de calor em função da resistência térmica de contato na interface tubo/concreto, por interface

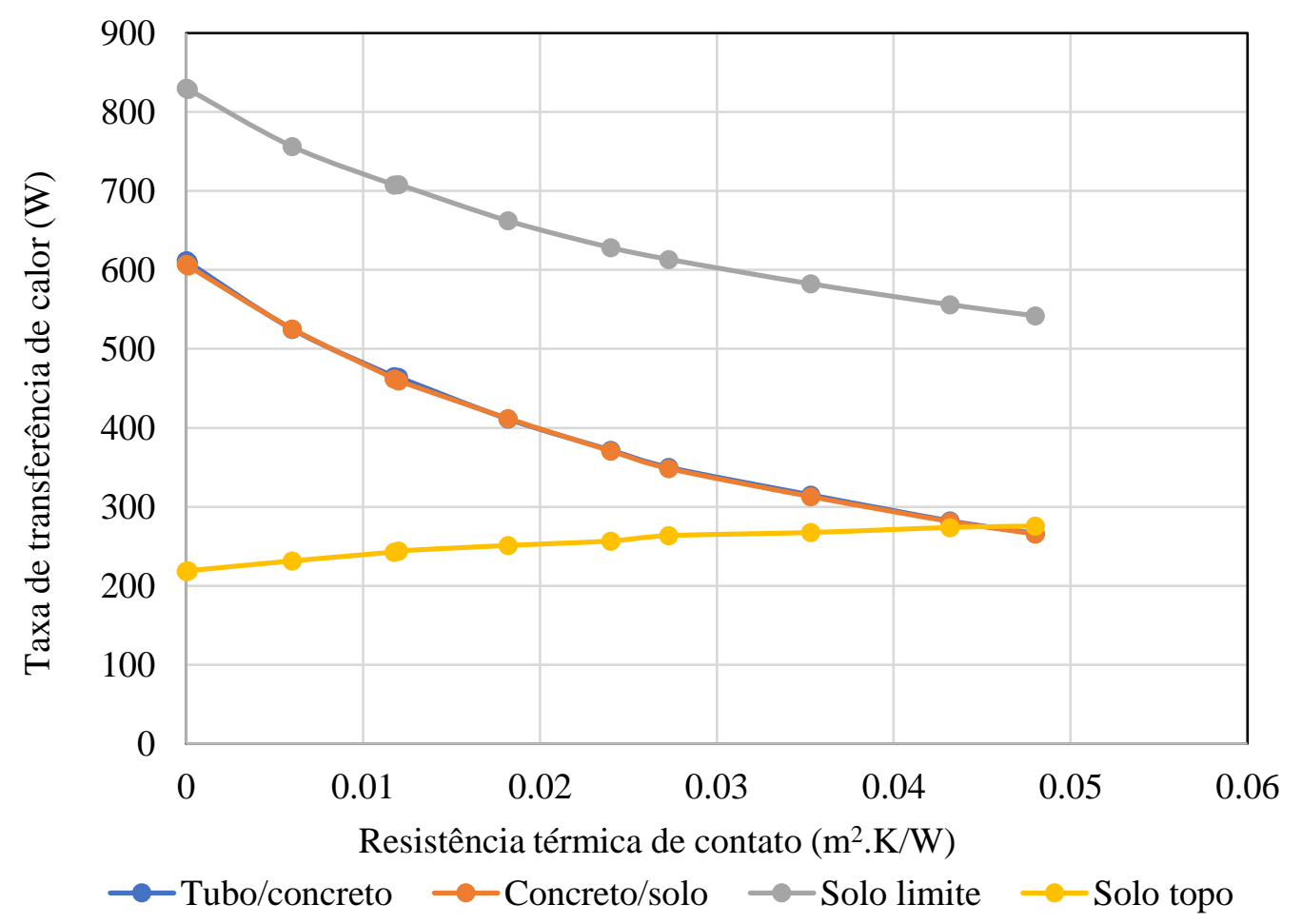

A Figura 5.61 mostra a distribuição de temperaturas médias nas superfícies do sistema geotérmico em função da resistência térmica de contato, simulada a partir do cenário base. Nas interfaces saída e tubo/concreto, as temperaturas são aproximadamente constantes, visto que tais superfícies são pouco afetadas pelas restrições ao fluxo de calor. Entretanto, a imposição de resistências térmicas variáveis à interface tubo/concreto afeta a distribuição de temperaturas nos materiais que se encontram na direção do fluxo radial de calor, a exemplo da diminuição de temperatura que ocorre na interface concreto/solo, ocasionada pelos menores valores de taxa de calor total que são transferidos dos tubos para o concreto e, em seguida, para o solo. A interface solo limite, por sua vez, apresenta valores de temperatura constantes de $297,3 \mathrm{~K}$, impostos por sua condição de contorno. Para os materiais aço $\left(R=0,00012 \mathrm{~m}^{2} . \mathrm{K} / \mathrm{W}\right.$ e $\left.e=6 \mathrm{~mm}\right)$ e polietileno de alta densidade 
( $R=0,048 \mathrm{~m}^{2} . \mathrm{K} / \mathrm{W}$ e $e=24 \mathrm{~mm}$ ), na interface concreto/solo, são observadas as temperaturas $307,7 \mathrm{~K}$ e $302,2 \mathrm{~K}$, respectivamente.

Figura 5.61 - Temperatura média em função da resistência térmica de contato na interface tubo/concreto, por interface

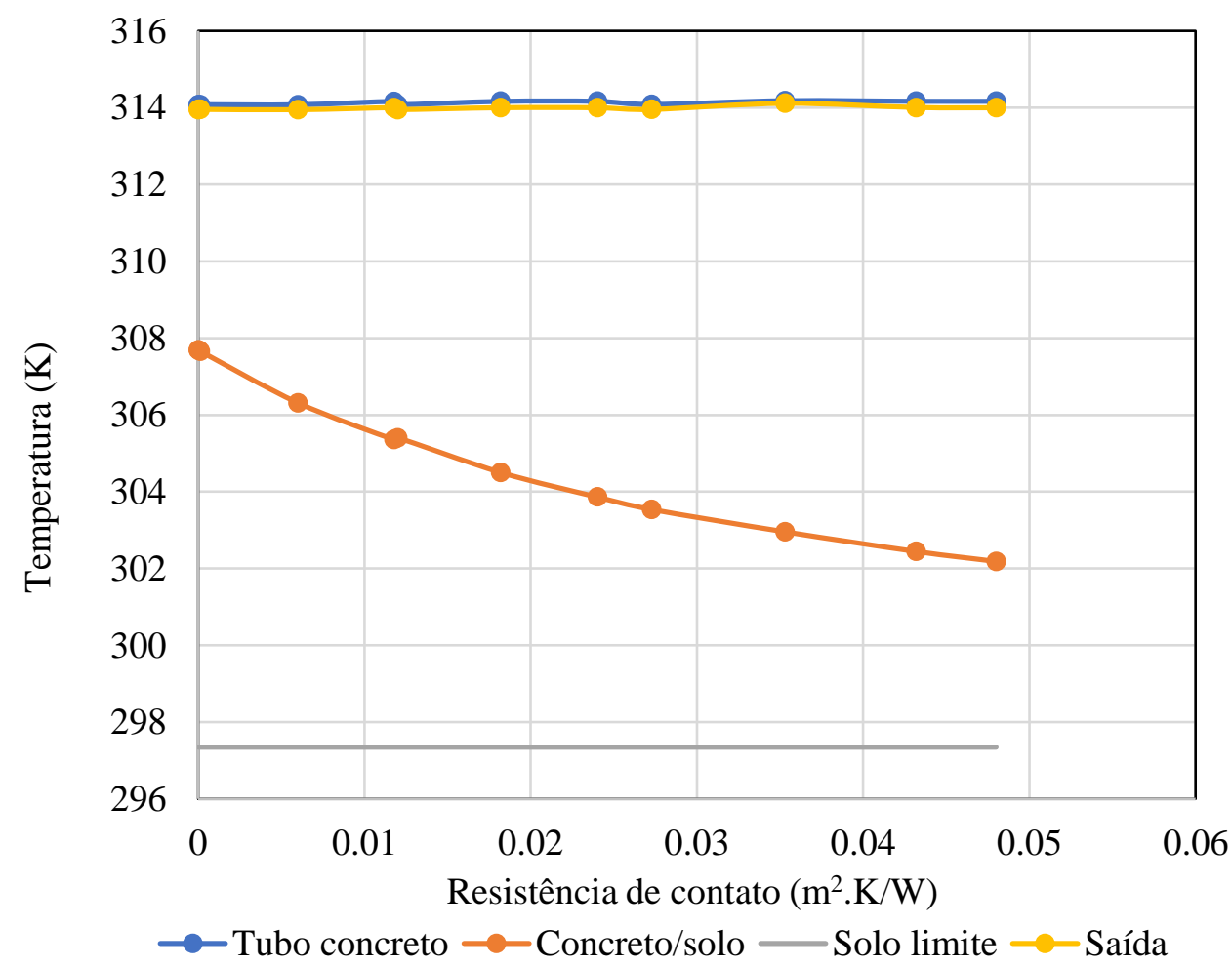

A diferença de temperaturas do fluido circulante nas superfícies de entrada e saída dos tubos apresentou diferenças centesimais, variando de $0,34 \mathrm{~K}$ para o cenário em que não se atribuiu resistência térmica de contato à superfície tubo/concreto a $0,29 \mathrm{~K}$ para o valor de resistência térmica de $0,048 \mathrm{~m}^{2} . \mathrm{K} / \mathrm{W}$. Como foi utilizado um método numérico aproximado, não é possível afirmar que ocorre diminuição da diferença de temperaturas do fluido circulante entre superfícies de entrada e saída, pois a diferença é desprezível.

O diâmetro de influência térmica diminuiu com a resistência térmica de contato, como mostra a Figura 5.62. A redução é aproximadamente linear, resultado da diminuição da taxa de transferência de calor com o aumento da resistência térmica de contato. Para resistência térmica de contato nula na interface tubo/concreto, obteve-se diâmetro de influência térmica de 4,55 m. Para o material aço, não se observaram variações na zona de influência térmica, que permaneceu com diâmetro de influência de 4,55 m. Para o maior valor de resistência térmica de contato atribuída à interface tubo/concreto $(0,048$ $\left.\mathrm{m}^{2} . \mathrm{K} / \mathrm{W}\right)$, verificou-se diâmetro de influência térmica de 2,90 m. 
Figura 5.62 - Diâmetro de influência térmica em função da resistência térmica de contato na interface tubo/concreto

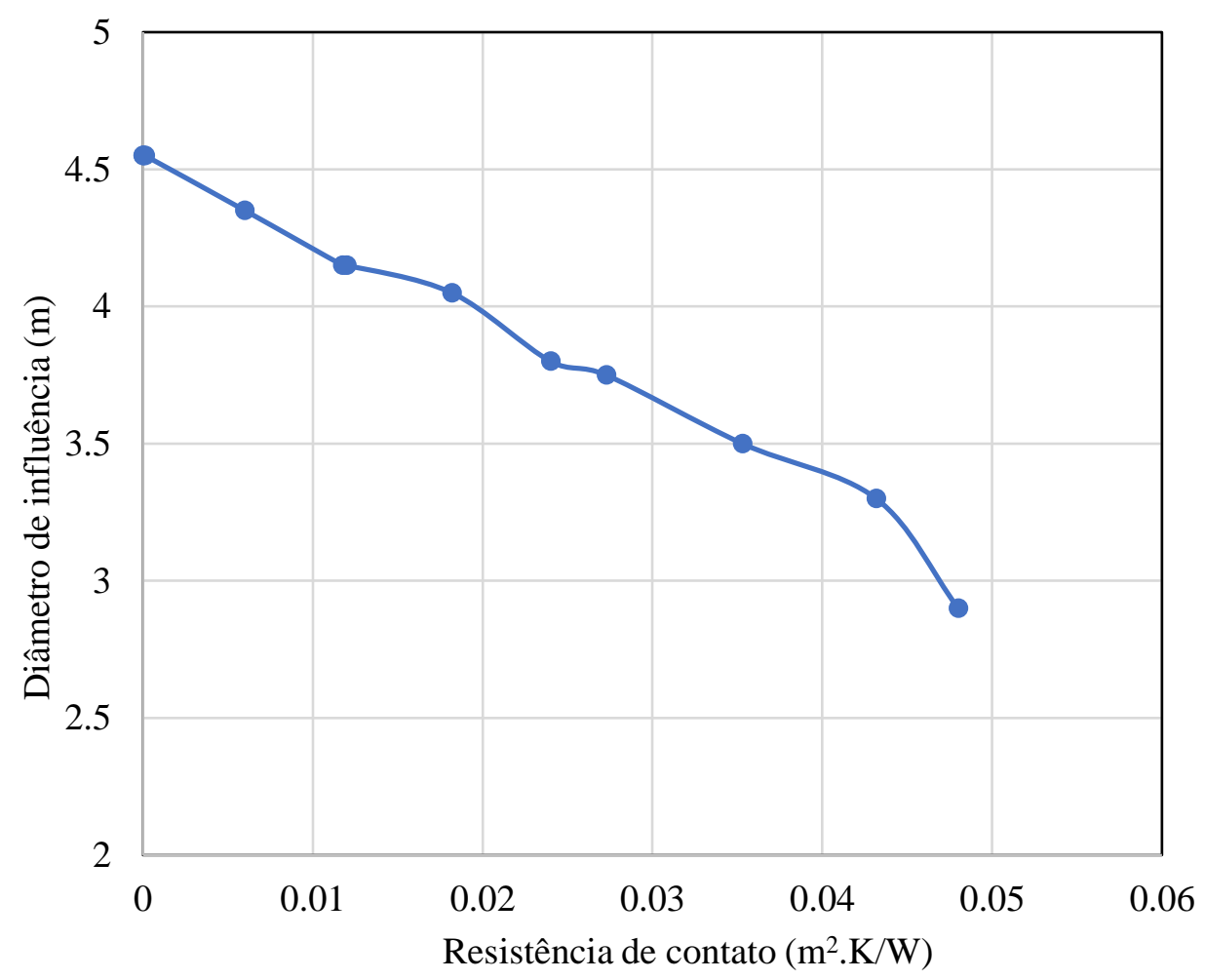

Conforme a resistência térmica de contato da interface tubo/concreto diminui, aumenta a taxa de transferência de calor da estaca para o solo, o que aumenta a eficiência do sistema geotérmico. A diminuição da resistência térmica de contato provoca maiores trocas térmicas entre os tubos de entrada e de saída de fluido. Assim, conforme diminuise a resistência térmica de contato, maior troca de calor ocorre entre os tubos de entrada e saída do fluido, de forma que a temperatura de saída do fluido tende a se aproximar de sua temperatura de entrada. Realmente, obtiveram-se valores aproximadamente constantes de diferença entre as temperaturas de entrada e de saída do fluido nos tubos. Em condições extremas, em que a resistência térmica de contato tende a valores pequenos enquanto se aumenta a quantidade de energia na forma de calor inserida por meio do fluido circulante, a estaca geotérmica apresentará comportamento similar ao de uma haste cilíndrica, em temperatura constante, trocando calor com o solo.

As Figuras 5.63, 5.64 e 5.65 ilustram, para a porção superior da estaca geotérmica, em um plano XZ localizado no centro do sistema geotérmico, o aumento das trocas térmicas entre os tubos de entrada e saída do fluido conforme é reduzida a resistência térmica de contato na interface tubo/concreto. A Figura 5.63 apresenta a distribuição de 
temperaturas no interior da estaca geotérmica para a resistência térmica de contato na interface tubo/concreto igual a $0,048 \mathrm{~m}^{2} . \mathrm{K} / \mathrm{W}$. As Figuras 5.64 e 5.65 consideram resistência térmica de $0,01818 \mathrm{~m}^{2} . \mathrm{K} / \mathrm{W}$ e $0,00012 \mathrm{~m}^{2} . \mathrm{K} / \mathrm{W}$, respectivamente.

\subsection{ANÁLISE GLOBAL}

A Figura 5.66 mostra as taxas de transferência de calor na interface concreto/solo em função da variação dos parâmetros analisados no cenário base. Para cada parâmetro são apresentados os valores máximos e mínimos empregados como dados de entrada nas simulações. Em marrom são destacados os valores a partir dos quais a taxa de transferência de calor total não varia mais com a variação do parâmetro estudado.

Observa-se que temperatura de entrada do fluido, diâmetro e comprimento da estaca são as variáveis que causam maiores aumentos nas taxas de transferência de calor. Conforme discutido, as variáveis comprimento e diâmetro não representam aumento real de eficiência térmica, pois as taxas de transferência de calor normalizadas pouco variaram. Por outro lado, comparando-se valores de taxa de transferência de calor por unidade do parâmetro, as variáveis que mais influenciam as taxas de transferência de calor são: resistência de contato, grau de saturação (até s $=20 \%$ ) e condutividade térmica do concreto.

Com intuito comparativo, destaca-se que Fare (2015) definiu a seguinte hierarquia (em termos de influência no desempenho térmico) para os parâmetros de entrada: condutividade térmica do solo, diferença entre a temperatura de entrada do fluido e a temperatura inicial do solo e a velocidade de circulação do fluido pelos tubos.

Por outro lado, o modelo numérico elaborado em regime transiente por Cecinato e Loveridge (2015) mostrou maior relevância das seguintes variáveis para o desempenho do sistema geotérmico: número de tubulações (não avaliado nesta pesquisa) e comprimento da estaca, bem como o valor total da superfície da tubulação disponível para trocas de calor por convecção forçada e sua condutividade térmica. 
Figura 5.63 - Distribuição de temperaturas na estrutura de concreto da estaca, no plano $\mathrm{XZ}$, com resistência térmica de contato de $0,048 \mathrm{~m}^{2} . \mathrm{K} / \mathrm{W}$

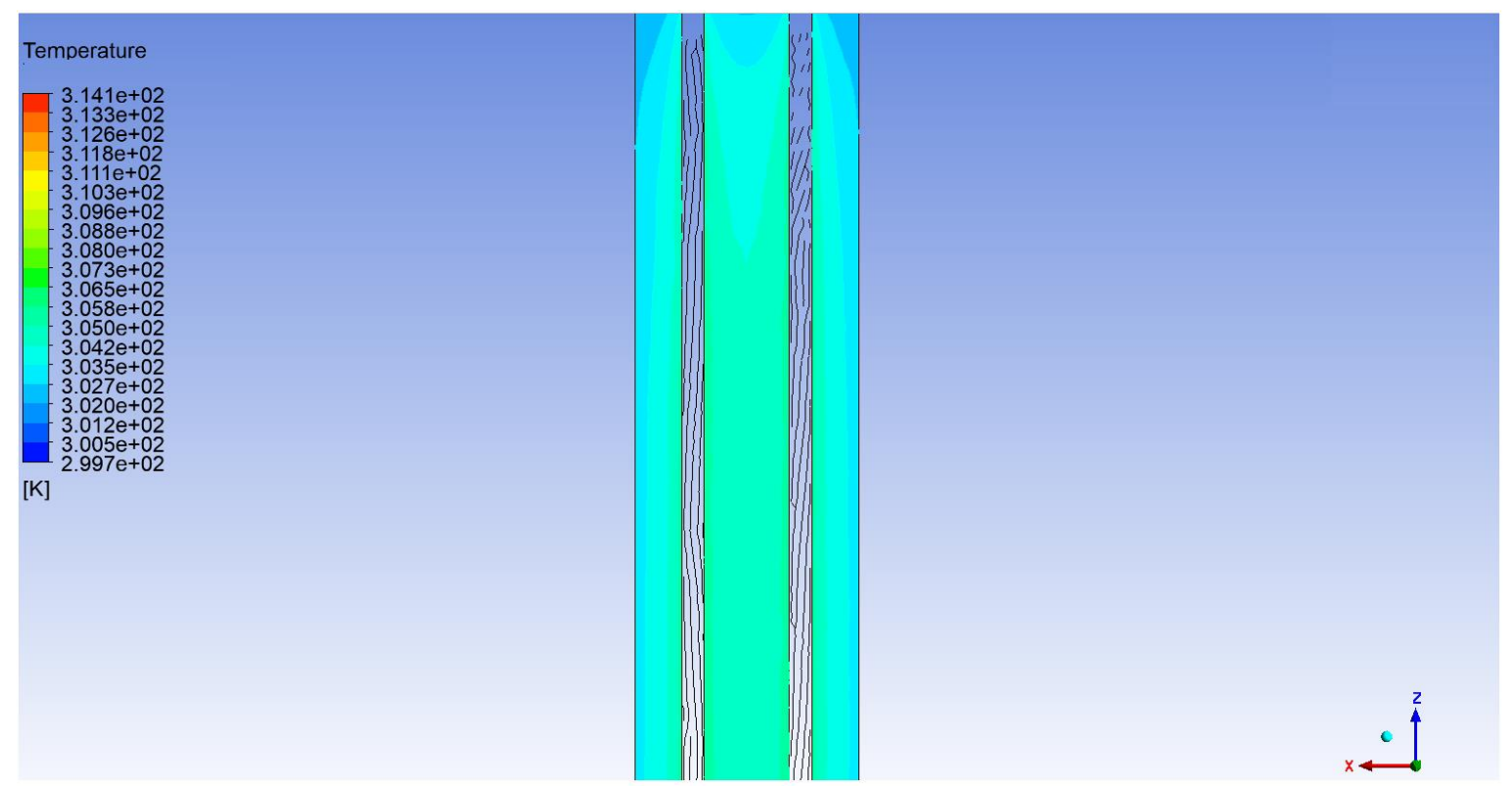

Figura 5.64 - Distribuição de temperaturas na estrutura de concreto da estaca, no plano $\mathrm{XZ}$, com resistência térmica de contato de $0,01818 \mathrm{~m}^{2} . \mathrm{K} / \mathrm{W}$

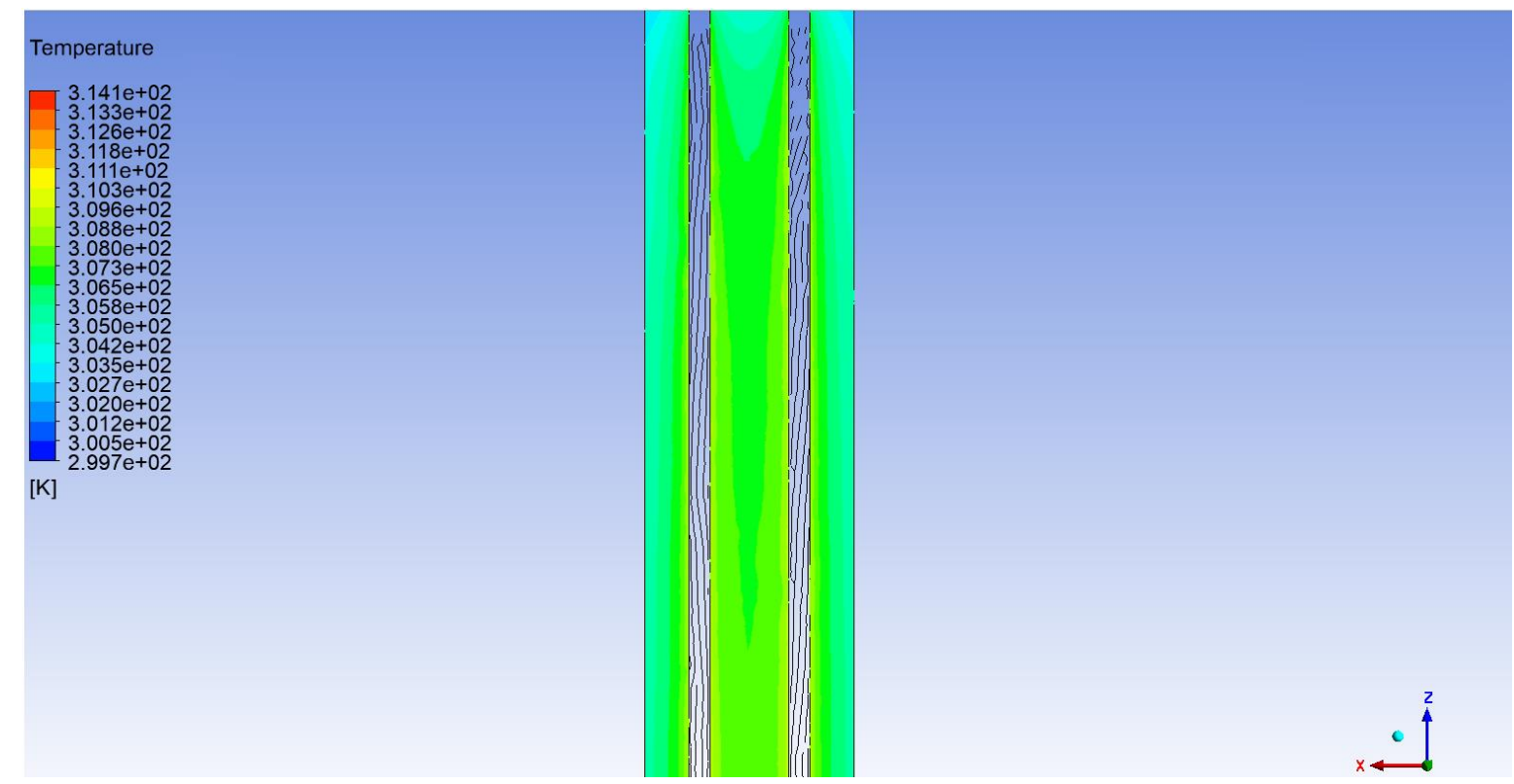


Figura 5.65 - Distribuição de temperaturas na estrutura de concreto da estaca, no plano $\mathrm{XZ}$, com resistência térmica de contato de $0,00012 \mathrm{~m}^{2} . \mathrm{K} / \mathrm{W}$

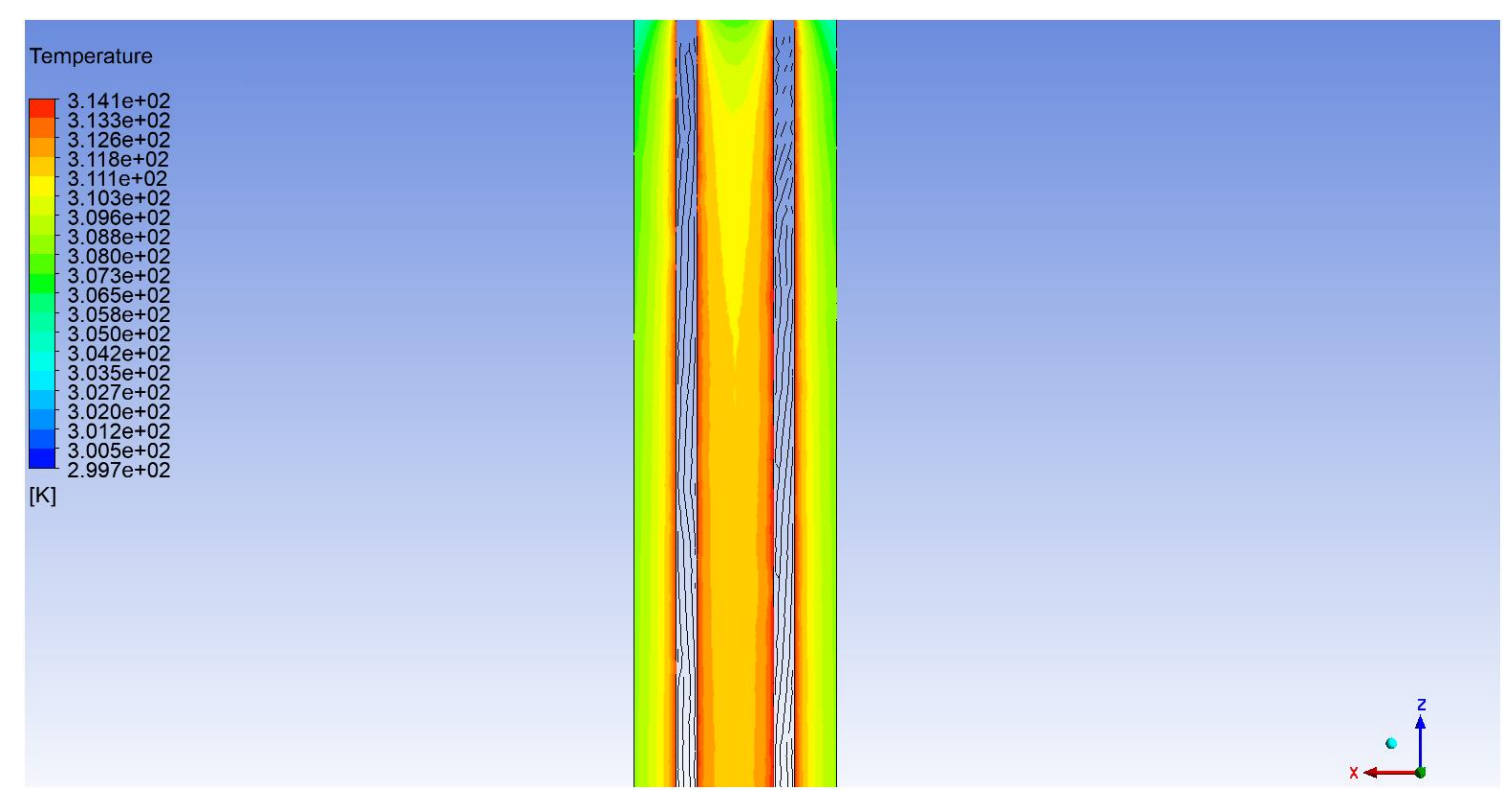


Figura 5.66 - Síntese das variações de taxas de transferência de calor total por parâmetro analisado

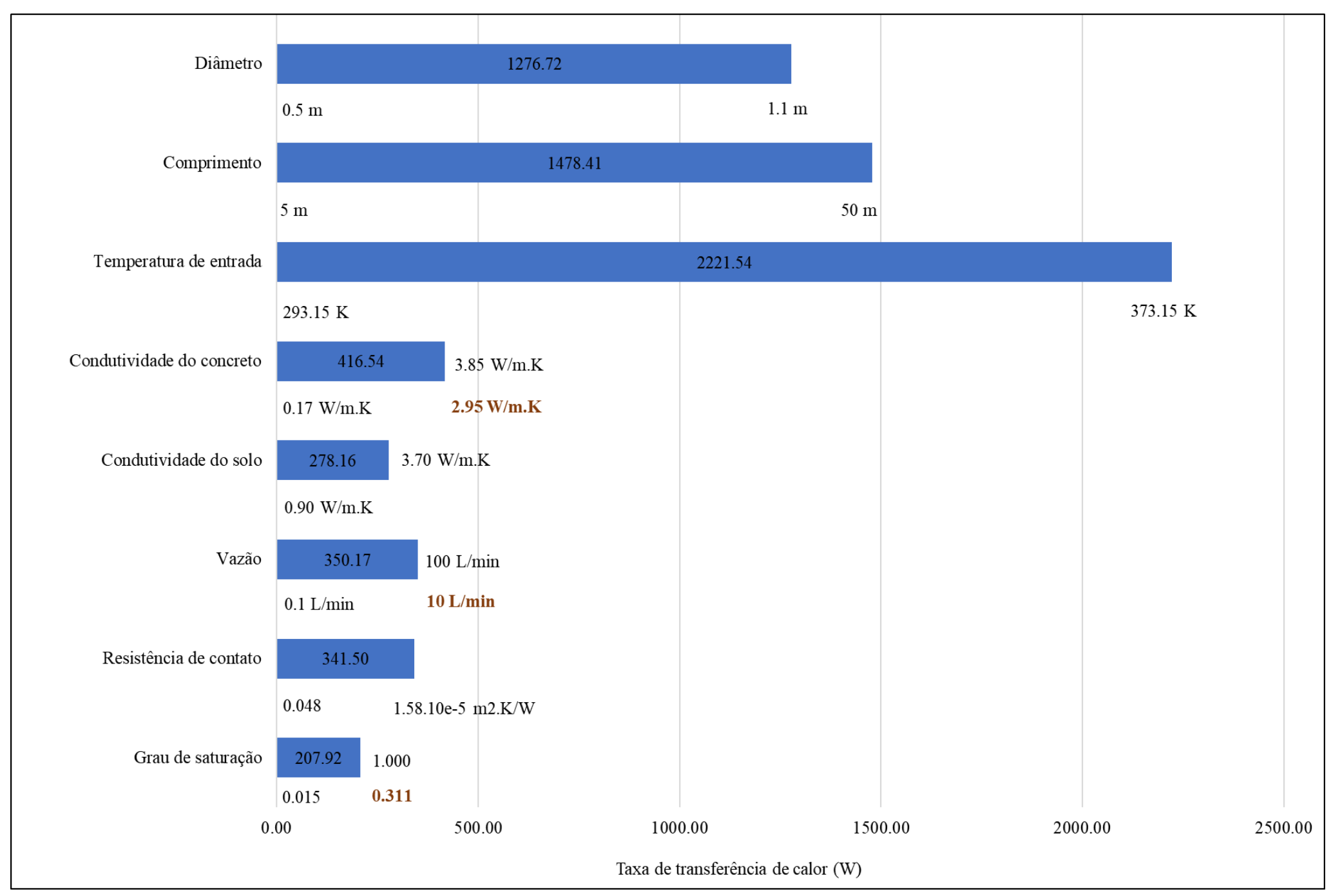




\section{CONCLUSÕES}

Este trabalho partiu de resultados experimentais de um ensaio TRT executado na Escola Politécnica da USP para a elaboração e validação de um modelo numérico, a partir do qual foi estudada a influência de parâmetros geotécnicos, hidráulicos, térmicos e geométricos na eficiência de uma estaca geotérmica assente em solo arenoso. Destacamse as seguintes conclusões:

- As simulações para validação do modelo numérico apresentaram erros inferiores a $5 \%$ e desvios menores ou iguais a $0,3 \mathrm{~K}$ considerando-se as diferenças de temperaturas de saída experimentais e numéricas do fluido circulante. Portanto, considerou-se o modelo numérico confiável para realizar estudo paramétrico em regime estacionário;

- Ainda na etapa de validação do modelo numérico, verificou-se que as taxas de transferência de calor, os diâmetros de influência térmica e as temperaturas em diferentes interfaces do sistema geotérmico aumentaram do instante $50 \mathrm{~h}$ até o instante $200 \mathrm{~h}$, que foi considerado o tempo de estabilização do ensaio TRT. Com o modelo numérico, isso pode ser confirmado por simulação em tempos maiores ou com simulação em regime transiente;

- No estudo de convergência de malha nota-se que, ao aumentar-se o número de elementos tetraédricos na região do fluido de 551.765 para 7.854.123 há um erro percentual de 0,07 \%. Essa verificação permite concluir que a realização de simulações menos refinadas, com 551.765 elementos, possibilita a obtenção de resultados confiáveis ao mesmo tempo em que reduz consideravelmente o custo computacional;

- As taxas de transferência de calor nas interfaces do sistema aumentam linearmente com o comprimento da estaca, porém as taxas de transferência de calor normalizadas pelo comprimento e pela área da superfície da estaca não mostraram melhoria substancial na eficiência da estaca;

- As taxas de transferência de calor nas interfaces do sistema, mesmo normalizadas pelo comprimento da estaca, aumentam linearmente com o diâmetro da estaca. Por outro lado, a taxa de transferência de calor normalizada pela área da superfície da estaca aumenta $7 \%$ na interface concreto/solo quando o diâmetro aumenta de 0,2 $\mathrm{m}$ a 1,1 m. Portanto, o aumento do diâmetro da estaca propicia maiores trocas de calor totais, mas a eficiência térmica da estaca por unidade de área de sua superfície é pouco alterada; 
- O índice de esbeltez individualmente não define a taxa de transferência de calor uma vez que, em termos de fatores geométricos, é a área da estaca disponível para trocas térmicas que determina a magnitude das taxas de transferência de calor total;

- As taxas de transferência de calor nas interfaces do sistema aumentam com a condutividade térmica do concreto. As temperaturas praticamente independem da condutividade térmica do concreto na interface saída do tubo e na interface tubo/concreto, porém na interface concreto/solo a temperatura aumenta $7 \mathrm{~K}$ quando a condutividade térmica do concreto aumenta de $0,17 \mathrm{~W} \cdot \mathrm{m}^{-1} \cdot \mathrm{K}^{-1}$ a $3,85 \mathrm{~W} \cdot \mathrm{m}^{-1} \cdot \mathrm{K}^{-1}$. O aumento da condutividade térmica do concreto também acarretou redução de trocas térmicas entre os tubos de entrada e de saída e aumento no diâmetro de influência térmica;

- Pequenos valores de resistência térmica na interface tubo/concreto acarretam relevantes reduções no desempenho do sistema geotérmico;

- A taxas de transferência de calor nas interfaces do sistema aumentam com a condutividade térmica do solo, sendo que esse acréscimo diminui com o aumento da condutividade térmica do solo. As temperaturas praticamente independem da condutividade térmica do concreto na interface saída do tubo e na interface tubo/concreto, porém na interface concreto/solo a temperatura diminui quanto maior a condutividade térmica do solo. $\mathrm{O}$ aumento da condutividade térmica do solo reduz as trocas térmicas entre os tubos de entrada e saída, a concentração de calor na estaca e o diâmetro de influência térmica;

- O efeito do grau de saturação foi analisado indiretamente, utilizando-se a variação de condutividade térmica em função da saturação de um solo arenoso encontrada na literatura. $\mathrm{O}$ aumento do grau de saturação causa pequenos incrementos de condutividade térmica e, consequentemente, pequenos aumentos de taxa de transferência de calor;

- O aumento da temperatura de entrada do fluido circulante resultou em crescimento linear das taxas de transferência de calor e das temperaturas médias nas interfaces do sistema; maior diferença de temperatura entre os pontos de entrada e saída dos tubos; e aumento linear do diâmetro de influência térmica até a temperatura de 313,1 $\mathrm{K}$, sendo que temperaturas mais altas não expandem mais a zona de influência térmica;

- O aumento da velocidade/vazão do fluido circulante causou acréscimo na taxa de transferência de calor entre a estaca e o solo e aumento das temperaturas nas interfaces do sistema geotérmico, até vazões de $10 \mathrm{~L} / \mathrm{min}$; maiores valores de vazão não resultaram em maior transferência de calor ou maiores temperaturas nas interfaces. Com o aumento 
da velocidade/vazão do fluido circulante, a diferença entre as temperaturas de entrada e saída do fluido circulante diminui e a zona de influência térmica aumenta;

- Para o aumento da resistência térmica do material dos tubos, houve redução das taxas de transferência de calor, as temperaturas médias nas interfaces tubo/concreto e saída praticamente não se modificaram, e as temperaturas médias na interface concreto/solo diminuíram. Os diâmetros de influência térmica diminuíram e ocorreram maiores trocas térmicas entre os tubos de entrada e de saída de fluido;

- Os parâmetros temperatura de entrada do fluido, diâmetro e comprimento da estaca são as variáveis que provocaram maiores aumentos nas taxas de transferência de calor total;

- Computando-se as taxas de transferência de calor total por unidade do parâmetro usado como dado de entrada, verifica-se que as variáveis que ocasionam maior variação de taxas de transferência de calor total são: resistência de contato, grau de saturação e condutividade térmica do concreto.

Dado o objetivo de se otimizar o projeto de estacas geotérmicas, são feitas as seguintes recomendações com relação:

- Ao comprimento e diâmetro da estaca geotérmica: não há aumento das taxas de transferência de calor total normalizadas por unidade de área da estaca geotérmica. Assim, deve ser analisada a possibilidade de se aumentar a área de transferência de calor por grupos de estacas, eliminando-se a necessidade de se projetar estacas de grandes dimensões para dissipar energia térmica em maciços de solo;

- Ao concreto da estaca: é preferível o uso de concretos de alta densidade que, de forma geral, propiciam maiores condutividades térmicas. Com o intuito de se analisar casos extremos, esta dissertação explorou casos especiais de concreto. Em termos práticos, tais usos devem ser alinhados com o projeto estrutural da obra. De qualquer forma, o uso de concretos com condutividade térmica superior a $2,95 \mathrm{~W} \cdot \mathrm{m}^{-1} \cdot \mathrm{K}^{-1}$ não propiciaram o aumento substancial das taxas de transferência de calor total;

- Ao grau de saturação do solo: maiores taxas de calor são transferidas da estaca para o solo com maiores valores de grau de saturação, de forma que é preferível a instalação de estacas geotérmicas para rejeição de calor em perfis de solo com nível de água elevado, cenário que ocorre no terreno em que será instalado o CICS Living Lab;

- À temperatura de entrada do fluido circulante: aumentar a temperatura de entrada do fluido circulante ocasiona maior gradiente de temperatura entre o solo e o fluido, 
acarretando maior eficiência térmica. Tal item deve respeitar os critérios de projeto da bomba de calor;

- À velocidade/vazão do fluido circulante: deve-se conferir ao fluido energia suficiente para circular em regime turbulento. A partir da vazão de $10 \mathrm{~L} / \mathrm{min}$ os valores de taxa de transferência de calor total estabilizaram-se, de forma que vazões a partir deste valor permitem a otimização das trocas térmicas do sistema geotérmico;

- Tomando-se a interface concreto/solo como base comparativa, pode-se afirmar que os valores obtidos nas simulações atendem a ordens de grandeza previstas na literatura, como evidencia Brandl (2006), que argumenta que estacas com diâmetro entre $30 \mathrm{~cm}$ e $50 \mathrm{~cm}$ devem dissipar taxas de transferência de calor normalizadas pelo comprimento da estaca de $40 \mathrm{~W} / \mathrm{m}$ a $60 \mathrm{~W} / \mathrm{m}$;

- À resistência térmica de contato: teoricamente, é preferível o uso de materiais condutores térmicos, a exemplo de aço e cobre, que permitem maiores trocas térmicas entre o fluido circulante e o restante do sistema geotérmico. Caso isso não seja possível por limitações de projeto, deve-se optar por diminuir a espessura dos tubos (da ordem de $2 \mathrm{~mm}$ a $3 \mathrm{~mm}$, respeitando-se limitações mecânicas), de forma a reduzir a resistência térmica de contato;

- Ao índice de esbeltez: não é evidente um padrão de influência no desempenho de estacas geotérmicas, uma vez que, em termos de fatores geométricos, é a área da estaca disponível para trocas térmicas que determina a magnitude das taxas de transferência de calor total;

- Ao solo: solos com maiores condutividades térmicas permitem a obtenção de maiores taxas de transferência de calor total no sistema geotérmico. Apesar de ser um parâmetro natural do solo em que a estaca está assente é possível recorrer-se a procedimentos para aumentar a condutividade térmica do solo. Por outro lado, é imprescindível a realização de investigações geotérmicas, a exemplo o ensaio TRT, para a determinação de parâmetros confiáveis que permitam o projeto adequado de estacas geotérmicas. 


\section{SUGESTÕES DE NOVAS PESQUISAS}

São feitas as seguintes sugestões para pesquisas futuras:

- Utilizar os resultados obtidos nesta dissertação para o estudo térmico do desempenho de ambientes internos da estrutura localizada acima da superfície do terreno;

- Comparar os resultados numéricos e experimentais apresentados nesta dissertação com dados provenientes do comportamento de estacas geotérmicas instaladas do terreno da Escola Politécnica da USP;

- Executar ensaios TRT com materiais condutores térmicos na posição dos tubos de PEAD;

- Isolar termicamente os tubos de entrada e saída do fluido circulante para diminuir as trocas térmicas para o fluido nas condições quente e fria;

- Desenvolver um modelo numérico, com base no Método de Volumes Finitos, para investigar a influência do fluxo de água subterrâneo na dissipação de calor da estaca geotérmica. Para isso é necessário modelar o solo como um meio poroso;

- Utilizar os valores de diâmetro de influência térmica como insumo para inferir a interferência entre estacas em grupo, determinando as zonas perturbadas. 


\section{REFERÊNCIAS}

ABDELAZIZ, S.L.; OZUDOGRU, T.Y.; OLGUN, C.G. Multilayer finite line source model for vertical heat exchangers. Geothermics, v.51, 406-416, 2014.

AMIS, T.; LOVERIDGE, F. Energy piles and other thermal foundations for GSHP developments in UK practice and research. REHVA Journal, 32-35, 2014.

ANSYS, Inc. ANSYS CFX-Solver Theory Guide. ANSYS CFX Release 17.0, 2016.

ASADI, I.; SHAFIGH, P.; HASSAN, Z.F.B.A.; MAHYUDDIN, N.B. Thermal conductivity of concrete - A review. Journal of Building Engineering, v.20, 81-93, 2018.

ASHRAE Handbook - HVAC Applications, SI Edition, Supported by ASHRAE Research.

ASSOCIAÇÃO BRASILEIRA DE NORMAS TÉCNICAS. NBR 15220: Desempenho térmico de edificações - Parte 1: definições, símbolos e unidades. Rio de Janeiro, 2003, $66 \mathrm{p}$.

AUSTIN, W.A. Development of an in-situ system for measuring ground thermal properties. 1998. Dissertação (Mestrado) - Oklahoma State University, Sillwater, Oklahoma, EUA, 1998.

BANDEIRA NETO, L.A. Estudo experimental da resposta térmica de fundações por estacas trocadoras de calor em solo não saturado. 2015. 130 p. Dissertação (Mestrado) - Universidade de São Paulo, São Paulo, 2015.

BAYESTEH, H.; KHODAPARAST, M.; KIANI, M.A. Numerical study of bearing capacity and consolidation settlement of energy piles in fine-grained soils. Proceedings of the $1^{\text {st }}$ International Conference on Energy Geotechnics, Kiev, Alemanha, 2016.

BERGMAN, T.L.; LAVINE, A.S.; INCROPERA, F.P.; DEWITT, D.P. Introduction to heat transfer. 5 ed. Nova Jersey, EUA: John Wiley \& Sons: 2007.

BOUAZZA, B.W.; SINGH, RM.; WANG, B.; HABERFIELD, C.H.; BAYCAN, S.; CARDEN, Y. Harnessing on site renewable energy through pile foundations. Australian Geomechanics, v.46, n.4, 79-89, 2011.

BOUAZZA, A.; WANG, B.; SINGH, R.M.; BARRY-MACAULAY, D. Field investigation of a geothermal pile: Initial observations. Proceedings of the International Conference on Soil Mechanics and Geotechnical Engineering, Paris, França, 2013. 
BOUAZZA, B.W.; SINGH, RM.; WANG, B.; HABERFIELD, C.H.; BAYCAN, S.; CARDEN, Y. Thermo and thermo-mechanical response of a geothermal energy pile. Proceedings World Geothermal Congress, Melbourne, Austrália, 2015.

BOURNE-WEBB, P.J; AMATYA, B.; SOGA, K.; AMIS, T.; DAVIDSON, C.; PAYNE, P. Energy pile test at Lambeth College, London: geotechnical and thermodynamic aspects of pile response to heat cycles. Géotechnique, v. 59, n.3, 237-248, 2009.

BRANDL, H. Energy piles for heating and cooling of buildings. Proceedings of the 7th International Conference \& Exhibition on Pilling and Deep Foundations, p. 6. Vienna, Austria. 1998.

BRANDL, H. Energy piles and other thermo-active Ground Source Systems. Géotechnique, 56(2), 81-122, 2006.

BRETTMANN, T.; AMIS, T.; KAPPS, K. Thermal conductivity analysis of geothermal energy piles. Proceeding of the 11th International Conference of Geotechnical Challenges in Urban Regeneration, Londres, 2010.

BRIAUD, J.L. The national geotechnical experimentation sites at Texas A\&M University: clay and sand. Report No. NGESTAMU-007, Department of Civil Engineering, Texas A\&M University, College Station, Texas, 1997.

CAMPANELLA, R.G.; MITCHELL, J.K. Influence of temperature variations on soil behaviour. Journal of the Soil Mechanics and Foundations Division, ASCE, 94: 704734, 1968.

CARSLAW, H.S.; JAEGER, J.C. Conduction of heat in solids. 1 ed. Londres, Inglaterra: OUP Oxford, 1986.

CARVALHO, A.D.C. High efficiency ground source heat pump systems for sustainable building space conditioning. 2015. 185p. Tese (Doutorado) - Universidade de Coimbra - Coimbra - 2015.

CECINATO, F.; LOVERIDGE, F.A. Influences of thermal efficiency of energy piles. Energy, v.82, 1021-1033, 2015.

COMITÊ EUROPEU DE NORMATIZAÇÃO, EUROCODE 7, TC 341 - Ground investigation and testing, N525 - Geothermal Testing - Determination of thermal conductivity of soils and rock using a borehole heat exchanger, 2011.

CONTECH. Medidor de vazão tipo turbina série SVT - L/G. 2018

CURTIS, R.; LUND, J.; RYBACH, L.; HELlSTROM, G. Ground Source Heat Pumps - Geothermal energy for anyone, anywhere: current worldwide activity. Proceedings World Geothermal Congress, Antalaya, Turquia, 24-29, 2005. 
DICKSON, M.H.; FANELLI, M. What is Geothermal Energy? Istituto di Geoscienze e Georisorse, CNR, Pisa, Itália, 2004.

ECES, I (2013). Annex 21 Thermal Response Test (TRT) - Final Report: www.ieaeces.org/files/a4.1_iea_eces_annex_21_final_report_1.pdf.

FADEJEV, J.; SIMSON, R.; KURSNITSKI, J.; HAGHIGHAT, F. A review on energy piles design, sizing and modelling. Energy, v. 122, 390-407, 2017.

FARE, O.G. Geothermal energy harvesting through pile foundations - analysis based prediction and performance assessment. 2015. 202 p. Tese (Doutorado) Pennsylvania State University, College of Engineering, Pensilvânia, EUA, 2015.

FAROUKI, O. Thermal properties of soils - Vol.11 of Series on rock and soil mechanics. 2 ed. University of California Berkeley - Institute of Transportation and Traffic Engineering: 1981.

FERREIRA, M.S. Resposta Termomecânica de Estaca Geotérmica. 2017. 115 p. Dissertação (Mestrado) - Universidade estadual do Norte Fluminense, Campo dos Goytacazes, RJ, 2017.

FU, Z. Thermo-hydro-mechanical effects on the behaviour of unsaturated soilstructure interfaces and the numerical analysis of energy piles. 2017. 158 p. Tese (Doutorado) - Universidade de Ottawa - Canadá - 2017.

GAO, J.; ZHANG, X.; LIU, J.; KUISHAN, L.; YANG, J. Numerical and experimental assessment of thermal performance of vertical energy piles: an application. Applied Energy, v.85 901-910, 2008.

GEHLIN, S. Test Response Test: Method Development and Evaluation. 2002. 44 p. Tese (Doutorado) - Division of water resources engineering. Department of Environmental Engineering, Lulea University of Technology, Lulea, Suécia, 2002

GEHLIN, S.; NORDELL, B. Thermal Response Test of Boreholes - Results from insitu measurements. Transaction of the geothermal project at Richard College Conference, 1998.

GONÇALVES, N.D.F. Método dos volumes finitos em malhas não-estruturadas. 2007. 72 p. Dissertação (Mestrado) - Faculdade de Ciências, Universidade do Porto, Porto, 2007.

HARLOW, F.H.; NAKAYAMA, P.I. Transport of turbulence energy decay rate. 1 ed. Los Alamos, Novo México: Los Alamos Scientific Laboratory of the University of California, 1968. 
HASSEN, G.; YAVARI, N.; TANG, A.M. Mechanical behaviour of a small-scale energy pile in saturated clay. Géotechnique, v.66, 878-887, 2016.

HILLEL, D. Environmental soil physics. 1 ed. San Diego, EUA: Academic Press, 1998. HOWELL, J.R.; SIEGEL, R.; MENGUC, M.P. Thermal radiation heat transfer. 6 ed. Londres, Inglaterra: CRC Press, 2016.

IENO, G.; NEGRO, L. Termodinâmica. 1 ed. SP, Pearson Universidades, 2004.

INCROPERA, F.P; DEWITT, D.P.; BERGMAN, T.L.; LAVINE, A.S. Fundamentals of heat and mass transfer. 6 ed. Nova Jersey, EUA: John Wiley \& Sons, 2001.

INTERNATIONAL ORGANIZATION FOR STANDARDIZATION. ISO 10456:2007: Building materials and products - hygrothermal properties. 2007, 25 p.

KAYS, W; CRAWFORD, M.E. Convective heat and mass transfer. 3 ed. McGrawHill Science, 1993.

KOLDITZ, O.; BILKE, L.; BAUER, S.; GRUNWALD, N. OpenGeoSys: An opensource initiative for numerical simulation of thermo-hydro-mechanical/chemical (THM/C) processes in porous media. Environmental Earth Sciences, DOI: 10.1007/s12665-012-1546-X, 2012.

KRAMER, C.A.; BASU, P.; Performance of a model geothermal pile in sand. Proceedings of the International Congress of Physical Modelling in Geotechnics. Perth, Australia. 2014

LALOUI, L.; NUTH, M.; VULLIET, L. Experimental and numerical investigations of the behaviour of a heat exchanger pile. International Journal for Numerical and Analytical Methods in Geomechanics, 30(8), 763-781, 2006.

LEE, S.R.; PARK, H; YOON, S.; CHOI, J.C. Evaluation of thermal response and performance of PHC energy pile: Field experiments and numerical simulation. Applied Energy, v.103, 12-24, 2013.

LHENDUP, T.; AYE, L.; FULLER, R.J. In situ measurement oh borehole thermal properties in Melbourne. Applied Thermal Engineering, v. 73, 285-293, 2014.

LOVERIDGE, F. A.; POWRIE, W. Pile heat exchangers: thermal behaviour and interactions. Proceedings of the Institute of Civil Engineers: Geotechnical Engineering, 166(2), 178-196, 2013.

MA, L.; G., ZHIYOU, G.; WANG, W.; SUN, Y.; ZHAO, J.; FENG, N. Numerical simulation of soil Thermal Response Test with thermal - dissipation corrected model. Applied Symposium and Forum: Low Carbon Cities \& Urban Energy Joint Conference, WES-CUE, Singapura, 2017. 
MALISKA, C.R. Transferência de calor e mecânica dos fluídos computacional. 2 ed. Rio de Janeiro, Brasil: Editora LTC, 2004.

MCCARTNEY, J.S.; MURPHY, J.S.; STEWARD, M.A. Thermo-mechanical behaviour of energy foundations. Proceeding of the $18^{\text {th }}$ International Conference on Soil Mechanics and Geotechnical Engineering, Paris, França, 2013.

MIMOUNI, T. Thermomechanical characterization of energy geostructures with emphasis on energy piles. 2014. 269 p. Tese (Doutorado) - École Polytechnique Fédérale de Lausanne, Lausanne, Suíça, 2014.

MITCHELL, J.K.; Fundamentals of Soil Behavior. 2 ed. Nova Jersey, EUA: John Wiley \& Sons: 1993.

MIYASHIRO, N.J. Engesolos: sondagens, locações e situações em terrenos da Escola Politécnica da USP. São Paulo, 2015.

MODEST, M.F. Radiative heat transfer. 3 ed. EUA: Academic Press, 2013.

MORAIS, T.S.O.; TSUHA, C.H.C. Energy pile and ground temperature response to heating test: a case study in Brazil. Bulgarian Chemical Communications, v. 48, 115$119,2016$.

MORAIS, T.S.O.; TSUHA, C.H.C. In-situ measurements of the soil thermal properties for energy foundation applications in São Paulo, Brazil. Bulgarian Chemical Communications, v.50, 34-41, 2018.

MORITZ, L. Geotechnical properties of clay at elevated temperatures. Swedish Geotechnical Institute, Linköping, Suécia, 1965.

MURPHY, K.D.; MCCARTNEY, J.S.; HENRY, K.S. Evaluation of thermo-mechanical and thermal behaviour of full-scale energy foundations. Acta Geotechnica, v.10, 179$195,2013$.

MURPHY, K.D.; MCCARTNEY, J.S. Thermal borehole shear device. Geotechnical Testing Journal, v.37, n.6, 2014.

NAGANO, K.; KATSURA, T.; TAKEDA, S.; SAEKI, E.; NAKAMURA, Y.; OKAMOTO, A.; NARITA, S. Thermal characteristics of steel foundations piles as ground heat exchangers. CRES Center for Renewable Energy Sources and Savings, 2005.

NARSILIO, G.; BIDARMAGHZ, A.; MAKASIS, N.; FRANCISCA, F.M. Geothermal energy in loess. Journal of Environmental Geotechnics, v.9, n.14, 2683-2696, 2015. 
NG, C.W.W.; SHI, C.; GUNAWAN, A.; LALOUI, L.; LIU, L. Centrifuge modelling of heating effects on energy pile performance in saturated sand. Canadian Geotechnical Journal, v.52, n.8, 1045-1057, 2014.

NGUYEN, V.T.; TANG, A.M.; PEREIRA, J.M. Long-term thermo-mechanical behaviour of energy pile in dry sand. Acta Geotechnica, v.12, 729-737, 2017.

OLGUN, C.G; OZUDOGRU, T.Y.; ARSON, C. Thermo-mechanical radial expansion of heat exchanger piles and possible effects on contact pressures at pile-soil interface. Géotechnique letters, v.4, n.3, 170-178, 2014.

OLIVEIRA, F.V. Avaliação de vazamentos internos em expansores scroll com o uso de simulação CFD. 2017. 118 p. Dissertação (Mestrado) - Centro Universitário FEI, São Bernardo do Campo, SP, 2017.

OROZCO, H.C. Validação do ensaio TRT para estudo paramétrico da troca de calor de uma estaca de energia em um solo tropical. 2016. 150 p. Dissertação (Mestrado) Universidade de Brasília, Brasília, 2016.

OZUDOGRU, T.Y.; OLGUN, C.G. 3D numerical modelling of vertical geothermal heat exchangers. Geothermics, v. 51, 312-324, 2014.

OZUDOGRU, T.Y.; OLGUN, C.G.; FARE, O.G. Numerical modelling of vertical geothermal heat exchangers using finite difference and finite element techniques. Geotechnical and Geological Engineering, DOI 10.1007/s10706-014-9822-z, 2014.

PAGOLA, M.A. Design and performance of energy pile foundations. 2018. 348 p. Tese (Doutorado) - Aalborg University, Dinamarca, 2018.

PATTERSON, J.E.; MIERS, R.J. The thermal conductivity of common tubing materials applied in a solar water heater collector. N. Carolina, 2009.

ROBERTSON, E. C. Thermal Properties of rocks. USGS. Reston, Virginia: U.S. Geological Survey, 1988.

ROTTA LORIA, A.F.; GUNAWAN, A.; SHI, C.; LALOUI, L.; NG, C. Numerical modelling of energy piles in saturated sand subjected to thermo-mechanical loads.

Geomechanics for Energy and the Environment, v.1, 1-15, 2015.

ROTTA LORIA, A.F.; LALOUI, L. The interaction factor method for energy pile groups. Computers and Geotechnics. V.80, 121-137, 2016.

SÁNCHEZ, M; AKROUCH, G.A.; BRIAUD, J.L. Thermo-mechanical behaviour of energy piles in high plasticity clays. Acta Geotechnica, v. 9, 399-412, 2014. 
SÁNCHEZ, M.; AKROUCH, G.A.; BRIAUD, J.L. An experimental, analytical and numerical study on the thermal efficiency of energy piles in unsaturated soils. Computers and Geotechnics, v. 71, 207-220, 2015.

SÁNCHEZ, M.; ACOSTA, N.P.L; GALDÁMEZ, D.F.B. Numerical analysis of thermo-mechanical behaviour of an energy pile in Mexico. International Symposium on Energy Geotechnics, 147-154, 2018.

SEKINE, K.; OOKA, R.; MUTSUMI, Y.; SHIBA, Y.; HWANG, S. Development of a ground source heat pump system with ground heat exchanger utilizing the cast-in-place concrete pile foundations of a building. ASHRAE Transactions, v.113, 2005.

SHAO, H.; HEIN, P.; SACHSE, A.; KOLDITZ, O. Geoenergy modelling II: Shallow geothermal systems. 1 ed. Cham, Suíça: Springer, 2012.

SHI, C.; VAL LAAK, P.A.; GUNAWAN, A.; NG, C.W.W. Development of a heating and cooling system for centrifuge modelling of energy piles at HKUST. Proceedings of the $15^{\text {th }}$ Asian Regional Conference on Soil Mechanics and Geotechnical Engineering, Fukuoka, Japão, 2016.

SIDEBOTHAM, G. Heat Transfer Modeling: An Inductive Approach. 2 ed. Berna, Suíça: Springer International Publishing.

SINGH, R.M.; BOUAZZA, A.; WANG, B. Near-field ground thermal response to heating of a geothermal energy pile: observations from a field test. Soils and foundations, v. 55, 1412-1426, 2015.

SOUSA JÚNIOR, R.P. Estudo paramétrico da resposta térmica de estacas trocadoras de calor em um solo tropical típico do DF. 2017. 166 p. Dissertação (Mestrado) - Universidade de Brasília, Brasília, 2017.

THOMPSON III, W.H. Numerical analysis of thermal behaviour and fluid flow in geothermal energy piles. 2013. 90 p. Dissertação (Mestrado) - Virginia Polytechnic Institute and State University, Virgínia, EUA, 2013.

VILELA, M.M. Estudo de método experimental para determinar a potencialidade do uso de energia geotérmica a baixa profundidade. 2004. 278 p. Tese (Doutorado) Universidade de São Paulo - São Paulo - 2004.

WANG, L.; GONG, W.; MARTIN II, J.R.; LUO, Z.; XIAO, J. Probabilistic geotechnical analysis of energy piles in granular soils. Engineering Geology, v.209, 119-127, 2016. YOU, S.; CHENG, X.; YU, C.; DANG, Z. Effects of groundwater flow on the transfer performance of energy piles: experimental and numerical analysis. Energy and buildings, v.155, 249-259, 2017. 
ÇENGEL, Y.A. Heat transfer: a practical approach. 2 ed. Nova Iorque, EUA: Mcgraw-Hill, 2003. 
APÊNDICE A - DETALHAMENTO DA OBTENÇÃO DOS VALORES DE INCERTEZA COMBINADA E DESVIOS 
A Tabela A.1 apresenta o detalhamento para a obtenção dos valores de incerteza combinada e desvios entre os valores experimentais e numéricos de temperatura de saída do fluido circulante. O limite de erro para equipamentos do tipo PT-100 é de $\pm 0,5 \mathrm{~K}$. (CONTECH, 2018)

Nesta seção, de forma particular, os valores foram apresentados com três casas decimais.

A incerteza padrão $\left(u_{\mathrm{i}}\right)$ é obtida a partir da Equação (A.1):

$$
u_{i}=\frac{\text { Limite de erro }}{2}
$$

Os valores de desvio padrão $(\sigma)$ para as temperaturas experimentais foram calculados considerando-se, em intervalos de 1 minuto, as temperaturas anteriores e posteriores às temperaturas medidas em ensaio TRT para os instantes 50 h, 100 h e 200 h.

A incerteza combinada $\left(u_{c}\right)$, por sua vez, foi calculada por meio da Equação (A.2):

$$
u_{c}^{2}=u_{i}^{2}+\sigma^{2}
$$

Tabela A.1 - Detalhamento dos valores de incerteza combinada e desvio em termos de temperatura de saída para os instantes 50 h, 100 h e 200 h

\begin{tabular}{|c|c|c|c|c|c|c|c|}
\hline $\begin{array}{c}\text { Inst. } \\
(\mathrm{h})\end{array}$ & $\begin{array}{c}\text { T s exp. } \\
(\mathrm{K})\end{array}$ & $\begin{array}{c}\text { Limite de } \\
\text { erro }(\mathrm{K})\end{array}$ & $\begin{array}{c}\text { Incerteza padrão } \\
(\mathrm{K})\end{array}$ & $\begin{array}{c}\text { Desvio padrão } \\
(\mathrm{K})\end{array}$ & $\begin{array}{c}\text { Incerteza } \\
\text { combinada }\left(\mathrm{K}^{2}\right)\end{array}$ & $\begin{array}{c}\mathrm{T}_{\mathrm{s}} \text { num. } \\
(\mathrm{K})\end{array}$ & $\begin{array}{c}\text { Desvio } \\
(\mathrm{K})\end{array}$ \\
\cline { 1 - 5 } 50 & 311,690 & & & 0,009 & 0,063 & 311,554 & 0,136 \\
\hline 100 & 312,500 & \multirow{2}{*}{ $\pm 0,5$} & \multirow{2}{*}{ $\pm 0,25$} & 0,015 & 0,063 & 312,735 & $-0,235$ \\
\hline 200 & 313,570 & & & 0,006 & 0,063 & 313,792 & $-0,222$ \\
\hline
\end{tabular}

A Tabela A.2 sintetiza os valores de temperatura de saída experimental e desvio e os associa à raiz da incerteza combinada de acordo com o formato explicitado na Equação (A.3):

$$
\text { Valor médio } \pm u_{c}
$$


Tabela A.2 - Síntese dos valores de temperatura de saída experimental e desvio associados à raiz da incerteza combinada

\begin{tabular}{|c|c|c|c|}
\hline Inst $(\mathrm{h})$ & $\mathrm{T}_{\mathrm{s}} \exp .(\mathrm{K})$ & Desvio $(\mathrm{K})$ & Incerteza combinada $(+/-)(\mathrm{K})$ \\
\hline 50 & 311,690 & 0,136 & 0,250 \\
\hline 100 & 312,500 & $-0,235$ & 0,250 \\
\hline 200 & 313,570 & $-0,222$ & 0,250 \\
\hline
\end{tabular}

Os medidores de vazão tipo turbina série SVT - L/G, de acordo com o fabricante, possuem limite de erro de $\pm 0,6 \%$ da leitura. (CONTECH, 2018) A Tabela A.3 apresenta o detalhamento dos valores de incerteza combinada em termos de vazão mássica para os instantes $50 \mathrm{~h}, 100 \mathrm{~h}$ e $200 \mathrm{~h}$.

Tabela A.3 - Detalhamento dos valores de incerteza combinada em termos de vazão mássica para os instantes 50 h, 100 h e $200 \mathrm{~h}$

\begin{tabular}{|c|c|c|c|c|c|}
\hline $\begin{array}{c}\text { Instante } \\
(\mathrm{h})\end{array}$ & $\begin{array}{c}\text { Vazão } \\
(\mathrm{kg} / \mathrm{s})\end{array}$ & $\begin{array}{c}\text { Limite de erro } \\
(+/-)(\mathrm{kg} / \mathrm{s})\end{array}$ & $\begin{array}{c}\text { Incerteza padrão } \\
(+/-)(\mathrm{kg} / \mathrm{s})\end{array}$ & $\begin{array}{c}\text { Desvio padrão } \\
(\mathrm{kg} / \mathrm{s})\end{array}$ & $\begin{array}{c}\text { Incerteza combinada } \\
(\mathrm{kg} / \mathrm{s})^{2}\end{array}$ \\
\hline 50 & 0,336 & 0,002 & 0,001 & 0,00047 & $1,239.10^{-6}$ \\
\hline 100 & 0,337 & 0,002 & 0,001 & 0,00059 & $1,372.10^{-6}$ \\
\hline 200 & 0,366 & 0,002 & 0,001 & 0,00067 & $1,657.10^{-6}$ \\
\hline
\end{tabular}

A Tabela A.4 sintetiza os valores de vazão mássica experimental e os associa à raiz da incerteza combinada de acordo com o formato da Equação (A.3).

Tabela A.4 - Síntese dos valores de temperatura de vazão mássica associados à raiz da incerteza combinada

\begin{tabular}{|c|c|c|}
\hline Instante $(\mathrm{h})$ & Vazão $(\mathrm{kg} / \mathrm{s})$ & Incerteza combinada $(\mathrm{kg} / \mathrm{s})$ \\
\hline 50 & 0,336 & 0,001 \\
\hline 100 & 0,337 & 0,001 \\
\hline 200 & 0,366 & 0,001 \\
\hline
\end{tabular}

